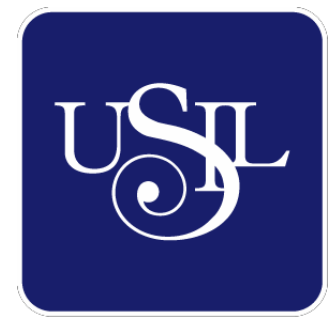

UNIVERSIDAD

SAN IGNACIO

DE LOYOLA

ESCUELA DE POSTGRADO

\title{
PLATAFORMA DE COMUNICACIÓN EN TIEMPO REAL ENTRE COLEGIO, PADRES DE FAMILIA Y ALUMNOS
}

Trabajo de Investigación para optar el grado de:

MARCO ANTONIO MORQUENCHO ALBURQUEQUE Maestro en Ciencias Empresariales con Mención en Gestión de Proyectos

HERNANDO EDUARDO MORENO MONTENEGRO

Maestro en Ciencias Empresariales con Mención en Gestión de Proyectos

CYNTHIA CAROLINA LAMA LIZARRAGA

Maestro en Ciencias Empresariales con Mención en Gestión del Capital Humano

\section{JESSY DEL PILAR ALFARO RODRIGUEZ}

Maestro en Ciencias Empresariales con Mención en Gestión de Proyectos

Asesor:

Horacio Javier Barrios Cruz

Lima - Perú

2018 


\section{Resumen Ejecutivo}

El Plan de Negocio tiene como objetivo evaluar la viabilidad económica, financiera y técnica luego de desarrollar el estudio para la implementación de una plataforma de comunicación en tiempo real entre colegio, padres de familia y alumnos.

El proyecto de investigación está dirigido a los colegios particulares de primaria y secundaria de los distritos de Barranco, Bellavista, Breña, Callao, Carmen de La Legua Reynoso, Chorrillos, Jesús María, La Molina, La Perla, La Punta, La Victoria, Lima, Lince, Los Olivos, Magdalena Del Mar, Miraflores, Pueblo Libre, Rímac, San Borja, San Isidro, San Luis, San Martin de Porres, San Miguel, Santiago de Surco y Surquillo.

El factor de diferenciación para el Plan de Negocio es buscar satisfacer a las instituciones educativas que no pueden acceder a una plataforma integral de gestión educativa y que buscan una alternativa que les permita acceder a herramientas de comunicación en línea, haciendo uso de la tecnología móvil entre los miembros de la comunidad educativa.

Con respecto a los factores de posicionamiento, la aplicación móvil primero tendrá un valor percibido por el cliente superior al coste. Además, el factor de diferenciación debe ser sostenible, es decir que logre mantener su valor para el cliente. Es por ello, que este factor de diferenciación gira en torno al precio tan atractivo que posee Eduline School y a la posibilidad de que colegios que no puedan acceder a un servicio de plataforma integral de colegios obtengan con Eduline School, una aplicación móvil que permitirá gestionar la comunicación de su comunidad educativa. Lo anterior, ayudará a mejorar la comunicación entre los padres, alumnos y profesores favoreciendo la interacción continua entre estos agentes que tendrá una repercusión positivamente en el desempeño de los educandos.

Otro aspecto que diferencia al servicio brindado por la Eduline School es la posibilidad de tener un excelente servicio de post venta en donde se tendrá a personal 
capacitado para brindar asesoría personalizada y continua que garantizará que nuestros clientes se sientan sumamente satisfechos.

Asimismo, las instituciones educativas que obtén por Eduline School (servicio específico de aplicación móvil que gestiona específicamente la comunicación) permitirán que el factor de la Tecnología se incorpore en sus escuelas logrando de esta manera que la imagen del colegio apunte a la modernidad y a la conectividad.

Gracias al estudio de mercado que se realizó se pudo determinar la existencia de la demanda del siguiente proyecto. En lo que respecta a la proyección del mercado, se concluye que el mercado potencial es de 1501 colegios que se ciñen a las características de la segmentación geográfica, privados y con niveles de enseñanza primaria y secundaria, los cuales conforman este mercado. El mercado disponible es 1051 colegios que muestran atracción por el servicio y que tienen facilidad para acceder a éste. El mercado efectivo está conformado por 546 colegios privados que estarían dispuestos a adquirir la plataforma y por último el mercado objetivo estaría compuesto por 71 colegios tomando como porcentaje de participación un $13 \%$.

A continuación, se detalla lo encontrado en las encuestas. Se encuestó de forma presencial y en línea a 306 directores de colegios privados de nivel primario y secundario dentro de Lima Metropolitana. Se pudo encontrar lo siguiente: el $87 \%$ de personas encuestadas se orienta a tener aceptación por el uso de aplicaciones similares a la que se propone. El 100\% de las personas encuestadas señala que valora la comunicación inmediata en la comunidad educativa. Existe un $70 \%$ de aceptación de las personas encuestadas en lo que respecta a trasladar la comunicación que se realiza en la comunidad educativa a una plataforma virtual y en línea. Al preguntar sobre las características deseables de la plataforma de comunicación en línea, los encuestados señalaron que el $70 \%$ desea que tenga un servicio de post venta y el 50\% valoró que la aplicación se identifique con la imagen del colegio. En 
cuanto el precio que el mercado objetivo está dispuesto a pagar, el 37\% escogió un rango entre 200 y 300 dólares.

En lo que respecta a la aceptación del servicio de la nueva plataforma de comunicación de la comunidad educativa, el 52\% señaló estar a favor de adquirir la plataforma de servicio de comunicación propuesta.

Luego de la evaluación económica y financiera de los flujos de caja del proyecto, se demuestra que es factible dentro de un escenario que no posee competencia directa sino indirecta. El valor actual neto es positivo en el segundo año de operaciones y la tasa interna de retorno es favorable para el proyecto. La inversión total será de S/ 226,689.47 se efectuará al $40 \%(\mathrm{~S} / .90,676)$ con financiamiento y $60 \%$ (S/. 136,013.68) con capital de socios.

Finalmente, se concluye que el Plan de Negocios de la aplicación móvil para la comunidad educativa es viable y rentable, lo cual está sustentado con un mercado interesado en entablar un vínculo más cercano entre la familia y colegio que genere un incremento en el sentido de pertenencia y confianza entre estos dos agentes esenciales. Por lo anterior, se recomienda ejecutar dicho plan de negocio no solo por la rentabilidad y viabilidad sino también por el beneficio que tendrá el sector educativo logrando un impacto positivo en la gestión de la comunicación de las instituciones educativas permitiendo una mayor compenetración de toda la comunidad educativa y una mejora del desempeño de los alumnos a través de una comunicación eficaz y a tiempo real. 


\section{Índice}

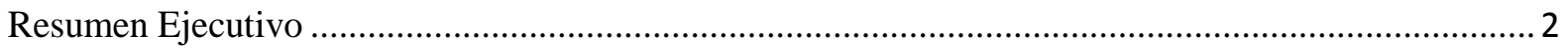

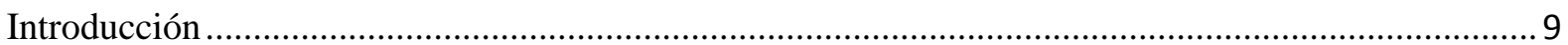

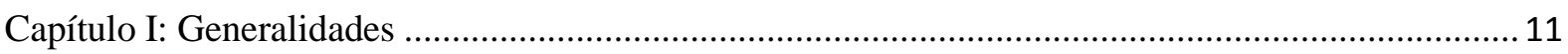

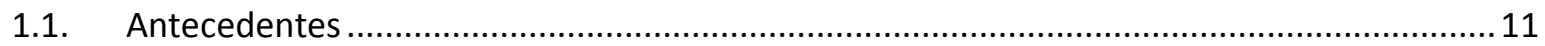

1.2. Determinación del problema u oportunidad .................................................................... 16

1.3. Justificación del Proyecto ............................................................................................ 17

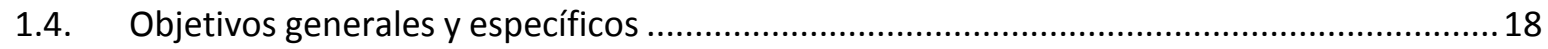

1.5. Alcances y limitaciones de la investigación....................................................................... 19

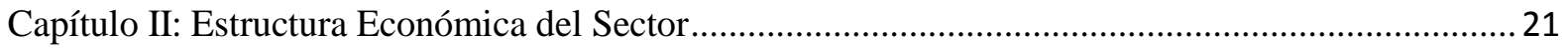

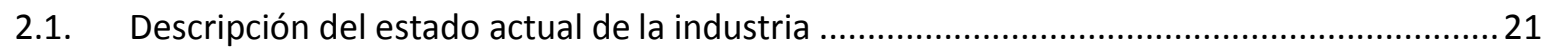

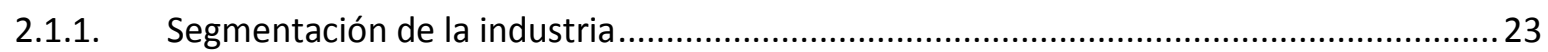

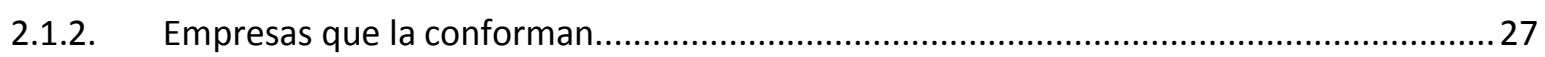

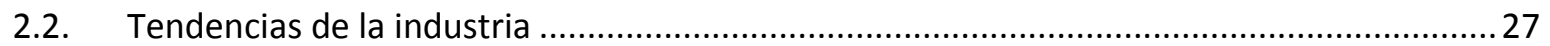

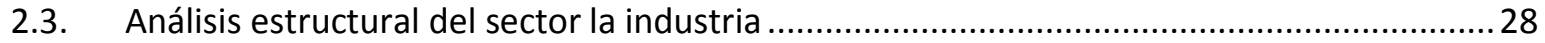

2.4. Análisis de la Competencia .......................................................................................... 49

2.4.1. Empresas que ofrecen el mismo producto o servicio ......................................................49

2.4.2. Participación de mercado de cada uno de ellos ..............................................................56

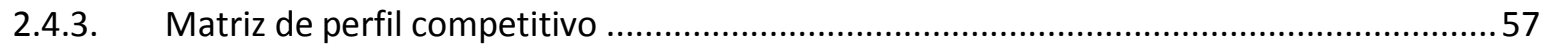

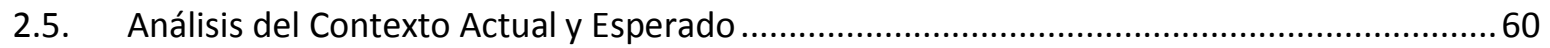

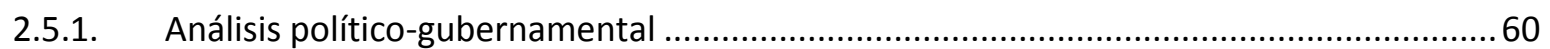

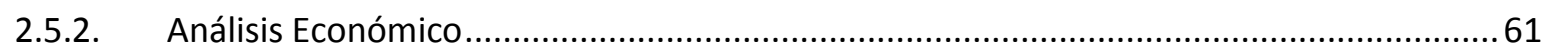

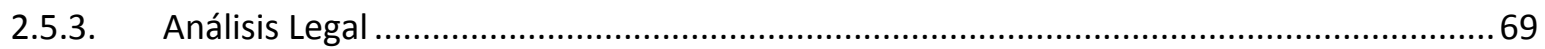

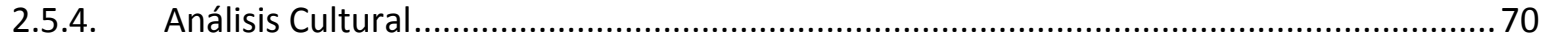

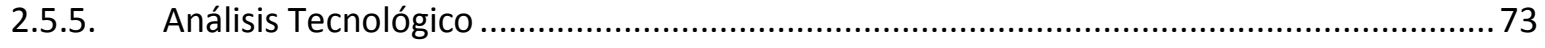

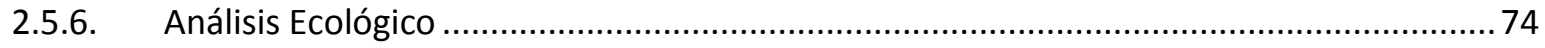

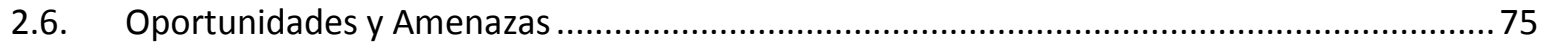

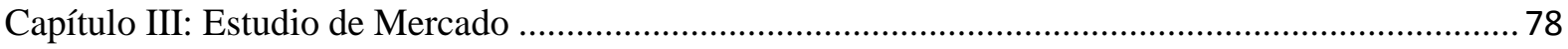

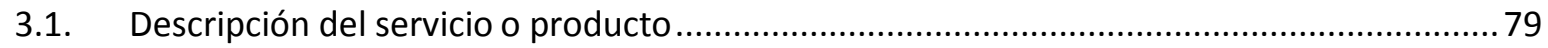

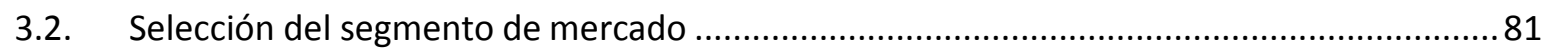

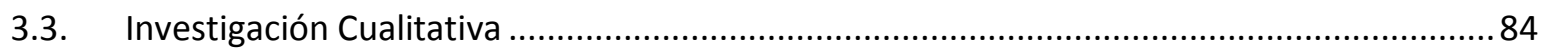

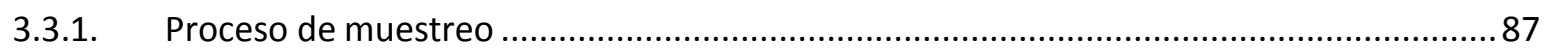

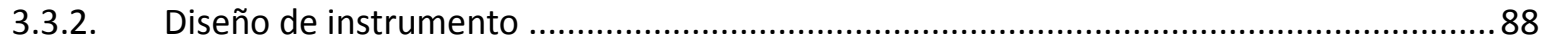

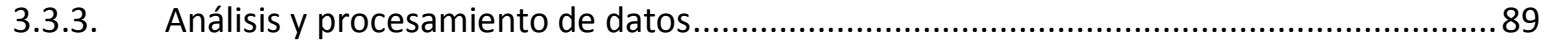

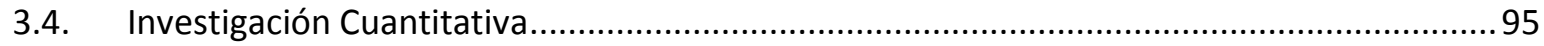




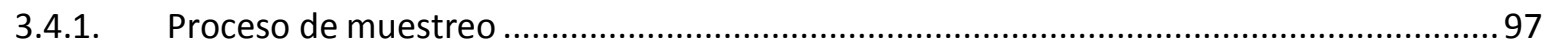

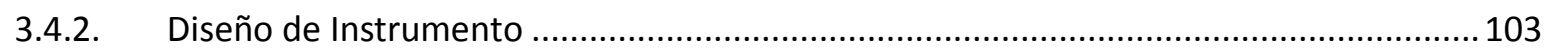

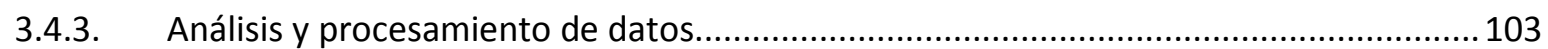

3.5. Conclusiones y recomendaciones del Estudio Cualitativo y Cuantitativo ..........................107

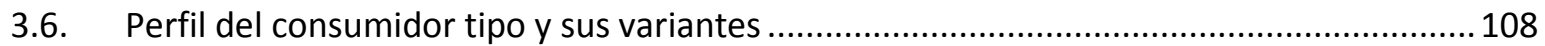

Capitulo IV: Proyección del Mercado Objetivo ................................................................................ 109

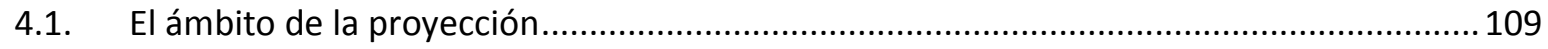

4.2. Selección del método de proyección ................................................................................ 109

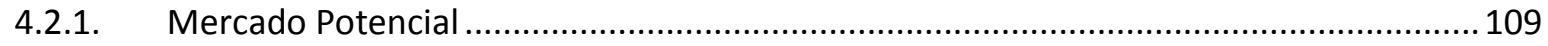

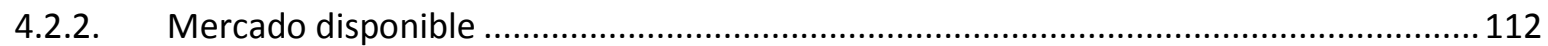

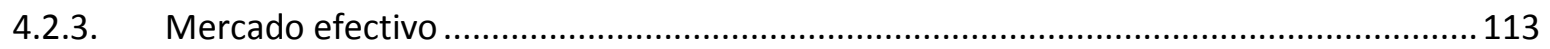

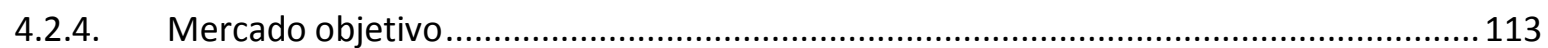

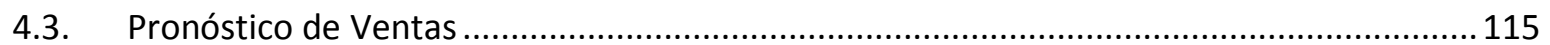

4.4. Aspectos críticos que impactan el pronóstico de ventas.....................................................119

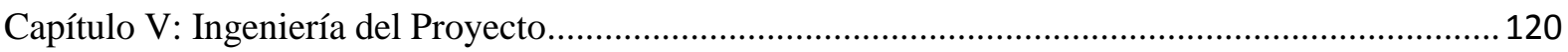

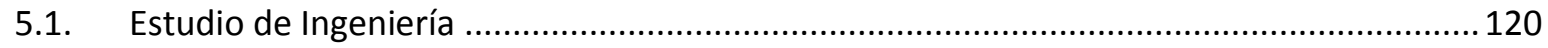

5.1.1. Modelamiento y selección de procesos........................................................................ 122

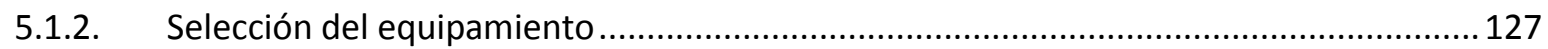

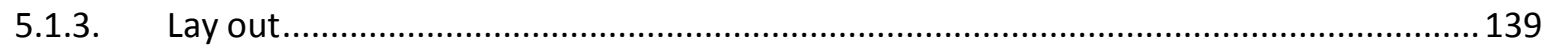

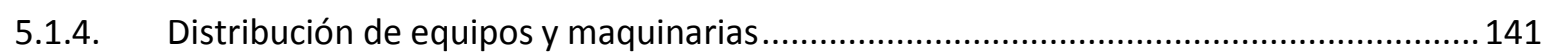

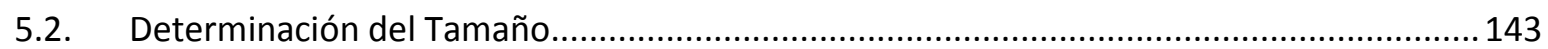

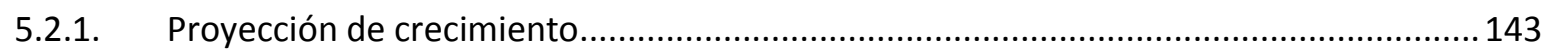

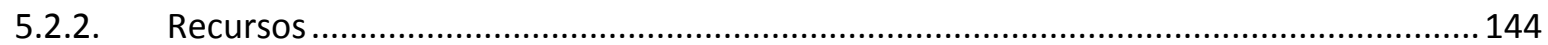

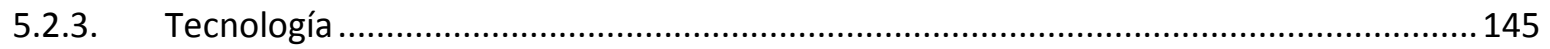

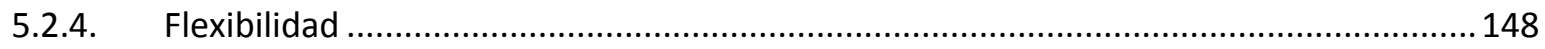

5.2.5. Selección del tamaño ideal ...................................................................................... 148

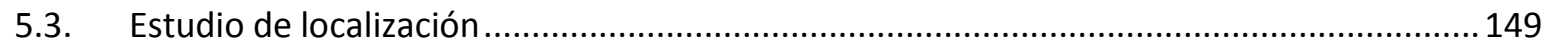

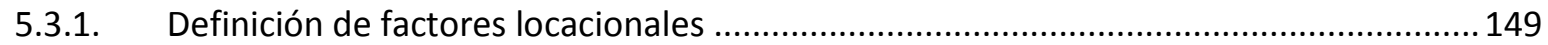

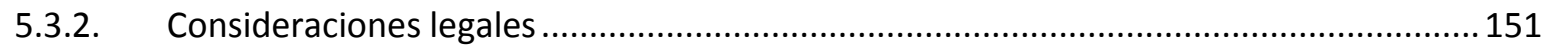

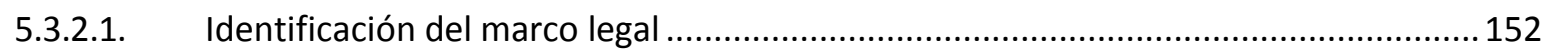

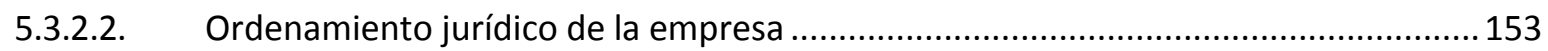

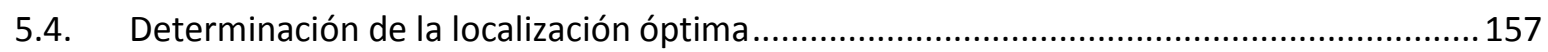

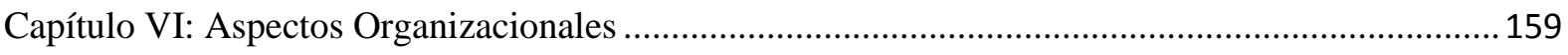

6.1. Caracterización de la cultura organizacional deseada ....................................................... 159 


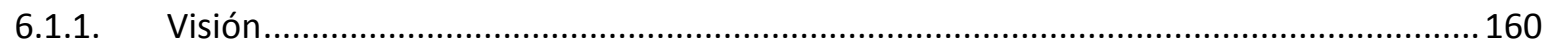

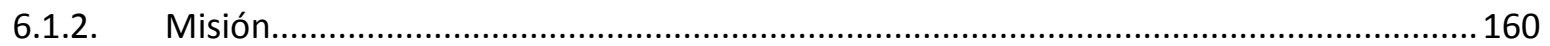

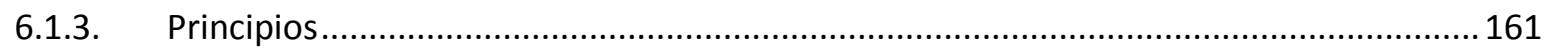

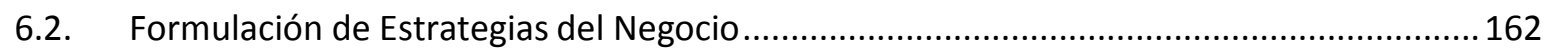

6.3. Determinación de las ventajas competitivas críticas........................................................ 164

6.4. Diseño de la estructura organizacional deseada .............................................................. 165

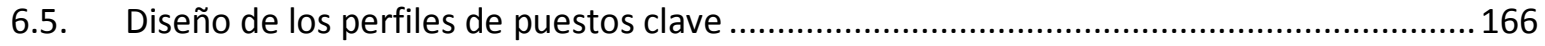

6.6. Remuneraciones, compensaciones e incentivos ….......................................................... 167

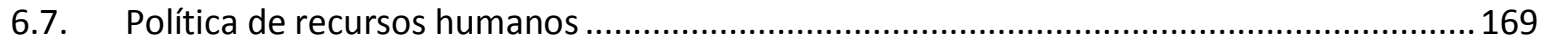

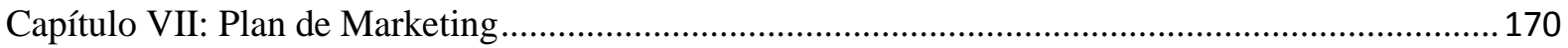

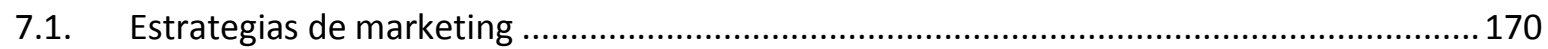

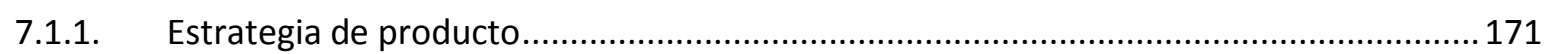

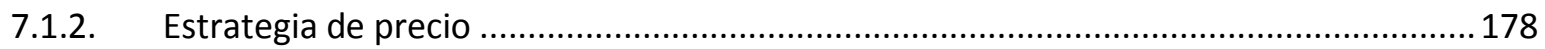

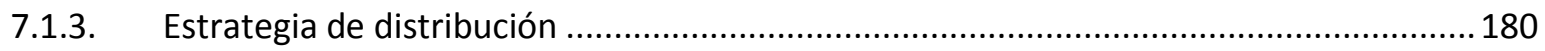

7.1.4. Estrategia de promoción y publicidad......................................................................... 181

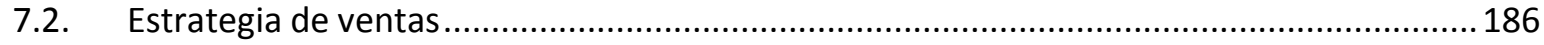

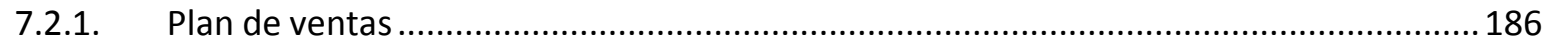

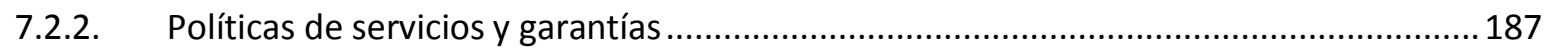

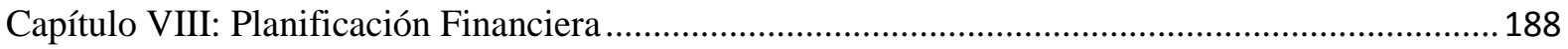

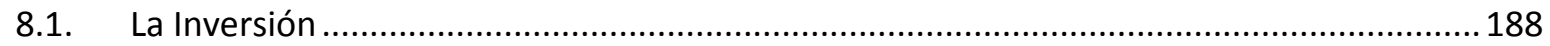

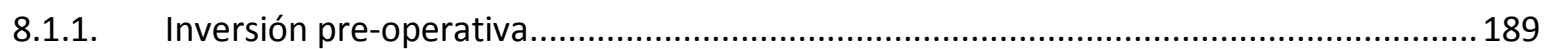

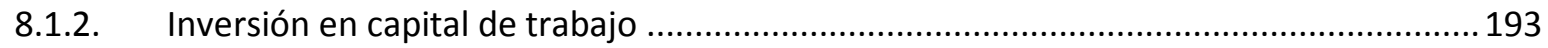

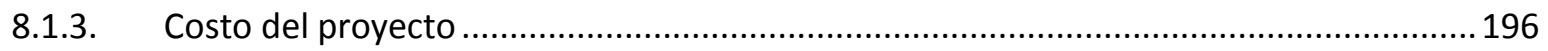

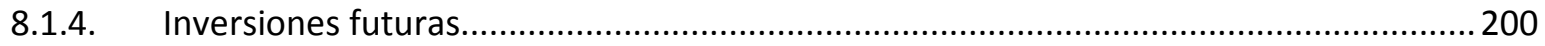

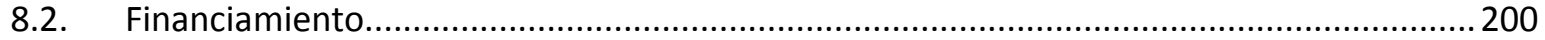

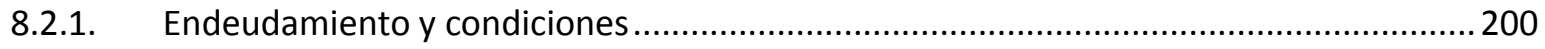

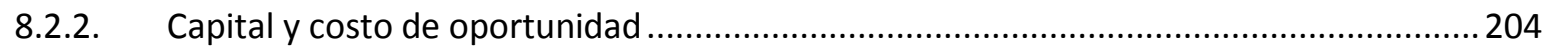

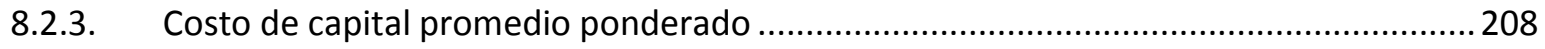

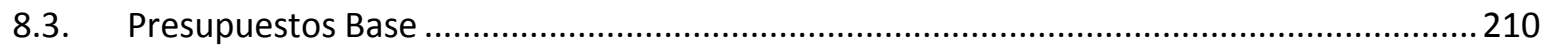

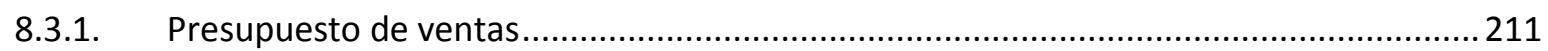

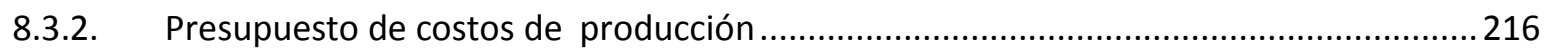

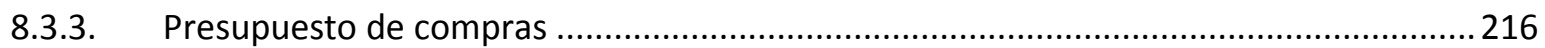

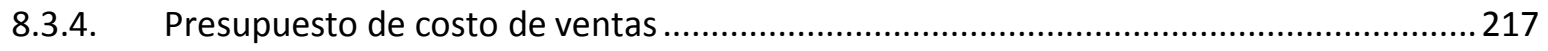

8.3.5. Presupuesto de gastos administrativos ...................................................................... 219 


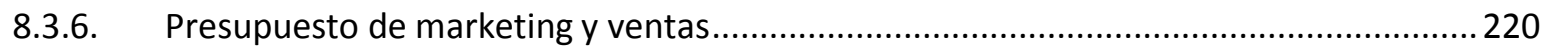

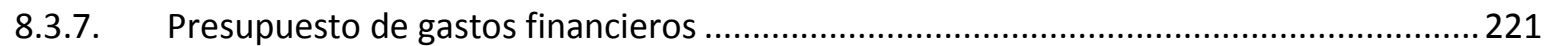

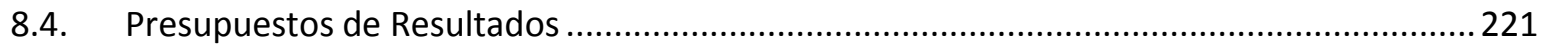

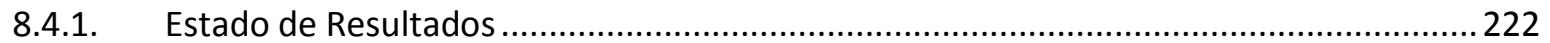

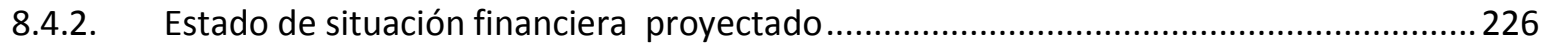

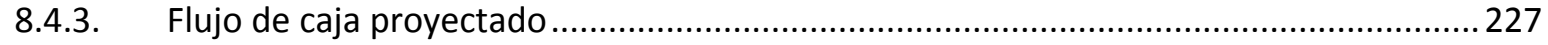

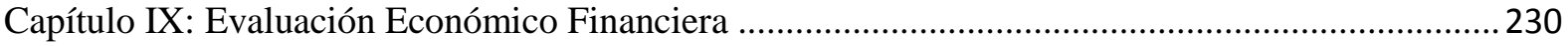

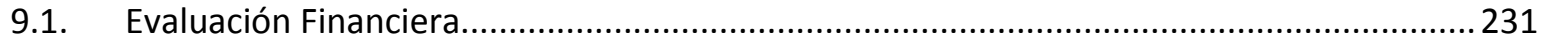

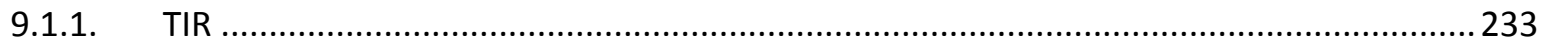

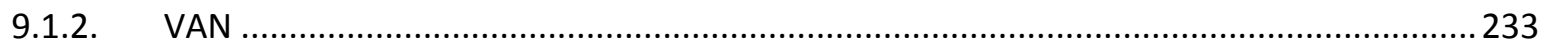

9.1.3. ROE

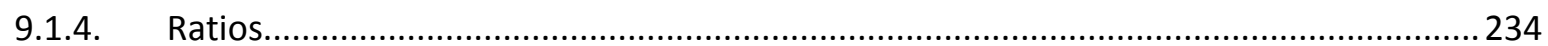

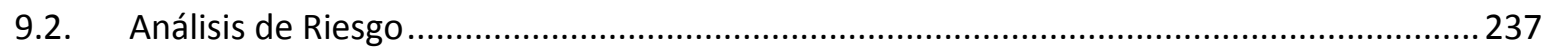

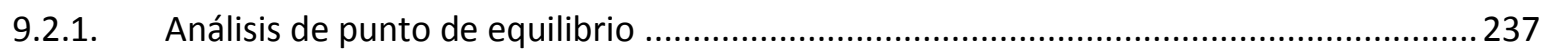

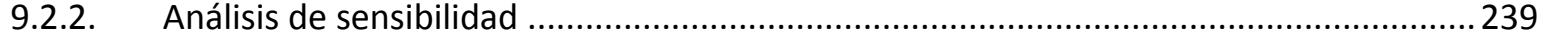

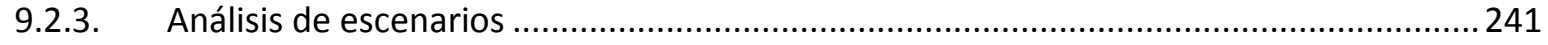

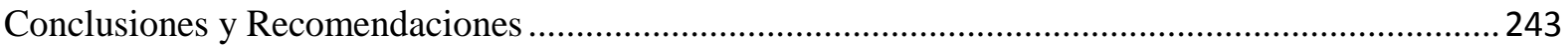

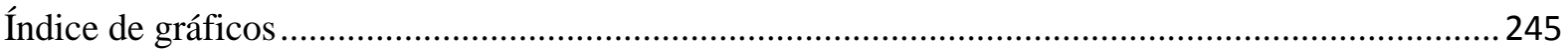

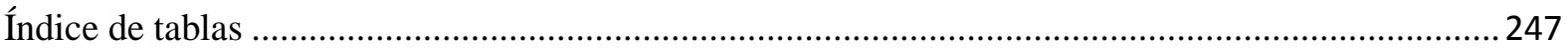

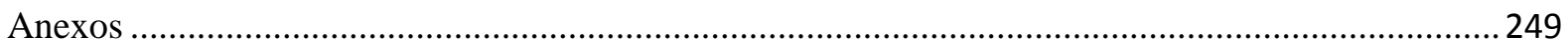

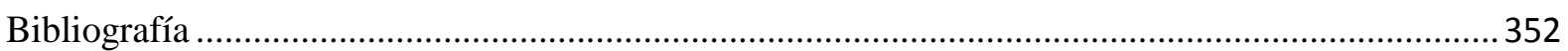

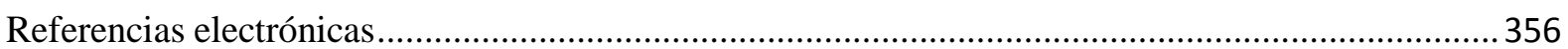




\section{Introducción}

En el Perú actualmente el mercado de aplicaciones móviles (APPs) crece en razón de un $80 \%$ al año, el sector Educación y Retail serán los que tendrán un buen dinamismo durante el año 2017 y los ingresos cada vez mayores de las Tecnología de Información y Comunicación (TIC) en el sector educación hacen atractivo este nicho de mercado.

El Plan de Negocios que presentamos busca la implementación de un servicio a través de una aplicación móvil (APP) para centros educativos escolarizados, adaptado a cada necesidad del cliente y que va a potenciar la comunicación entre los padres, colegios y alumnos. El desarrollo de este proyecto de inversión, va a permitir atender este nicho del mercado que aún se encuentra poco explotado en el Perú.

El Plan de Negocios para la implementación del nuevo servicio presenta las acciones a seguir para la implementación de manera exitosa desde la creación de la empresa que será la encargada de comercializar el producto.

El desarrollo del trabajo comprende los siguientes capítulos:

Capítulo I, presentamos la oportunidad encontrada y la justificación del plan de negocios, así como objetivos, alcances y limitaciones que deben ser consideradas.

Capítulo II, abarcamos el análisis del sector, para ello utilizamos las herramientas de Porter, Pestel y el impacto sobre el negocio.

Capítulo III, se realiza el estudio de mercado para la implementación de este nuevo servicio de comunicación en línea con los padres, colegios y alumnos. La investigación se ha dividido en: cualitativa para la cual se hicieron entrevistas de profundidad, focus group y cuantitativa con encuestas a la muestra obtenida. Por cada tipo de investigación se muestran 
resultados y conclusiones que nos indican que debemos continuar con la elaboración del proyecto.

Capítulo IV, basados en nuestra investigación de mercado en este capítulo definimos los mercados objetivo, potencial, efectivo y disponible y el pronóstico de ventas para los cinco años que es materia de este plan de negocios.

Capítulo V, la ingeniera de proyecto es analizada, se revisa y detalla las instalaciones necesarias para poder brindar el servicio, así como la determinación de la mejor localización para el proyecto.

Capítulo VI, aspectos organizacionales presentamos los aspectos fundamentales del proyecto como organización, la visión y misión.

Capítulo VII, plan de marketing para el plan de negocios, previa definición de los objetivos e investigación de mercado, planteamiento de las estrategias del marketing mix y ventas.

Capítulo VIII y IX, planificación financiera y evaluación económica financiera, los dos identifican y calculan las inversiones, la forma cómo se financiará el proyecto, así como la determinación de los presupuestos de ingresos y gastos.

Finalmente presentamos las conclusiones y las recomendaciones del presente trabajo. 


\section{Capítulo I: Generalidades}

\subsection{Antecedentes}

Gran parte de la literatura relacionada a la Psicología y Educación señala que uno de los factores esenciales que tiene influencia en la experiencia educativa formal de los alumnos es la interacción entre la familia y la escuela (Sarmiento \& Zapata, 2014).

Asimismo, Weiss, Bouffard, Bridglall y Gordon (2009), coinciden en que el involucramiento entre ambos contextos de aprendizaje es un elemento fundamental para asegurar el triunfo escolar en el alumnado.

Años atrás, esta relación entre ambos contextos de aprendizaje (escuela y familia) se plasmaba en una distribución clara e independiente de funciones en la cual la familia ejercía la tarea de socializar a los niños y la escuela se encargaba de impartir conocimientos. Hoy en día, debido a los diferentes cambios que han ocurrido en la sociedad, las funciones que ambos contextos de aprendizaje tenían establecidas se han invertido, ya que se puede adquirir conocimientos en el contexto familiar gracias a los medios de comunicación y a la tecnología, como también las escuelas cumplen un rol importante actualmente en el proceso de socialización de los niños. (ntic.educacion.es, 2015)

En estos tiempos, es vital que ambos contextos de aprendizaje ejerzan un esfuerzo como equipo para cumplir con el papel fundamental de educar a las nuevas generaciones. Es necesario que, tanto la familia y escuela consoliden una alianza para lidiar conjuntamente con lo diferentes desafíos que puede implicar la educación (ntic.educacion.es, 2015).

Existen ciertos estudios que pueden evidenciar el impacto positivo que tiene la interacción entre la familia y la escuela, como es el caso de estudios internacionales 
como (SERCE Y PISA), que indican que esta interacción entre la familia y escuela ejerce un impacto notorio en el desempeño y en los aciertos de aprendizaje (Sarmiento \& Zapata, 2014). De la misma forma, Brassett-Grundy (2002) y Desforges y Abouchaar (2003) concuerdan en que existe una correlación positiva y alta entre el desempeño y participación de la familia en la escuela.

La preocupación de los padres por mantener su trabajo se ve acrecentada por el último informe de la Organización Internacional del trabajo (OIT) que señala que, debido a las complicadas condiciones del mercado laboral en Brasil, la tasa de desempleo en América Latina y el Caribe aumentará en un 0.3\%. Se estima que durante el 2017 el Perú tendrá una tasa de desempleo de 8.4\% lo cual significará una reducción del empleo en el país (Elcomercio.pe, 2017). Lo anterior, por lo tanto, podría generar menos involucramiento de la familia en la escuela ya, que estarían los padres más focalizados en no desatender sus trabajos para no perder sus ingresos mensuales para el afronte mensual de la carga familiar.

De acuerdo a Macia (2016) recomienda que, para enfrentar el gran reto de educación, tanto la familia y la escuela deben de trabajar conjuntamente en establecer un lazo estrecho de comunicación sólido y eficaz. Para entablar un vínculo más cercano entre la familia y colegio, que genere un incremento en el sentido de pertenencia y confianza entre estos dos agentes esenciales, es fundamental contar con un canal de comunicación bidireccional que ofrezca posibilidad de tener acceso a información transparente, actualizada y clara y en que se puedan intercambiar diferentes datos para propiciar una mejor dinámica entre la familia y escuela. Lo anterior describe que, para poder cimentar una adecuada relación entre familia y colegio, es vital darles importancia a los canales de comunicación entre, estos dos importantes agentes. 
Como señala Jaramillo, Castañeda \& Pimienta (2009) las tecnologías de Información y Comunicación son recursos que se centran en la tecnología digital y que comprometen al computador y al internet permitiendo el almacenamiento, procesamiento, recuperación, transmisión y presentación de buena cantidad de información. Asimismo, se relacionan con las aplicaciones empleadas por los procesadores para agilizar y gestionar la información (software, base de datos, multimedia, etc.), como también con las nuevas tecnologías en el entorno de internet (chat, lista de distribución y plataforma para E- learning). Generalmente, se emplea el termino TIC para abarcar estos diversos conceptos (software, base de datos, multimedia, programas y aplicaciones utilizadas por computadores, plataforma Elearning, chat, lista de distribución)

Macia (2016) manifiesta que las Tecnología de Información y Comunicación (TIC) es un recurso importante para poder potenciar la relación entre los agentes y poseer un canal de comunicación bidireccional eficaz.

Cabe señalar que, haciendo un análisis de manera más general el sector de TIC, (Becerra, 2016) señala que el sector de Tecnología de Información (TI) a nivel mundial crecerá de 4\% a 5\% en el 2016 y 2017 siendo este un crecimiento moderado; en donde Estados Unidos contará con el mercado más amplio; las tecnologías de elevado crecimiento serán Cloud y Analytics y SaaS que continuará siendo la pieza primordial del software en los subsiguientes dos años. Asimismo, se dará una gran aceptación de CRM (customer relationship management ) para la gestión del capital humano, las compras on line, la gestión, análisis financieros y soluciones analíticas. (cio.com, 2016) 
De acuerdo a Cruzado (2016), considera que el sector de TIC junto con los de Educación y Retail serán los que tendrán un buen dinamismo durante el año 2017 en el Perú y por consiguiente, se fomentará la contratación de personal profesional competente con elevado conocimiento en innovación digital. Lo anterior señala, que el sector de tecnología actualmente se encuentra sólido en el país. (Gestion.pe, 2016)

Los datos que se pueden encontrar en el Instituto Nacional de Estadística e Informática, dentro de los Índices Temáticos, específicamente la sección de tecnologías de la información y comunicación, son datos de población de 6 y más años de edad que hacen uso de internet, según nivel educativo. 
Tabla 1

Población que accede a internet de 6 años a más

\begin{tabular}{l|rrrrrrr}
\hline Nivel educativo / Año & 2009 & 2010 & 2011 & 2012 & 2013 & 2014 & 2015 \\
Primaria & 8,6 & 9,8 & 9,6 & 10,2 & 10,6 & 9,5 & 9,5 \\
Secundaria & 28,0 & 29,0 & 30,4 & 29,8 & 33,0 & 34,7 & 35,9 \\
Superior no universitaria & 34,8 & 37,1 & 18,7 & 17,2 & 17,3 & 17,7 & 17,6 \\
Superior universitaria & 28,6 & 24,2 & 41,4 & 42,8 & 39,1 & 38,1 & 37,0
\end{tabular}

Expresado en porcentajes

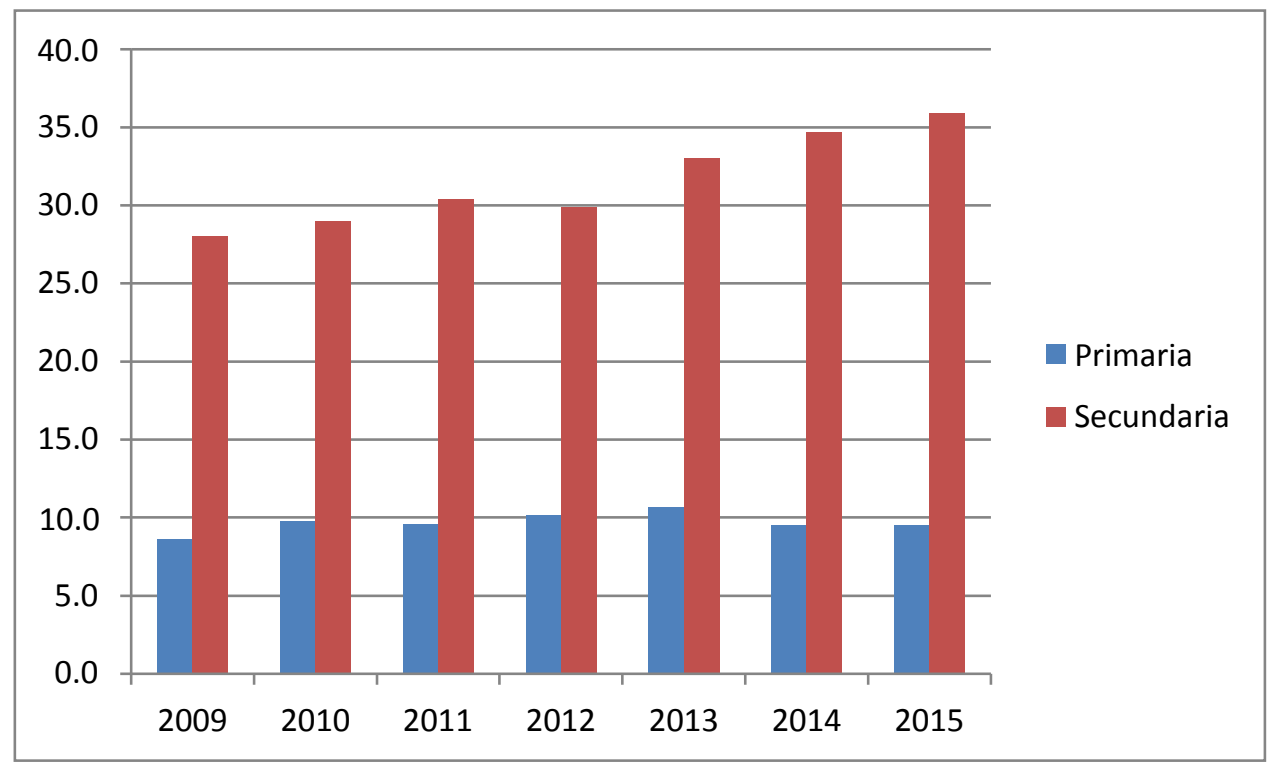

Figura 1. Evolución del uso de internet en la población escolar. Recuperado de https://www.inei.gob.pe/estadisticas/indice-tematico/tecnologias-de-la-informacion-ytelecomunicaciones/

Como muestra el gráfico con los datos tomados del INEI las TIC en el sector educación secundario en el Perú tiene un crecimiento de $+1.00 \%$ anualmente.

El sector de la Tecnología se encuentra poco a poco introduciéndose en la educación, proveyéndola de diversos recursos y herramientas con la finalidad de beneficiar familias, colegios y alumnos mejorando a través de sus avances la comunicación entre los mismos. Actualmente, se evidencia ciertas alternativas novedosas de comunicación para dar información e involucrar a las familias y a los 
colegios, esto se debe al reciente ingreso de la Tecnología de la Información y la Comunicación (TIC) en las diferentes instituciones educativas. Sin embargo, se necesita fortalecer aún más las TICs con respecto a la interacción entre la familia y la escuela. (Macia, 2016)

Un caso de éxito, en relación a la inserción de TIC en la gestión educativa y por lo tanto en la consolidación de la interrelación entre colegio y familia, se hace evidente en América Latina en el país de Argentina. Se trata de una plataforma escolar de comunicación llamada Blended, para la gestión de colegios y para el fortalecimiento de la comunicación entre los diversos agentes. Actualmente, tiene una buena aceptación en el mercado argentino y cuenta con módulos de Calificaciones, Asistencia y Aula Virtual. Consiste en que por medio de los dispositivos móviles los docentes pueden enviar tareas, reportes, anuncios, estableciendo un canal de comunicación más cercano con los padres. (Pagola, 2016)

Es necesario aprovechar las herramientas tecnológicas ya que tienen un potencial comunicativo que permitirá mejorar de manera eficaz la relación entre colegio y familia.

Además, Macia (2016) destaca la multiplicidad de funciones que pueden realizar dichos recursos electrónicos y que se pueden plasmar en beneficios evidentes para la gestión educativa.

\subsection{Determinación del problema u oportunidad}

Existen pocas herramientas integrales y efectivas en el mercado peruano que permitan mejorar la comunicación entre las familias y el colegio. El mercado de aplicaciones móviles ('apps') en el Perú crece $80 \%$ al año, con lo cual alcanzaría un 
total de 1,500 apps en el 2015, según la Oficina Comercial de Perú en Washington. (Gestion.pe, 2014)

Haciendo uso de la tecnología móvil y el desarrollo de Apps se pueden crear herramientas que permitan mejorar la comunicación entre padres, alumnos, profesores y personal administrativo de los colegios. De acuerdo a Aguilar y Leiva (2012) y Sánchez y Cortada (2015) la introducción de las Tecnologías de la Información y la Comunicación (TIC) en los centros escolares ha abierto nuevas posibilidades de comunicación y nuevas perspectivas para informar e implicar a las familias en la escuela.

Hay casos de éxito de soluciones tecnológicas, que ayudan a mejorar las interrelaciones entre las familias y el colegio, aplicadas a otros países como México, Argentina y España, los cuales se pueden tomar como referencia para implementar el plan de negocios.

Actualmente, existe una mayor predisposición de los docentes y padres de familia al uso de canales de comunicación tecnológicos. Según Macia (2016).

\subsection{Justificación del Proyecto}

La herramienta que se utilizará para desarrollar el proyecto será un Plan de Negocios que permitirá definir, elaborar y evaluar la viabilidad de un proyecto de inversión El proyecto tiene por objeto la creación de un nuevo negocio. Asimismo, es considerada útil esta herramienta (Plan de Negocio) ya que permitirá hacer una debida identificación de la oportunidad, un perfil del proyecto en el cual se realizará un estudio comercial, análisis del mercado, estrategia comercial, estudio técnico, estudio 
legal, estudio administrativo y estudio económico financiero. Todo ello para determinar finalmente si dicho proyecto generará valor o no.

El proyecto consistirá en la creación de un nuevo negocio que elaborará Apps de gestión de colegios adaptadas a la necesidad del cliente y que potenciarán la comunicación entre los padres, colegios y alumnos. El desarrollo de este proyecto de inversión, (empresa desarrolladora de Apps de gestión educativa) permitirá atender este nicho del mercado que aún se encuentra poco explotado en el Perú.

La elaboración de Plan de Negocios es una herramienta que ofrecerá la oportunidad para plasmar y demostrar en la práctica todos los conocimientos adquiridos en la maestría.

\subsection{Objetivos generales y específicos}

El objetivo general de este plan de negocios es determinar la viabilidad de la oportunidad encontrada, haciendo un análisis del entorno, mercado, financiero, legal y del producto que ayude a encontrar la mejor alternativa a seguir.

Objetivos específicos del proyecto

a) Analizar el entorno con la finalidad de realizar una identificación y evaluación de oportunidades y amenazas claves, todo ello para formular estrategias y finalmente lograr obtener una ventaja competitiva.

b) Desarrollar el estudio de mercado para conocer el comportamiento del mercado ante el nuevo servicio que se desea brindar, el pronóstico de demanda, la capacidad de respuesta de la competencia, el precio que generará el proyecto, el perfil del consumidor y la identificación y definición de los canales de comercialización. 
c) Desarrollar la ingeniería del producto con la finalidad de conocer el alcance y desarrollo del estudio técnico del proyecto en cuanto a tamaño, tecnología y procesos como también localización.

d) Elaborar la estructura de la administración de la organización con la intención de diseñar la organización de la empresa nueva a elaborarse, planteando una visión, misión, valores, organigrama, perfiles de puestos, políticas, etc.

e) Analizar el marco legal del producto y de la organización con el objeto de conocer y aplicar el marco legal relacionado al proyecto (societario, laboral y tributario). Este estudio ayudará a conocer las normas y regulaciones existentes relacionadas a la naturaleza del proyecto y de la actividad económica que se desea desarrollar.

f) Diseñar el plan de marketing y ventas para fijar los planes de acciones que se emprenderán en diferentes aspectos. Es decir, permite elaborar estrategias del producto, estrategia de precios, estrategia de distribución, de promoción y publicidad como también realizar un pronóstico de ventas a futuro.

g) Realizar la evaluación financiera para poder desarrollar una proyección financiera del proyecto que permita determinar los presupuestos ingreso y gasto, rentabilidad y viabilidad del negocio propuesto.

\subsection{Alcances y limitaciones de la investigación}

Temporal. - Teniendo en cuenta que el plan de negocios involucra tecnología, por lo tanto, se asumirá que existirá un nivel elevado de complejidad y acelerados cambios, y que en dicho sector los cambios son constantes, acelerados y la complejidad del negocio, planteamos un horizonte de proyección del plan de negocios de cinco años. 
Espacial.- El ámbito de influencia serán los centros educativos escolarizados, privados de nivel primaria y secundaria ubicados en la ciudad de Lima Metropolitana para los siguientes distritos de:

Barranco, Bellavista, Breña, Callao, Carmen de la Legua Reynoso, Chorrillos, Jesús María, La Molina, La Punta, La Victoria, Lima, Lince, Los Olivos, Magdalena del Mar, Miraflores, Pueblo Libre, Rímac, San Borja, San Isidro, San Luis, San Martin de Porres, San Miguel Santiago de Surco y Surquillo.

Estos conforman el mayor volumen de colegios en Lima Metropolitana. 


\section{Capítulo II: Estructura Económica del Sector}

\subsection{Descripción del estado actual de la industria}

El servicio está ubicado en el sector de Información y Comunicaciones, específicamente en el desarrollo de software para dispositivos móviles inmerso en las tecnologías de información y comunicación (TIC), sobre esto, un estudio realizado en enero del año 2015, sobre el uso de aplicaciones en los Smartphones y Tablets de usuarios en seis países de Latinoamérica (Brasil, México, Argentina, Colombia, Perú y Chile) realizada por la empresa americana comScore, tuvo en su cuestionario una pregunta, que decía ¿Cuántas horas por semana pasa en Internet usando cada uno de los siguientes dispositivos? El resultado fue que nueve de cada diez latinoamericanos usan su tiempo en internet y poseen o usan un dispositivo móvil con regularidad.

A la pregunta ¿Tiene aplicaciones descargadas en tu Smartphone / Tablet?, la respuesta fue que el $99 \%$ de encuestados tienen aplicaciones descargadas en su Smartphone o Tablet. (ver Figura 2).

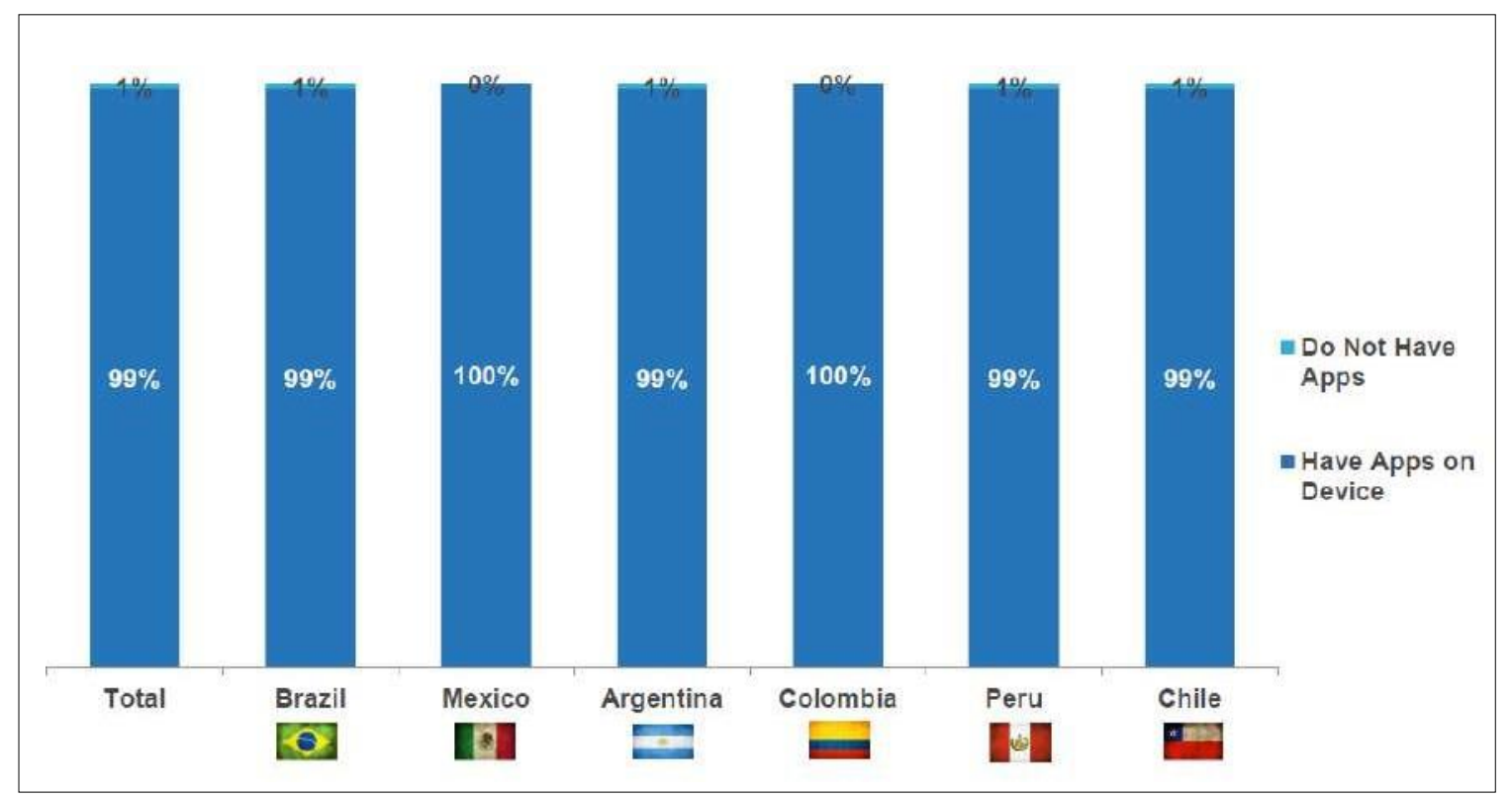

Figura 2. Adaptado Gráfico de barras "App Usage on Mobile Devices”. Tomado de "comscrore / IMS Mobile in Latam Study," por el IMS, 2015. Recuperado de https://www.comscore.com/lat/Productos/Analiticas-de-Audiencia/Mobile-Metrix\#publishers 
Este estudio muestra que el $88 \%$ de los peruanos participantes en la investigación accede a internet a través de un Smartphone o una Tablet y que en su mayoría tienen Apps descargadas en sus dispositivos móviles.

Por otro lado, el 15 de abril del año 2015 el Foro Económico Mundial (WEF) publicó la 14ª edición del Informe Global de Tecnología de la Información 2015, donde se evaluó el impacto de las TICs en el proceso de desarrollo y competitividad de los países.

Según datos publicados el boletín N 1 La Asociación Peruana de Productores de Software - APESOFT, el Sector del Software y Servicios informáticos en el Perú cerraría en 996,3 millones de dólares en el 2014, representando un crecimiento de 20,8\% para el software y 23\% para servicios TI respecto al año 2013, de acuerdo a estimados de Dominio Consultores.

El mercado de las Tecnologías de Información para el 2014 se estimaba un cierre de 3,786 millones de dólares, con un 15.3\% de crecimiento respecto al 2013. Para el 2015 se esperaba que las ventas de software y servicios se incrementen en 11,3\% y $14.6 \%$, respectivamente, (Apesoft.org, 2014)

En Lima Metropolitana hay instituciones de educación básica regular que cuentan con plataformas de red informática, que utilizan software diseñado para ayudar a los educadores a crear cursos en línea y entornos de aprendizaje virtuales (ejemplo Moodle). Pero, no tienen un canal de comunicación en tiempo real entre colegio, padres de familia y alumnos. 
Por otro lado, en el mercado español podemos encontrar Alexia que es una plataforma de gestión y comunicación presente en más de 1,200 colegios, en cuanto a la gestión de alumnos tiene evaluación flexible, gestión económica avanzada, transporte, comedor, etc. La comunicación en esta plataforma es vía web, sms, email. Esta plataforma Alexia pertenece al Grupo Educaría Perú (Educaría es un grupo de empresas dedicadas al mundo educativo en España y Latinoamérica, fundada en el año 2000) la cual ha firmado un convenio con Futura Schools para que a su comunidad educativa le permita tener acceso a la plataforma Alexia con la finalidad de mejorar gestión administrativa y comunicación entre toda la comunidad de colegios (sedes en Arequipa, Chiclayo, Ica, Piura, Tacna, Trujillo). Por los puntos mencionados la diferencia es amplia ya que se trata de una plataforma muy cercana a un ERP (Resource Planning - Planificación de Recursos Empresariales).

\subsubsection{Segmentación de la industria}

En la publicación de la consultora IDC de setiembre del año 2015, se indicaba que el mercado de software en Latinoamérica que incluye aplicaciones de negocio, herramientas de desarrollo e integración y aplicaciones de infraestructura, tuvo un crecimiento de $12.8 \%$ en 2014, 4.4\% menor que en 2013, debido a factores principalmente macroeconómicos, como el fluctuante precio del petróleo y la pérdida del valor del tipo de cambio. El valor del mercado de software al cierre del 2014 fue de 13,305 millones de dólares y la consultora estimaba que, para el 2015, el crecimiento continuaría con una tendencia positiva, motivado principalmente por la industria manufacturera, de retail y de servicios. (ver Figura 3) 


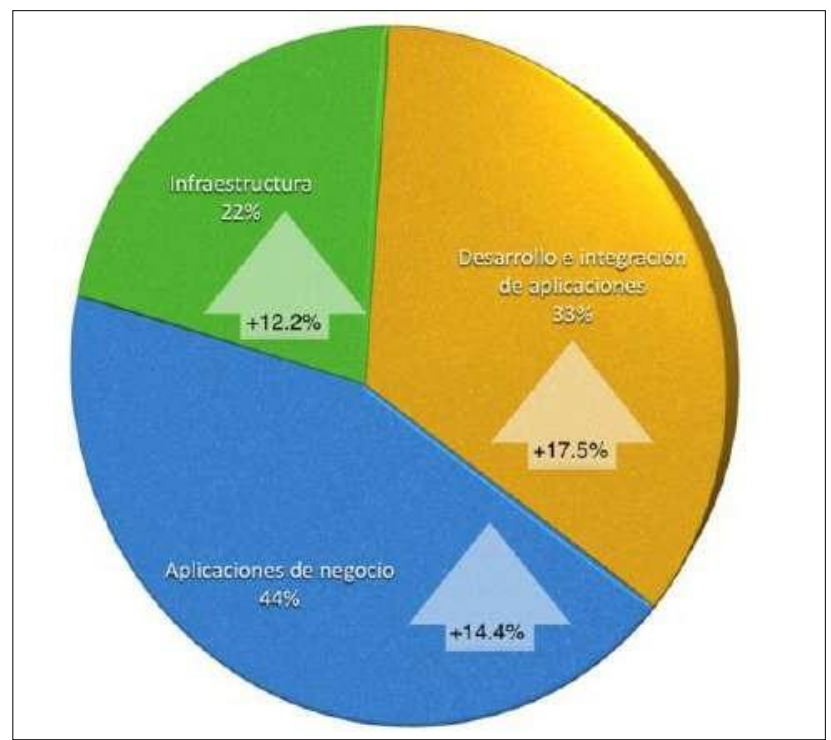

Figura 3. Composición y crecimiento del mercado de software en América Latina. Tomado de («Se frena el crecimiento del mercado de software en 2014, según IDC», n. d.). Recuperado de http://searchdatacenter.techtarget.com/es/noticias/4500253770/Se-frena-elcrecimiento-del-mercado-de-software-en-2014-segun-IDC.

En la siguiente tabla (ver Tabla 2) podemos visualizar que la categoría “Aplicaciones de plataforma" con crecimiento de $+16.70 \%$, está relacionada con el interés de las empresas en seguir desarrollando soluciones en una plataforma ágil y eficiente.

Tabla 2

Crecimiento de mercado de software año 2014 en América Latina

\begin{tabular}{lll}
\hline $\begin{array}{l}\text { Desarrollo e integración de } \\
\text { aplicaciones }+\mathbf{1 7 . 5 0} \%\end{array}$ & $\begin{array}{l}\text { Aplicaciones de negocio } \\
\mathbf{+ 1 4 . 4 0 \%}\end{array}$ & $\begin{array}{l}\text { Software de } \\
\text { infraestructura } \mathbf{+ 1 2 \%}\end{array}$ \\
\hline $\begin{array}{l}\text { Acceso, análisis y entrega de } \\
\text { datos }+20.20 \%\end{array}$ & $\begin{array}{l}\text { Aplicaciones de } \\
\text { colaboración }+20.40 \%\end{array}$ & $\begin{array}{l}\text { Software para la } \\
\text { administración del sistema } \\
+14.70 \%\end{array}$ \\
$\begin{array}{l}\text { Software de soporte a la } \\
\text { integración y orquestación }\end{array}$ & $\begin{array}{l}\text { Soluciones de ingeniería } \\
+18.50 \%\end{array}$ & $\begin{array}{l}\text { Software de seguridad } \\
+17.50 \%\end{array}$ \\
$\begin{array}{l}\text { Aplicaciones de plataforma } \\
+16.70 \%\end{array}$ & $\begin{array}{l}\text { Aplicaciones de operaciones } \\
\text { y manufactura }+12.60 \%\end{array}$ & $\begin{array}{l}\text { Software de almacenamiento } \\
+11.80 \%\end{array}$ \\
\hline
\end{tabular}

Nota. Adaptado de Crecimiento de mercado de software año 2014 en América Latina («Se frena el crecimiento del mercado de software en 2014, según IDC», n.d.). Recuperado de http://searchdatacenter.techtarget.com/es/noticias/4500253770/Se-frena-el-crecimientodel-mercado-de-software-en-2014-segun-IDC 
En cuanto al mercado peruano, las Tecnologías de Información para el 2014 se estimó cerrar con 3,786 millones de dólares, con un 15.3\% de crecimiento con relación al 2013. (Ver Tabla 3)

Tabla 3

Tamaño del mercado peruano de tecnologías de información (millones de dólares USA)

\begin{tabular}{lrrrrr}
\hline & \multicolumn{1}{c}{2013} & \multicolumn{1}{c}{$2014 \mathrm{e}$} & $2014 / 13$ & $2015 \mathrm{p}$ & $2015 / 14$ \\
\hline Hardware & $2,469.8$ & $2,789.9$ & $13.0 \%$ & 3386.02 & $21.4 \%$ \\
Software & 184.0 & 222.2 & $20.8 \%$ & 247.301 & $11.3 \%$ \\
Servicios TI & 629.1 & 774.1 & $23.0 \%$ & 887.442 & $14.6 \%$ \\
Mercado Total & $3,282.9$ & $3,786.2$ & $15.3 \%$ & $4,520.8$ & $19.4 \%$
\end{tabular}

Nota. Adaptado de («Boletín 1», n.d.). Recuperado de http://www.apesoft.org/boletines/boletin-1/

Solamente $20 \%$ del total de las inversiones en TI en el Perú es destinado a servicios, el grueso de la inversión 74\%, se encuentra destinado al hardware. Esto muestra las oportunidades de crecimiento. (ver Figura 4)

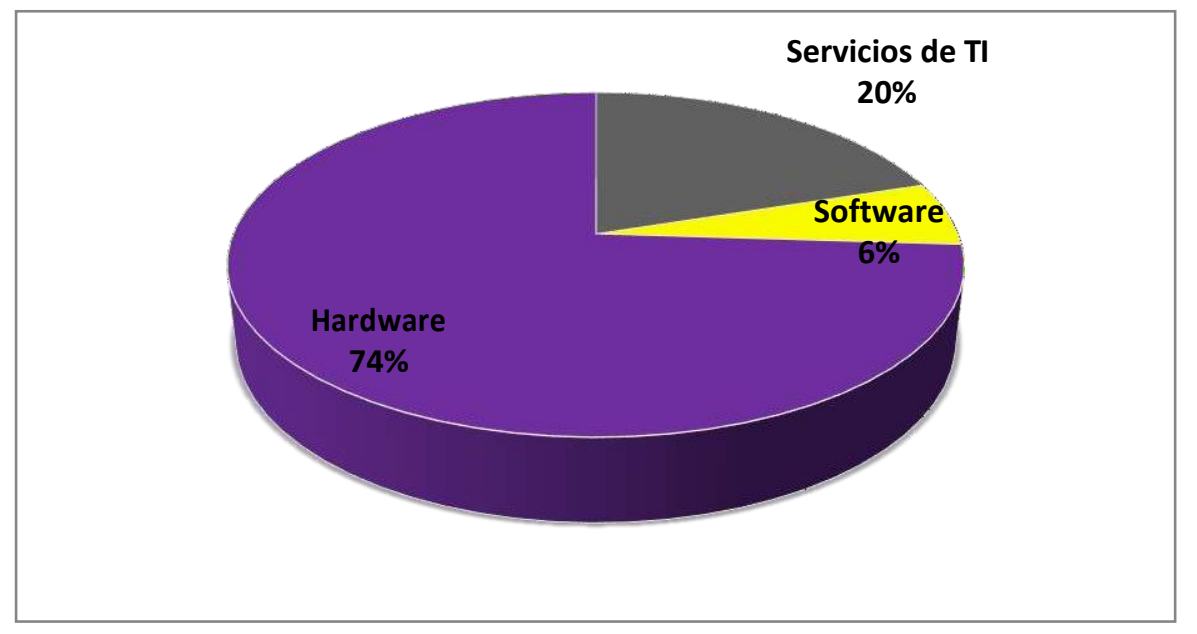

Figura 4. Mercado de TI en Perú año 2014. («Boletín 1», n. d.). Recuperado de http://www.apesoft.org/boletines/boletin-1/ 
De acuerdo a la consultara de marketing digital emultiplied las principales empresas desarrolladoras de Apps en Perú son

Tabla 4

Principales empresas desarrolladoras de Apps en Perú

\begin{tabular}{lr}
\hline Nombre de Empresa & Número de Clientes \\
\hline+1 SAC & 30 \\
Abcdroid & 10 \\
Apps Lovers SAC & 10 \\
Belatrix Software & 5 \\
Andes pacifico sur S.R.L. & 4 \\
Beyond Mobile 15 & 15 \\
Doapps & 5 \\
\hline
\end{tabular}

Estas empresas tienen la mayor participación en el mercado.

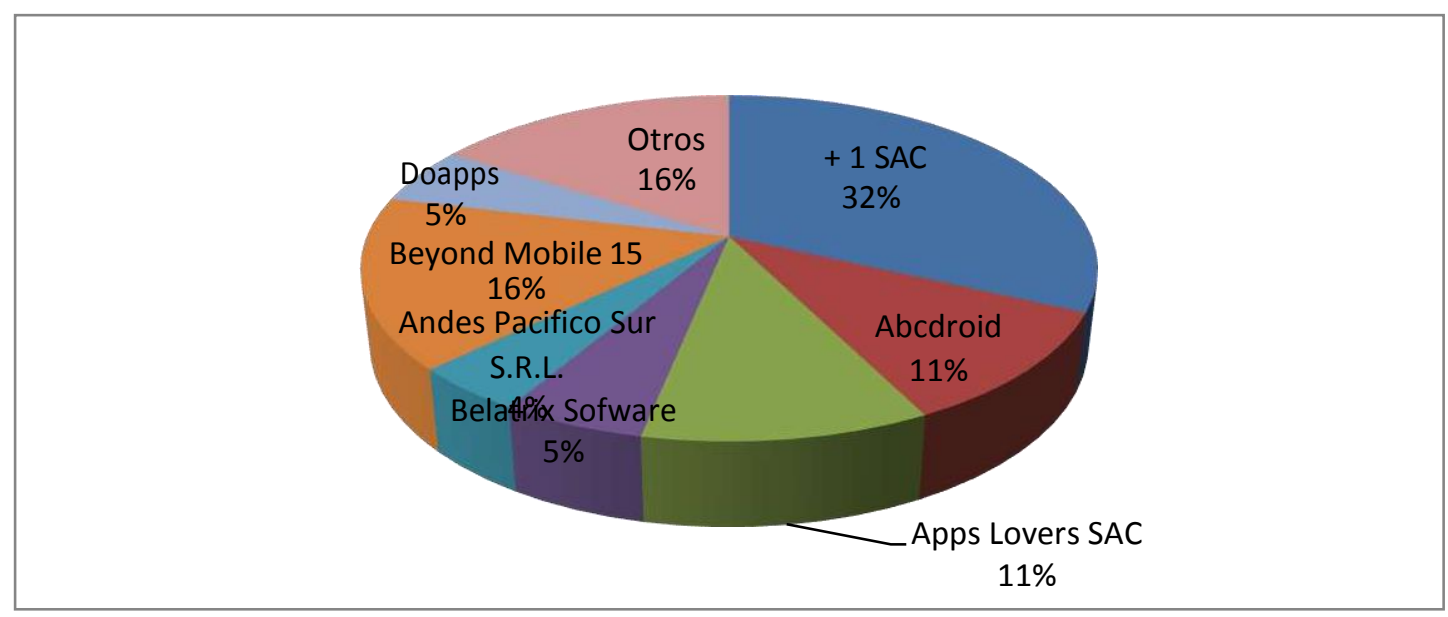

Figura 5. Según Denniss Carranza, gerente de desarrollo de negocios para +1los rubros que se desarrollan son Retail, Banca, Finanzas, Televisión, Medios de comunicación, Educación y Otros 


\subsubsection{Empresas que la conforman}

En octubre del año 2015 Juan Daniel Huapaya, gerente general de Software Enterprise Services mencionó al diario el Comercio que el crecimiento promedio del sector de desarrollo de software estaba alrededor del 30\%, lo que permitió llegar a facturar aproximadamente US\$500 millones en el año 2015. Según Huapaya, en el país, el sector formal de desarrolladores de software emplea a más de ocho mil ingenieros, de los cuales al menos unos seis mil trabajan en los seis principales fabricantes. En cuanto a las exportaciones, crece la mitad de rápido que la demanda local solo 15\%. (Elcomercio.pe, 2015)

\subsection{Tendencias de la industria}

En Perú, el mercado de las TIC está comenzando a tomar fuerza, con perspectivas alentadoras para los próximos cuatro años. Según proyecciones de Business Monitor International (BMI 2015), el crecimiento de las Tecnologías de Información (TI) entre 2012 y 2019 será de $106.7 \%$, y las ventas de servicios asociados con la industria de TI crecerá en $151.2 \%$.

Business Monitor International identificó una serie de market drivers (impulsores del mercado) para la industria de las TI, que justifican sus proyecciones alentadoras. Entre los principales drivers, se señalan el mayor gasto en hardware por parte del sector retail y las mejoras en soporte de infraestructura de las TI; sin embargo, el driver (impulsor de rendimiento) que más destaca es la modernización de las Pymes a fin de mantenerse competitivas. (Mercadosyregiones.com, 2016).

Por su parte, el gobierno peruano a través del Programa Nacional de Innovación para la Competitividad y Productividad - Innóvate Perú del Ministerio de la Producción, en el año 2012, introdujo Start Up Perú, un programa de incubación de pequeñas empresas 
tecnológicas. “Año a año, las aplicaciones a StartUp Perú han aumentado en un $12 \%$ en promedio y el número de startups beneficiarias han aumentado en un 48\%”, indicó Gonzalo Villarán Córdova, director general de Innovación, Transferencia Tecnológica y Servicios Empresariales del Ministerio de la Producción.

En el país, el Consejo Nacional de Ciencia, Tecnología e Innovación (Concytec) también fomenta la creación de startups de investigación científica. Incluso, existe un programa de beneficios tributarios que permite deducir el Impuesto a la Renta de las empresas y centros especializados que inviertan en investigación científica, desarrollo tecnológico e innovación tecnológica.

Universidades y el sector privado también fomentan la creación de empresas en el Perú, como es el caso de Wayra de Telefónica, que ha cumplido cinco años en el país.

Además, Cofide acaba de introducir el fomento a los startups, al capital de riesgo y la inclusión financiera en las empresas, indica el Centro de Desarrollo de la OCDE y el Instituto Nacional del Emprendedor (INADEM) de México.

Villarán reveló que la creciente tendencia por desarrollar emprendimientos de alto impacto hace presumir que el número de startups que saldrán al mercado, superará el 50\% en el 2017, con relación al año 2016. (Gestion.pe, 2016)

Los indicadores mencionados muestran que la tendencia de la TIC va en aumento donde podremos encontrar oportunidades para desarrollar la Plataforma de Comunicación En Tiempo Real Entre Colegio Padres de Familia y Alumnos.

\subsection{Análisis estructural del sector la industria}

En este sentido, Michaux y Cadiat (2009) señalaron que para poder comprender la estructura competitiva de cualquier industria es esencial emplear como instrumento al Modelo de las 5 Fuerzas de Porter. Este modelo visto como herramienta, plantea un análisis 
profundo de la industria en el cual se identifica a la competencia y se reconoce su vulnerabilidad. Asimismo, permite tomar decisiones estratégicas que pueden traducirse en una ventaja competitiva ya que por medio del análisis de las 5 fuerzas es posible prever o adelantar cambios dentro de la industria y en la competencia.

De acuerdo a Porter (2009), es esencial comprender el interior de la industria ya que es esta la que propicia la rentabilidad y la competencia. Asimismo, la forma como se conforman las fuerzas va depender del sector. Para el mismo autor, la rentabilidad de una industria va estar influenciada directamente por la fuerza predominante.

Siguiendo con Porter (2009) el modelo de las 5 Fuerzas de Porter consta de las siguientes fuerzas: amenaza de los nuevos competidores, poder de negociación de los proveedores, poder de negociación de los clientes, amenaza de los productos sustitutos y rivalidad en la competencia entre rivales. 


\section{Factores de la Estructura Industrial del Sector}

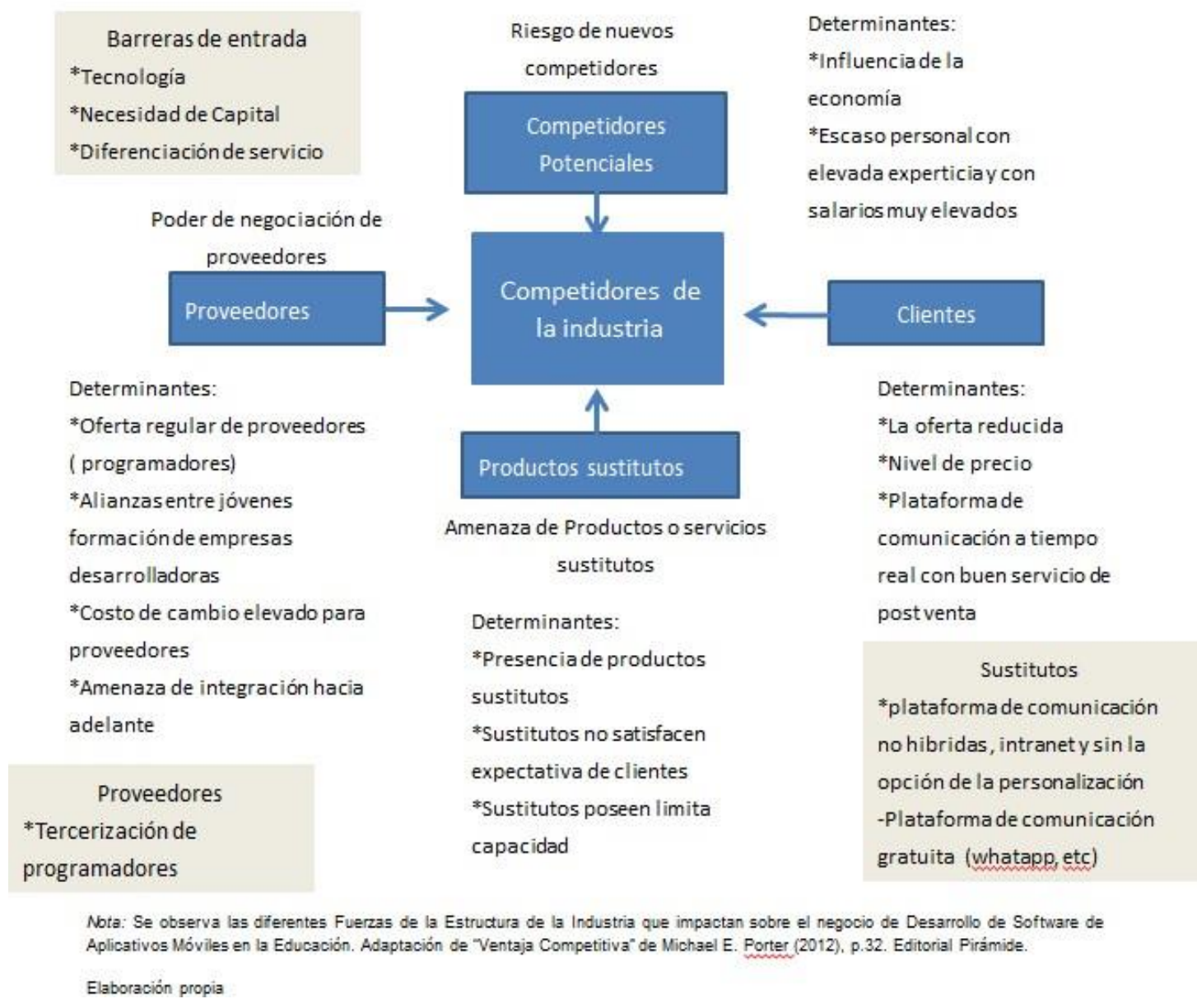

Figura 6. Factores de la Estructura Industrial del Sector. Tomado de Ventaja Competitiva (p.32) por Micharl Porter, 2002, México: Editorial Piramide.

Se empleó la Matriz de la Atractividad de la Industria como una herramienta para analizar y evaluar cada una de las fuerzas de la industria en relación a su Atractividad y su relevancia.

Cada uno de los factores que conforman cada fuerza fue calificada de acuerdo a una escala de 1 al 5 en relación a su atractividad. En donde 1 significa poca atractividad y 5 mucha atractividad. De la misma forma, se califica cada fuerza de acuerdo a la relevancia empleando una escala del 1 al 5. 
Para la calificación se empleó la opinión y asesoría de un grupo de expertos ligados al sector educativo y TI lo cual permitió tener un punto de vista más acertado en relación al análisis y calificación de las diferentes fuerzas de Porter.

Amenaza de ingreso de nuevos competidores

De acuerdo a Porter (2009), el potencial de beneficios de una industria para los empresarios existentes se ve disminuido o desacelerado por el ingreso de los nuevos competidores

Según Hitt, Ireland y Hoskisson (2004) los nuevos competidores que ingresan a un sector generan una gran capacidad competitiva y es ahí en donde radica la amenaza.

Es probable que el ingreso de nuevos competidores represente una amenaza para las empresas consolidadas del sector de desarrollo de software para dispositivos móviles aplicado a la educación.

Actualmente, se pudo reconocer la existencia de algunas empresas en el mercado que otorgan servicio de desarrollo de software para dispositivos móviles especialmente aplicado a la educación. Entre estas están:

- Netschool 360 S.A.C: es una empresa peruana pequeña que se encarga otorgar el servicio de tecnología educativa. Otorga el servicio de plataforma de gestión educativa.

- H\&O SYSTEM S.A.C (Sieweb): empresa peruana con más de 15 años de experiencia, provee diferentes soluciones (sistemas) integrales para mejorar la gestión de colegios. Posee más de 200 clientes en todo el Perú. Otorga diversos sistemas integrales y funcionalidades.

- SIA- NET Sistemas Integrados Empresariales S.A.C: empresa peruana 
- Alexia - Educaría: es una empresa de capitales españoles que proviene de España y desarrolla herramientas tecnológicas que mejoran la educación. Desde el 2014 se encuentran en el Perú y han establecido ciertas alianzas con colegios tanto de la capital como de provincia. Brindan el servicio de una plataforma integral tanto de gestión del colegio administrativa y educativa con diferentes funcionalidades.

A continuación, se detallará los factores que influyen directamente en esta fuerza: amenaza de ingreso de nuevos competidores

i) Influencia de la economía

La economía es un factor que influye en la aceleración del sector de desarrollo de software para dispositivos móviles. Según sondeo Blomberg, la economía peruana crecerá en 4.2\% en el 2017. Lo anterior podría alentar a empresarios peruanos como a extranjeros a invertir en el país, en un negocio relacionado con el desarrollo de software para dispositivos móviles. Cabe señalar, que existe una oportunidad importante de crecimiento en dicho sector. (Gestión.pe, 2017)

ii) Personal con elevada experticia en desarrollo de software para aplicativos móviles son escasos y poseen salarios elevados: En el Perú se evidencia un gran potencial sin embargo aún el emprendimiento de las personas con respecto a desarrollar software es bajo. Una probable causa sea déficit de personas que cuentan con una elevada experticia y porque generalmente estas personas solicitan un salario bien remunerado.

De acuerdo, al observatorio de Educación y Empleo "Ponte en carrera" una de las carreras que se encuentra dentro de las son mejor pagadas en el Perú es la carrera de "Ingeniería de Software" que posee un ingreso promedio nacional de S/ 3488 soles mensuales. Lo anterior, podría generar en los nuevos competidores se les dificulte la 
búsqueda y contratación de dicho personal ya que no sería fácil de identificar y además los salarios que solicitarían serían elevados. (Gestión.pe, 2015)

De acuerdo a Experis Perú, los profesionales mejores pagados en el mercado laboral de país son los profesionales que son expertos en tecnologías de información. (Gestión.pe, 2015)

iii) Barreras de entrada en el sector de construcción de aplicaciones para dispositivos móviles:

i. Tecnología: la tecnología es una barrera costosa y de difícil reproducción. Necesaria para la construcción de software para equipos móviles aplicados a la educación.

ii. Necesidad de Capital: para la inversión en el negocio sea para el pago del alquiler, mobiliario, el pago de licencias de software, impuestos, seguros, salarios de personal administrativo y personal tercero, para la implementación del plan de marketing, pago de servicios como agua, teléfono, electricidad, limpieza, internet, etc.

iii. Diferenciación de producto: Los servicios que ofrecen se diferencian ya que existen algunas empresas que se enfocan en elaborar una plataforma de comunicación adaptada a las necesidades de los colegios mientras que otras empresas sólo ofrecen sus servicios estándar sin posibilidad ni facilidad para adaptarse a las características del colegio.

Es más probable que ingresen competidores extranjeros ya que en el Perú de acuerdo existe un nivel bajo de emprendimiento de las personas en relación al desarrollo de software el cual se plasma en un porcentaje menor al $1 \%$ de participación en el mercado. (Gestion.pe 2016) 
iv) Barreras de salida:

i. Sinergias estratégicas: al realizar este negocio se pueden realizar diversas alianzas que finalmente beneficiarían y permitirían un mayor crecimiento del mismo.

ii. Costos Hundidos: son los diversos desembolsos de dinero relacionados a licencias de funcionamiento y conformación de la empresa, los gastos para la adaptación de la oficina, publicidad, etc.

iii. $\quad$ Costos de salida: son los gastos legales y laborales en los que se pueden incurrir cuando se decide que la empresa deje de funcionar. 
Tabla 5

Matriz de Atractividad para la amenaza de ingreso de nuevos competidores

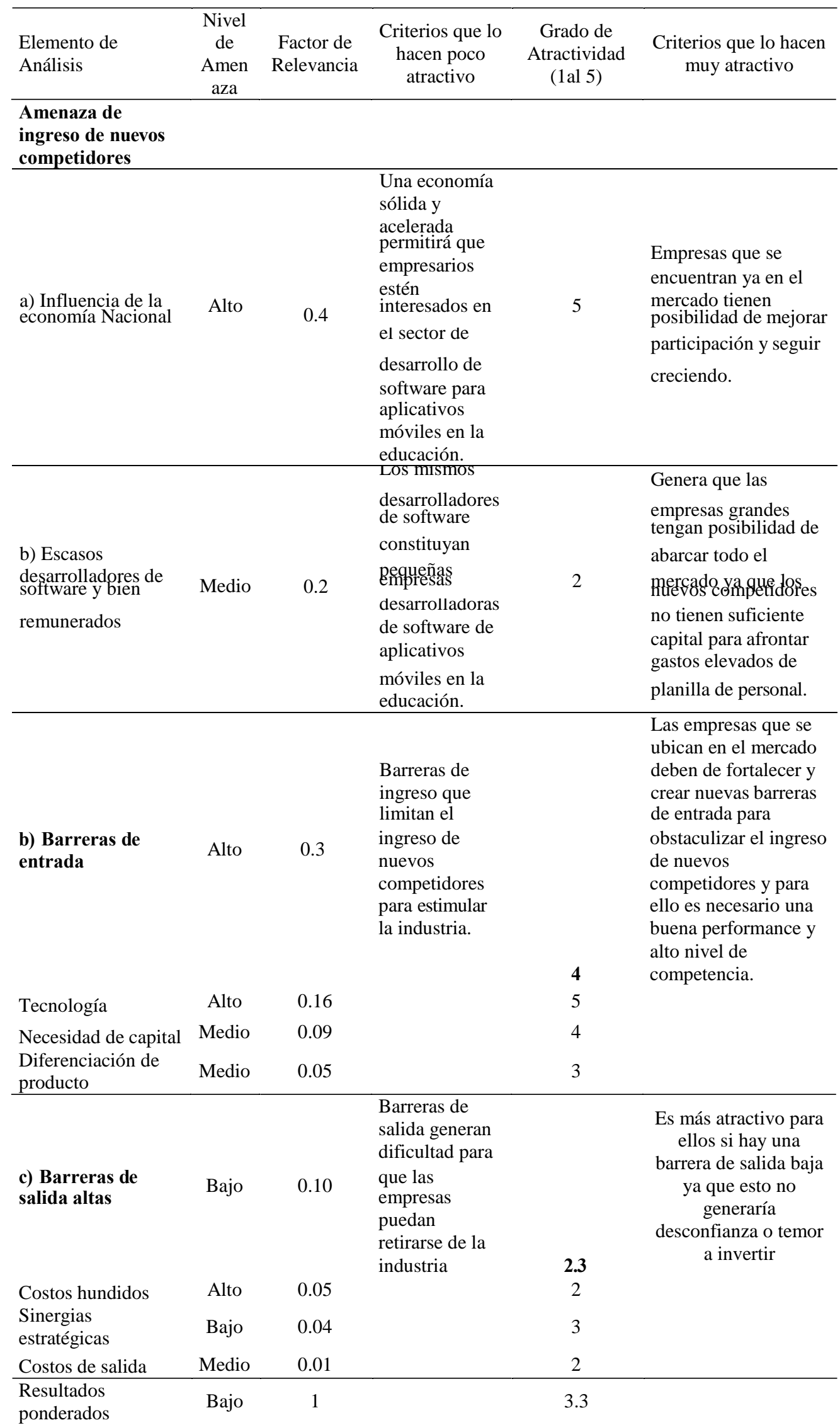


Se obtuvo una calificación de 3.3 en relación a la amenaza de nuevos competidores lo cual señala de que existe un nivel de atractividad elevado sin embargo se observa un nivel de amenaza bajo ya que por el tipo de negocio "tecnología " y la presencia de barreras de entrada como la necesidad de una buena suma de capital; tecnología; necesidad de que el producto se diferencie de los demás para que sea atractivo hacen un tanto difícil su ingreso. Sin embargo, no se pueden decir rotundamente de que dichos obstáculos de ingreso son lo suficientes efectivos.

Por ejemplo, no existe una barrera arancelaria que limite la entrada a nuevos competidores, al contrario, al no existir adecuadas y fuertes, barreras de entrada, podría motivar empresarios tanto peruanos como extranjeros a invertir en dicho sector.

Esto es visible actualmente ya que existen en el sector de desarrollo de software de aplicativos móviles empresas de capitales extranjeros que en estos últimos años han abierto filiales en el mercado peruano como es el caso de Alexia.

B. Rivalidad entre competidores actuales

Según Hitt et al. (2004) existe una dependencia entre empresas rivales ya que las estrategias que siguen unas, impactan en otras, provocando un nivel de competencia importante. Existen dos ocasiones en las cuales la rivalidad competitiva aumenta y esta es cuando el accionar de un competidor son percibidos como un reto por una organización o son vistas como una forma de mejorar su participación en el mercado.

De acuerdo a APESOFT, en la actualidad, existe un número importante de empresas que desarrollan software en el Perú y satisfacen las necesidades de diversos rubros. (APESOFT. Org, 2015) 
Sin embargo, existen pocas empresas que desarrollan software para aplicativos móviles relacionados a la educación y muy pocas que se dedican a elaborar software específicamente dedicado a la mejora de la comunicación entre los padres, alumnos y profesores y al fortalecimiento de la gestión de los colegios.

A continuación, se identificaron los factores críticos relacionados a la fuerza de rivalidad entre competidores actuales.

i) Competencia empresas transnacionales y nacionales:

Existe en el mercado empresas trasnacionales que ofrecen el servicio de plataforma de comunicación y poseen cierta experiencia en el mercado peruano. Generalmente, son de capitales extranjeros que en su país natal tienen mucha experiencia en educación y tecnología como es el caso de Alexia Educaría. Dicha posee amplia experiencia y amplio capital para disponer. Sin embargo, no la consideramos como competencia ya que no se ajusta a las características y proporción del negocio que deseamos establecer.

Existe competencia entre empresas pequeñas como Netschool360 la cual es una empresa peruana y posee un reducido número de personal que genera costos fijos reducidos que se traducen en una mayor ganancia para la empresa. Asimismo, se considera a la empresa H\&O SYSTEM de capital peruano que tiene gran presencia en el mercado peruano y a SIA NET.

Cabe recalcar, que H\&O SYSTEM, SIE NET Y NETSCHOOL 360 son empresas que ofrecen una plataforma integral de gestión de colegios que incluyen dentro de uno de sus módulos al módulo de gestión de comunicación. Se les considera como empresas que ofrecen en parte un servicio con ciertas características a fines al que se propone con EDULINE SCHOOL. 
ii) Crecimiento de la demanda del sector/ tamaño del mercado:

Por un lado, VGB Sistemas, líder en la provisión de sistemas contables, señaló que la industria nacional del Software ha crecido a un ritmo promedio anual alrededor del $15 \%$. (Gestion.pe, 2016)

Lo anterior podría señalar la existencia en el mercado peruano de una creciente demanda del servicio desarrollo de software.

Por otro lado, el Sr. Gustavo Mendoza, gerente comercial de Ofisis, (compañía parte de Softland, desarrolladores de software de gestión ERP Enterprise Resource Planning) señala que el Perú no se caracteriza por ser un país productor de software, que el emprendimiento de las personas que se dedican a desarrollar software es muy bajo y además indica que las empresas que ofrecen dicho servicio sólo han abarcado el 1\% del mercado, que es un parte pequeña, por lo cual existe una gran oportunidad para poder explotarlo. (Gestion.pe 2016)

Todo ello señala que existe una demanda de software y por lo tanto potenciales clientes interesados ya que actualmente se visualiza la importancia que tienen las TIC en la actualidad, en los diferentes rubros, pero en este caso centrándonos en el rubro educativo y en mejoramiento de la comunicación entre padres, alumnos y colegio.

iii) Diferenciación de producto:

En todas las industrias es trascendental el empleo de diversas estrategias para lograr una debida identificación de la marca que permita la fidelización del cliente como también el uso de una estrategia diferenciadora que ayude a establecer parámetros delimitantes entre una empresa y otra en relación al servicio que ofrece. 
En este caso, dentro del sector de desarrollo de software en la educación, existen algunas empresas que ofrecen un servicio personalizado y otras que apuntan a que los colegios se adapten a un servicio estándar. Cabe señalar, que la diferenciación del producto gira en torno al tamaño de la empresa que la ofrece.

Por un lado, las empresas grandes como Alexia ofrecen un servicio de plataforma de comunicación sumado con una serie de funcionalidades como asistencia, gestión de notas, gestión administrativa, ventas, contable, etc.) que abarcan un servicio más integral que gestiona todos los procesos que cuenta un colegio.

Por otro lado, las empresas pequeñas no suelen arriesgarse y se focalizan en una cosa en especial. Sin embargo, las empresas de gran tamaño a pesar de estar en el Perú hace algunos años no han logrado una recordación e identificación de marca en los consumidores como el logro de una cartera variada de clientes, lo cual puede indicar ciertas falencias en su plan de marketing o posiblemente un inadecuado estudio previo del mercado peruano.

En este caso, el negocio que proponemos apunta a personalizar el servicio ante las necesidades reales que poseen el colegio (logos e imagen).

\section{iv) Costos fijos}

Este factor es importante de mencionar ya que como se comentó previamente solo existen algunas pocas empresas que ofrecen el servicio de desarrollo de software de aplicativos móviles en la educación y que generalmente diferencian el servicio que ofrecen en relación al tamaño de su empresa. Como se mencionó, las empresas grandes ofrecen servicios más integrales y personalizados, las pequeñas apuntan a un servicio más estándar y que no poseen muchas funcionalidades.

Las empresas grandes necesitan mayores recursos humanos, por lo cual le demanda a la empresa mayores gastos administrativos, ya que en su planilla existen un gran 
número de personas, alquileres de oficinas grandes, gastos excesivos en servicio de agua, luz, internet y limpieza.

Por otra parte, en empresas más pequeñas suelen tercerizar algunos puestos y no incurren en gastos excesivos, por lo tanto, los costos fijos son reducidos en comparación con las empresas grandes. 
Tabla 6

Matriz de Atractividad para la rivalidad entre competidores actuales

\begin{tabular}{lccccc}
\hline Elemento de Análisis & $\begin{array}{c}\text { Nivel de } \\
\text { Amenaza }\end{array}$ & $\begin{array}{c}\text { Factor de } \\
\text { Relevancia }\end{array}$ & $\begin{array}{c}\text { Criterios que lo hacen } \\
\text { poco atractivo }\end{array}$ & $\begin{array}{c}\text { Grado de } \\
\text { Atractividad } \\
\text { (1al 5) }\end{array}$ & $\begin{array}{c}\text { Criterios que lo hacen } \\
\text { muy atractivo }\end{array}$ \\
\hline
\end{tabular}

Rivalidad entre

competidores actuales

\begin{tabular}{|c|c|c|c|c|c|}
\hline $\begin{array}{l}\text { Competencia con } \\
\text { empresas tradicionales } \\
\text { de comunicación }\end{array}$ & Medio & 0.2 & $\begin{array}{l}\text { Los métodos } \\
\text { tradicionales como el } \\
\text { uso de plataformas de } \\
\text { comunicación que solo } \\
\text { emplean la WEB y los } \\
\text { journals siguen siendo } \\
\text { usados. }\end{array}$ & 3 & $\begin{array}{l}\text { Ayudará a establecer } \\
\text { una diferenciación } \\
\text { entre el servicio, el } \\
\text { cual será un servicio } \\
\text { híbrido (web/ } \\
\text { Smartphone), de alta } \\
\text { personalización y de } \\
\text { fomenta de la marca } \\
\text { Perú. }\end{array}$ \\
\hline $\begin{array}{l}\text { Crecimiento de la } \\
\text { demanda del sector }\end{array}$ & Alto & 0.3 & $\begin{array}{l}\text { Disponer de diversas } \\
\text { estrategias para que la } \\
\text { empresa pueda atender } \\
\text { las diversas necesidades } \\
\text { de los diferentes } \\
\text { colegios. }\end{array}$ & 5 & $\begin{array}{l}\text { Ayuda a potenciar el } \\
\text { sector y permite la } \\
\text { adquisición de } \\
\text { potenciales clientes. }\end{array}$ \\
\hline $\begin{array}{l}\text { Diferenciación del } \\
\text { servicio }\end{array}$ & Medio & 0.3 & $\begin{array}{l}\text { Se emplearán recursos } \\
\text { económicos para } \\
\text { elaborar un adecuado } \\
\text { plan marketing que } \\
\text { permita generar } \\
\text { diferenciación en el } \\
\text { servicio. }\end{array}$ & 3 & $\begin{array}{l}\text { Permitirá tener } \\
\text { adecuado } \\
\text { posicionamiento de la } \\
\text { empresa e } \\
\text { identificación con la } \\
\text { marca y el servicio. }\end{array}$ \\
\hline Costos fijos elevados & Medio & 0.2 & $\begin{array}{l}\text { Las empresas grandes } \\
\text { destinan mayor recurso } \\
\text { económico en los costos } \\
\text { fijos ( planillas, } \\
\text { alquileres, servicios } \\
\text { básicos, etc) lo cual } \\
\text { generara poca } \\
\text { focalización en } \\
\text { elaboración de } \\
\text { estrategias que permitan } \\
\text { mayor posicionamiento } \\
\text { de marca. }\end{array}$ & 3 & $\begin{array}{c}\text { El empleo de la } \\
\text { tercerización permitirá } \\
\text { una disminución de los } \\
\text { costos fijos y } \\
\text { focalización en la } \\
\text { gestión de empresa } \\
\text { como en la elaboración } \\
\text { del plan de marketing } \\
\text { y posicionamiento. }\end{array}$ \\
\hline Resultados ponderados & Bajo & 1 & & 3.5 & \\
\hline
\end{tabular}

Nota: Elaboración propia

Se observa que el grado de atractividad para la rivalidad entre competidores es de 3.5 y su nivel de amenaza es bajo. Cabe señalar, que la industria es concentrada ya que existe un número de competidores muy reducido con una participación de mercado desequilibrada con niveles de competencia bajos, falta de diferenciación , costos fijos altos y existencia de barreras de salida. 
C. Amenaza de productos o servicios sustitutos.

Iborra et al. (2014) afirman que el objetivo de analizar esta fuerza radica en evaluar la amenaza que involucran los productos sustitutos para reemplazar a los productos que existen en el sector.

Existen dos posibles servicios sustitutos, el primero estaría en el empleo de intranet en la cual es posible comunicarse tan solo por correo y no a tiempo a real y que realiza diversas funciones relacionadas a la administración de los colegios. Sin embargo, es válido indicar que es un canal de comunicación entre alumno, padres y colegio, que puede ser empleado como posible sustituto de lo que actualmente se propone, pero con la existencia de limitaciones ya que no se adapta a la necesidad que posee la sociedad en relación al uso actual e incremental de los Smartphone.

El segundo sustituto hace referencia a la existencia de aplicaciones básicas y gratuitas que permiten la comunicación en tiempo real (whatsapp, y otras existentes) entre la escuela, familias y alumnos por medio de sistema de notificaciones a los dispositivos móviles de los usuarios y adicionalmente permite una gestión de colegios muy básica y no hecha a medida. Es decir, que no se adapta a las necesidades únicas de cada colegio lo cual hace referencia a la debilidad que poseen dichas aplicaciones y a su limitado ámbito de trabajo.

No obstante, es necesario remarcar que pueden ser consideradas de cierta manera sustitutos. Debido a que ambos sustitutos poseen limitaciones importantes, se considera que la amenaza de estos sustitutos es media. Lo anterior puede tener un impacto medio en el negocio que desea proponer por lo que sería necesario emplear una estrategia de diferenciación. Sin embargo, es necesario recalcar que en el primer caso no es una plataforma de comunicación a tiempo real y que el segundo caso no se adapta a las necesidades de las escuelas. 
A continuación, se señalan los factores determinantes de la fuerza de amenaza de servicios sustitutos:

a) Presencia de productos sustitutos: como se mencionó previamente existen algunos sustitutos. En este caso mencionarán dos, intranet y whatsapps que no ofrecen el mismo servicio ya que el primero se centra en otorgar el servicio vía web y el último en prestar servicio gratuito, pero sin la facilidad de personalizarlo y oficializarlo. Sin embargo, tienen aceptación.

b) Sustitutos no satisfacen las necesidades o expectativa del cliente: esto puede ser usado como una herramienta para fomentar la diferenciación del servicio que queremos ofrecer el cual será personalizado, con la facilidad para poder adaptarlo a los smartphones y a un precio competitivamente accesible en relación a los demás.

c) Sustitutos poseen una limitada capacidad: Se evidencia limitaciones en el servicio ofrecido por los sustitutos ( falta de personalización, de uso de smarthphones los cuales son altamente empleados por todos los actores educativos y sociedad en general y el precio accesible ) que pueden ser empleadas a favor por el negocio para desarrollo de un servicio que satisfaga debidamente al cliente y que permita posicionar a la empresa como un buen referente de plataforma de comunicación para colegios, alumnos y familias. 
Tabla 7

Matriz de Atractividad para la amenaza de productos o servicios sustitutos

\begin{tabular}{lrrcrl}
\hline Elemento de Análisis & $\begin{array}{r}\text { Nivel de } \\
\text { Amenaza }\end{array}$ & $\begin{array}{c}\text { Factor de } \\
\text { Relevancia }\end{array}$ & $\begin{array}{c}\text { Criterios que lo } \\
\text { hacen poco atractivo }\end{array}$ & $\begin{array}{c}\text { Grado de } \\
\text { Atractividad } \\
\text { (1al 5) }\end{array}$ & $\begin{array}{c}\text { Criterios que lo } \\
\text { hacen muy atractivo }\end{array}$ \\
\hline
\end{tabular}

Amenaza de servicios sustitutos

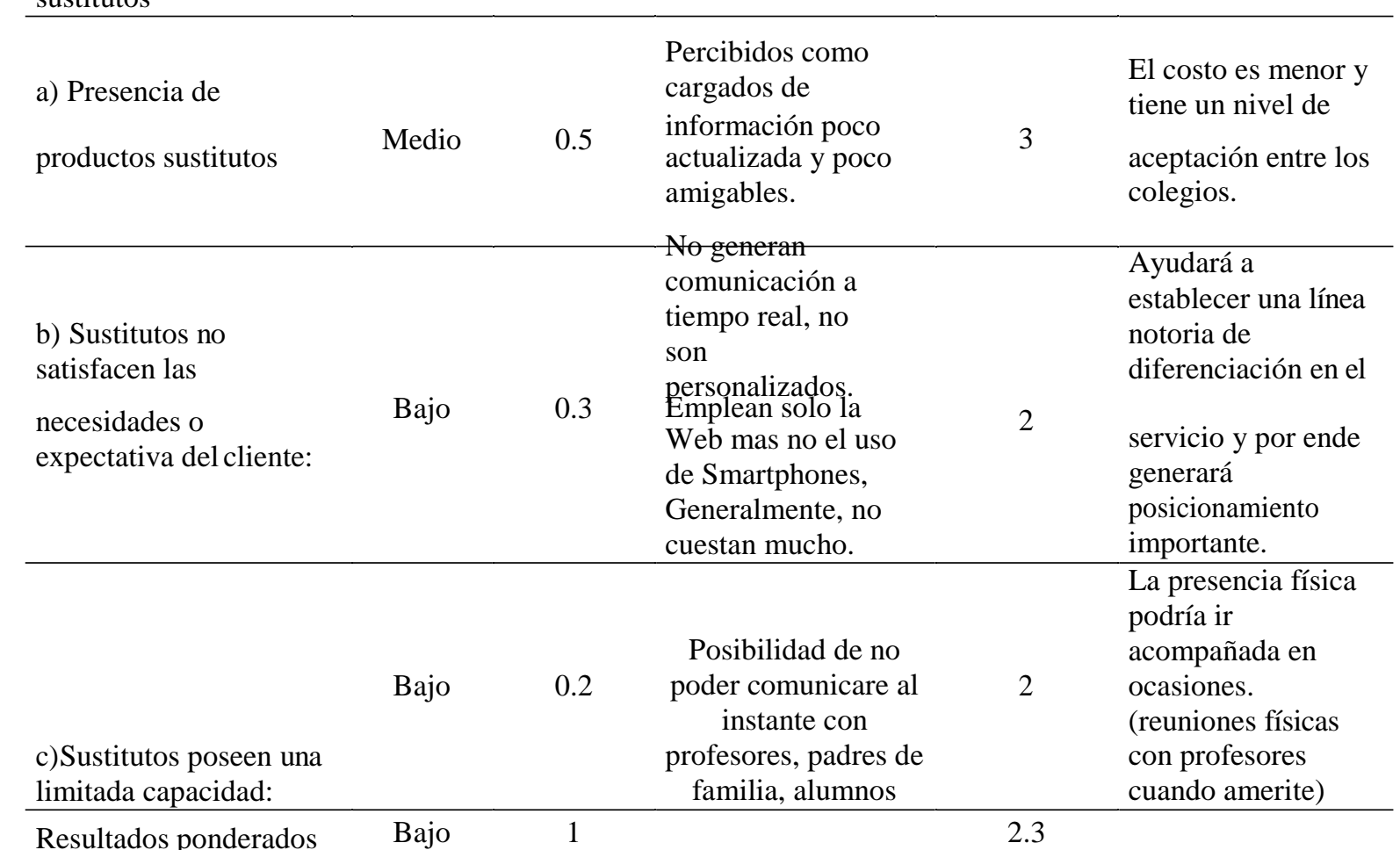

Nota: Elaboración propia

Se observa que el nivel de la atractividad para la fuerza de amenaza de productos sustitutos es de 2.3 y dicha fuerza tiene un nivel de amenaza bajo. Los sustitutos no representan amenaza potencial debido a que poseen capacidad limitada y no se ajustan a las necesidades de cada colegio. La propuesta se diferencia en precio y los beneficios que ofrece.

D. Poder de negociación de los clientes.

Siguiendo a Iborra et al (2014) es cuando los clientes tienen la suficiente influencia para poder establecer las reglas en las interacciones con las empresas del sector. Si los 
clientes poseen un poder de negociación alto esto quiere decir que tiene el poder de cambiar las condiciones.

El poder de negociación de los clientes en el sector de desarrollo de software para dispositivos móviles en la educación tiene un impacto Bajo.

A continuación, se muestran los factores más importantes de esta Fuerza:

a) La oferta del servicio es reducida: esto genera que el cliente no tenga muchas opciones para cambiar de empresa. En el Perú actualmente no existen muchas empresas que ofrezcan el servicio de plataforma de comunicación a tiempo real para profesores, alumnos y familias.

b) Nivel de Precio: El precio será un punto diferenciador que permitirá que esta propuesta sea vista por los clientes como una alternativa interesante debido a que la tarifa mensual a pagar sería accesible y al mismo tiempo se realizarían diversas promociones que permitiría acceder rápidamente a diversos tipos de clientes.

c) Plataforma de comunicación a tiempo real con un buen servicio de post- venta: Esto permitirá ofrecer servicio diferenciador que ayude a ofrecer una ventaja competitiva que finalmente logre la fidelización de clientes e identificación con la marca. El servicio que se desea ofrecer es un servicio personalizado en el cual se levante las necesidades de los colegios para elaborar paquetes que satisfagan los requerimientos de cada uno de los usuarios. Asimismo, el tener un excelente servicio de post venta permitira mejorar el servicio continuamente ya que contará con personal que asista cualquier consulta o duda con la plataforma como también de solución en línea de inconvenientes que pueden presentarse.

Los clientes tienen leves oportunidades de manipular el precio ya que no existe una oferta variada por ello no tendrá alternativas y al no tenerlas no podrá ejercer presión. 
Lo que se busca con la alternativa de negocio a proponer es ofrecer un servicio personalizado, de muy buena calidad y a un precio competitivo que permita a futuro traducirse en una ventaja competitiva sobre las demás alternativas.

\section{Tabla 8}

Matriz de Atractividad para el poder de negociación de los clientes

\begin{tabular}{|c|c|c|c|c|c|}
\hline Elemento de Análisis & $\begin{array}{l}\text { Nivel de } \\
\text { Amenaza }\end{array}$ & $\begin{array}{l}\text { Factor de } \\
\text { Relevancia }\end{array}$ & $\begin{array}{c}\text { Criterios que } \\
\text { lo hacen poco } \\
\text { atractivo }\end{array}$ & $\begin{array}{l}\text { Grado de } \\
\text { Atractividad } \\
\quad(1 \text { al 5) }\end{array}$ & $\begin{array}{c}\text { Criterios que lo } \\
\text { hacen muy } \\
\text { atractivo }\end{array}$ \\
\hline \multicolumn{6}{|l|}{$\begin{array}{l}\text { Poder de negociación de } \\
\text { los clientes }\end{array}$} \\
\hline a) Oferta reducida & Mediano & 0.3 & $\begin{array}{l}\text { Cliente puede } \\
\text { percibir que no } \\
\text { existe variedad } \\
\text { de opciones } \\
\text { que satisfagan } \\
\text { sus } \\
\text { expectativas }\end{array}$ & 3 & $\begin{array}{l}\text { Gran Oportunidad } \\
\text { ya que existe } \\
\text { mercado más } \\
\text { grande }\end{array}$ \\
\hline b) Nivel de precio & Bajo & 0.4 & $\begin{array}{l}\text { La mayoría de } \\
\text { colegios no } \\
\text { está dispuestos } \\
\text { a incluir una } \\
\text { elevada } \\
\text { cantidad }\end{array}$ & 2 & $\begin{array}{l}\text { Clientes van a } \\
\text { pagar una renta } \\
\text { muy baja }\end{array}$ \\
\hline $\begin{array}{l}\text { c)Plataforma de } \\
\text { comunicación con buen } \\
\text { servicio de post venta }\end{array}$ & Bajo & 0.3 & $\begin{array}{l}\text { Podría ser } \\
\text { percibido por } \\
\text { el cliente como } \\
\text { un gasto } \\
\text { adicional. }\end{array}$ & 2 & $\begin{array}{l}\text { percibirían un } \\
\text { servicio diferente y } \\
\text { orientado a mejora } \\
\text { de la satisfacción } \\
\text { del cliente. } \\
\text { Búsqueda de la } \\
\text { mejora continua. }\end{array}$ \\
\hline
\end{tabular}

Resultados ponderados

Bajo

4

Nota: Elaboración propia

Se observa que el nivel de la atractividad para la fuerza de poder de negociación de los clientes es de 2.3 y dicha fuerza tiene un nivel de amenaza Bajo

E. Poder negociador de los proveedores

Iborra, Dasí, Dolz, \& Ferrer (2014) encontraron que los proveedores son aquellas empresas que satisfacen la necesidad de materia prima, recurso humano, maquinaria y otras necesidades del sector. Son ellos los que van a influenciar en la estructura de costos del sector. 
Hitt et al. (2004) encontraron que este poder de negociación de los proveedores se evidencia cuando estos incrementan los precios y disminuyen la calidad como medios para generar presión sobre las organizaciones que compiten en el sector.

Se reconoce como principal proveedor a la empresa desarrolladora (tercerizar) quien se encargará del proceso de construcción de la plataforma de comunicación a tiempo real.

Se ha determinado tercerizar el proceso de la construcción a medida de la plataforma debido a que permita adquirir mayor velocidad y asegurar que la primera versión de la plataforma de comunicación sea más estable y con mínimos errores para luego dedicarnos completamente al perfeccionamiento de acuerdo a las características y exigencias de los clientes.

Se presentan los factores determinantes del poder de negociación de los proveedores:

a) Oferta regular de proveedores: Existen una variedad de Ingenieros programadores, pero es difícil encontrar programadores que tengan la suficiente experiencia en la elaboración de software relacionados a mejorar la comunicación entre los diversos actores.

b) Alianzas entre jóvenes programadores que forman pequeñas empresas de desarrollo de software de apps: lo anterior podría influir de cierta forma en el precio.

c) Costos de cambio elevado para proveedores de servicio: los programadores que trabajan como personal externo poseen una variada cartera de clientes que pierde cada vez que se cambian a otros trabajos. Esto genera que se pierda clientes cotidianos y hasta fidelizados.

d) Integración hacia delante: La empresa desarrolladora que trabajen con nosotros podrían cometer una mala práctica o un acto no ético al tratar de adquirir todos los contactos 
de los clientes que poseemos con la finalidad de lograr un vínculo laboral futuro a su

conveniencia.

Tabla 9

Matriz de Atractividad para el poder de negociación de los proveedores

\begin{tabular}{|c|c|c|c|c|c|}
\hline Elemento de Análisis & $\begin{array}{l}\text { Nivel de } \\
\text { Amenaza }\end{array}$ & $\begin{array}{l}\text { Factor de } \\
\text { Relevancia }\end{array}$ & $\begin{array}{c}\text { Criterios que lo } \\
\text { hacen poco atractivo }\end{array}$ & $\begin{array}{c}\text { Grado de } \\
\text { Atractividad } \\
\quad(1 \text { al 5) } \\
\end{array}$ & $\begin{array}{c}\text { Criterios que lo } \\
\text { hacen muy } \\
\text { atractivo }\end{array}$ \\
\hline \multicolumn{6}{|l|}{$\begin{array}{l}\text { Poder de Negociación de } \\
\text { los proveedores }\end{array}$} \\
\hline $\begin{array}{l}\text { a) Reducida oferta de } \\
\text { proveedores }\end{array}$ & Bajo & 0.3 & $\begin{array}{l}\text { Generaría que los } \\
\text { proveedores puedan } \\
\text { influenciar } \\
\text { directamente en el } \\
\text { precio para el } \\
\text { desarrollo básico de } \\
\text { la plataforma }\end{array}$ & 2 & $\begin{array}{l}\text { Se eleva el } \\
\text { poder del } \\
\text { proveedor para } \\
\text { manipular } \\
\text { precios y } \\
\text { reducir la } \\
\text { calidad }\end{array}$ \\
\hline $\begin{array}{l}\text { b) Alianzas entre jóvenes } \\
\text { programadores que forman } \\
\text { pequeñas empresas de } \\
\text { desarrollo de software de } \\
\text { apps: }\end{array}$ & Bajo & 0.3 & $\begin{array}{l}\text { Posible de que } \\
\text { generen que los } \\
\text { clientes migren. }\end{array}$ & 2 & $\begin{array}{l}\text { Generarían } \\
\text { mayor } \\
\text { competencia e } \\
\text { interés por } \\
\text { mejorar el } \\
\text { desempeño }\end{array}$ \\
\hline $\begin{array}{l}\text { c) Costos de cambio } \\
\text { elevado para proveedores } \\
\text { de servicio: }\end{array}$ & Bajo & 0.2 & & 2 & \\
\hline
\end{tabular}

\begin{tabular}{|c|c|c|c|c|}
\hline $\begin{array}{l}\text { d) Amenaza de integración } \\
\text { hacia delante }\end{array}$ & Medio & 0.2 & $\begin{array}{l}\text { Programadores de } \\
\text { empresa tercera toma } \\
\text { clientes como si } \\
\text { fuera de su posesión } \\
\text { para lanzar un } \\
\text { negocio personal. } \\
\text { (caso anti- ético) }\end{array}$ & 3 \\
\hline Resultados ponderados & Medio & 1 & & 2.25 \\
\hline
\end{tabular}

Nota: Elaboración propia

Se observa que el nivel de la atractividad para la fuerza de poder de negociación de los clientes es de 2.25 y dicha fuerza tiene un nivel de amenaza medio.

Lo anterior se sustenta en la existencia de una oferta reducida de proveedores con experiencia en soluciones tecnológicas relacionadas al sector educativo. Esto puede incurrir mayores gastos de planilla. Además, existe posibilidad de que dicho proveedor puede convertirse en un competidor. (amenaza de integración hacia delante) 
Luego de realizar la industria por medio del Modelo de las 5 fuerzas de porter se puede concluir lo siguiente:

El sector de Información y Comunicación, desarrollo de software para dispositivos móviles es un sector atractivo y económicamente rentable, y representa una oportunidad importante para la inversión.

\subsection{Análisis de la Competencia}

Para que la empresa Eduline School pueda determinar sus estrategias, objetivos, debilidades y fortalezas es necesario primero determinar quiénes son sus principales detractores realizando de esta forma un análisis detallado de la competencia.

Actualmente, Eduline School no cuenta con competidores directos ya que no existen empresas que ofrezcan netamente el servicio específico de gestión de comunicación de instituciones educativas a través de una aplicación móvil. Sin embargo, existen empresas que otorgan el servicio de plataforma integral de colegios. Dentro de esta plataforma existe un módulo que gestiona la comunicación como también otros temas.

Es por ello, que no se pueden precisar competidores directos sino más bien indirectos. Consideramos a los competidores indirectos en este caso son los señalados en el punto 2.4.1

\subsubsection{Empresas que ofrecen el mismo producto o servicio}

Actualmente, la empresa Eduline School posee algunos competidores indirectos en la ciudad de Lima.

Las empresas que ofrecen un servicio de cierta manera a fin al que otorga Eduline School son las siguientes:

Tabla 10 
Empresas que ofrecen servicio de cierta manera a fin al que otorga

Eduline School

$\mathrm{N}^{\circ} \quad$ Nombre de la empresa

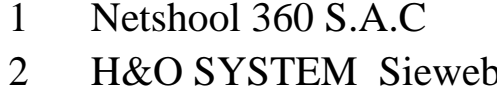

3 Sie - Net Sistemas Integrales empresariales S.A.C

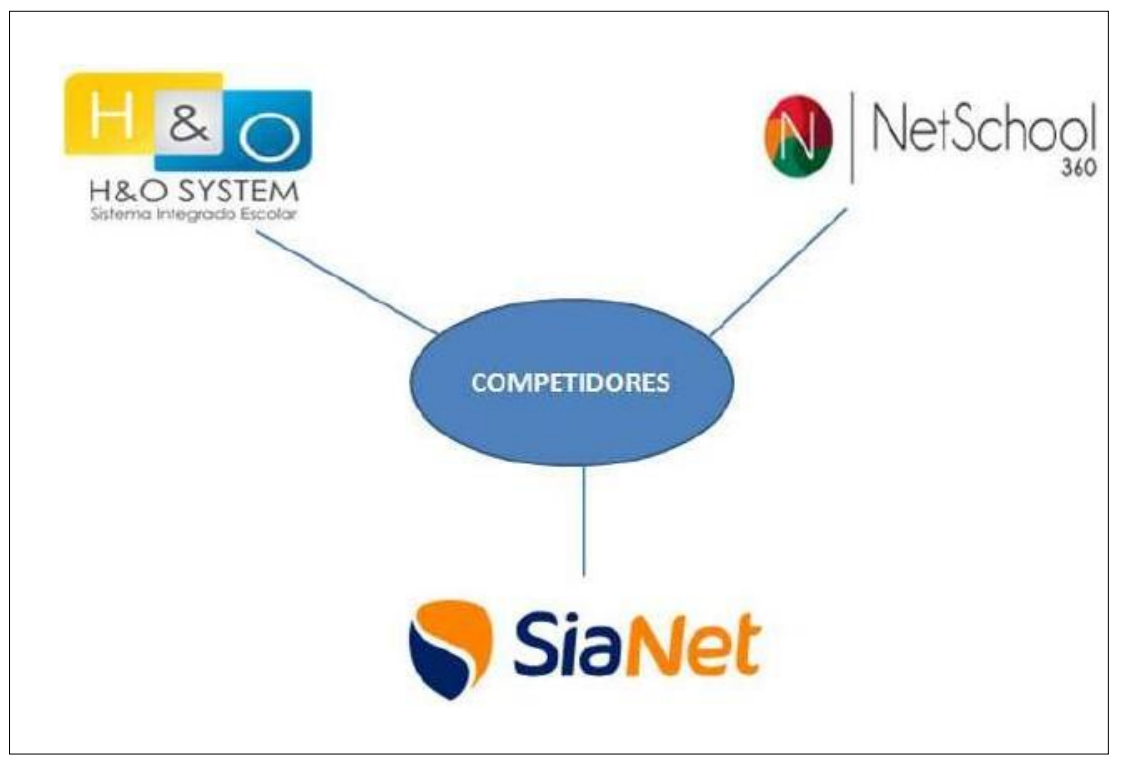

Figura 7. Empresas que ofrecen un servicio de cierta manera a fin al que otorga Eduline School. Elaboración Propia.

La empresa Net school360 S.A.C es una empresa peruana que se especializa en otorgar tecnología educativa para mejorar los procesos educativos y administrativos en las instituciones educativas. Ofrece el servicio de plataforma educativa completa.

A continuación, se detalla las características de la plataforma educativa completa de la empresa Netschool 360:

i) Elabora el registro de notas con posibilidad de exportar la información al SieGie.

ii) Permite el acceso a la información, subir archivos y enlaces de internet

iii) Posee modulo que permite a las escuelas tener un control absoluto de las asistencias del alumnado. 
iv) Realiza administración de las aulas y gestionar cambios en los horarios y carga académica de los maestros y alumnos.

v) Cuenta con agenda inteligente que permite al alumno organizarse

vi) Permite a los maestros generar tareas en línea

Asimismo, el padre podrá visualizarlo desde su dispositivo.

vii) Permite el acceso a la plataforma desde cualquier dispositivo con internet con un usuario y contraseña.

viii) Permite la comunicación con los padres, alumnos, plana docente o administrativa del colegio.

ix) Permite matricular al alumnado desde su hogar por medio de un módulo online.

x) Permite crear comunicados con recordatorios de las fechas y horas (citas, tareas, etc.)

xi) Permite al alumno, profesor y padres visualizar horarios diarios.

xii) Envía alertas dinámicas en tiempo real de todas las actividades, mensajes o comunicados, vía Smartphone o web.

http://www.netschool360.com/

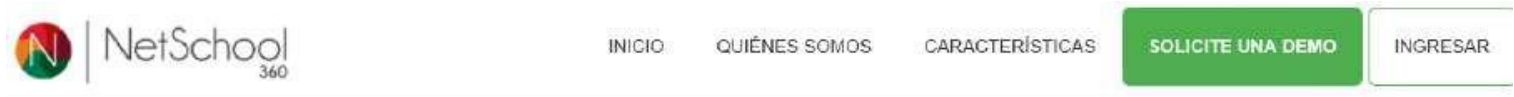

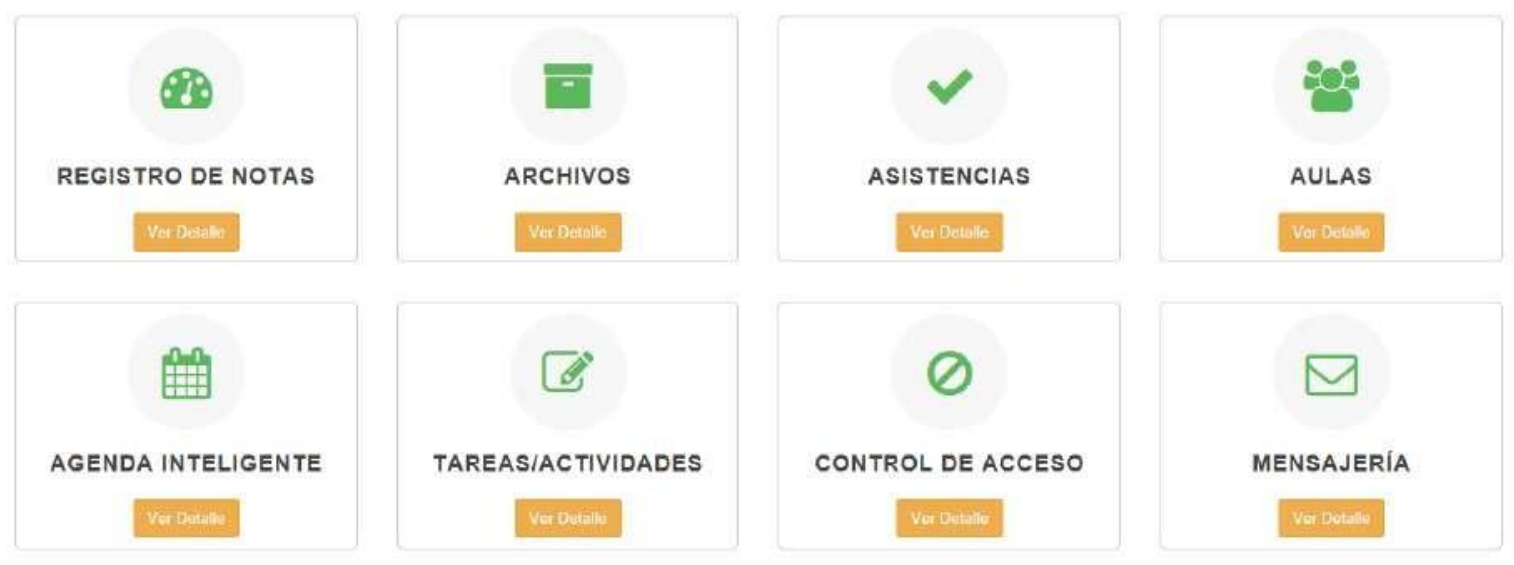

Figura 8. Características del servicio que ofrece NetSchool $360^{\circ}$. Recuperado de http://www.netschool360.com/. 
Otra de las empresas que se clasifica como competidor es la empresa H\&O SYSTEM Sistema Integrad Escolar S.A.C la cual es una sociedad anónima cerrada que inicio sus actividades el 15 de junio del año 2000. Su actividad comercial es programación y suministro informativo. H\&O SYSTEM se califica como empresa líder en lo que respecta a sistemas integrados de colegios. (Entre los sistemas que ofrece: académico, intranet, pensiones, biblioteca, médico, vacaciones útiles). Cuenta con 15 años de experiencia y actualmente posee como cliente a más de 200 colegios en todo el Perú. Asimismo, poseen diferentes sistemas integrados que son creados de acuerdo a las necesidades de cada institución educativa.

La empresa H\&O SYSTEM cuentas con diferentes sistemas entre ellos están:

i) Sieweb Académico: Permite el control del proceso escolar, desde la matricula hasta la evaluación de los resultados.

ii) Sieweb pensiones: permite llevar el control de las pensiones y registro de cobros, define calendario de pagos, saldos, etc.

iii) Sieweb intranet: permite comunicación constante entre padres y profesores

iv) Sieweb biblioteca: permite el ingreso de código, controla préstamos y educa

v) Sieweb Médico: Permite controlar el bienestar de los alumnos por medio de un sistema de atención de salud escolar.

vi) Sieweb Vacaciones útiles: permite administrar la distribución de los cursos en el periodo vacacional.

vii) Sieweb Postulante: permite el registro de datos y tramites que debe realizar el postulante

viii) Sieweb Histórico

Asimismo, H\&O SYSTEM ofrece diversos servicios entre ellos están:

i) Diseño Web 
ii) Hosting y Dominio: H\&O SYSTEM brinda el servicio de hosting en donde permiten al cliente alojar su página web en Servidores seguros permitiendo almacenar información, imágenes y videos.

http://sieweb.com.pe/

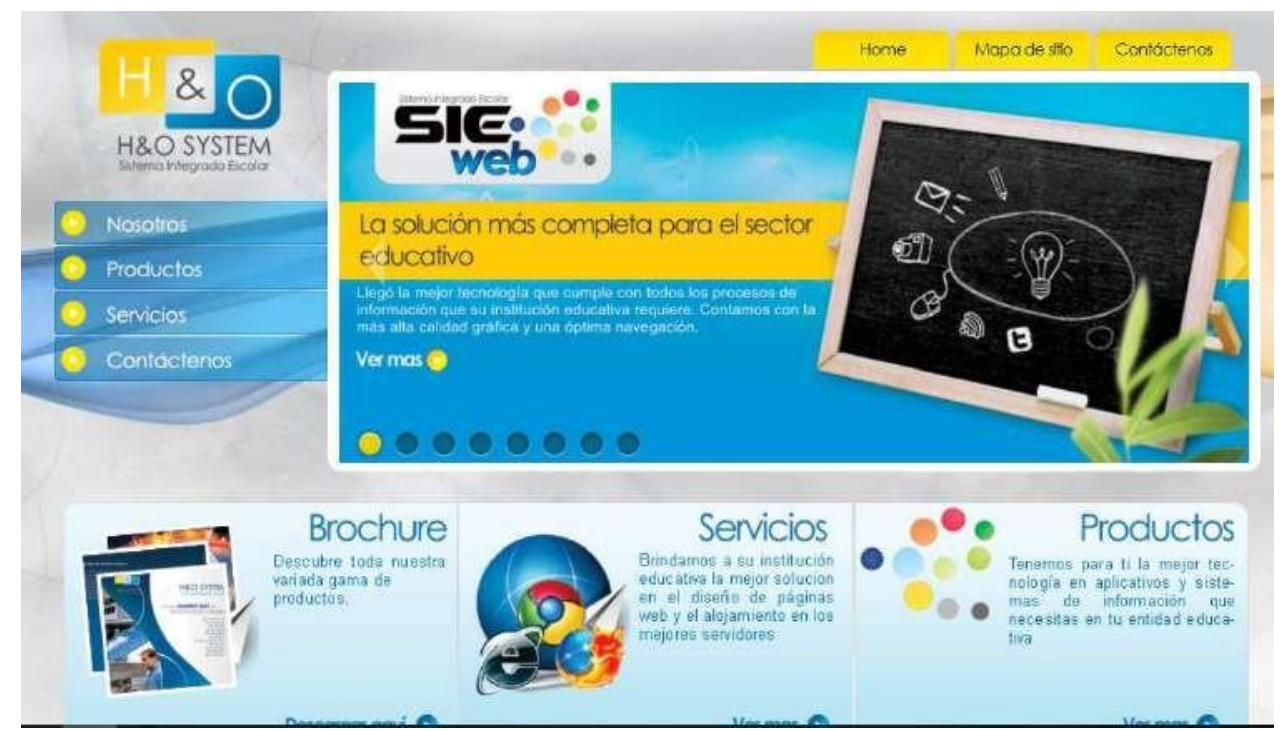

Figura 9.Presentación de página Web de Sie Web. Recuperado de http://sieweb.com.pe/

La empresa Sie - Net Sistemas Integrales empresariales S.A.C es otra de las empresas peruanas competidoras que se especializa en el desarrollo de herramientas tecnológicas hace 11 años. Desde el 2004 SiaNet funciona en los colegios del país. Asimismo, ha desarrollado una variedad de módulos que satisfacen las diversas necesidades de cada colegio. Desarrollan diferentes módulos con funcionalidades variadas.

Módulos que desarrollan:

i) Sistema de notas

ii) Sistema de tesorería

iii) Programación curricular

iv) Nominas actas y registros oficiales

v) Exámenes virtuales

vi) Encuestas virtuales 
vii) Matricula online

viii) Preceptoría

ix) Psicología

x) Médico

xi) Roles de exámenes

xii) Horario de clases

xiii) Apafa

xiv) Foros

xv) Escuela de Padres

xvi) Notificaciones

xvii) Mensajería interna

xviii) Admisión

xix) Exalumnos

xx) Consejo de administración

xxi) Galería de fotos

xxii) Certificados de estudios

xxiii) Tareas, agendas, archivos y enlaces

xxiv) móviles

Las características del servicio que ofrecen son: fácil de usar, reducción de tiempos y costos, sistema de notas, matriculas, generación de reportes, no requiere de software ni hardware adicional, mensajería, soporte técnico. http://www.sianet.com.pe 

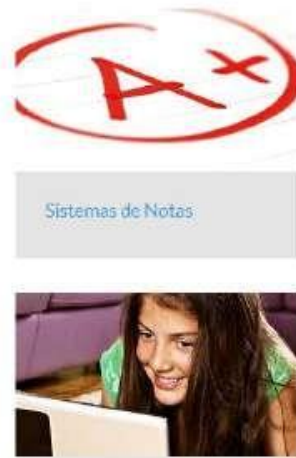

Exámeries Virtuales
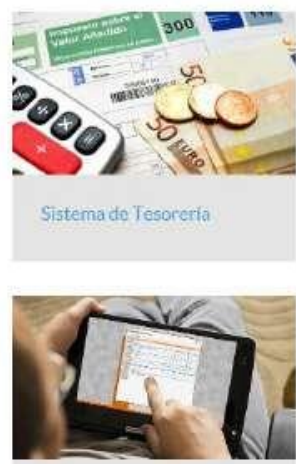

Encuestas Virtuale:
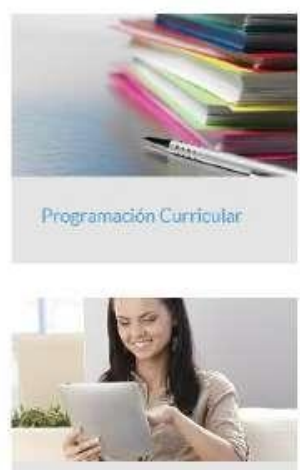

Matricula Online
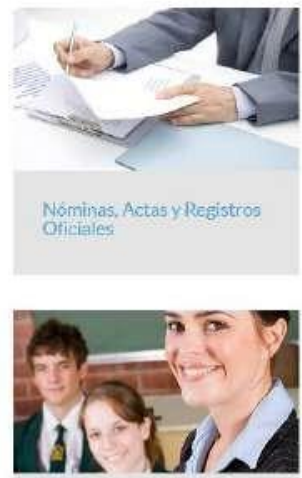

Figura 10. Módulos del servicio otorgado por SieNet. Recuperado por

http://www.sianet.com.pe/modulos.html

A continuación, se muestra las semejanzas y diferencias entre la propuesta de servicio de

Eduline School en contraposición con sus competidores Netschool360, Sieweb y SiaNet.

Tabla 11 Semejanzas y diferencias entre la propuesta de servicio y los competidores

Semejanzas y diferencias entre la propuesta de servicio y los competidores

\begin{tabular}{|c|c|c|c|c|}
\hline Característica analizada & $\begin{array}{l}\text { Propuesta de } \\
\text { Servicio }\end{array}$ & $\begin{array}{l}\text { Net School } \\
360\end{array}$ & $\begin{array}{c}\text { H\&O System } \\
\text { S.A.C - Sia Web }\end{array}$ & $\begin{array}{l}\text { Sia-Net Sistemas } \\
\text { Integrales } \\
\text { empresariales S.A.C }\end{array}$ \\
\hline
\end{tabular}

\begin{tabular}{lccc}
\hline a) Funcionalidad & Bueno & Muy Bueno & Muy Bueno \\
b) Fiabilidad & Bueno & Bueno & Muy Bueno \\
c) Usabilidad & Regular & Muy Bueno & Muy Bueno \\
d) Eficiencia & Regular & Muy Bueno & Bueno \\
e) Mantenibilidad & Bueno & Muy Bueno & Bueno \\
f) Portabilidad & Bueno & Muy Bueno & Bueno
\end{tabular}

\begin{tabular}{lllll}
\hline Precio S/ & 749 & 1500 & 2500 & 2000 \\
\hline
\end{tabular}




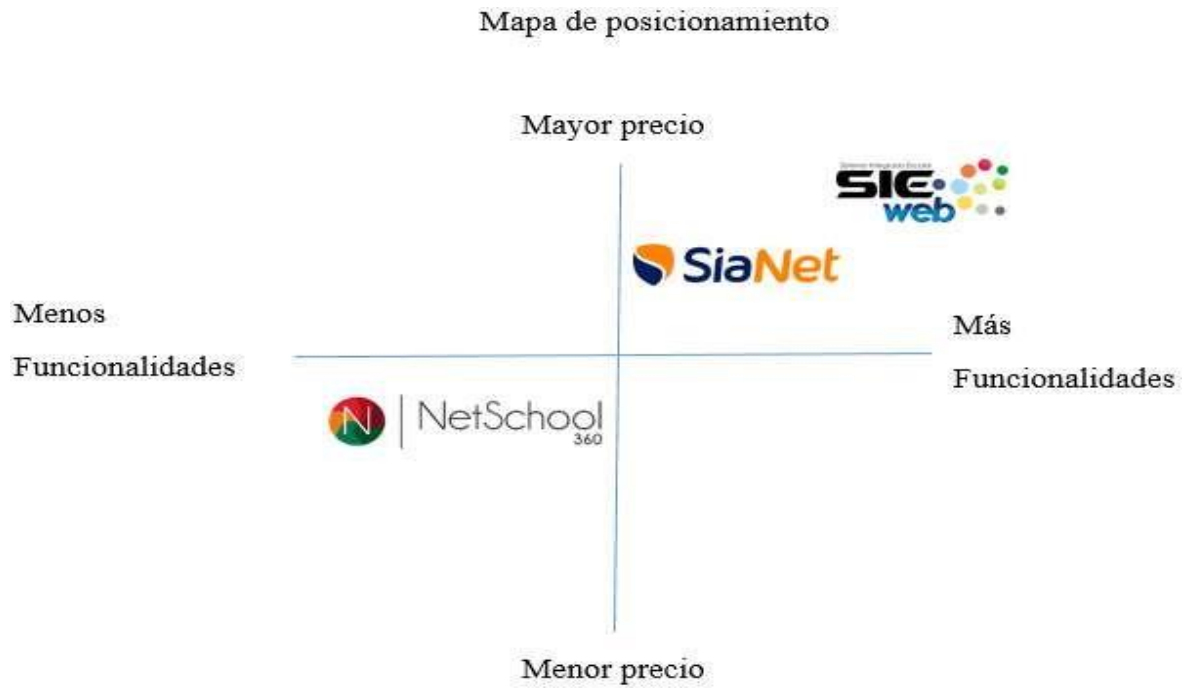

Figura 11. Mapa de posicionamiento. Elaboración Propia

\subsubsection{Participación de mercado de cada uno de ellos}

Tabla 12

Participación de mercado

\begin{tabular}{lcccc}
\hline Empresa que ofrece el servicio & $\begin{array}{c}\text { Año de } \\
\text { fundación }\end{array}$ & $\begin{array}{c}\text { Tiempo en el } \\
\text { mercado }\end{array}$ & $\begin{array}{c}\text { Colegios afiliados al } \\
\text { servicio }\end{array}$ & $\begin{array}{c}\text { Participación } \\
\%\end{array}$ \\
\hline Net School 360 & 2014 & 3 años & 30 & $15 \%$ \\
H\&O System S.A.C - Sieweb & 2002 & 15años & 150 & $45 \%$ \\
$\begin{array}{l}\text { Sia - Net Sistemas Integrales } \\
\text { empresariales S.A.C }\end{array}$ & 2006 & 11 años & 80 & $24 \%$ \\
Otros & & & 50 & $15 \%$
\end{tabular}

Fuente: Datos extraídos de la web de la empresa y de la web de los colegios 
Tanto Net School 360, H\& O System S.A.C y Sia- Net Sistemas Integrales empresariales S.A.C son tres suites completas que podrían ser de cierta manera algo comparables a la propuesta que deseamos proponer con Eduline School.

Cabe señalar, que en el mercado no existen aplicaciones similares sino más bien suites mucho más integrales que se focalizan en la gestión de toda la institución educativa ofreciendo diversos módulos. Sin embargo, no existe de modo específico una suite que se focalice en tan solo gestionar adecuadamente la comunicación.

Debido a la inexistencia de una empresa de servicio que ofrezca el mismo servicio y de acuerdo a lo señalado por el asesor de la siguiente investigación, se decidió comparar Eduline School con Net School 360, H\& O System S.A.C y Sia- Net Sistemas Integrales empresariales S.A.C ya que son suites completas que ofrecen un servicio que no es idéntico pero que posee ciertas características que la asemejan a una suite de comunicación pero solo por vía mensaje electrónico.

\subsubsection{Matriz de perfil competitivo}

De acuerdo a David (2013) la Matriz de Perfil Competitivo (MPC) ayuda reconocer a los competidores más importantes, identificando sus fortalezas y debilidades comparándola con la empresa, con el objetivo de determinar la posición estratégica del mercado de esta última.

El mismo autor señala que los factores críticos de éxito en una Matriz de Perfil Competitivo toman en cuenta lo interno como lo externo. El análisis comparativo que se realiza entre las compañías detractoras y la compañía abastece de importante información estratégica interna. 
En este caso, la Matriz de Perfil competitivo (MPC) permitirá evaluar y analizar tanto las fortalezas y debilidades de los competidores directos con respecto a las de la empresa Eduline School tomando en cuenta los factores críticos de éxito para la industria.

A continuación, se indican los procedimientos que se realizan para poder elaborar la matriz de Perfil Competitivo:

i) Los factores críticos de la industria serán seleccionados previamente con sumo cuidado por un grupo de expertos quienes determinarán cuales son los que se considerarán en la MPC.

ii) Luego, se solicita a tres expertos con gran experiencia relacionada a la educación, que realicen la ponderación de cada uno de los factores críticos de éxito. Cabe señalar, que ninguno tiene influencia sobre el otro ya que ponderaron de manera separada y cada opinión permanece en resguardo imposibilitando su influencia.

iii) Posteriormente, se obtuvo la ponderación con la que se trabajaría en la MCP por medio de un promedio simple.

iv) Por último, se procede a colocar la ponderación.

Para evaluar la Matriz de Perfil Competitivo se seleccionaron los siguientes factores críticos de éxito referente al negocio:

a) Calidad del servicio: es esencial otorgar un excelente servicio que permita fidelizar al cliente.

b) Participación del mercado: es importante una mayor participación del mercado ya que esto posibilita un crecimiento importante de la empresa y de esta forma ayuda a reducir posibilidad de competidores.

c) Competitividad en los precios: es esencial gozar de un precio atractivo sin embargo es de igual manera importante la calidad del servicio. La calidad no debe sacrificarse por 
un precio bajo. Cada empresa fijara sus precios en torno a la estrategia que hayan elegido.

d) Seguridad: en este tipo de negocios en donde se pone en juego información reservada es muy importante la confiabilidad y seguridad de la información. Deben de existir formas de salvaguardar la información ya que este es un factor sumamente importante y valorado por los colegios y que determinaría el optar o no por el servicio.

e) Accesibilidad: de igual forma es de vital importancia el tener facilidad en el acceso a la plataforma, sea amigable e intuitiva.

f) Posición financiera: este factor tiene una influencia importante ya que permite saber si la empresa goza de solvencia, posee estabilidad y si existe productividad.

g) Innovación: es de vital importancia ya que el actualizarse y continuamente buscar nuevas formas de satisfacer las necesidades reales de la comunidad educativa permitiría de estar vigente y tener la aceptación de la mayoría de los colegios.

h) Publicidad: la forma como se publicita y se llega a la población objetivo es también un factor determinante para el éxito ya que se debe de encontrar la manera más adecuada.

i) Personalización: La personalización del servicio es básico hoy en día ya que permite ajustarse a los requerimientos y necesidades del cliente y por lo tanto genere una mayor compenetración e identificación del cliente para con el servicio.

En la tabla se presenta los promedios realizados por los expertos, se adiciona también el promedio final para cada factor con el cual se elabora la Matriz de Perfil Competitivo.

Los competidores elegidos para este análisis son Netschool 360 S.A.C, H\&O SYSTEM S.A.C. y Sie- Net Sistemas Integrales Empresariales S.A.C. 
Tabla 13

Análisis FCE

\begin{tabular}{llcccc} 
& & \multicolumn{3}{c}{ Ponderación } \\
$\mathrm{N}^{\circ}$ & Factores Críticos de Éxito & Experto 1 & Experto 2 & Experto 3 & $\begin{array}{c}\text { Ponderado } \\
\text { Promedio }\end{array}$ \\
\hline 1 & Calidad de servicio & $12 \%$ & $10 \%$ & $11 \%$ & $11 \%$ \\
2 & Participación de mercado & $13 \%$ & $11 \%$ & $12 \%$ & $12 \%$ \\
3 & Competitividad en los precios & $11 \%$ & $10 \%$ & $10 \%$ & $10 \%$ \\
4 & Seguridad & $9 \%$ & $9 \%$ & $9 \%$ & $9 \%$ \\
5 & Accesibilidad & $10 \%$ & $10 \%$ & $10 \%$ & $10 \%$ \\
6 & Posición financiera & $10 \%$ & $10 \%$ & $12 \%$ & $11 \%$ \\
7 & Innovación & $14 \%$ & $17 \%$ & $16 \%$ & $16 \%$ \\
8 & Publicidad & $9 \%$ & $11 \%$ & $10 \%$ & $10 \%$ \\
9 & Personalización & $12 \%$ & $12 \%$ & $10 \%$ & $11 \%$ \\
& Total & & & & \\
\hline
\end{tabular}

Elaboración propia

Se necesitó la opinión de tres expertos para dar valor a cada uno de los factores críticos con la finalidad de analizar un servicio de plataforma de comunicación en tiempo real entre colegios, padres de familia y alumnos.

\subsection{Análisis del Contexto Actual y Esperado}

Según D’Alessio (2013) los factores externos principales se analizan de manera global y sistémica, analizando las fuerzas políticas, sociales, tecnológicas, económicas, competitivas y ecológicas.

Para este análisis se ha utilizado el método PESTEL, el cual agrupa los factores del macro ambiente, político, económico, social, tecnológico, ecológico y legal.

\subsubsection{Análisis político-gubernamental}

Según D’Alessio (2013) las fuerzas políticas, al igual que las legales, son las que determinan las reglas que debe regir una organización y se encuentran vinculadas a los procesos de poder que rodean a las organizaciones, así como a la competencia de intereses de los involucrados. 
Las medidas tomadas por el actual gobierno como la reducción del IGV, la disminución del pago del tributo a la renta y el aumento del salario de los trabajadores públicos tendrían un gran impacto en la capacidad de gasto de las familias este año.

En el ámbito de las facultades legislativas otorgadas por el legislativo, a partir del 1 de julio de este año, la tasa del IGV pasará de $16 \%$ a 15\%. A ello se suma el $2 \%$ del Impuesto de Promoción Municipal, lo que arroja una nueva tasa conjunta de 17\%., esta reducción está sujeta al alcance de una meta de recaudación del IGV neto del 7.2\% del PBI (elcomercio.pe, 2017)

Otro factor relevante en la política actual es el regreso del Impuesto a la Renta del $28 \%$ al $30 \%$ con la finalidad de que las grandes empresas contribuyan más y disminuir el impacto del punto porcentual en el IGV, las empresas pequeñas que facturen menos de 30UIT pagaran el 10\% por un plazo de diez años (gestion.pe, 2016)

\subsubsection{Análisis Económico}

Según Thompson, Peteraf, Gamble y Strickland (2012) esta fuerza del macroambiente involucra a los factores de los ámbitos internacionales, nacionales, regionales y locales que impactan a los diversos sectores, en la confianza de los clientes y en su capacidad de gasto.

En los años recientes el Perú ha obtenido niveles de crecimiento de su economía por encima del promedio en la región, el Producto Bruto Interno muestra un importante crecimiento, debido a la sólida gestión macroeconómica del país de los últimos años existiendo actualmente grandes proyectos de inversión en cartera.

En enero del presente año, el Fondo Monetario Internacional (FMI) había pronosticado que la economía peruana iba a crecer $4.1 \%$ en el 2017 pero en su nuevo informe de proyecciones mundiales decidió subir a $4.3 \%$ su pronóstico para el Perú. (gestion.pe, 2016) logrando ser la segunda de mayor crecimiento en Sudamérica. 
Según el FMI, Perú sigue siendo una de las mejores economías en América, por sus firmes políticas macroeconómicas. («Peru: 2015 Article IV Consultation--Press Release; Staff Report; and Statement by the Executive Director for Peru; IMF Country Report 15/133; May 5, 2015 - cr15133.pdf», n. d

De acuerdo al informe de actualización de proyecciones macroeconómicas del Ministerio de Economía y Finanzas MEF del 30 de abril del 2017, la economía peruana crecerá este año 3,0\% y mantendrá su posición de liderazgo en Sudamérica, a pesar de hacer frente a dos problemas: El Niño Costero y la paralización de importantes obras de infraestructura vinculadas a empresas brasileñas.

El entorno internacional favorable permitirá compensar parte del impacto adverso de El Niño Costero y la paralización de obras de infraestructura asociadas al caso Odebrecht. De acuerdo a estimaciones del MEF, el 2017 es la primera vez en cinco años que el entorno internacional será un factor que contribuya positivamente con la actividad económica (alrededor de 0,3 p.p. de mayor crecimiento a la economía peruana respecto del 2016). Ver figura 12

\begin{tabular}{|c|c|c|c|c|c|c|c|c|c|c|}
\hline \multicolumn{11}{|c|}{$\begin{array}{c}\text { PBI Mundo y Socios Comerciales } \\
\text { (Var \% real anual) }\end{array}$} \\
\hline & \multirow[b]{2}{*}{ 2011-2015 } & \multirow[b]{2}{*}{2016} & \multicolumn{3}{|c|}{ MMMR 2017-2019 } & \multicolumn{5}{|c|}{ Informe de Actualización } \\
\hline & & & 2017 & 2018 & 2019 & 2017 & 2018 & 2019 & 2020 & 2021 \\
\hline Mundo & 3,5 & 3,1 & 3,0 & 3,2 & 3,4 & 3,5 & 3,6 & 3,7 & 3,7 & 3,7 \\
\hline Economias Avanzadas & 1,6 & 1,7 & 1,6 & 1,6 & 1,8 & 2,0 & 2,0 & 1,9 & 1,7 & 1,7 \\
\hline Estados Unidos & 2,1 & 1,6 & 2,0 & 2,1 & 2,2 & 2,3 & 2,5 & 2,1 & 1,8 & 1,7 \\
\hline Zona Euro & 0,7 & 1,7 & 1,3 & 1,2 & 1,2 & 1,7 & 1,6 & 1,6 & 1,5 & 1,5 \\
\hline Japón & 0,6 & 1,0 & 0,6 & 0,5 & 0,5 & 1,2 & 0,6 & 0,8 & 0,2 & 0,7 \\
\hline $\begin{array}{l}\text { Economias Emergentes y en } \\
\text { Desarrollo }\end{array}$ & 5,0 & 4,1 & 4,4 & 4,9 & 4,9 & 4,5 & 4,8 & 4,9 & 4,9 & 5,0 \\
\hline China & 7,9 & 6,7 & 5,7 & 5,2 & 5,0 & 6,6 & 6,2 & 6,0 & 5,9 & 5,8 \\
\hline India & 6,7 & 6,8 & 7,5 & 7,6 & 7,7 & 7,2 & 7,7 & 7,8 & 7,9 & 8,1 \\
\hline América Laina y el Caribe & 2,3 & $-1,0$ & 0,4 & 1,7 & 2,1 & 1,1 & 2,0 & 2,5 & 2,6 & 2,7 \\
\hline PBI Socios Comerciales ${ }^{1}$ & 3,8 & 2,7 & 1,6 & 2,0 & 2,1 & 3,2 & 3,3 & 3,2 & 3,2 & 3,1 \\
\hline
\end{tabular}

1/ 20 principales socios comerciales en base a la ponderación del 2015. Fuente: WEO - FMI (abril 2017), Proyecciones MEF.

Figura 12. PBI Mundo y Socios Comerciales. Tomado de "Informe de actualización de proyecciones macroeconómicas," por el Ministerio de Economía y Finanzas MEF, 2017. 
Recuperado de https://www.mef.gob.pe

/contenidos/pol_econ/marco_macro/informe_actualizacion_proyecciones.pdf

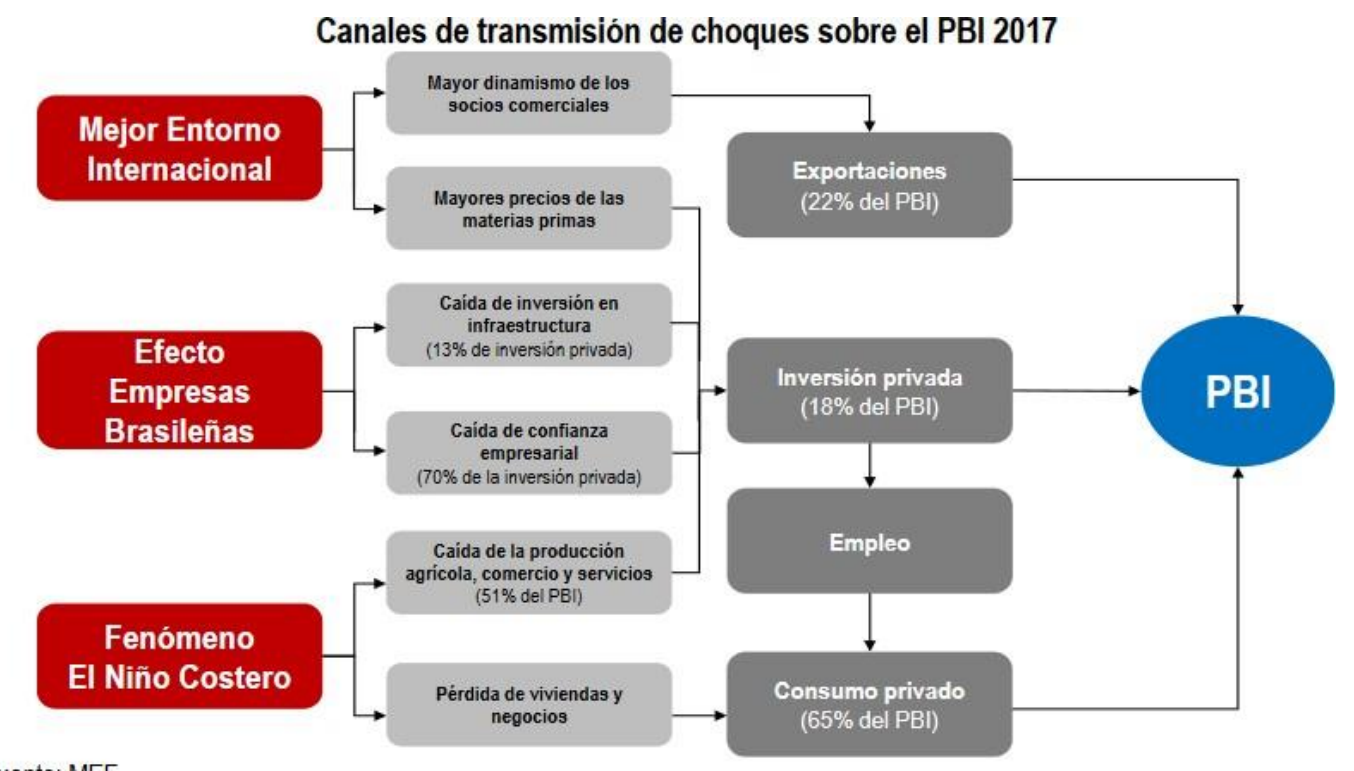

Figura 13. Canales de transmisión de choques sobre el PBI 2017. Tomado de "Informe de actualización de proyecciones macroeconómicas," por el Ministerio de Economía y Finanzas MEF, 2017. Recuperado de https://www.mef.gob.pe

/contenidos/pol_econ/marco_macro/informe_actualizacion_proyecciones.pdf

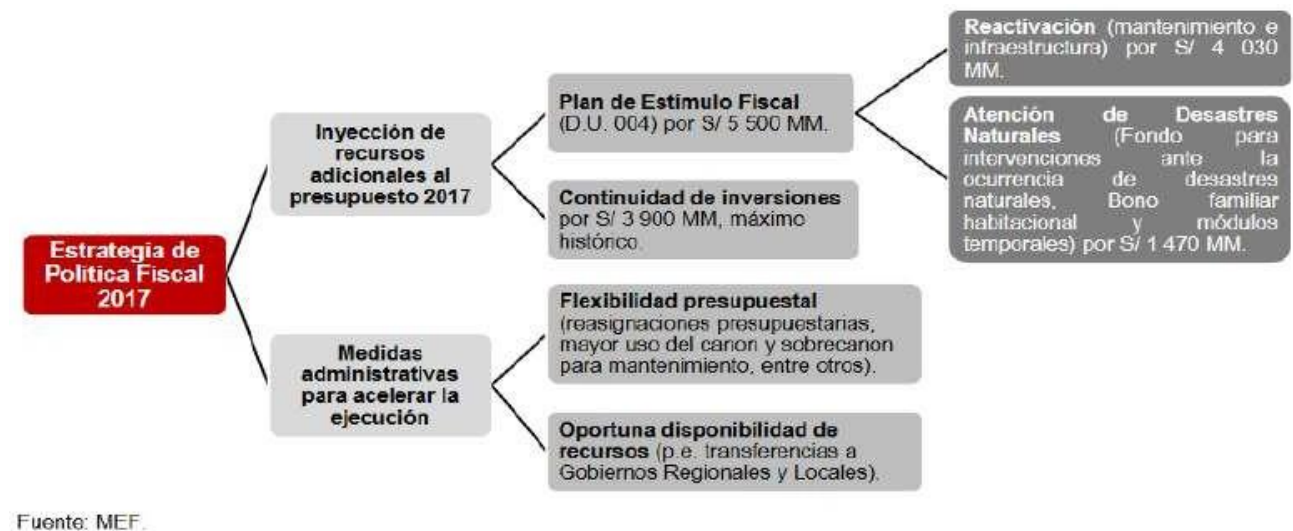

Figura 14. Estrategia de Política Fiscal 2017. Tomado de "Informe de actualización de proyecciones macroeconómicas,” por el Ministerio de Economía y Finanzas MEF, 2017. Recuperado de https://www.mef.gob.pe /contenidos/pol_econ/marco_macro/informe_actualizacion_proyecciones.pdf 
El Instituto de Economía y Desarrollo Empresarial (IEDEP) de la Cámara de Comercio de Lima proyectó que el Producto Bruto Interno (PBI) peruano se situará en 3.8\% en el 2016 y $4.2 \%$ en el 2017, por debajo de las proyecciones del MEF para el 2017 de $4.8 \%$ y BCR de 4.5\%. (Gestion.pe, 2016c) 


\section{PBI por Sectores}

\begin{tabular}{|c|c|c|c|c|c|c|c|}
\hline & $\begin{array}{l}\text { Peso Año } \\
\text { Base } 2007 \\
\end{array}$ & 2016 & 2017 & 2018 & 2019 & 2020 & 2021 \\
\hline Agropecuario & 6,0 & 1,8 & 2,1 & 4,5 & 4,6 & 4,6 & 4,6 \\
\hline Agricola & 3,8 & 0,6 & 1,0 & 4,6 & 5,0 & 4,8 & 4,8 \\
\hline Pecuario & 2,2 & 3,6 & 3,6 & 4,2 & 4,2 & 4,3 & 4,3 \\
\hline Pesca & 0,7 & $-10,1$ & 27,0 & 13,5 & 2,6 & 2,0 & 2,1 \\
\hline $\begin{array}{l}\text { Minería e hidrocarburos } \\
\text { Mineria metalica } \\
\text { Hidrocarburos }\end{array}$ & $\begin{array}{r}14,4 \\
12,1 \\
2,2\end{array}$ & $\begin{array}{r}16,3 \\
21,2 \\
-5,1\end{array}$ & $\begin{array}{l}6,0 \\
6,5 \\
4,7\end{array}$ & $\begin{array}{l}5,4 \\
5,3 \\
5,9\end{array}$ & $\begin{array}{l}2,9 \\
3,0 \\
5,0\end{array}$ & $\begin{array}{l}3,1 \\
3,5 \\
5,0\end{array}$ & $\begin{array}{l}3,2 \\
3,3 \\
5,0\end{array}$ \\
\hline $\begin{array}{l}\text { Manufactura } \\
\text { Primaria }\end{array}$ & $\begin{array}{r}16,5 \\
4,1\end{array}$ & $\begin{array}{l}-1,6 \\
-0.5\end{array}$ & $\begin{array}{r}1,4 \\
10,0\end{array}$ & $\begin{array}{l}4,2 \\
8.5\end{array}$ & $\begin{array}{l}4,5 \\
4,4\end{array}$ & $\begin{array}{l}4,2 \\
3,0\end{array}$ & $\begin{array}{l}4,4 \\
3,4\end{array}$ \\
\hline No primaria & 12,4 & $-2,0$ & $-0,8$ & 2,8 & 4,5 & 4,6 & 4,8 \\
\hline Electricidad y agua & 1,7 & 7,3 & 3,5 & 5,0 & 5,5 & 5,4 & 5,4 \\
\hline Construcción & 5,1 & $-3,1$ & 3,8 & 7,3 & 6,7 & 6,8 & 6,9 \\
\hline Comercio & 10,2 & 1,8 & 1,0 & 3,0 & 5,0 & 4,9 & 4,8 \\
\hline Servicios & 37,1 & 4,2 & 2,8 & 4,5 & 5,2 & 5,5 & 5,5 \\
\hline PBI & 100,0 & 3,9 & 3,0 & 4,5 & 5,0 & 5,0 & 5,0 \\
\hline PBI primario & 25,2 & 9,8 & 6,0 & 5,8 & 3,5 & 3,4 & 3,5 \\
\hline PBI no primario ${ }^{2}$ & 66,5 & 2,3 & 2,1 & 4,3 & 5,2 & 5,4 & 5,4 \\
\hline
\end{tabular}

Figura 15. PBI por Sectores. Tomado de "Informe de actualización de proyecciones macroeconómicas,” por el Ministerio de Economía y Finanzas MEF, 2017. Recuperado de https://www.mef.gob.pe/contenidos/pol_econ/marco_macro/informe_actualizacion_proyecci ones.pdf 


\begin{tabular}{|c|c|c|c|c|c|c|c|}
\hline & 2015 & 2016 & 2017 & 2018 & 2019 & 2020 & 2021 \\
\hline \multicolumn{8}{|l|}{ PBI SOCIOS COMERCIALES } \\
\hline Mundo (Variación porcentual real) & 3,2 & 3,1 & 3,5 & 3,6 & 3,7 & 3,7 & 3,7 \\
\hline EE.UU. (Variación porcenual real) & 2,6 & 1,6 & 2,3 & 2,5 & 2,1 & 1,8 & 1,7 \\
\hline Zona Euro (Variación porcentual real) & 2,1 & 1,7 & 1,7 & 1,6 & 1,6 & 1,5 & 1,5 \\
\hline China (Variación porcenual real) & 6,9 & 6,7 & 6,6 & 6,2 & 6,0 & 5,9 & 5,8 \\
\hline Socios Comerciales (Variación porcentual real) & 3,2 & 2,7 & 3,2 & 3,3 & 3,2 & 3,2 & 3,1 \\
\hline \multicolumn{8}{|l|}{ PRECIOS DE COMMODITIES } \\
\hline Oro (USS/ozt.) & 1161 & 1248 & 1217 & 1217 & 1217 & 1217 & 1217 \\
\hline Cobre $(\varangle \cup 5 \$ / \mathrm{lb})$. & 249 & 221 & 264 & 264 & 264 & 264 & 264 \\
\hline Plomo (\&\US\$/b.) & 81 & 85 & 103 & 103 & 103 & 103 & 103 \\
\hline Zinc (\&US \$/B.) & 88 & 95 & 126 & 126 & 126 & 126 & 126 \\
\hline Peróleo (USS/bar.) & 49 & 43 & 53 & 54 & 54 & 54 & 54 \\
\hline \multicolumn{8}{|l|}{ TÉRMINOS DE INTERCAMBIO } \\
\hline Términos de intercambio (Variación porcentual) & $-6,3$ & $-0,8$ & 3,1 & $-1,0$ & 0,0 & 0,0 & 0,0 \\
\hline Indice de Precios de Exportación (Variación porcentual) & $-14,9$ & $-3,8$ & 7,3 & 0,0 & 0,0 & 0,0 & 0,0 \\
\hline Indice de Precios de Importación (Variación porcentual) & $-9,2$ & $-3,0$ & 4,2 & 1,0 & 0,0 & 0,0 & 0,0 \\
\hline \multicolumn{8}{|l|}{ PRODUCTO BRUTO INTERNO } \\
\hline Product Brub interno (Mies de milones de Soles) & 613 & 659 & 707 & 756 & 815 & 877 & 942 \\
\hline Product Bruts inferno (Variación porcentual real) & 3,3 & 3,9 & 3,0 & 4,5 & 5,0 & 5,0 & 5,0 \\
\hline Brecha products ( $\%$ del PBI potencial) ${ }^{1}$ & $-0,8$ & $-0,2$ & $-0,8$ & $-0,5$ & $-0,1$ & 0,1 & 0,4 \\
\hline Demanda interna (Variación porcentual real) & 3,1 & 0,9 & 1,9 & 4,1 & 4,8 & 4,9 & 4,9 \\
\hline Consumo Privado (Variación porcenual real) & 3,4 & 3,4 & 3,0 & 3,3 & 3,6 & 4,0 & 4,0 \\
\hline Consumo Público (Variación porcentual real) & 9,8 & $-0,5$ & 2,3 & 3,0 & 2,5 & 2,5 & 2,5 \\
\hline Inversion Privada (Variación porcentual real) & $-4,4$ & $-6,1$ & 0,5 & 5,0 & 5,7 & 6,3 & 6,5 \\
\hline Inversion Púbica (Variación porcenual real) & $-7,3$ & $-0,5$ & 15,0 & 15,0 & 5,0 & 4,5 & 4,5 \\
\hline Inversión Privada (Porcentaje del PBI) & 19,3 & 17,7 & 17,2 & 17,4 & 17,7 & 18,0 & 18,4 \\
\hline Inversión Pública (Porcentaje del PBI) & 5,0 & 4,8 & 5,3 & 5,9 & 5,9 & 5,9 & 6,0 \\
\hline \multicolumn{8}{|l|}{ SECTOR EXTERNO } \\
\hline Cuent Corriente (Porcentaje del PBI) & $-4,9$ & $-2,8$ & $-2,6$ & $-2,6$ & $-2,6$ & $-2,6$ & $-2,6$ \\
\hline Balanza comercial (Millones de US dólares) & -3150 & 1730 & 3706 & 3434 & 3581 & 3830 & 3785 \\
\hline Exportaciones (Millones de US dólares) & 34236 & 36838 & 41045 & 42737 & 44525 & 46395 & 48339 \\
\hline Importaciones (Milones de US dólares) & -37385 & -35107 & -37338 & -39303 & -40945 & -42565 & .44554 \\
\hline \multicolumn{8}{|l|}{ SECTOR PÚBLICO NO FINANCIERO } \\
\hline Ingresos del GG (Porcentaje del PBI) & 20,1 & 18,7 & 18,5 & 18,3 & 18,6 & 19,0 & 19,7 \\
\hline Intereses del GG (Porcentaje del PBI) & 1,1 & 1,1 & 1,2 & 1,4 & 1,4 & 1,3 & 1,3 \\
\hline Resutado primario (Porcentaje del PBI) & $-1,0$ & $-1,5$ & $-1,8$ & $-2,1$ & $-1,5$ & $-0,8$ & 0,3 \\
\hline Resutado económico (Porcentje del PBI) & $-2,1$ & $-2,6$ & $-3,0$ & $-3,5$ & $-2,9$ & $-2,1$ & $-1,0$ \\
\hline Resulado económico estructural (Porcentaje del PBI) ${ }^{1}$ & $-1,6$ & $-1,9$ & $-2,6$ & $-3,1$ & $-2,7$ & $-2,0$ & $-1,0$ \\
\hline \multicolumn{8}{|l|}{ SALDO DE DEUDA PÚBLICA } \\
\hline Externa (Porcentaje del PBI) & 11,1 & 10,3 & 9,9 & 11,0 & 10,1 & 10,0 & 9,7 \\
\hline Interna (Porcentaje del PBI) & 12,2 & 13,5 & 16,0 & 16,5 & 17,1 & 16,8 & 16,5 \\
\hline Total (Porcentaje del PBI) & 23,3 & 23,8 & 25,9 & 27,5 & 27,1 & 26,7 & 26,2 \\
\hline \multicolumn{8}{|c|}{ Memo: cirras proyectadas a partir de la Encuesta Mensual de Expectativas Macroeconómicas del BCRP } \\
\hline Precios (Variación porcentual acumulada) ${ }^{2}$ & 4.4 & 3,2 & 3,0 & 2,7 & 2,5 & 2,0 & 2,0 \\
\hline Tipo de Cambio Promedio (Soles por US dólar) ${ }^{3}$ & 3,19 & 3,38 & 3,32 & 3,42 & 3,45 & 3,45 & 3,45 \\
\hline
\end{tabular}

$1 /$ /El cálculo se elabora considerando la metodología de cálculo de las Cuentas Estructurales aprobada por la Resolución Ministerial $\mathrm{N}^{\circ}$ 024-2016-EF/15.

2/ 2017-2019, tomado de la Encuesta Mensual de Expectativas Macroeconómicas: marzo 2017 - BCRP, publicado el 06 de abril del 2017. Para el 2020-2021 consistente con el punto medio del rango meta del BCRP.

3/ 2017-2019, consistente con el tipo de cambio fin de periodo de la Encuesta Mensual de Expectativas Macroeconómicas: marzo

2017 - BCRP, publicado el 06 de abril del 2017. Para el 2020-2021 se asume el mismo valor del 2019.

Fuente: FMI, BCRP, MEF, Proyecciones MEF.

Figura 16. Principales Indicadores Macroeconómicos. Tomado de "Informe de actualización de proyecciones macroeconómicas,” por el Ministerio de Economía y Finanzas MEF, 2017.

Recuperado de

https://www.mef.gob.pe/contenidos/pol_econ/marco_macro/informe_actualizacion_proyecci ones.pdf 


\section{Inflación}
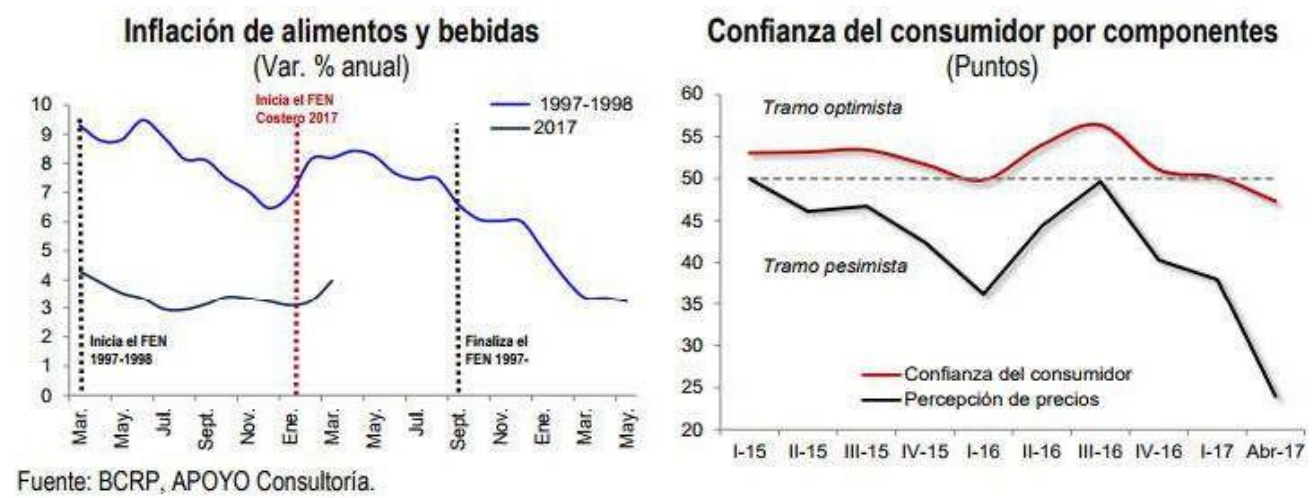

Figura 17. Inflación de alimentos y bebidas y Confianza del consumidor por componentes.

Tomado de "Informe de actualización de proyecciones macroeconómicas," por el Ministerio de Economía y Finanzas MEF, 2017. Recuperado de https://www.mef.gob.pe/contenidos/pol_econ/marco_macro/informe_actualizacion_proyecci ones.pdf

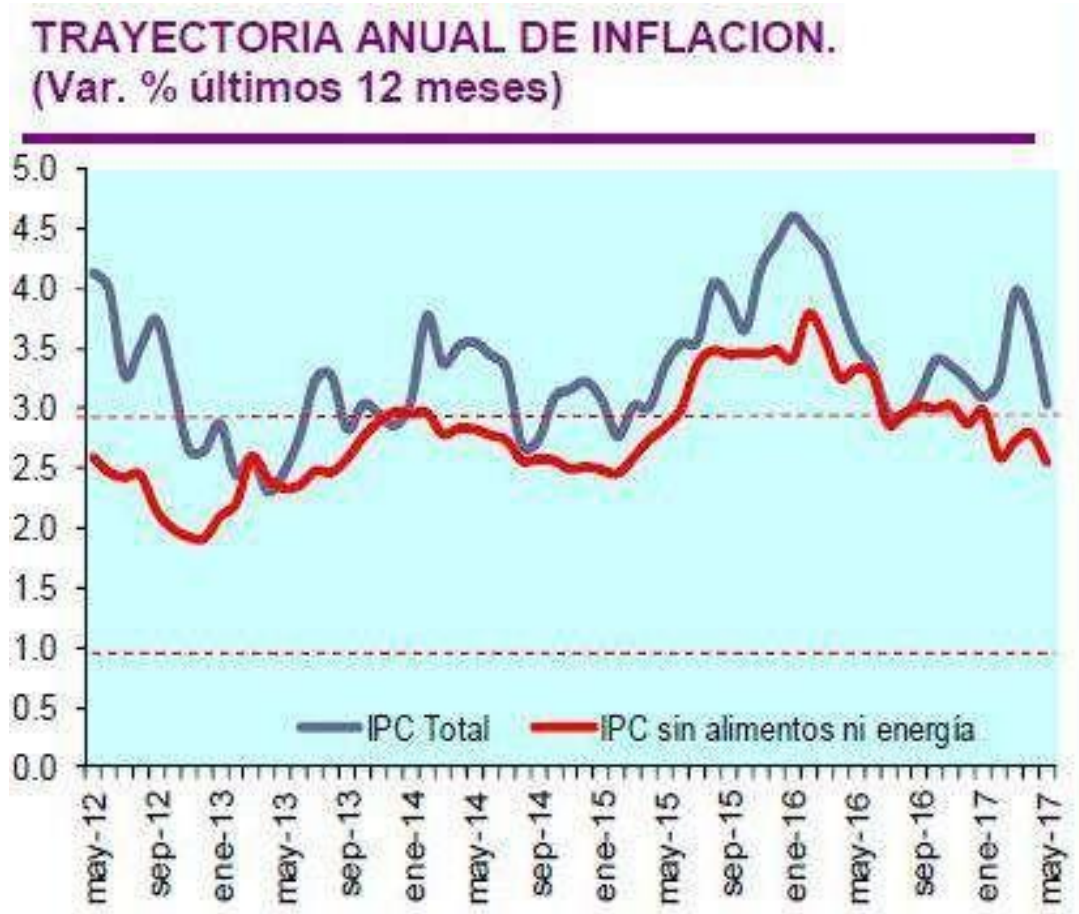

Fuente:BCR Elaboración:Estudios Económicos-Scotiabank

Figura 18. Trayectoria anual de Inflación. Tomado de Diario Gestión, 2017. Recuperado de http://gestion.pe/economia/scotiabank-mayor-probabilidad-nuevo-recorte-tasa-bcr- 
El diario local gestión basándose en el Reporte de inflación de marzo 2017 señala que la trayectoria anual de la inflación tuvo un descenso de 3.7\% en el mes de abril a $3 \%$ en el mes de mayo. Esto propicio que haya un cambio total en el impacto en la oferta del mes de marzo debido a los estragos del El Niño Costero.

Se espera que la inflación para el periodo del 2017- 2018 se halle en $2 \%$. La inflación tendrá una ubicación en el primer semestre del año alrededor de sus límites.

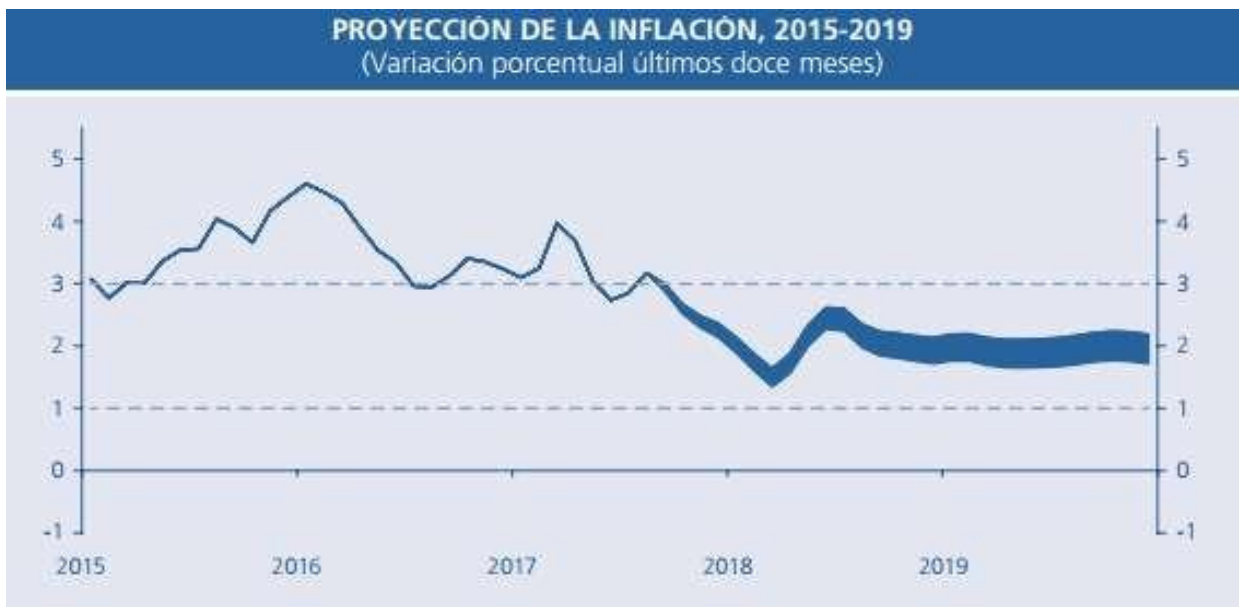

Figura 19. Proyección de la Inflación, 2015-2019. Tomado de "Reporte de Inflación

Setiembre 2017, Panorama actual y proyecciones macroeconómicas 2017-2019” por el Banco Central de Reserva del Perú, 2017. Recuperado de http://www.bcrp.gob.pe/docs/Publicaciones/Reporte-Inflacion/2017/setiembre/reporte-deinflacion-setiembre-2017.pdf

En lo que respecta al cambio de moneda extranjera, la SUNAT señaló que en el mes de enero del 2018 el tipo de cambio en el día 5 de enero fue el siguiente: la compra es de 3.206 y la venta de 3.208 . 
Enero - 2018

\section{Tipo de cambio publicado al :}

\begin{tabular}{|c|c|c|c|c|c|c|c|c|}
\hline Dia & Compra & Venta & $D_{i}^{\prime}$ & Compra & Venta & Día & Compra & Venta \\
\hline 1 & 3.238 & 3.245 & 4 & 3.227 & 3.230 & 5 & 3.206 & 3.208 \\
\hline
\end{tabular}

Figura 20. Tipo de cambio Enero 2018. Tomado de SUNAT, 2017. Recuperado de http://www.sunat.gob.pe/cl-at-ittipcam/tcS01Alias

De acuerdo al reporte de inflación de marzo 2017, el tipo de cambio durante el inicio del mes tuvo una reducción de 2,0 por ciento y se espera que no haya un incremento mayor en lo que respecta al resto del año.

\subsubsection{Análisis Legal}

Esta fuerza corresponde a la normatividad y leyes que las empresas del sector analizado deben adoptar y cumplir (Thompson et al, 2012)

Un beneficio importante para el sector de las TICs es que las empresas que contribuyan a la investigación, desarrollo e innovación podrán deducir sus gastos hasta en un 175\% para el cálculo del tributo a la Renta, gracias a la Ley de Promoción de la Investigación Científica, Desarrollo Tecnológico e Innovación Tecnológica, promulgada el 2015. (Concytec.gob.pe, 2015)

El Programa Nacional de Innovación para la Competitividad y Productividad (Innóvate Perú) tiene como meta impulsar el emprendimiento innovador y facilitar la absorción y adaptación de tecnologías para las empresas. Para el logro de estos objetivos, Innóvate Perú administra los Fondos del Proyecto de Innovación para la Competitividad 
(FINCyT), el Fondo de Investigación y Desarrollo para la Competitividad (FIDECOM) y el Fondo Marco para la Innovación, Ciencia y Tecnología (FOMITEC).

\subsubsection{Análisis Cultural}

D’Alessio (2013), indica que esta fuerza define las características de los consumidores, canaliza los hábitos de compra, define el tamaño del mercado y está relacionada con los estilos de vida, creencias, actitudes y valores del entorno.

El usuario móvil peruano con acceso a Internet ya realiza transacciones online porque le ahorran tiempo. "El consumidor limeño se baja una aplicación porque responde a una necesidad puntual. Para este usuario, el smartphone tiene un espacio limitado, no descarga más de 20 aplicaciones", comenta Alexander Chiu, director de business development de la agencia de investigación digital Futuro Labs. (Semanaeconomica.com.pe, 2015).

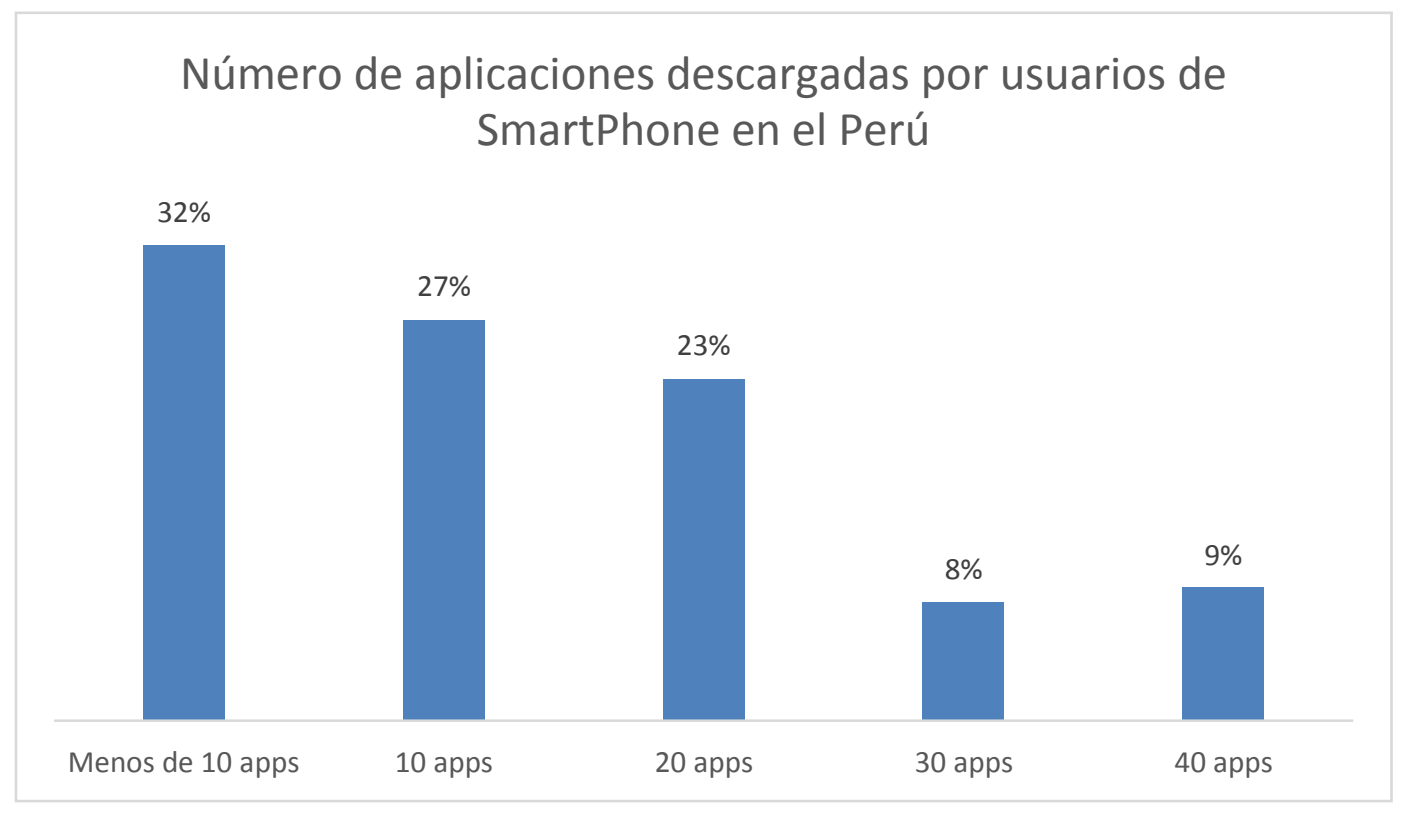

Figura 21. Número de aplicaciones descargadas por usuarios de SmartPhone en el Perú. Tomado de "Estudio del Usuario de Smartphone 2015-Q2," por Futuro Labs, 2015. Recuperado de https://gestion.pe/noticias/futuro-labs 
La piratería de software en las empresas y el Gobierno Peruano se ha reducido en dos puntos porcentuales en el último año, pasando de $65 \%$ a $63 \%$ de penetración, informó Rodger Correa, director regional de la BSA. (Elcomercio.pe, 2016). La tendencia del uso de software ilegal se ha reducido en los últimos diez años debido a las políticas implementadas.

Finalmente, es importante indicar que, según la BSA | The Software Alliance, el Perú ha bajado su tasa de piratería de software en alrededor de cuatro puntos porcentuales en los últimos cinco años y ahora está en 63\%. (gestion.pe, 2016b)

Al año 2015, en un 92.3\% del total de hogares de Lima Metropolitana y Callao, al menos un miembro de la familia tiene teléfono celular y un $40.1 \%$ de hogares de ese mismo ámbito geográfico accede al servicio de Internet; asimismo el $49.7 \%$ de la población mayor de 25 años de Lima Metropolitana y el Callao, accede a internet (inei.pe, 2015)

El emprendimiento de personas dedicadas a la elaboración de programas informáticos para empresarios todavía es reducido en el país, ya que no llega ni al 1\% del mercado por lo que es una gran oportunidad. (gestión.pe, 2016)

Otro aspecto importante de este análisis social es considerar las últimas investigaciones realizadas en relación a los efectos que tienen las tecnologías de información y comunicación en el comportamiento de las personas.

En este sentido, de acuerdo Sánchez, Crespo, Aguilar, Bueno, Aleixandre y Valderrama (2015) señalan aspectos positivos y negativos que pudiesen influenciar en el uso de las tecnologías de información y comunicación.

Por una parte, señalan que el empleo de las Tecnologías de información y comunicación (TIC) ha generado un cambio sumamente importante en la manera como las personas se comunican y comparten información ya que abren una ventana de oportunidades para el establecimiento de comunicación constante con el entorno cercano y no tan cercano. 
Asimismo, permite la transmisión y el envío de información y facilita nuestra vida diaria en diversos ámbitos.

Por otro parte, los autores anteriores señalan también las desventajas en el uso de las TICS. Entre estas están: la posibilidad de que se genere un mayor aislamiento que posibilite inadecuado desarrollo de las habilidades sociales; que interfiera en otras actividades rutinarias; posibilidad de que otros pueden controlar y visualizar las cosas que realizamos; la exposición a contenidos inadecuados ( violentos, racistas, pornográficos) que pueden tener una repercusión negativa en la vida de las personas como en su desarrollo; generación de trastornos en la conducta como el trastornos obsesivo compulsivo (adicciones al internet, redes sociales, whatsapp), déficit de atención, etc.

Alvarez, Nuñez, Alvarez, Dobarro y Rodriguez (2011) señalan que el uso inapropiado de las TICS ha propiciado la aparición de diversas conductas agresivas en el ser humano como el cyberbulling. Además, catalogan como violencia a través de las TIC a aquella conducta que tiene la intención de generar un daño o perjuicio por medio Tecnologías de la Información y de la Comunicación, esencialmente, el teléfono móvil e Internet"

Por lo anterior, muchas personas visualizan la inserción de las TIC como una potencial amenaza ya que puede generar efectos negativos en la conducta de los seres humanos.

Todo lo anterior, puede afectar notablemente el desarrollo de sector de las TIC ya que existe una gran mayoría de personas que considera que el uso de las TICS es una potencial amenaza ya que puede generar efectos negativos en los seres humanos y por ende en su salud mental y esto puede ser una causa potencial por la cual se resistan en su uso. 


\subsubsection{Análisis Tecnológico}

Thompson et al. (2012), señala que este factor está referido a la velocidad de los cambios tecnológicos y su impacto a favor o en contra de las industrias

El acceso a Internet creció 22.7 puntos porcentuales entre el 2013 y el 2015 (Osiptel.gob.pe, 2016).

10 millones de personas tienen un Smartphone, según la Encuesta Residencial de Servicios de Telecomunicaciones del OSIPTEL (Osiptel.gob.pe, 2016)-

Según los resultados de la Encuesta Residencial de Servicios de Telecomunicaciones al 2015, que realizó el OSIPTEL, en el Perú, más de 4 millones 650 mil hogares tienen acceso a Internet (Osiptel.gob.pe, 2016)

7 millones 694 mil familias cuentan con servicio móvil, cifra que representa un 93.4\% de los hogares. Asimismo, la demanda de smartphones muestra un importante crecimiento: al 2015, el 54.5\% de familias tenía un celular con esas características. (Osiptel.gob.pe, 2016)

Comparado con los servicios de telefonía móvil, fija y cable, el acceso a Internet representa el de mayor crecimiento al acumular un avance de 22.7 puntos porcentuales entre el 2013 y el 2015 al pasar de 33.7\% a 56.4\%. Solo en el último año, más de un millón 482 mil familias se incorporaron al grupo de hogares con Internet en el último año. (Osiptel.gob.pe, 2016)

El número de hogares con Internet móvil es el que más aumentó, al pasar de $18.5 \%$ a 52.6\%, alcanzando los 4 millones 331 mil 052. En tanto, los hogares que además de acceso al internet móvil cuentan con Internet fijo representan un 22.6\%.(Osiptel.gob.pe, 2016)

El sector viene creciendo a un ritmo anual de 8,5\% desde el 2010, Específicamente, el sector de soluciones informáticas bordea los US\$ 600 millones anuales generados por unas 300 empresas. De dicho total alrededor de US\$ 45 millones provienen de la exportación de software, apenas US\$ cinco millones más de lo registrado el año anterior. Eso significa que 
las exportaciones solo representan el 7,5\% de lo facturado, cuando en otros países de la región bordean el 20\%. (elcomercio.pe, 2016)

De acuerdo a un artículo publicado en la Web de la BBC mundo, señala que la tecnología sufre cambios y avances continuos y muy rápidos que son difíciles de entender y que los fabricantes deben de planear todo producto que elaboran tomando en cuenta los ciclos de vida.

http://www.bbc.com/mundo/noticias/2015/04/150325_tecnologia_obsoleta_sem_yv

Alvarez. D, Nuñez. J, Alvarez. L, Dobarro. A, Rodriguez. C (2011) Violencia a través de las tecnologías de la información y la comunicación en estudiantes de secundaria.

Lo anterior puede ser visto como una amenaza ya que la mayoría de las empresas que están en dicho sector deben de estar atentos en el ciclo de sus productos como también realizar una fuerte inversión constante en la creación e innovación de sus productos que permitan satisfacer la demanda de los potenciales consumidores y continuar vigentes en el mercado.

\subsubsection{Análisis Ecológico}

En relación a este factor D’Alessio (2013) señala que en los últimos tiempos ha tomado importancia y es impulsada por grupos diversos que protegen el ecosistema, afectando a la organización en su imagen, operaciones y ventas.

Se observa interés del Estado de impulsar iniciativas que permitan reducir el uso de papel, como la desarrollada desde mayo del año 2014, por la Presidencia del Consejo de Ministros PCM a través de la Oficina Nacional de Gobierno Electrónico e Informática ONGEI, con el apoyo de RENIEC y otras instituciones del Sistema Nacional de Informática, impulsando el uso de firmas y certificados digitales (Ongei.gob.pe, 2017) 


\subsection{Oportunidades y Amenazas}

\section{Tabla 14}

Oportunidades y Amenazas

$\begin{array}{lll}\text { Elemento de } & \text { Factor } & \text { Oportunidad /Amenaza } \\ \text { Análisis } & \text { Comentario }\end{array}$

Análisis Político

Gubernamental

Reducción del IGV Oportunidad Se incrementa la capacidad de

consumo.

Subida del Impuesto a la Renta

para las grandes empresas de $28 \%$ a $30 \%$
Disminuye el atractivo para que grandes empresas competidoras del sector desarrollo de software ingresen al Perú.

Análisis

Económico

Crecimiento de la economía

Oportunidad

Crecimiento del PBI

Tendencia a la baja del tipo de cambio

Bajo nivel de inflación
Oportunidad

Oportunidad

Oportunidad
A mayor crecimiento económico, hay mayor demanda de servicios, acceso a la tecnología e inversión privada.

El PBI se encuentra relacionado al crecimiento de la economía lo cual implica que su crecimiento refleja posibles mayores empleos que a su vez generen ingresos y oportunidad de acceso a la tecnología.

La oportunidad radica en que los servicios de alojamiento en la nube entre otros son facturados por los proveedores extranjeros en dólares, lo cual reduciría los costos en la industria nacional del Software.

Permite reducir la incertidumbre y favorece la inversión, contribuyendo a la confianza en el desarrollo de proyectos tecnológicos.
Ley de Promoción de la Investigación Científica, Desarrollo Tecnológico e Innovación Tecnológica
Es posible reducir el impuesto a la renta si se desarrollan proyectos de innovación tecnológica como es el

Oportunidad caso del desarrollo de software para mejorar la comunicación entre familias y colegios, lo cual genera una ventaja en relación a otras industrias. 


\begin{tabular}{llc}
\hline Elemento de & Oportunidad & Comentario \\
Análisis & Factor & /Amenaza
\end{tabular}

\section{Análisis Cultural}

Crece tendencia a las transacciones online desde dispositivos móviles

Reducción de la piratería

Oportunidad

Incremento del acceso a internet en hogares

Oportunidad Oportunidad
Esta tendencia sugiere que hay más predisposición de los consumidores a utilizar Smartphone para realizar transacciones lo cual genera una oportunidad de mercado para las aplicaciones que se puedan desarrollar sobre estos equipos que ofrezcan operaciones en línea.

Las políticas nacionales de protección de la propiedad intelectual que han logrado reducir la piratería en el país alientan a las empresas a desarrollar software para su uso el mercado local.

Esto ofrece una oportunidad de brindar servicios sobre internet que se encuentren a disposición de las familias.
Incremento de \% de hogares con al menos un miembro de la familia con acceso a celular

Incremento de investigaciones que apoyan las desventajas que pueden generar el uso contante

$$
\text { de las TICS }
$$

Se abre la oportunidad de brindar

Oportunidad servicios, soportados en la telefonía móvil.

Posibilita mayor resistencia en el uso de las TICS debido a la presencia de diversos trastornos en la conducta de

Amenaza las personas como trastornos en la atención, trastornos obsesivos compulsivos, ansiedad, violencia con las TIC por el uso continua de las tecnologías de información.

\section{Análisis

\begin{tabular}{|c|c|c|c|}
\hline & $\begin{array}{l}\text { Crecimiento del acceso } \\
\text { a internet }\end{array}$ & Oportunidad & $\begin{array}{l}\text { Se presenta como una oportunidad } \\
\text { debido a que más instituciones } \\
\text { educativas y familias pueden contar } \\
\text { con servicio de internet necesario para } \\
\text { las comunicaciones online mediante } \\
\text { dispositivos móviles. }\end{array}$ \\
\hline & $\begin{array}{l}\text { Crecimiento de la } \\
\text { demanda de Smartphones }\end{array}$ & Oportunidad & $\begin{array}{l}\text { Al igual que en el caso anterior el } \\
\text { crecimiento en el uso de equipos } \\
\text { Smartphone se presenta como una } \\
\text { oportunidad para el mercado de las } \\
\text { aplicaciones móviles, debido a su cada } \\
\text { vez más fácil acceso. }\end{array}$ \\
\hline & $\begin{array}{l}\text { Crecimiento del } \\
\text { número de empresas de software } \\
\text { en el Perú }\end{array}$ & Amenaza & $\begin{array}{l}\text { Se incrementa el número de } \\
\text { competidores cada año, disminuyendo } \\
\text { la participación de mercado. }\end{array}$ \\
\hline \multirow[t]{2}{*}{$\begin{array}{l}\text { Elemento de } \\
\text { Análisis }\end{array}$} & Factor & $\begin{array}{l}\text { Oportunidad } \\
\text { /Amenaza }\end{array}$ & Comentario \\
\hline & $\begin{array}{l}\text { Vigencia y ciclo de vida de los } \\
\text { productos } \quad \text { y } \quad \text { servicios } \\
\text { tecnológicos es muy corto }\end{array}$ & Amenaza & $\begin{array}{l}\text { Periodo de vida de un producto o } \\
\text { servicio tecnológico muy corto lo cual } \\
\text { fomenta que haya gran inversión en } \\
\text { creación e innovación. }\end{array}$ \\
\hline
\end{tabular} \\ Tecnológico}


Gobierno impulsa iniciativas para reducir el uso de papel
Este factor se presenta como una oportunidad de contribución a la conservación del medio ambiente al presentar una alternativa de comunicación entre familias y colegios que reduzca el uso de papel, mediante el uso de la tecnología móvil.

\section{Tabla 15}

Matriz EFE

Factores determinantes del éxito Peso Calificación Promedio

Oportunidades

Reducción del IGV

0.01

0.05

0.04

Subida del Impuesto a la Renta para las grandes empresas de $28 \%$ a $30 \%$

Crecimiento de la economía

0.05

0.04

0.05

0.05

0.05

0.10

Reducción de la piratería

0.10

2

Incremento del acceso a internet en hogares

0.20

Incremento de \% de hogares con al menos un miembro de la familia con

Crecimiento de la demanda de Smartphones

Gobierno impulsa iniciativas para reducir el uso de papel

0.01

Amenazas

Crecimiento del número de empresas de software en el Perú

2

Incremento de investigaciones que apoyan las desventajas que pueden generar el uso contante de las TICS

0.01

5

Vigencia y ciclo de vida de los productos y servicios tecnológicos es muy corto

El total ponderado de 3.88 está por encima de 2.5 lo cual indica que el sector está preparado para afrontar satisfactoriamente las oportunidades y amenazas presentadas. 


\section{Capítulo III: Estudio de Mercado}

Investigación de Mercado

De acuerdo a Kotler y Armstrong (2012) señalan que la investigación de mercado es el esfuerzo de una organización para lidiar con una circunstancia específica de marketing que tiene como resultado el diseñar, recabar, el analizar y el realizar informes continuos de los datos de dicha circunstancia. Los mismos autores señalan que la investigación de mercado es de gran utilidad ya que permite realizar una evaluación del potencial de mercado y su participación, permite saber que tan eficaz es la fijación de precios, del producto o servicio, de la promoción o de la distribución; ayuda a comprender el comportamiento de compra, que es lo que motiva a las personas y la satisfacción de los consumidores. Asimismo, los mismos autores advierten de la existencia de cuatro pasos para realizar el proceso de investigación de mercado entre ellos están: la identificación y definición del problema y de los objetivos de investigación, elaboración del plan de investigación, aplicación del plan de investigación e interpretación e informe de los resultados. (p. 103)

Según Naresh y Malhotra (2008), la investigación de mercado tiene como finalidad mejorar la toma de decisiones que tiene relación con el poder identificar y dar solución a debilidades y oportunidades de marketing por medio de la identificación, recopilación, análisis, comunicación masiva y uso continuo y estratégico de la información.

Al igual de Naresh y Malhotra (2008) y Merino (2010) establecen que la investigación de mercado es una herramienta o instrumento que permite la toma de decisiones más acertadas debido a que ayuda anticiparse y disminuir los riesgos que pueden presentarse al recabar información pertinente de los diversos actores del mercado. Asimismo, Merino (2010) señala que este instrumento sirve para que el marketing pueda realizar adecuadamente su objetivo. 
En este capítulo se realiza el estudio de mercado para la nueva plataforma de comunicación a tiempo real para alumnos, familia y colegio.

Se plantea una investigación mixta ya que se emplea el estudio cualitativo y cuantitativo para posteriormente realizar un análisis la información que finalmente generará toma de decisiones más acertadas y ajustadas a la realidad.

\subsection{Descripción del servicio o producto}

El producto a desarrollarse es la creación de una Aplicación Móvil (App) para usuarios de la comunidad educativa (colegios, profesores, padres de familia y alumnos) será un sistema informático que soporte la gestión de la comunicación.

La Aplicación Móvil (App) va a estar disponible para celulares con Sistema Operativo Android y IOS, y pueden ser descargados desde Play Store y App Store, respectivamente. La interface de gestión se podrá acceder desde un navegador.

El nuevo servicio de plataforma de comunicación a tiempo real entre colegios, profesores, padres de familia y alumnos tiene como características:

I. Comunicación en tiempo real

a. Envió de mensajes con posibilidad de adjuntar un archivo o foto a un padre o grupo de padres por el profesor del aula

b. Envió de comunicados a los padres de toda la comunidad educativa mediante SMS, emails, mensajes internos, avisos, web del centro.

c. Envió de mensajes de los padres o alumnos a los profesores.

II. Gestión de Notas-Tareas

a. Ingreso de notas por cada profesor de curso desde la aplicación móvil o desde la interface web del sistema. 
b. Seguimiento de cumplimiento de las tareas asignada a los estudiantes por los padres de familia y profesores.

III. Asistencia de Alumnos

a. Toma de asistencia en línea.

b. Reporte de asistencia de uno o más alumnos.

IV. Gestión de Citas

a. Los padres de familia tendrán acceso desde la aplicación la posibilidad de solicitar una cita a un profesor en fechas disponibles y recibir la confirmación.

b. Los profesores serán informados de la solicitud de una cita y tendrán la posibilidad de aceptarla o denegarla. Si una cita fuese denegada el profesor podría indicar la razón y proponer una nueva fecha en caso sea necesario.

V. Acceso a la aplicación desde la Nube

a. Los padres, profesores y alumnos tendrán acceso a la aplicación desde un Teléfono Inteligente (Smartphone) o un navegador web (browser) con acceso a internet. La Aplicación Móvil (App) estará disponible en las tiendas de aplicaciones app store y play store (google play) para ser descargada e instalada en los Teléfonos Inteligentes (Smartphones).

b. La configuración de la aplicación por los administradores debe ser realizada desde un navegador web (browser).

c. La solución de Tecnología de Información propuesta es del tipo Software como un Servicio (Software as a Service, SaaS), el cliente no necesita una infraestructura de servidores o software en su local para su implementación. La tecnología tipo SAAS, usada nos permite ofrecer el servicio de alojamiento de Hosting Privado Virtual donde se va a encontrar la aplicación personalizada y la base de datos por cada cliente.

VI. Sobre licenciamiento y derechos de uso 
a) El cliente hace un pago inicial por concepto de licenciamiento y personalización. La personalización consiste en cambios de interfaces de diseño acorde con la identificación del colegio.

b) Existe un pago mensual por derecho de uso, no existe un contrato por periodo de tiempo mínimo o máximo.

\subsection{Selección del segmento de mercado}

La segmentación de mercado seleccionada es del tipo geográfica que Según Kotler y Armstrong (2013), "División de un mercado en diferentes unidades geográficas tales como países, estados, regiones, municipios o incluso, vecindarios”. Cap6, pag 165 Fundamentos de Marketing.

Los clientes (colegios) que adquieren plataformas de comunicación a tiempo real difieren en sus deseos, gustos, necesidades, recursos, localización, actitudes de compra, poder adquisitivo y práctico de compra. La meta será crear más valor que los competidores para los clientes.

Para poder hallar el mercado meta se seleccionará grupos definidos en base a la segmentación, donde agruparemos a los clientes/consumidores de acuerdo a sus características comunes. Todo ello con la finalidad de seleccionar el mercado que mejor se ajuste al producto y característica de la empresa; elaborar una estrategia comercial ajustada al target y generar por ende fidelidad del consumidor / cliente hacia el producto al adaptarse mejor a sus necesidades.

Se segmenta el mercando considerando el criterio:

Geográfico: se emplea dicho criterio para segmentar a los clientes (colegios privados escolarizados de primaria y secundaria) en relación a la ubicación física (distritos). Se consideran 25 distritos los cuales se seleccionaron por su ubicación física ya que se 
encontrarían cerca al centro de operaciones y oficina administrativa de Eduline School. Dicha selección se establece por conveniencia.

De acuerdo al informe de Lima Metropolitana de INEI 2014, Lima Metropolitana y

Callao se zonifican en :

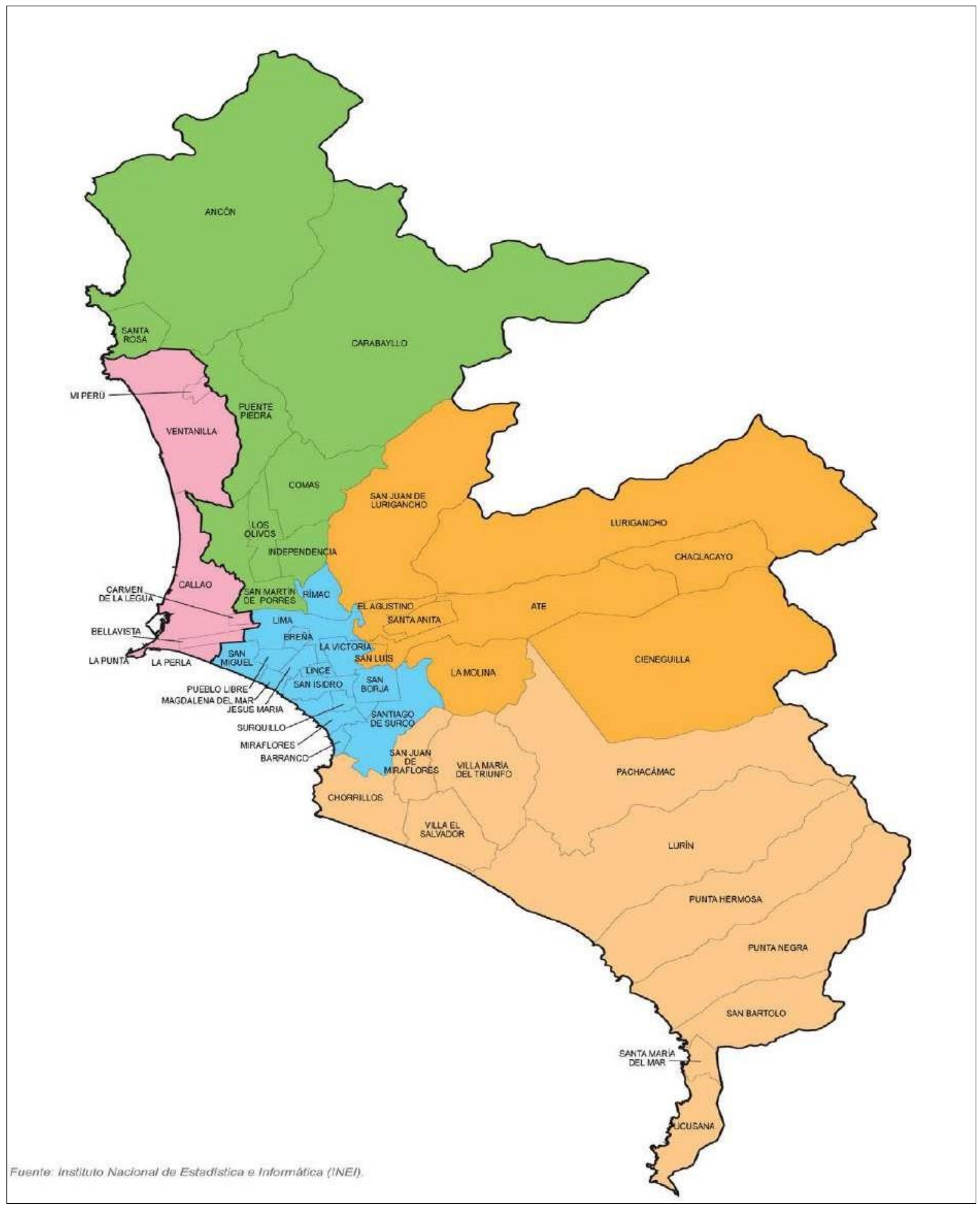


Figura 22. Lima Metropolitana. Recuperado de https://www.inei.gob.pe /media/MenuRecursivo/publicaciones_digitales/Est/Lib1168/libro.pdf

\section{Lima Norte}

Conformada por los distritos de Ancón, Carabayllo, Comas, Independencia, Los Olivos, Puente de Piedra, San Martin de Porres, Santa Rosa.

\section{Lima Centro}

Conformada por los distritos de Barranco, Breña, Jesús María, La Victoria, Lima, Lince, Magdalena del Mar, Miraflores, Pueblo Libre, Rímac, San Borja, San Isidro, San Miguel, Santiago de Surco, Surquillo.

\section{Lima Sur}

Conformada por los distritos de Chorrillos, Lurín, Pachacamac, Pucusana, Punta Hermosa, Punta Negra, San Bartolo, San Juan de Miraflores, Santa María del Mar, Villa el Salvador, Villa María del Triunfo.

\section{Lima Este}

Conformada por los distritos de Ate, Chaclacayo, Cieneguilla, El Agustino, La Molina, Lurigancho, San Juan de Lurigancho, San Luis, Santa Anita.

Callao

Conformada por los distritos de Bellavista, Callao, Carmen de la Legua Reinoso, La Perla, La Punta, Mi Perú, Ventanilla.

\section{Mercado Potencial}

El mercado potencial son aquellas instituciones educativas particulares de Nivel Primaria y Secundaria, escolarizados ubicados en la ciudad de Lima Metropolitana y Callao, en la Zona de Lima Centro y distritos cercanos, de esta manera el mercado 
comprende : Barranco, Bellavista, Breña, Callao, Carmen de la Legua Reynoso, Chorrillos, Jesús María, La Molina, La Perla, La Punta, La Victoria, Lima, Lince, Los Olivos, Magdalena del Mar, Miraflores, Pueblo Libre, Rímac, San Borja, San Isidro, San Luis, San Martin de Porres, San Miguel, Santiago de Surco y Surquillo.

Población Meta

"Población meta: conjunto de elementos u objetos que poseen la información buscada por el investigador, y acerca de la cual se harán inferencias”, (Malhotra et al., 2008).

El segmento de mercado meta, está conformado por:

a. Colegios Particulares en Lima.

b. Colegios de Nivel Primaria y Secundaria

c. Colegios Escolarizados.

El estudio se ha realizado en los Centros Educativos de Nivel Primaria y Secundaria ubicados en la ciudad de Lima Metropolitana para los distritos de:

Barranco, Bellavista, Breña, Callao, Carmen de la Legua Reynoso, Chorrillos, Jesús María, La Molina, La Punta, La Victoria, Lima, Lince, Los Olivos, Magdalena del Mar, Miraflores, Pueblo Libre, Rímac, San Borja, San Isidro, San Luis, San Martin de Porres, San Miguel Santiago de Surco y Surquillo.

\subsection{Investigación Cualitativa}

De acuerdo a Malhotra (2008), nos genera un mayor conocimiento y comprensión del ambiente que rodea al problema, por ser del tipo exploratoria no posee estructura. El mismo autor, señala que en la etapa exploratoria, la investigación cualitativa adquiere un valor fundamental debido a que ayuda en la definición del problema de investigación. 
Según Hernández, Fernández y Baptista (2010) la investigación cualitativa se centra en explorar los fenómenos desde la visión del participante en su entorno natural, focalizándose en su comprensión y exploración profunda. Asimismo, los mismos autores señalan que la investigación cualitativa demanda un esfuerzo previo de preparación de parte del investigador ya que de forma global debe realizar un análisis, por medio de un método no numérico, de la calidad y las características de las relaciones, actividades y circunstancias o materiales.

Se emplea la investigación cualitativa con el fin de abastecernos de información vital que nos dé una mayor comprensión y conocimiento del objeto de estudio y que al mismo tiempo beneficie al estudio cuantitativo a realizar.

El objetivo de este estudio cualitativo es de nutrirnos de la experiencia de expertos relacionados en el sector educación de nivel primario y secundario sobre la aceptación de una plataforma de comunicación entre padres, alumnos y colegios y el aporte de las TIC en este rubro y las opiniones de padres de familia con hijos en edad escolar.

Los objetivos de esta investigación cualitativa para este estudio son:

i. Conocer la experiencia de los involucrados en relación a la importancia de la comunicación entre la comunidad educativa.

ii. Conocer la experiencia sobre ventajas y desventajas sobre los medios usados actualmente en la comunidad educativa para la comunicación

iii. Identificar los aportes que puede hacer las TIC en el sector educación y el mejoramiento de la comunicación.

iv. Conocer la opinión sobre la viabilidad de un servicio en línea de comunicación para colegios. 
Para esta investigación se ha elegido las entrevistas de profundidad en forma individual, explicando el propósito del estudio a expertos en educación (enfoque directo), ingeniería de sistemas y posibles clientes.

El enfoque directo, dependiendo de la entrevista, se caracteriza por ser una forma de investigación cualitativa que tiene por finalidad darle a conocer a la persona el objetivo del proyecto.

Cabe señalar, que las entrevistas a profundidad son entrevistas estructuradas que de acuerdo a Llanos (2005) requieren de un especialista con vasta experiencia, de tiempo y de preguntas generalmente abiertas que permitan volver a preguntar y explorar diversos aspectos de la vida del entrevistado que permitan finalmente ayude obtener una mayor información.

De acuerdo a Malhotra (2008) la entrevista a profundidad es realizada por un entrevistador experto que realiza diversas preguntas a un encuestado, de forma más personal, directa y sin seguir una estructura especifica. Tiene como objeto identificar valores, creencias, actitudes, motivaciones, sentimientos relacionados a un asunto.

La otra herramienta que se ha elegido es Sesión de Grupo (focus group) dirigido a padres de familia de los distritos seleccionados, con hijos en edad escolar de primaria y secundaria en colegios privados, esta entrevista como indica Malhotra (2008) es realizada por un moderador capacitado con un grupo pequeño de individuos, de una forma no estructurada y natural. (p. 145)

De acuerdo a Huenachua y\& Paredes (2007), los Focus Group aplicadas en las áreas de marketing, la psicología social, la mercadotecnia política, entre otras es la herramienta de investigación más utilizada en investigación por los científicos sociales. (p. 36)

Según Barragán, Salman, Ayllón, Córdoba, Langer, Sangines \& Rojas. (2003) manifiestan que "los grupos focales son una técnica cualitativa de investigación que realiza 
entrevistas a grupos de 6 a 12 personas, en las que el moderador desarrolla de manera flexible un conjunto de temas que tienen que ver con el objeto de estudio" (p. 158)

Se elaboraron dos focus group para recoger la información cualitativa que nos de a conocer las preferencias, expectativas, características y disposición de uso, de la plataforma de comunicación por los padres de familia los cuales finalmente son los actores educativos que usaran dicha herramienta.

Los dos focus group se desarrollaron en lugares neutrales cuidando la posible intromisión de variables extrañas. Fue necesaria la separación de una sala con suficiente iluminación, ventilación y asientos cómodos. La moderadora propició la conversión generando un clima de confianza para que todos los participantes puedan dirigirse con naturalidad.

Los focus group tuvieron una duración de 90 minutos y cada grupo tuvo 6 participantes de diversas edades que cumplían con el perfil deseado.

\subsubsection{Proceso de muestreo}

De acuerdo a Hernández, Fernández y Baptista (2010) señalan que en el Muestreo no probabilístico la elección de elementos en un subgrupo de la población está determinada por la decisión de propio investigador y no por la probabilidad. Las muestras probabilísticas dependerán de los atributos de la investigación y de quien realiza la investigación.

De acuerdo a Malhotra (2008) la técnica que el muestreo no probabilístico emplea es el juicio de investigador para seleccionar los elementos de una población los cuales son elegidos al azar.

La muestra seleccionada es de cinco expertos relacionados directamente al estudio, con experiencia en educación, ingeniería de sistemas y aplicaciones móviles. 
Los entrevistados seleccionados como marco muestral no probabilístico y por conveniencia para este estudio fueron:

i. 5 Directores de colegio

ii. $\quad 5$ Docentes

iii. Ingeniero de Sistemas con experiencia en aplicaciones móviles

\subsubsection{Diseño de instrumento}

Entrevista de profundidad

La entrevista de profundidad se realizó en forma presencial con cada especialista seleccionado, las preguntas nos estructuradas preparadas para cada especialista nos permitió conocer y valorar la información proporcionada para este estudio.

Las entrevistas de profundidad giraron en base a los siguientes temas:
a) El involucramiento y la interrelación entre el colegio y los padres
b) La educación y las Tecnologías de Información
c) Las plataformas de comunicación en la educación
d) La aceptación de una plataforma de comunicación en línea frente a productos que ofrecen una suite completa de gestión educativa.
e) Aplicaciones móviles y servicios en la nube.
f) Precio

Sesión de grupo (focus group)

La sesión de grupo tiene por objetivo nutrirnos de la percepción, los sentimientos, las actitudes y las opiniones de grupos de padres de familia sobre una plataforma de comunicación entre padres, alumnos y colegios.

El contenido tendrá los siguientes los temas: 
a) Conocer la experiencia de los involucrados sobre la importancia de la comunicación entre la comunidad educativa.

b) Conocer la experiencia de los involucrados con el uso de las Tecnologías de Información.

c) Conocer la experiencia de los involucrados sobre el uso de los smartphones y aplicaciones móviles.

d) Los aportes que puede hacer las TIC en el sector educación y el mejoramiento de la comunicación.

e) Las plataformas de comunicación en educación usadas actualmente con el apoyo de TI.

f) La aceptación de una plataforma de comunicación en línea frente a productos que ofrecen una suite completa de gestión educativa.

Las encuestas se encuentran los anexos número 1.

\subsubsection{Análisis y procesamiento de datos}

Las entrevistas de profundidad efectuadas a los directores de colegios, docentes y expertos de TI deja las siguientes conclusiones:

\section{Objetivo I}

Conocer la experiencia de los involucrados en relación a la importancia de la comunicación entre la comunidad educativa.

a) Análisis directores

i. La comunicación en tiempo real en la comunidad educativa es considerada muy importante en todo nivel, formas y tipo: escritas, verbales, telefónicos, agendas. 
ii. El desempeño académico de los estudiantes está relacionado a una comunicación más activa y asertiva y acompañamiento a los estudiantes por los padres de familia.

b) Análisis docentes

i. La comunicación en tiempo real es importante para los docentes, para coordinar con los padres de familia o incluso en situaciones urgentes, situaciones de salud, comportamientos académicos y otros puntos por lo cual se necesite comunicación rápidamente entre padres y profesores.

c) Análisis experto TI

i. Existen barreras actuales en las formas de comunicación tiempo real por el desconocimiento de una herramienta de TI que ayude en este proceso.

Objetivo 2

Conocer la experiencia sobre ventajas y desventajas sobre los medios usados actualmente en la comunidad educativa para la comunicación.

a) Análisis directores

i. Los medios usados actualmente para comunicación incluyen agendas, correos electrónicos, redes sociales y no necesariamente están actualizados en tiempo real. En algunos casos las redes sociales o páginas web se usan para comunicados con anticipación o calendarización del año escolar.

ii. Consideran importante tomar más provecho de las tecnologías de información para mejorar las comunicaciones y en tiempo real con los padres de familia.

b) Análisis docentes 
i. Consideran importante tomar más provecho de las tecnologías de información para mejorar las comunicaciones y en tiempo real con los padres de familia.

ii. En las instituciones que usan la comunicación con los padres por medio de correo electrónico o aplicaciones donde se necesita ingresar a la intranet para leer las comunicaciones, se percibe que los padres no ingresan a la intranet o al correo electrónico leer las comunicaciones

Objetivo 3

Identificar los aportes que puede hacer las TIC en el sector educación y el mejoramiento de la comunicación.

a) Análisis directores

i. Las TIC son muy importantes en la formación de los estudiantes, actualmente se están usando herramientas de apoyo multimedia para la enseñanza, capacitación en herramientas usadas en el mundo laboral como Office, automatización de la gestión administrativa, herramientas que ayuden en el desarrollo de asignaturas y seguimiento de desempeño del alumno.

b) Análisis docentes

i. En un futuro cercano se esperan que las TI acerquen a los padres de familia con herramientas de comunicación más efectivas.

Objetivo 4

Conocer la opinión sobre la viabilidad de un servicio en línea de comunicación para colegios.

a) Análisis Directores

i. La plataforma de comunicación en tiempo real permitiría una comunicación más asertiva e inmediata sobre un Teléfono Inteligente (Smartphone) 
incluso ante una comunicación de emergencia, y permite una comunicación abierta en ambos sentidos y no solo de alertas o notificaciones.

ii. El trabajo en equipo conformado por padres de familia, profesores para el desempeño del alumno sería una de las poderosas ventajas que haría viable esta herramienta.

iii. El precio que estarían dispuesto las instituciones educativas a pagar mensualmente por este servicio están en el rango de 990 a 2,310 soles (300 a 700 dólares americanos).

b) Análisis docentes

i. La institución que adquiere esta herramienta debe poner parámetros y reglas sobre su uso para no desvirtuar su uso, así como no perder el contacto visual con los padres.

c) Análisis experto TI

i. La herramienta debe asegurar la seguridad de la información de los participantes.

ii. La solución móvil debe estar disponible para todo tipo de smartphones, de características amigables y de fácil uso.

iii. La conexión a internet ilimitada puede ser una variable de análisis en cada colegio para la implementación de esta solución en tiempo real, que será usada por los docentes.

En relación a los dos Focus Group realizados a los padres de familia, se detalla a continuación el marco muestral. El muestro probabilístico realizado se hizo por conveniencia. 
Marco muestral: Padres de familia

i. Pertenecientes a los 25 distritos seleccionados (Barranco, Bellavista, Breña, Callao, Carmen de la Legua Reynoso, Chorrillos, Jesús María, La Molina, La Punta, La Victoria, Lima, Lince, Los Olivos, Magdalena del Mar, Miraflores, Pueblo Libre, Rímac, San Borja, San Isidro, San Luis, San Martin de Porres, San Miguel Santiago de Surco y Surquillo).

ii. Con hijos en edad escolar, de primaria y secundaria de colegios privados y escolarizados.

Se menciona las conclusiones extraídas de los focus group:

a) Sobre la importancia de la comunicación entre la comunidad educativa, les parece muy importante debido a que pueden hacer seguimiento a sus hijos. Un padre de familia hizo hincapié en el seguimiento que puede realizar a su hijo adolescente.

b) Sobre la experiencia de los involucrados o padres de familia con el uso de las Tecnologías de Información, todos ellos tienen experiencia en el manejo de aplicaciones, todos ellos cuentan con un Smartphone y están familiarizados desde aplicaciones de comunicación, pasando por compra y venta por aplicaciones móviles y también el manejo de aplicaciones bancarias.

c) Hay padres de familia que usan la aplicación social del WhatsApp para comunicarse con grupos de padres del colegio, sin embargo estos no son oficiados por el centro educativo.

d) Los entrevistados consideran que los aportes que puede hacer las TIC en el sector educación y el mejoramiento de la comunicación es muy alta cuando es bien 
empleada. Indican que han tenido experiencia negativas con aplicaciones pero que han sido muy pocas. (ejemplo, le cobraron una compra que página se Saga Falabella que ella no había realizado, hizo el trámite de anulación y la tienda la atendió).

e) La aceptación de una plataforma de comunicación en línea frente a productos que ofrecen una suite completa de gestión educativa, este punto fue muy receptivo ya que la suite completa en su caso está asociado a ingresar a una plataforma de pc, en cambio a tener un producto APP (aplicación móvil) siempre lo tienen activo en su Smartphone.

f) Características que debe tener la plataforma: diseño amigable, intuitivo, fácil de usar, fácil acceso sin password y claves.

g) Las aplicaciones que usan los padres en sus smartphones en su mayoría son libres de pagos, solo las de ocio o juegos son pagadas.

h) El grupo de enfoque conformada por los padres usan la apps para comprar en línea, realizar transacciones bancarias.

i) Padres considera que deberían enterarse del uso de esta plataforma por medio circulares, correos, reuniones explicativas ( funcionalidad, avance )

j) Desventajas ( no encuentran alguna) ventajas ( que puede ser usada por medio de smartphones, portabilidad, información y comunicación real inmediata,

k) Funcionalidades que añadirían: asistencias con huella, descargar clases ( si es que hijos no van a clases, obviamente con políticas y normativa, límites y horarios; aula virtual, GPS a movilidades para saber la ubicación de los hijos), adicionalmente sugieren que debe ser necesario que tenga un buzón de sugerencias como medida de mejora de la plataforma 
1) Obstáculos que visualizan: tiempos, fijación de límites, disponibilidad de profesores, actualización de información y cuidado con errores en la subida de información.

m) Consideran que si podrían reemplazar la agenda pero que de alguna manera podrían quedarse como medio de organización del alumno. Si podría reemplazar la plataforma que se esté usando que no tenga acceso con su Smartphone.

n) Todos consideran importante y están de acuerdo en cuanto a emplear esta plataforma.

\subsection{Investigación Cuantitativa}

De acuerdo a Malhotra (2008) la investigación cuantitativa tiene como finalidad la aplicación del análisis y de la estadística ya que se valoriza mucho la cuantificación de la data.

Hernández, Fernández y Baptista (2010) establecen que la investigación cuantitativa prueba hipótesis por medio del empleo el análisis estadístico y la medición numérica con la finalidad de estimar patrones de comportamiento y de verificar teorías. (p. 4)

El estudio se ha realizado con encuestas en forma presencial y en línea usando formularios de Google Drive como herramienta.

El marco muestral de las encuestas:

i. Directores de colegio de colegios escolarizados y privados que se encuentren dentro de Lima Metropolitana específicamente dentro de los 25 distritos seleccionados.

ii. Directores de colegio de nivel primario y secundario dentro de Lima Metropolitana 
iii. No incluyo padres de familia, ni alumnos de educación primaria y secundaria.

La investigación cualitativa sirvió para validar lo encontrado en la investigación cuantitativa en lo respecta a los directores de colegios.

Los objetivos identificados para este estudio cuantitativo son:

i. Identificar la predisposición al uso de internet y tecnologías móviles.

ii. Identificar la importancia de la comunicación entre familias y colegios.

iii. Identificar el nivel de aceptación de una plataforma de comunicación en línea entre familias y colegios.

iv. Identificar las características más valoradas de la nueva plataforma de comunicación en línea entre familias y colegios.

v. Conocer el porcentaje del mercado interesado en el nuevo servicio de plataforma educativa.

vi. El precio dispuesto a pagar por el mercado objetivo.

vii. $\quad$ Conocer e identificar a los competidores principales. 


\subsubsection{Proceso de muestreo}

El estudio cuantitativo ha tomado como muestra a los colegios privados escolarizados de nivel primario y secundario en los distritos seleccionados de:

Barranco, Bellavista, Breña, Callao, Carmen de la Legua Reynoso, Chorrillos, Jesús María, La Molina, La Punta, La Victoria, Lima, Lince, Los Olivos, Magdalena del Mar, Miraflores, Pueblo Libre, Rímac, San Borja, San Isidro, San Luis, San Martin de Porres, San Miguel Santiago de Surco y Surquillo. 
Tabla 16

Colegios privados escolarizados en la Lima Metropolitana y Callao

Disinge

Anoda

Ate

Barraseo

Betlovista

Breta

Catho

Carabsto

Carmea de La Lega Reyooso

Chachasase

chiles

Coeritles

Cesegoilla

Comas

퍼 Agertios

Indepeodexcia

Jerta Mark

La Moling

La Perla

La Peata

La Vhora

Lima

Liove

Los ohw

Lxigantbo

Lerin

Magdaleas del Mar

Me Pers
Nro Colegios

36

447

26

$\mathrm{n}$

6

26

264

24

44

1

205

21

39

n

113

5

107

42

4

94

145

36

321

142

37

35

29 
Miraflones 57

Pachacamac 70

Prowa4 10

Pebbo Labe 41

Poente Piedra $2 m$

Peat Hermoga

Peata Negra 9

Rimac $\quad 95$

San Bartab 4

San Borja 99

San Iritro 33

San Jan de Lvigantho 67

San Jaa de Mrafleses 247

San Lois 43

San Martin de Porres 60

San Mged 110

Santa Anita 134

Sana Marta del Mar 2

Santa Rosa $\quad 16$

Santago de Suroo 179

Sxquatio 33

$\begin{array}{ll}\text { Veatanith } & 179\end{array}$

Vitla el Sahnder 300

Vtla Marka del Trinafo 298

\begin{tabular}{lcl}
\hline Total & 6565
\end{tabular}

Recuperado de http://escale.minedu.gob.pe /padron-de-iiee 
En la tabla se observa que los distritos de mayor concentración de colegios son los que se encuentra en Lima Provincia, puntualmente dentro de Lima Metropolitana por lo que el grupo objetivo se extraerá de la información mostrada en la Tabla 17

Tabla 17

Colegios privados escolarizados en distritos seleccionados de Lima Metropolitana y Callao.

Distritos Nro. Colegios

Barranco

Bellavista 37

Breña 30

Callao

Carmen de La Legua Reynoso

Chorrillos

Jesús María

La Molina

La Perla

La Punta

La Victoria 42

Lima

Lince

Los Olivos

Magdalena Del Mar

Miraflores

Pueblo Libre

Rímac

San Borja 22

San Isidro

San Luis

San Martin de Porres

San Miguel

Santiago de Surco

108

Surquillo

19

Total 
Recuperado de http://escale.minedu.gob.pe/padron-de-iiee

El total del universo para la extracción de la muestra es de 1501 colegios escolarizados de nivel primario y secundario, para hallar el número de encuestas efectivas a realizar usamos la fórmula para cálculo de número de muestras para una población finita:

$$
n=\frac{N^{*} Z_{z}^{2} p^{*} q}{d^{2} *(N-1)+Z_{z}^{2} p^{*} q}
$$

Se considera lo siguiente:

*Posibilidad de éxito: $\mathrm{p}=0.50$

*Probabilidad de fracaso: $\mathrm{q}=(1-0.50)$

*error: $\mathrm{d}=5 \%$ (0.5) el valor estándar usado en las investigaciones

*Nivel de confianza: $Z=95 \%=1.96$

Por lo tanto, la muestra del estudio cuantitativo se compone de la siguiente manera:
a) Elementos : 306
b) Medio : Encuesta en línea o presencial
c) Tiempo: 60 días

La distribución de la muestra se hizo en base al número de alumnos por colegio y la cantidad de colegios por distrito para que sea representativa, por lo que queda conformada de la siguiente manera:

\section{Tabla 18}

Muestra de Colegios privados escolarizados en la Lima y Callao Metropolitano 
Tabla 18

Tabla

Distribucion de la Muestra

Distritos

Número de alumnos

Total de colegios seleccionados por

\begin{tabular}{|c|c|c|c|c|c|c|c|c|c|c|c|}
\hline & $0-50$ & 50 a 99 & 100 a 199 & 200 a 299 & 300 a 399 & 400 a 499 & 500 a 599 & 600 a 699 & 700 a 1499 & 1500 a 4000 & distrit \\
\hline 1 San Martin de Porres & 18 & 15 & 17 & 10 & 5 & 3 & 3 & 1 & 7 & 1 & 80 \\
\hline 2 Los Olivos & 9 & 7 & 8 & 5 & 2 & 2 & 2 & 1 & 3 & 0 & 39 \\
\hline 3 Callao & 6 & 5 & 6 & 3 & 2 & 1 & 1 & 0 & 2 & 0 & 26 \\
\hline 4 Chorrillos & 5 & 4 & 5 & 3 & 1 & 1 & 1 & 0 & 2 & 0 & 22 \\
\hline 5 Santiago de Surco & 5 & 4 & 5 & 3 & 1 & 1 & 1 & 0 & 2 & 0 & 22 \\
\hline 6 Lima & 3 & 3 & 3 & 2 & 1 & 1 & 1 & 0 & 1 & 0 & 15 \\
\hline 7 San Miguel & 3 & 3 & 2 & 2 & 1 & 1 & 1 & 0 & 1 & 0 & 14 \\
\hline 8 Rimac & 3 & 2 & 2 & 1 & 1 & 1 & 0 & 0 & 1 & 0 & 11 \\
\hline 9 La Molina & 2 & 2 & 2 & 1 & 1 & 0 & 0 & 0 & 1 & 0 & 9 \\
\hline 11 Bellavista & 2 & 1 & 2 & 1 & 1 & 0 & 0 & 0 & 1 & 0 & 8 \\
\hline 12 Breña & 1 & 1 & 1 & 1 & 1 & 0 & 0 & 0 & 1 & 0 & 6 \\
\hline 13 Miraflores & 1 & 1 & 1 & 1 & 1 & 0 & 0 & 0 & 1 & 0 & 6 \\
\hline 14 Jesus Maria & 1 & 1 & 1 & 1 & 0 & 0 & 0 & 0 & 1 & 0 & 5 \\
\hline 15 La Perla & 1 & 1 & 1 & 1 & 0 & 0 & 0 & 0 & 1 & 0 & 5 \\
\hline 16 Magdalena Del Mar & 1 & 1 & 1 & 1 & 0 & 0 & 0 & 0 & 0 & 0 & 4 \\
\hline 17 San Borja & 1 & 1 & 1 & 1 & 0 & 0 & 0 & 0 & 0 & 0 & 4 \\
\hline 18 San Luis & 1 & 1 & 1 & 1 & 0 & 0 & 0 & 0 & 0 & 0 & 4 \\
\hline 19 Surquillo & 1 & 1 & 1 & 1 & 0 & 0 & 0 & 0 & 0 & 0 & 4 \\
\hline 20 Lince & 1 & 1 & 1 & 0 & 0 & 0 & 0 & 0 & 0 & 0 & 3 \\
\hline 22 San Isidro & 1 & 1 & 1 & 0 & 0 & 0 & 0 & 0 & 0 & 0 & 3 \\
\hline 23 Barranco & 1 & 0 & 1 & 0 & 0 & 0 & 0 & 0 & 0 & 0 & 2 \\
\hline 24 Carmen de La Legua Reynoso & 1 & 0 & 1 & 0 & 0 & 0 & 0 & 0 & 0 & 0 & 2 \\
\hline 25 La Punta & 0 & 0 & 0 & 0 & 0 & 0 & 0 & 0 & 0 & 0 & 0 \\
\hline Total de colegios seleccionadc & 71 & 59 & 67 & 40 & 19 & 11 & 10 & 2 & 26 & 1 & 306 \\
\hline
\end{tabular}
número de alumnos 


\subsubsection{Diseño de Instrumento}

A través del estudio cuantitativo se han elaborado encuestas con preguntas estructuradas, que puedan responder a los objetivos planteados y que permitan extraer información importante que permita saber las preferencias, expectativas y gustos en torno a la aceptación de la plataforma de comunicación a tiempo real para padres, alumnos y familias.

Las encuestas giraron en base a los siguientes temas:

a) Acceso a internet y actitud hacia uso de Teléfono Inteligente (Smartphone).

b) Importancia de la comunicación inmediata en la comunidad educativa.

c) Preferencia por uso de una plataforma comunicación online.

d) Características deseables en la plataforma de comunicación en línea.

e) Precio que el mercado objetivo está dispuesto a pagar.

f) Identificar a los principales competidores.

\subsubsection{Análisis y procesamiento de datos}

Para el estudio cuantitativo se ha elaborado encuestas con preguntas estructuradas, que puedan responder a los objetivos planteados y que permitan extraer información importante que permita saber las preferencias, expectativas y gustos en torno a la aceptación de la plataforma de comunicación a tiempo real para padres, alumnos y familias.

Las encuestas giraron en base a los siguientes temas:

g) Acceso a internet y actitud hacia uso de Teléfono Inteligente (Smartphone). Este objetivo nos permite saber la actitud de los educadores y administrativos de los centros educativos hacia el uso de aplicaciones móviles, reflejada en la pregunta número 3 de la encuesta. El resultado fue un categórico 87 \% de aceptación de uso de este tipo de aplicaciones, que es del tipo que tendrá la solución. 


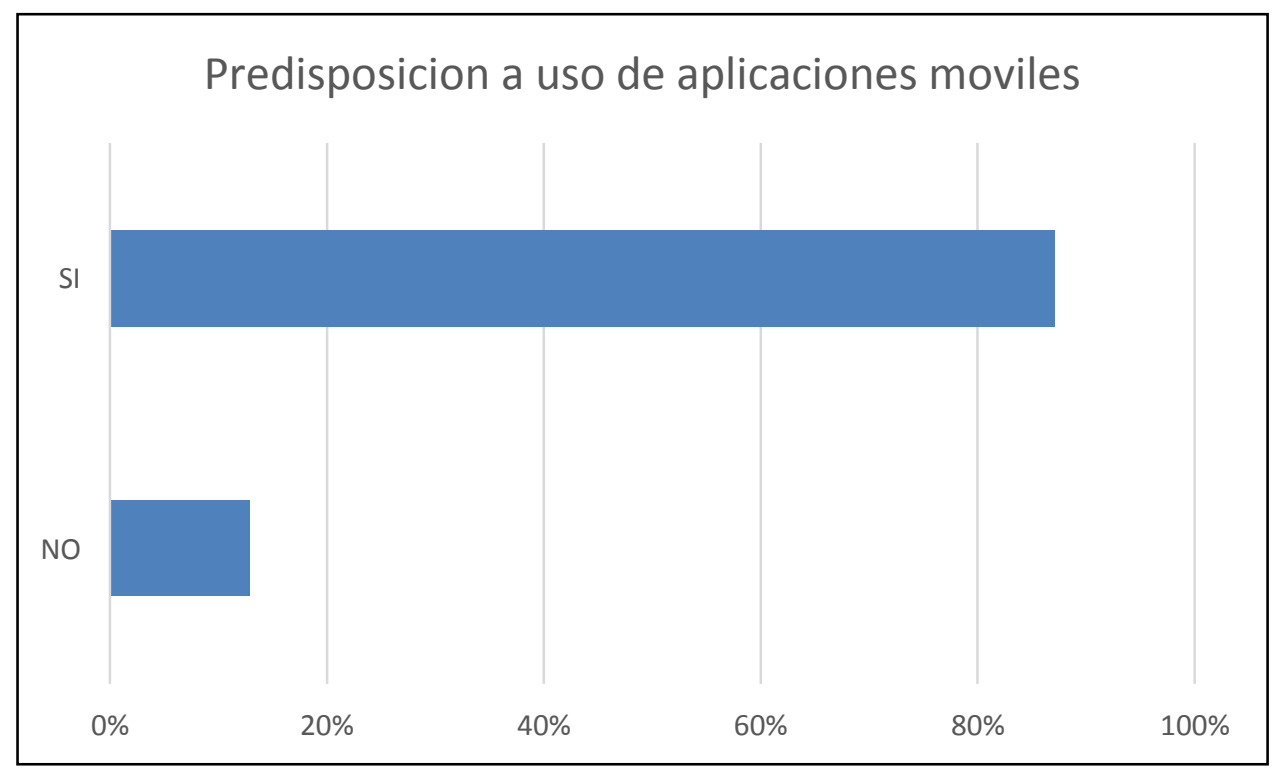

Figura 23. Empresas Predisposición a uso de aplicaciones móviles. Elaboración Propia.

h) Importancia de la comunicación inmediata en la comunidad educativa.

La medición de este objetivo estuvo relacionada con la pregunta numero 5 ¿Piensa que es importante la comunicación inmediata entre profesores, padres de familia y alumnos?, el resultado no lleva a mayor análisis que simplemente es un $100 \%$ valora la comunicación inmediata en la comunidad educativa.

i) Preferencia por uso de una plataforma comunicación online.

La pregunta nro. Seis “¿Cree usted que es efectivo el uso de una plataforma de comunicación online para la comunidad educativa a través de smartphones?” busca medir la actitud de trasladar la comunicación que se realiza en la comunidad educativa a una plataforma virtual y en línea, el grado de aceptación fue de un $70 \%$. 
Uso de plataforma online para comunicacion

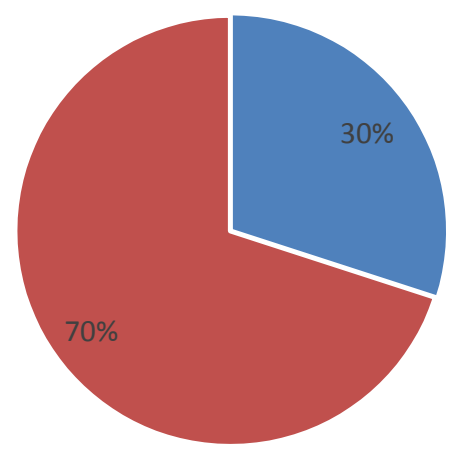

$\square$ NO $\mathbf{S I}$

Figura 24. Uso de plataforma online para comunicación. Elaboración Propia.

j) Características deseables en la plataforma de comunicación en línea.

La encuesta busco obtener respuestas sobre qué características de la aplicación para Smartphone era más valorada por los clientes, así tenemos que un $70 \%$ de los encuestados valoraron un servicio de post-venta, seguido de un $50 \%$ que valoraban que la aplicación se identifique con la imagen del colegio. (Logos, colores, escudos, etc.).

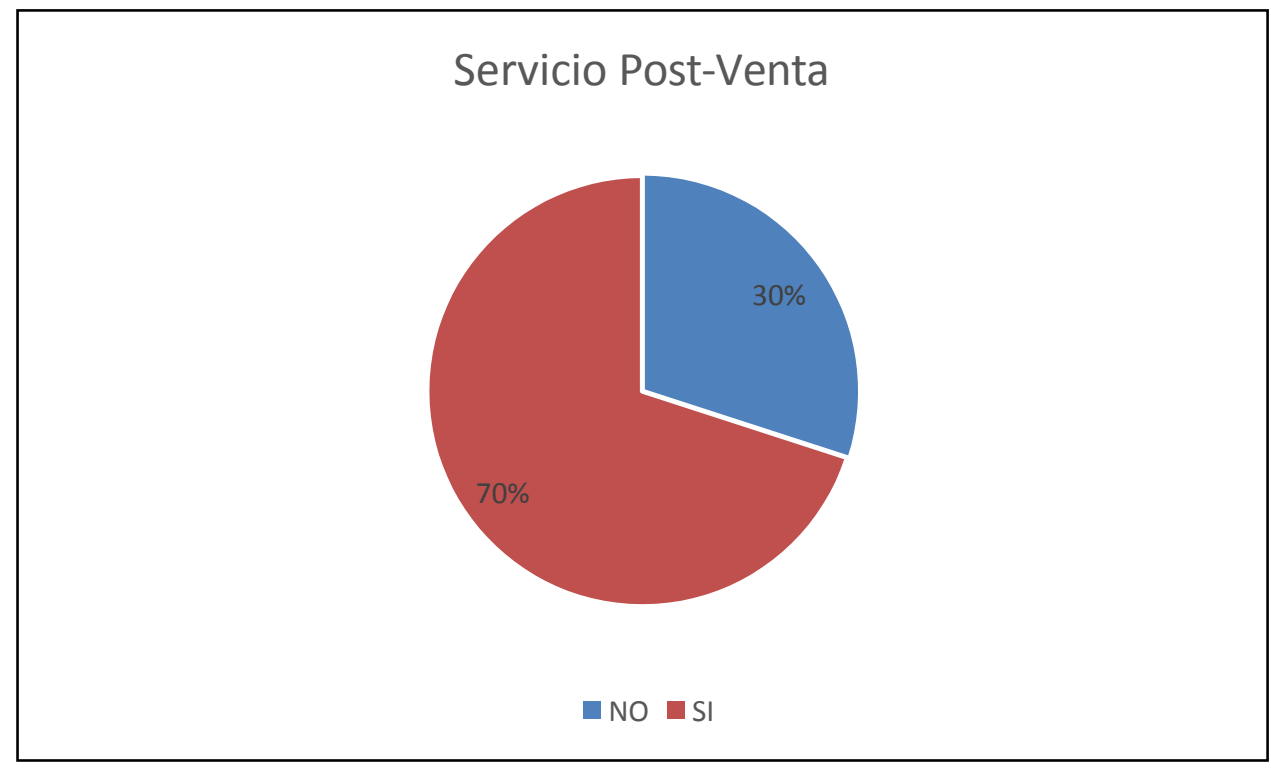

Figura 25. Servicio Post-Venta. Elaboración Propia. 
k) Identificar a los principales competidores.

1) Precio que el mercado objetivo está dispuesto a pagar.

Se ha incluido dentro del estudio cuantitativo la pre disposición que es aceptable pagar mensualmente por el servicio de la plataforma de comunicación en línea, los montos expresados son en dólares americanos. El 37 \% escogió un rango entre 200 y 300.

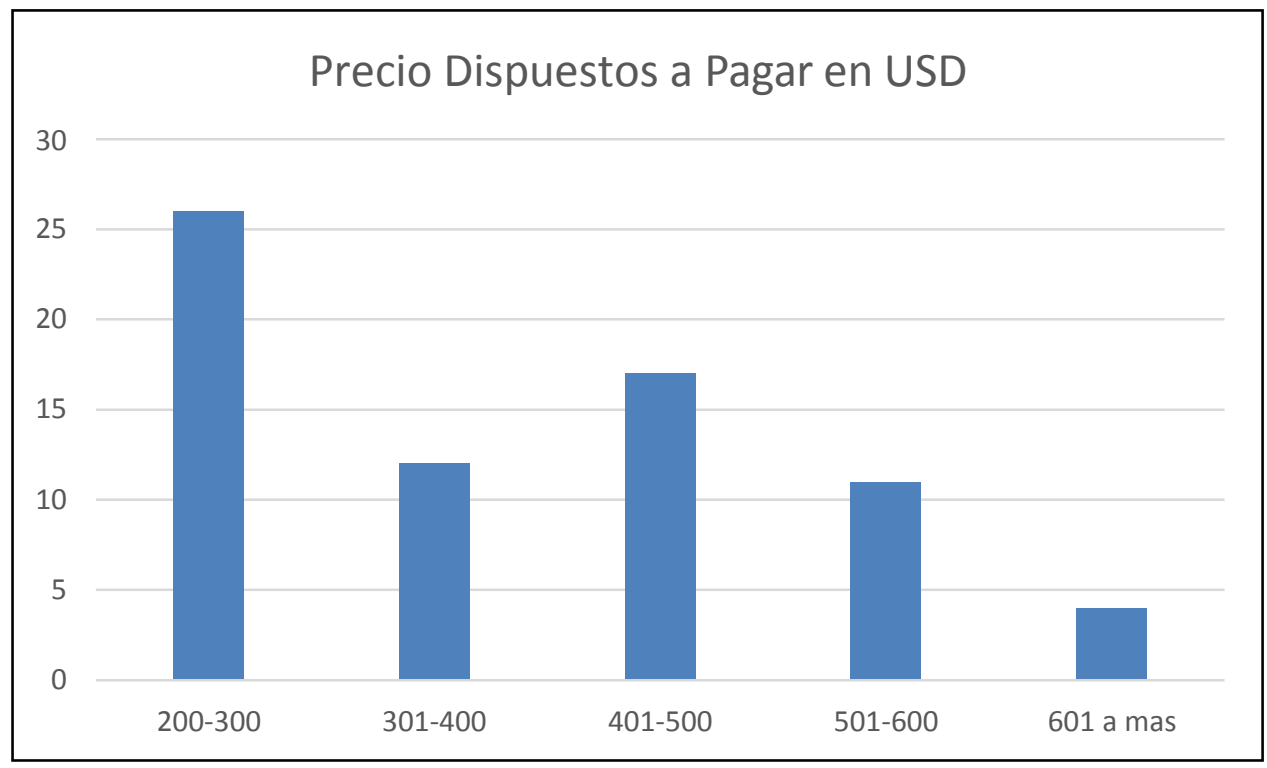

Figura 26. Precio Dispuesto a Pagar en USD. Elaboración Propia.

m) Aceptación el servicio de la nueva plataforma de comunicación de la comunidad educativa.

El nivel de aceptación de la nueva plataforma fue incluido en la pregunta nro. 20 de la encuesta cuantitativa "Usted estaría dispuesto a adquirir el servicio de plataforma en tiempo real para la comunicación entre familias, colegio y alumnos?, los resultados son positivos, obteniendo un $52 \%$ a favor de adquirir la plataforma de servicios de comunicación. 


\section{ACEPTACION DE LA PLATAFORMA}

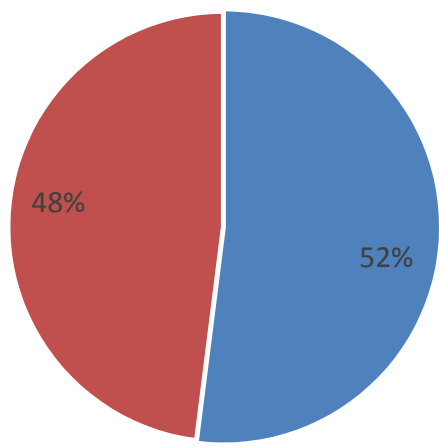

- SI NO

Figura 27. Precio Aceptación de la plataforma. Elaboración Propia.

Las encuestas se encuentran en los Anexos

\subsection{Conclusiones y recomendaciones del Estudio Cualitativo y Cuantitativo}

a) La investigación cuantitativa ( encuesta directores) permite validar lo encontrado en la investigación cualitativa (entrevistas a profundidad directores) en lo que respecta a los directores de los colegios . En este caso, se emplea el mismo marco muestral.

b) Es importante mencionar que a los que se les realiza el focus group (investigación cualitativa) no se les realiza las encuestas (investigación cuantitativa) específicamente a los padres de familia.

c) Las aplicaciones para Smartphone son de gran aceptación en la comunidad educativa y se obtienen opiniones favorables sobre el uso de las mismas por los expertos consultados en la encuesta cualitativa. 
d) Los entrevistados valoran la comunicación entre la comunidad educativa, es importante debido al seguimiento que puedan hacer a sus hijos y mantener una fluidez de comunicación con los profesores.

e) Las características deseables producto de los estudios cualitativo y cuantitativo reflejan que la aplicación debe ser de diseño amigable, intuitivo, fácil de usar y en especial un servicio de post-venta.

f) El rango de precios comprendido entre 200 y 300 dólares americanos es el de mayor preferencia representada por un $37 \%$ de los encuestados.

\subsection{Perfil del consumidor tipo y sus variantes}

El perfil del consumidor es colegios educativos privados de educación primaria y secundaria ubicado en los distritos de Barranco, Bellavista, Breña, Callao, Carmen de La Legua Reynoso, Chorrillos, Jesús María, La Molina, La Perla, La Punta, La Victoria, Lima, Lince, Los Olivos, Magdalena Del Mar, Pueblo Libre, Rímac, San Borja, San Isidro, San Luis, San Martin de Porres, San Miguel, Santiago de Surco y Surquillo, que estén dispuestos a pagar entre 200 y 300 dólares americanos. 


\section{Capitulo IV: Proyección del Mercado Objetivo}

Para realizar el pronóstico del mercado para el servicio de plataforma de comunicación entre familia, alumnos y colegios es necesario hacer un análisis de algunas variables previamente seleccionadas que van a determinar posibles comportamientos futuros que permitirán hacer una proyección de cómo será el mercado.

De acuerdo con Kotler y Keller (2016), pronóstico de mercado señala la demanda de mercado que se espera (p.86).

\subsection{El ámbito de la proyección}

Se pueden emplear diversos métodos para poder pronosticar el comportamiento futuro de las variables que se usaran en el proyecto.

A continuación, se detallan algunos criterios que se consideran importantes:

a) Para efectuar un adecuado pronóstico del mercado es fundamental cerciorarse de la calidad de la data, es decir saber si en realidad existe veracidad de los resultados.

b) Es indispensable establecer cuál será el resultado que se espera como también realizar una adecuada y eficaz elección del método a utilizar.

\subsection{Selección del método de proyección}

\subsubsection{Mercado Potencial}

De acuerdo a Kotler \& Keller (2016), el mercado potencial es definido como un cúmulo de compradores que poseen un alto nivel de atracción por la oferta del mercado.

De la misma forma Belén y Sellers (2006), señala que todos los clientes que se encuentran interesados en los artículos o productos vienen a ser el mercado potencial. 
Kotler \& Keller (2016) indican que mercado potencial es cuando existe una gran demanda de mercado que se acerca a los limites unido a grandes y continuos gastos en marketing de parte de industria.

Según Planificación aplicada a empresas asociativas rurales (2006) el mercado potencial es una agrupación de consumidores que tiene una gran inclinación por la oferta de un artículo o producto. El gran interés puesto consumidor no va a determinar el mercado.

El mercado potencial está conformado por los colegios que cumplen con las características de la segmentación geográfica y cuyas variables para este estudio sean colegios privados con niveles de enseñanza primaria y secundaria.

En el proyecto, se presenta que el servicio de comunicación en línea para la comunidad educativas online aplique solo para los distritos de:

Barranco, Bellavista, Breña, Callao, Carmen de la Legua Reynoso, Chorrillos, Jesús María, La Molina, La Punta, La Victoria, Lima, Lince, Los Olivos, Magdalena del Mar, Miraflores, Pueblo Libre, Rímac, San Borja, San Isidro, San Luis, San Martin de Porres, San Miguel Santiago de Surco y Surquillo. 


\section{Tabla 19}

Distribución de Colegios por distrito y número de alumnos.

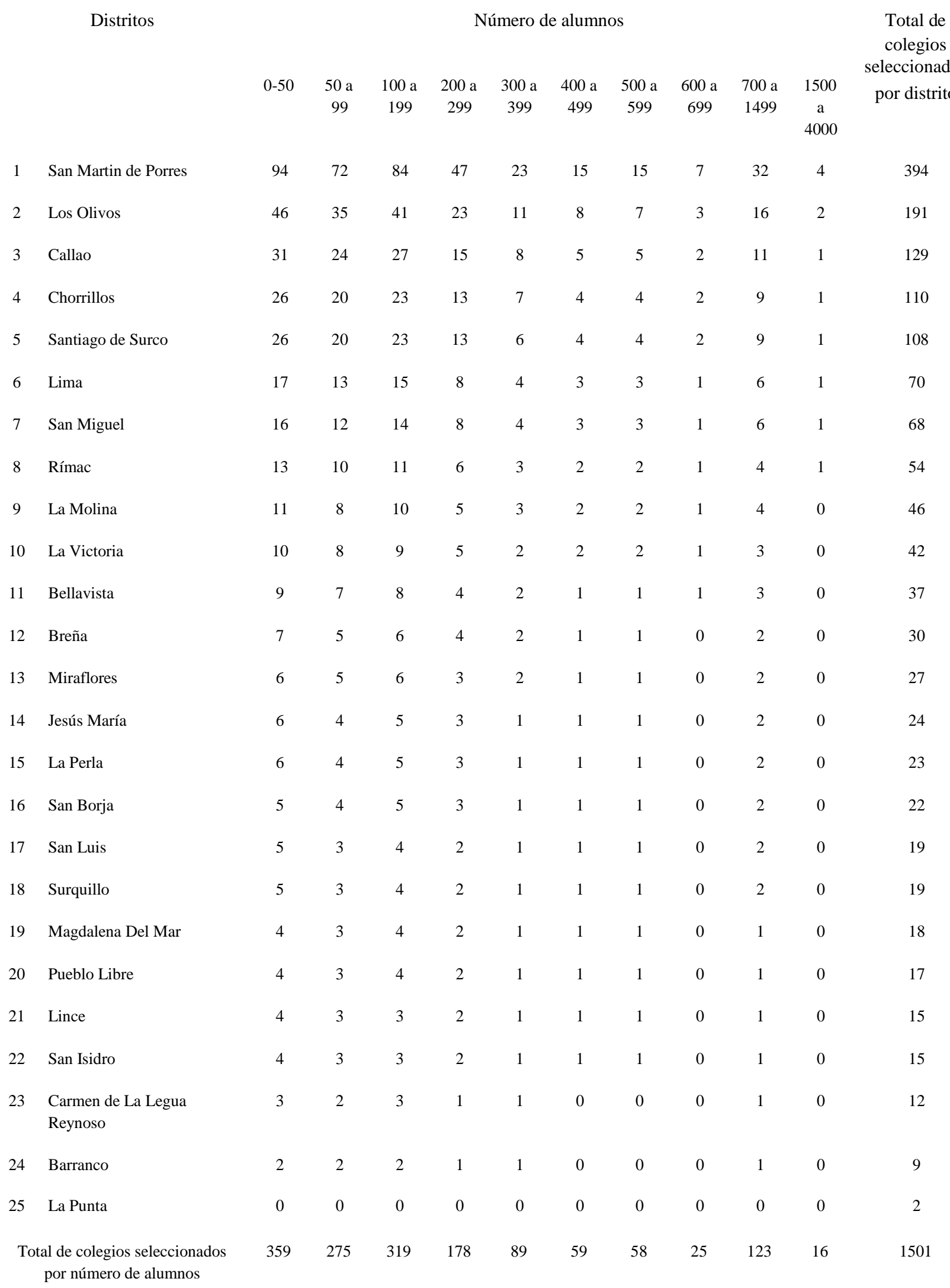




\subsubsection{Mercado disponible}

De acuerdo a Kotler y Keller (2016) el cúmulo de consumidores que poseen una gran inclinación por cierto producto, recursos económicos y facilidad para poder acceder a una oferta específica viene a ser el mercado disponible. (p.86)

De la misma forma Belén \& Sellers (2006) coinciden con los autores anteriores ya que también consideran que el mercado disponible son los consumidores que muestran atracción por un producto, poseen suficiente dinero y tiene acceso rápido a la oferta. Asimismo, los mismos autores señalan que el mercado disponible se encuentra dentro del mercado potencial siendo el primero su subconjunto. (p. 92)

De acuerdo a Reyes (2013) el mercado disponible sale de aplicación de una encuesta y viene a ser una parte del mercado potencial que tiene la necesidad y está dispuesto a comprar

El mercado disponible se obtiene de las encuestas realizadas a los colegios privados y es parte del mercado potencial que podría requerir el servicio comunicación en línea en la comunidad educativa. La medición ha sido efectuada con la pregunta: “¿Cree usted que es efectivo el uso de una plataforma online para la comunidad educativa a través de smartphones?" (Pregunta No 6 de la encuesta); el resultado de la encuesta es que el $70 \%$ “definitivamente sí” es efectivo el uso..

Mercado Potencial x $70 \%$ que cree una plataforma para smartphones online es efectiva Mercado Disponible $1501 * 0.70=1051$ 


\subsubsection{Mercado efectivo}

De acuerdo a Kotler y Keller (2016) el mercado efectivo es grupo de clientes que compran el producto. p.87

El mercado efectivo está conformado por los colegios privados que comprarían el producto ofrecido. La pregunta que nos responde este mercado es: “¿Usted estaría dispuesto a adquirir el servicio de plataforma en tiempo real para la comunicación entre familias, colegio? (Pregunta No 20 de la encuesta)

\begin{tabular}{l} 
Mercado Disponible x 52 \% estarían dispuestos a adquirir la plataforma \\
\hline $1050.7 * 0.52=546$
\end{tabular}

\subsubsection{Mercado objetivo}

De acuerdo a Kotler y Keller (2016) "El mercado meta / objetivo es cuando la empresa toma la decisión de atender solo al mercado que ha calificado como propicio es decir como target (p.87)

Belén \& Seller (2006) señalan que el mercado Objetivo forma parte del mercado disponible y es el mercado al que la empresa está interesada en direccionar su oferta de producto p.92)

De acuerdo a Reyes (2013) el objetivo a ser logrado en un proyecto de inversión viene a ser el mercado meta.

Para determinar la participación en el mercado, usaremos dos fuentes, la guía de aproximaciones de porcentaje de participación de mercado y el resultado de las preguntas 7 y 8 de las encuestas cuantitativas.

La siguiente tabla que nos permite aproximar la participación en base a competidores y la similitud de sus productos. 
Tabla 20

Gufa de Aproximaciones de Porcentaje de Participacion de Mercado

Nro. Que tan grandes

son sus competidores

\section{Que tantos} competidores tiene

Que tan similares son

sus productos a los

suyos

\section{Cual parece ser su} porcentaje

$0 \%-0.5 \%$

Muchos

Algunos

Uno

Muchos

Algunos

Uno

Muchos

Algunos

Muchos

Algunos

Uno

Uno

Pequeños

Sin Competencia

Similares

Similares

Similares

Diferentes

Diferentes

Diferentes

Similares

Similares

Diferentes

Diferentes

Similares

Diferentes

Sin Competencia
$0 \%-0.5 \%$

$0.5 \%-5 \%$

$0.5 \%-5 \%$

$0.5 \%-5 \%$

$10 \%-15 \%$

$5 \%-10 \%$

$10 \%-15 \%$

$10 \%-15 \%$

$20 \%-30 \%$

$30 \%-50 \%$

$40 \%-80 \%$

$80 \%-100 \%$

Fuente:

http://repository.ean.edu.co/bitstream/handle/10882/1961/QuinteroHugo2012.pdf? sequence= 5. Fundación E, Macro Plan. Guía de diseño. Mentoría para el emprendedor.

En base a esta guía y al análisis realizado en la identificación de competidores y productos similares, podemos ubicarnos en el registro número 9, que considera una participación de mercado de entre $10 \%$ y $15 \%$. 
Tabla 21

Empresa que ofrecen el servicio

Net School 360

H\&O System S.A.C - Sieweb

Sia - Net Sistemas Integrales empresariales S.A.C

Otros
Numero de

Colegios

7

21

10

14
Participación \%

$13 \%$

$40 \%$

$19 \%$

$27 \%$

\begin{tabular}{lll}
\hline Total usan Herramientas & 52 & $74 \%$ \\
\hline No usan herramientas & 18 & $26 \%$ \\
\hline
\end{tabular}

Fuente: Elaboración propia

Los resultados de las encuestas realizadas, que se muestran en la tabla 21, indican una participación del 13\% del competidor de cierta manera considerado directo Net School Perú, con su producto NetSchool 360.

Adicionalmente, se especifica que de la pregunta n $^{\circ} 20$ de las encuestas: ¿Usted estaría dispuesto a adquirir el servicio de plataforma en tiempo real para la comunicación entre familias, colegio? se obtiene que un $14 \%$ se encuentra dentro del top two box o la suma de dos valores de la escala Liker que tienen mayor intención de compra.

En base al resultado de las fuentes expuestas y considerando un enfoque conservador se ha determinado el valor de $13 \%$ como participación de mercado para el producto.

Mercado efectivo x $13 \%$

$547 * 0.13=71$ colegios

\subsection{Pronóstico de Ventas}

El pronóstico de ventas de la empresa es la proyección de las ventas basándose en un ambiente de marketing específico y en un plan de marketing. 
Los tres primeros meses las ventas son tímidamente pronosticadas de 5 clientes, a partir del cuarto mes se estima crecimiento del $10 \%$ del mercado meta es decir 8 clientes mensuales, al mes 12 se cierra con la meta de 71 clientes.

El precio de la licencia, es único y no está afectado por número de usuarios que un colegio pueda tener. El precio se ha establecido en S/ 749.00 soles mensuales, un precio competitivo a comparación de los competidores.

A continuación se muestra las tablas 22, 23 y 24 donde se muestra los pronósticos de ventas en base al punto anterior.

La tabla 22 muestra la venta en unidades mensuales para el año 2018, el mercado objetivo de $13 \%$ es igual a 71 clientes, al finalizar el año se tendría un total de 408 servicios. En la tabla 23 se muestra en las ventas del año 2018 en soles. 
Tabla 22

Pronóstico de ventas en unidades año 2018

\begin{tabular}{lcccccccccccccc}
\hline $\begin{array}{l}\text { Detalle por } \\
\text { unidades }\end{array}$ & $\begin{array}{c}\text { Mercado } \\
\text { objetivo Año } \\
2018\end{array}$ & Ene & Feb & Mar & Abr & May & Jun & Jul & Ago & Sep & Oct & Nov & Dic & Total \\
Año & \\
\hline Clientes & 71 & 1 & 2 & 2 & 8 & 8 & 8 & 8 & 8 & 8 & 8 & 8 & 2 & 71 \\
Servicios & & 1 & 3 & 5 & 13 & 21 & 29 & 37 & 45 & 53 & 61 & 69 & 71 & 408
\end{tabular}

mensuales

Tabla 23

Pronóstico de ventas expresado en soles

\begin{tabular}{|c|c|c|c|c|c|c|c|c|c|c|c|c|c|}
\hline $\begin{array}{l}\text { Ventas } \\
(\mathrm{S} / .)\end{array}$ & Ene & Feb & Mar & Abr & May & Jun & Jul & Ago & Sep & Oct & Nov & Dic & Año 2018 \\
\hline $\begin{array}{l}\text { Ventas } \\
\text { (sin igv) }\end{array}$ & $\mathrm{S} / .635$ & $\mathrm{~S} / .1,904$ & $\mathrm{~S} / .3,174$ & $\mathrm{~S} / .8,252$ & $\mathrm{~S} / 13,330$ & $\mathrm{~S} / 18,408$ & $\mathrm{~S} / .23,486$ & $\mathrm{~S} / 28,564$ & $\mathrm{~S} / 33,642$ & $\mathrm{~S} / 38,719$ & $\mathrm{~S} / 43,797$ & $\mathrm{~S} / .45,067$ & $\mathrm{~S} / .258,976$ \\
\hline IGV & $\mathrm{S} / .114$ & $\mathrm{~S} / 343$ & $\mathrm{~S} / 571$ & $\mathrm{~S} / .1,485$ & $\mathrm{~S} / 2,399$ & $\mathrm{~S} / .3,313$ & $\mathrm{~S} / .4,227$ & $\mathrm{~S} / .5,141$ & $\mathrm{~S} / 6,055$ & $\mathrm{~S} / 6,970$ & $\mathrm{~S} / .7,884$ & $\mathrm{~S} / 8,112$ & $\mathrm{~S} / .46,616$ \\
\hline $\begin{array}{l}\text { Ventas } \\
\text { (con igv) }\end{array}$ & $\mathrm{S} / .749$ & $\mathrm{~S} / 2,247$ & $\mathrm{~S} / .3,745$ & $\mathrm{~S} / .9,737$ & $\mathrm{~S} / .15,729$ & $\mathrm{~S} / .21,721$ & $\mathrm{~S} / .27,713$ & $\mathrm{~S} / .33,705$ & $\mathrm{~S} / 39,697$ & $\mathrm{~S} / .45,689$ & $\mathrm{~S} / .51,681$ & $\mathrm{~S} / .53,179$ & $\mathrm{~S} / 305,592$ \\
\hline
\end{tabular}


Tabla 24

Pronóstico de ventas en soles, del año 2019 al 2022

\begin{tabular}{lcccc}
\hline Ventas (S/.) & 2019 & 2020 & 2021 & 2022 \\
\hline Ventas (sin igv) & S/.571,271 & S/.594,122 & S/.624,590 & S/.655,058 \\
IGV & S/.102,829 & S/.106,942 & S/.112,426 & S/.117,910 \\
Ventas (con igv) & S/.674,100 & S/.701,064 & S/.737,016 & S/.772,968 \\
\hline
\end{tabular}

En las tablas anteriores se detalla el pronóstico de venta anual para los años 2018 al2022. Para el año 2018 se proyecta una venta anual de S/ 305,592, y para el ultimo año 2022 S/ 772,968 


\subsection{Aspectos críticos que impactan el pronóstico de ventas}

a. Variables económicas:

Pueden existir ciertas variables económicas que afecten los pronósticos de ventas entre ellas podrían ser la tasa de inflación, el producto bruto interno y las tasas de interés.

b. Impacto de la tecnología:

El pronóstico de venta se ve directamente afectado por el papel fundamente que juega la tecnología en el día de hoy. Debido a los cambios, los avances de investigación y a las nuevas necesidades que brotan la tecnología hoy es cambiante y debe ajustarse a dichos cambios.

c. Políticas de gobierno:

Hoy en día, no existen políticas claras en relación a la venta de servicios de software. Aun se evidencia que no existe un mayor obstáculo para la venta de aplicaciones móviles. Es importante señalar que las decisiones que tome el gobierno si afectaran directamente un pronóstico de ventas.

d. Los planes que posea la competencia:

Los planes que tenga en la mente puede poner el riesgo el pronóstico de ventas que se tenga es por eso es importante un estudio previo de la competencia y de sus posibles acciones para lograr una anticipación.

e. Presencia de desastres naturales en el país:

Actualmente, los desastres vividos en nuestra capital como los huaycos podrían afectan directamente la economía del país y por ende, el pronóstico de venta. 


\section{Capítulo V: Ingeniería del Proyecto}

\subsection{Estudio de Ingeniería}

Según Baca 2013, señala que el estudio técnico o ingeniería de un proyecto permite construir la organización de una empresa en un sentido más extenso ya que se enfoca en definir el tamaño y localización adecuados; identificar los costos de los insumos y suministros, reconocer y detallar procesos involucrados, definir el capital humano necesario y diseñar la organización jurídica requerida para formalizar la empresa y llevar a cabo el proyecto.

El producto a desarrollarse consiste en la creación de una Aplicación Móvil (App) para usuarios de la comunidad educativa (colegios, profesores, padres de familia y alumnos) será un sistema informático que soporte la gestión de la comunicación.

La Aplicación Móvil (App) va a estar disponible para celulares con Sistema Operativo Android y IOS, y pueden ser descargados desde Play Store y App Store respectivamente. La interface de gestión se podrá acceder desde un navegador.

Cabe señalar, que desde el año 2010 se ha generado un cambio abismal en la manera como se ingresa y navega en la Internet debido a la arquitectura y concepción de los dispositivos móviles. En la actualidad, la movilidad -navegación y el uso de la PC no son compatibles. Cada vez, la información está más cerca de donde nos encontremos.

Los desarrolladores de aplicaciones web adaptan el contenido de sus páginas a los dispositivos móviles tecnológicos. Es preciso mencionar, que las aplicaciones móviles son versiones de contenido más adaptables y emplean un lenguaje especial denominado HTML5, mezclado con hojas de estilo CSS3, que hacen posible dicha adaptabilidad, llamada en el 
idioma inglés Responsive Web Design. Recuperado de https:// es.wikipedia.org/ wiki/Aplicaci\%C3\%B3n_m\%C3\%B3vil

De acuerdo a Cuello y Vittone (2013) existen cinco etapas secuenciales que estructuran el proceso de diseño y desarrollo de un App. Entre ellas están:

A. Conceptualización: todo se origina por una idea la cual permite satisfacer a cierto sector de la población tomando en cuenta sus necesidades y problemática. Se debe de realizar un análisis exhaustivo que permita llegar a una idea que responda a lo que se espera en términos de factibilidad y objetividad y asegure la viabilidad de dicho concepto.

B. Definición: está supeditada por la posibilidad de realizar el proyecto, se determinan las funcionalidad de la App tomando en consideración el perfil de los usuarios, las especificaciones técnicas, los objetivos a establecer y parámetros de conectividad al hardware del dispositivo. Todo ello permitirá determinar el alcance del proyecto, complejidad, costos, duración como también la programación de la aplicación.

C. Diseño: es esta etapa se logra materializar los aspectos de la etapa de definición (especificaciones, funcionalidades, etc.). Para poder lograr la etapa de diseño se hace necesario primero elaborar un diseño tipo esquema sin gráficos (wireframe) que será probado por un grupo usuarios. Posteriormente, se haya superado esta prueba se otorgará un diseño final al desarrollador. Dicho diseño estará en archivos y pantallas para que pueda agregar los códigos de programación. Los sistemas operativos posibilitan la interacción con el usuario presentando en la pantalla los elementos necesarios para ello de forma diferente. 


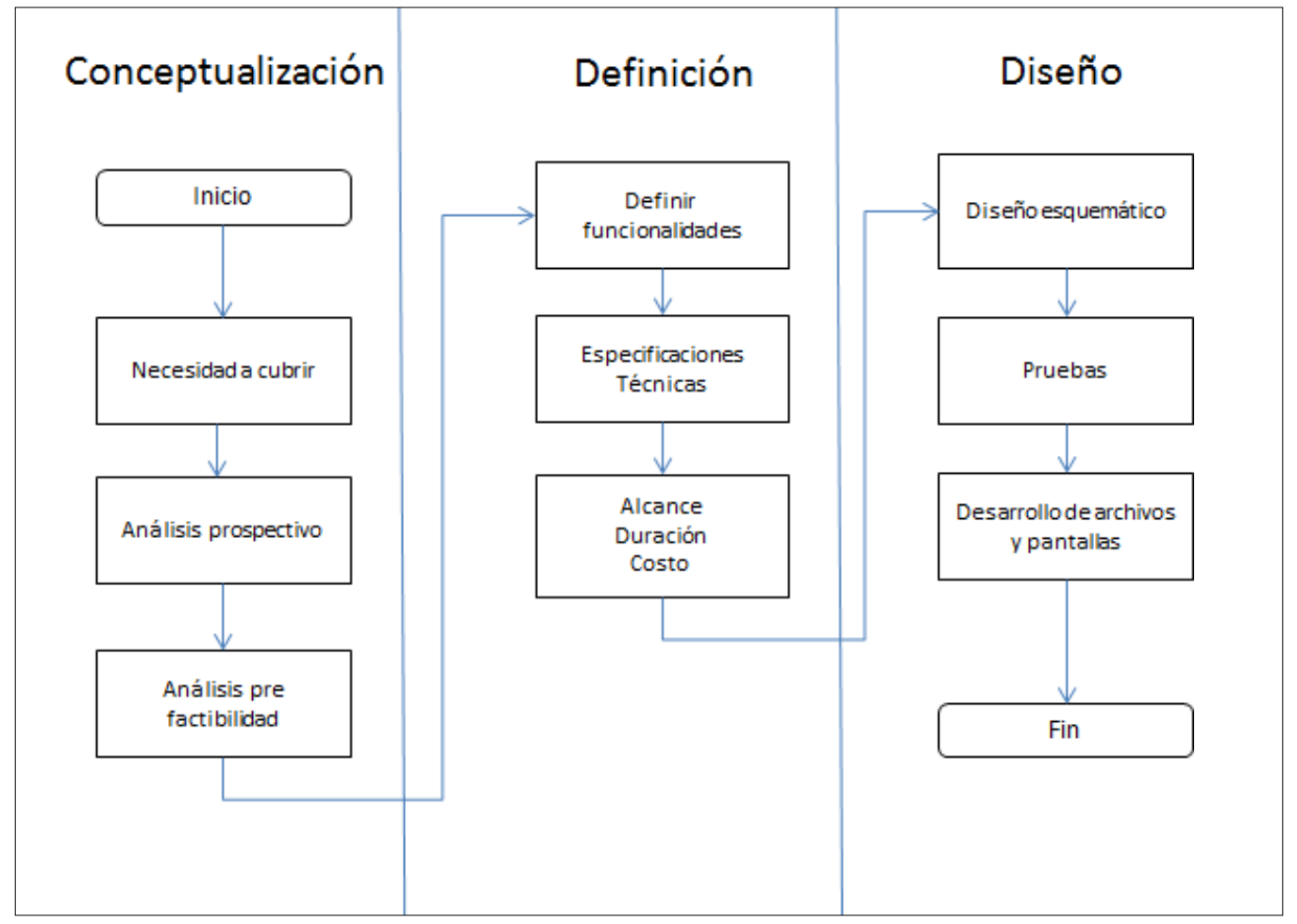

Figura 28. Proceso diseño de software. Adaptado de "Diseñando apps para móviles" por Cuello y Vittone (2013). Recuperado de https://es.wikipedia.org/wiki/Aplicaci\%C3\%B3n_m\%C3\%B3vil

\subsubsection{Modelamiento y selección de procesos}

Según Carro \& González (2012), la selección del proceso está relacionada con una evaluación de diversas opciones posibles de procesos de producción y a la elección del que más de adecue a las necesidades del proyecto. Se tomarán en cuenta diversos campos como el de los recursos humanos, materiales, equipos, tecnología en donde será necesario evaluar para poder tomar decisiones acertadas en torno a la selección del proceso adecuado.

Marketing y ventas

Este proceso tiene como propósito principalmente, comercializar el Software Eduline School, así como de los servicios profesionales inherentes para su implementación y soporte. 
El proceso de Marketing y Ventas (a cargo del área comercial) está compuesto de las siguientes etapas:

1 Requerimientos funcionales del cliente.

2 Revisión y entrega de la propuesta.

3 Negociación del contrato.

1. Requerimientos Funcionales del Cliente

El área comercial estudia constantemente el comportamiento del mercado objetivo y las nuevas oportunidades de negocio que pueden derivarse de:

a) Propuestas a un nuevo cliente.

b) Solicitudes de cambio de clientes actuales.

Los requisitos de ambas iniciativas son formalizados por la propuesta al cliente o en su defecto se comunica al cliente la confirmación de los requisitos específicos solicitados a través de una carta, correo electrónico u otro medio.

2. Revisión y Entrega de la Propuesta

En esta etapa la Gerencia de Sistemas en conjunto con el analista funcional, revisa toda la información recopilada en la etapa previa y la facultad que posee la empresa para responder a las necesidades propuestas o presentadas. Los trabajos identificados pueden ser realizados de forma interna.

Culminada esta etapa, se coordina con el área Comercial para considerar la parte económica, y solicitar las propuestas a terceros o de recursos que pueden ser incorporados en la solución. 
Luego el área Comercial entrega a la Gerencia General la propuesta para su revisión y aprobación para ser remitida al cliente, para su aprobación final.

\section{Negociación del Contrato}

Esta etapa se inicia una vez que el cliente acepta la propuesta. Posteriormente, la Gerencia General realiza la revisión legal del Contrato para su aprobación, luego de ello es enviado al Cliente.

\section{Soporte post venta}

1. El procedimiento se inicia con la comunicación del cliente, ya sea por teléfono, correo, relacionada al producto instalado, el cual incluye la atención de incidencias, servicios de apoyo, atención de consultas y/o reportes de fallas.

2. La comunicación del cliente debe realizarse en primera instancia con la central telefónica de soporte o con el correo asignado.

3. El responsable de soporte técnico encargado de turno registra el incidente.

4. El responsable (Analista) del turno respectivo procede a analizar lo indicado por el cliente y de ser necesaria su presencia se dirigirá a las oficinas del mismo, caso contrario resuelve el incidente de manera remota.

5. Si el técnico encargado logra resolver el incidente, registra la solución y procede a cerrar el incidente.

6. Si en base al reporte del cliente no se puede encontrar una solución, es posible solicitar algún tipo de información al cliente y derivarlo al proveedor de software.

7. El proveedor de software remite la solución al correo de soporte post venta para ser aplicado en la solución por el analista responsable de turno.

8. El analista responsable de turno, comunica al cliente la solución y solicita hacer las validaciones. 
9. Con la confirmación del cliente, se procede a cerrar el incidente y se registra la solución aplicada.

Los horarios de atención de soporte post-venta son de Lunes a Viernes 7:00 a.m. a 11:00 p.m. y sábados de 7:00 a.m. a 3:00 p.m.

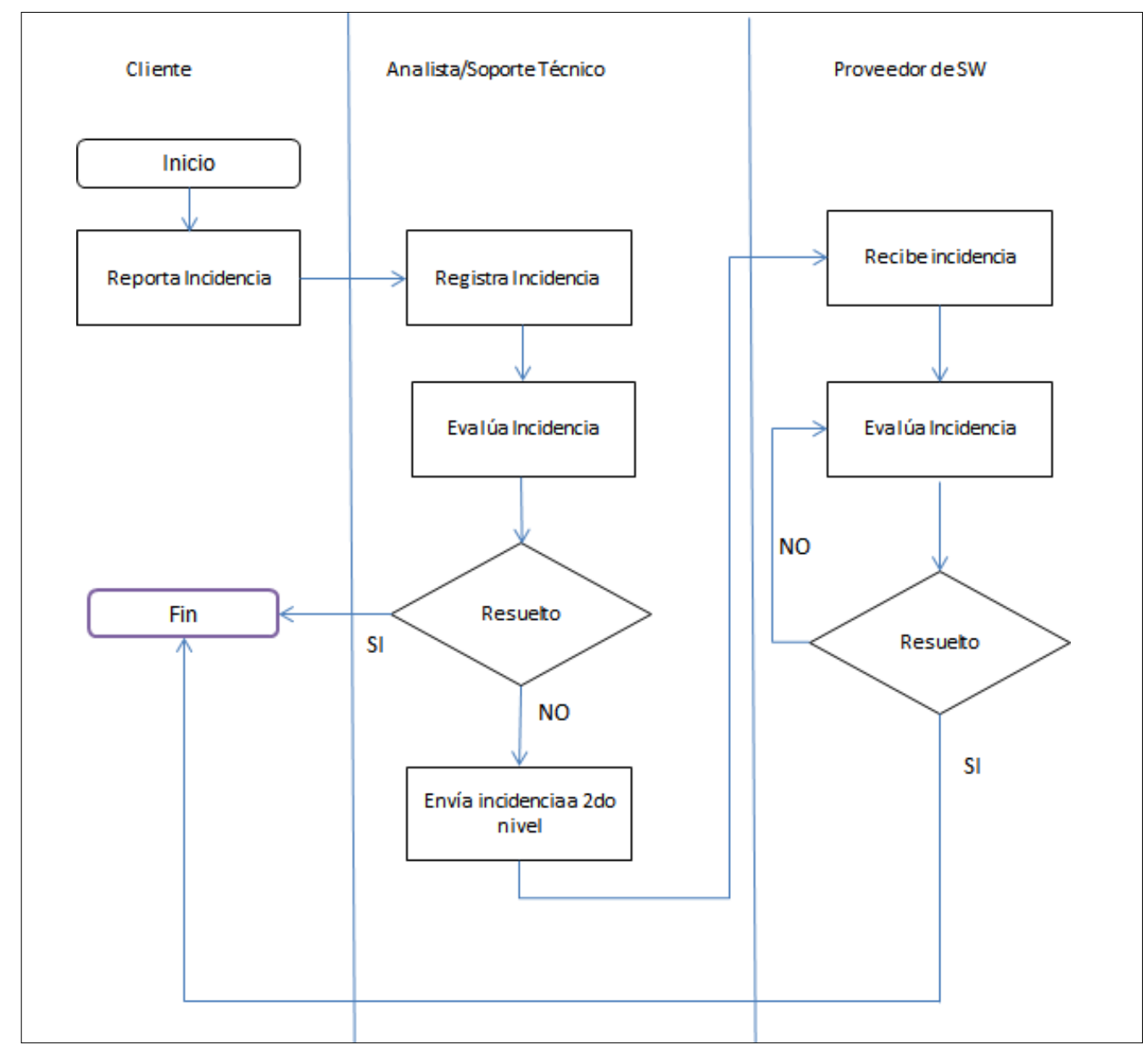

Figura 29. Flujo de actividades proceso Soporte Post Venta. Elaboración Propia.

Instalación y personalización de software

En general toda personalización del producto, nace con contrato autorizado por el cliente y remitido por el área comercial a la gerencia de sistemas, que procede a: 
1. Elaborar el acta de constitución de proyecto, debe indicarse las fechas programadas de entrega, supuestos y limitaciones.

2. Requisitos del Proyecto

3. Describir las especificaciones y lineamientos de los productos entregables del proyecto para satisfacer el contrato.

4. Las necesidades, deseos y expectativas se traducen en requisitos que son aprobados por el cliente y la empresa en un documento de especificaciones funcionales y técnicas del proyecto. Solo si este documento es aprobada pasa al siguiente paso.

5. Si las especificaciones se ajustan al producto estándar, evaluar si se deben hacer personalizaciones de configuración, en ambos casos pasamos al proceso de instalación

6. Si las especificaciones denotan una personalización al producto estándar, solicitamos al proveedor de software una propuesta formal con los cambios aprobados por el cliente y con las fechas de entrega.

7. Si la propuesta es aceptada, se espera a la recepción de la versión personalizada para el cliente y pasamos al proceso de instalación.

8. Instalado el servicio, posteriormente se inicia el proceso de certificación conjunta con el cliente, al finalizar el mismo se solicita un acta de conformidad de producto y se programa su pase a producción. 


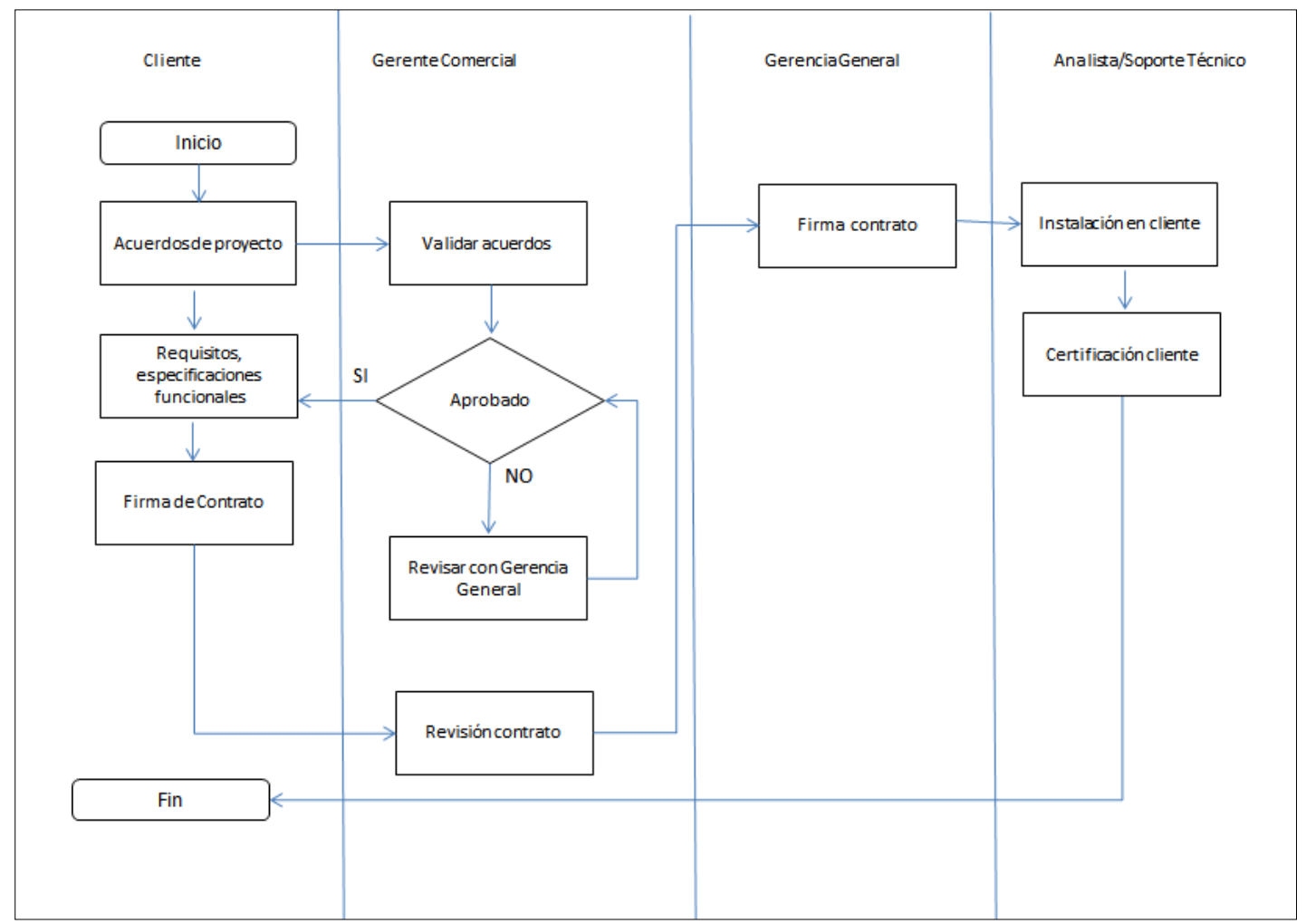

Figura 30. Flujo de actividades proceso Instalación y personalización de software. Elaboración Propia.

\subsubsection{Selección del equipamiento}

Baca (2013), hace mención de una serie de factores que repercuten de manera directa en la elección del equipamiento y maquinaria y que deben de tomarse en cuenta para una decisión adecuada.

A continuación, se hace mención de los factores:

a. Proveedor, para la exposición formal de la estimación del costo del servicio.

b. Precio, para estimar el monto del capital inicial invertido.

c. Dimensiones, para delimitar los espacios en la planta.

d. Capacidad, para determinar el número de máquinas a adquirir.

e. Flexibilidad. 
f. Mano de obra, para calcular el trabajo realizado de forma directa en la elaboración del producto y/o servicio y el grado de formación de los colaboradores.

g. Costo de mantenimiento, para estimar el costo anualizado, lo determina el fabricante.

h. Consumo de energía eléctrica, para realizar el cálculo de su costo.

i. Infraestructura necesaria, con la que operan algunos equipos especiales.

j. Equipos auxiliares, necesarios para que operen los principales.

k. Costo de los fletes, verificar si se incluye.

1. Costo de instalación, verificar si se incluye.

El equipamiento necesario para poder brindar el servicio en forma adecuada y cubriendo los procesos productivos necesitaremos los siguientes equipamientos:

a) Cinco laptops, serán asignados de la siguiente manera: gerente general, gerente de sistemas, gerente comercial, asistente de gerencia y otro en forma rotativa para los turnos de soporte post-venta.

b) Una impresora multifuncional, con conectividad Wi-Fi para ser compartida por todos los integrantes de la oficina.

c) Cinco celulares móviles que serán asignados a gerente general, gerente de ventas, gerente de sistemas y dos a los ingenieros de soporte las 24 horas al día.

d) La central telefónica con soporte a 5 anexos o más, identificador de llamadas y monitoreo de llamadas.

e) Los Cinco anexos distribuidos para sala de reuniones, gerencia general, gerencia de sistemas, secretaría y soporte.

f) Un HUB / Modem con soporte WI-FI para brindar conexión a internet en los diferentes ambientes de la oficina. 
g) Un servidor virtual y dominio de hosting, el servidor usado para tener la solución en la nube de internet y a su vez todos los centros educativos puedan acceder en forma remota.

h) Cinco licencias de Sistemas Operativo Windows 8 para las laptops usadas en las oficinas.

i) Cinco licencias software de oficina

j) Una oficina de dimensiones aproximadas de $90 \mathrm{~m} 2$.

Tabla 25

Mueblería

Cantidad Descripción

Características

Costo

Costo Total S/

Unitario S/

1

Escritorio

$1.50 \mathrm{~m}$ x $0.50 \mathrm{x}$

$2,475.00$

$2,475.00$

Gerencia General $0.75 \mathrm{~m}$

2

Escritorios

$1.20 \mathrm{~m} \times 0.50 \mathrm{x}$

$2,100.00$

$4,200.00$

Ingeniería

$0.75 \mathrm{~m}$

1

Escritorio Ventas

$1.20 \mathrm{~m} \times 0.50 \mathrm{~m} \mathrm{x}$

$2,100.00$

$2,100.00$

$0.75 \mathrm{~m}$

1

Escritorio

$1.00 \mathrm{~m} \times 0.50 \mathrm{~m} \mathrm{x}$

$2,250.00$

$2,250.00$

Secretaria

$0.75 \mathrm{~m}$

1

Mesa de

$2.40 \mathrm{~m} \mathrm{x} 1.10 \mathrm{~m} \mathrm{x}$

$2,700.00$

$2,700.00$

Reuniones

$0.75 \mathrm{~m}$

18

Sillas Escritorio

Modelo Teddy

350.60

$6,310.80$

Garruchas de

Nylon

1
Sofá 3 piezas o
Hunt silla de
tres sillas de
brazos
espera Escritorio

526.50

526.50 
Tabla 26

Hardware y Software

Hardware

Descripción

Características

Costo

Unitario S/

5

Laptops

1

4

1

Central Telefónic
Lenovo

Notebook 15,6"

AMD A8 8 GB 1

Epson

Multifuncional

Galaxy J7

Galaxy J1

Intebral Pack

Impacta 8

8 anexos
$1,699.00$

$8,495.00$

749.00

749.00

629.00

629.00

$269.00 \quad 1076.00$

$4,300.00$

$4,300.00$

Software

Can. Descripción

Características

Costo Unitario

Costo Total S/

Mínimas

Mensual S/

5

Licencias Office

Office 2010

26.00

130.00 
Tabla 27

Servicios Mensuales Conexión

Descripción

Características

Costo Unitario

Costo Total S/

Mínimas

Mensual S/

1

Conexión a

$30 \mathrm{Mbps}$

129.00

129.00

internet/telefonía

fija

Llamadas a fijos

ilimitadas

$1 \quad$ Conexión a red

Minutos

105.00

105.00

móvil

ilimitados a

cualquier

operador

3GB

4

Conexiones redes

800 minutos otro

79.00

316.00

móviles

operador.

Llamadas

internas

ilimitadas

2 GB internet

1 Servidor Virtual 4 GB RAM 2

65.00

65.00

Cores $\mathrm{CPu}$ y 1.5

TB 
Tabla 28

Materiales de oficina

\begin{tabular}{lrrr}
\hline \multicolumn{1}{c}{ Materiales de Oficina } & Cantidad & Costo Unitario & Total \\
\hline Archivadores & 5 & 20.00 & 100.00 \\
Bandejas para escritorios & 6 & 10.00 & 60.00 \\
Cartuchos de tinta & 2 & 120.00 & 240.00 \\
Clips \# 1 (Caja x100unid) & 3 & 5.00 & 15.00 \\
Clips Mariposa Wingo (Caja x 100unid) & 3 & 5.00 & 15.00 \\
Agendas & 6 & 5.00 & 30.00 \\
File Manila oficio (Pate 50 unid) & 3 & 10.00 & 30.00 \\
Grapas 23/6 (Caja x 5000unid) & 10 & 2.00 & 20.00 \\
Lapicero azul punta fina Faber Castell & 12 & 1.00 & 12.00 \\
Notas adhesivas 3"x3" (100hojas) Post it & 12 & 8.00 & 96.00 \\
Papel Bond 75gr. & 10 & 10.00 & 100.00 \\
Perforador & 3 & 15.00 & 45.00 \\
Porta clips cilíndrico & 3 & 2.00 & 6.00 \\
Resaltador 48 & 12 & 1.00 & 12.00 \\
Saca grapas & 3 & 3.00 & 9.00 \\
Sello fechador & 3 & 6.00 & 18.00 \\
Sello Trodat & 1 & 6.00 & 6.00 \\
Sobre Manila A4 (Pqte 50 unid) & 3 & 10.00 & 30.00 \\
Tachos de basura & 3 & 12.00 & 36.00 \\
Tampón & 1 & 6.00 & 6.00 \\
\hline Total & & & 886.00 \\
\hline & & & \\
\hline
\end{tabular}


Diseño del producto - prototipo

Útil al usuario final, otros factores de éxito es la facilidad de su uso (una interfaz amigable).

A continuación se muestra el menú de la aplicación que consta de cinco submenús.

En el submenú Datos se encuentra la división de tercer nivel para datos personales del alumno y otra división para los datos de los integrantes del salón o sección del alumno.

En el submenú Horarios se encuentra la división de tercer nivel para los horarios de clase del alumno y los horarios de cada profesor.

En el submenú Mensajería se encuentra la división de tercer nivel de los mensajes de entrada y de salida.

En el submenú Notas se encuentra la división de tercer nivel de mensuales y el último submenú es de configuración, donde se podrá seleccionar si el usuario de la aplicación dese que le llegue $\mathrm{n}$ las notificaciones o alertas.

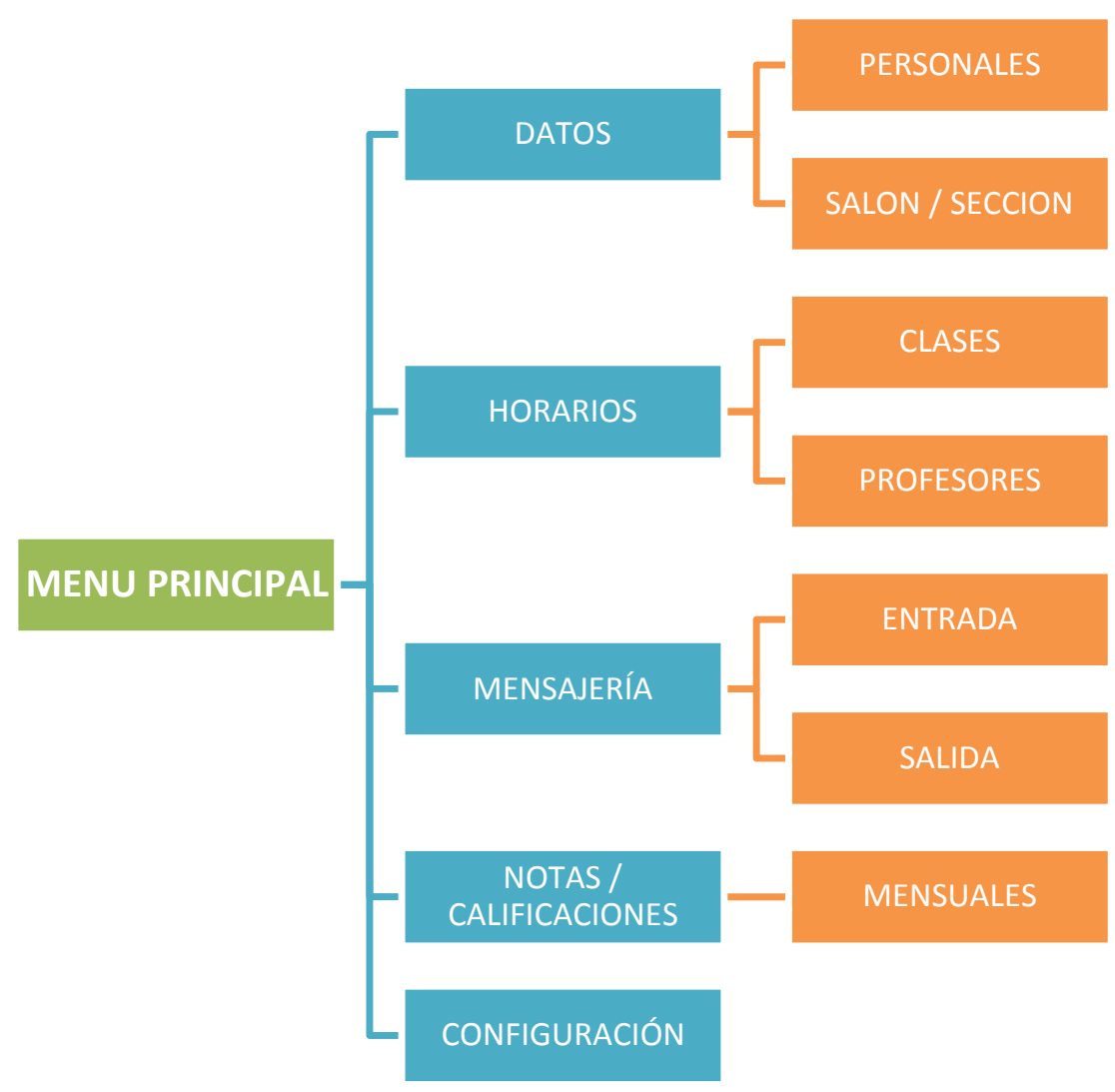

Figura 31. Menú aplicación. Elaboración Propia. 
A continuación se muestra las pantallas prototipo de la aplicación

En esta primera pantalla se visualiza las cinco opciones del menú principal

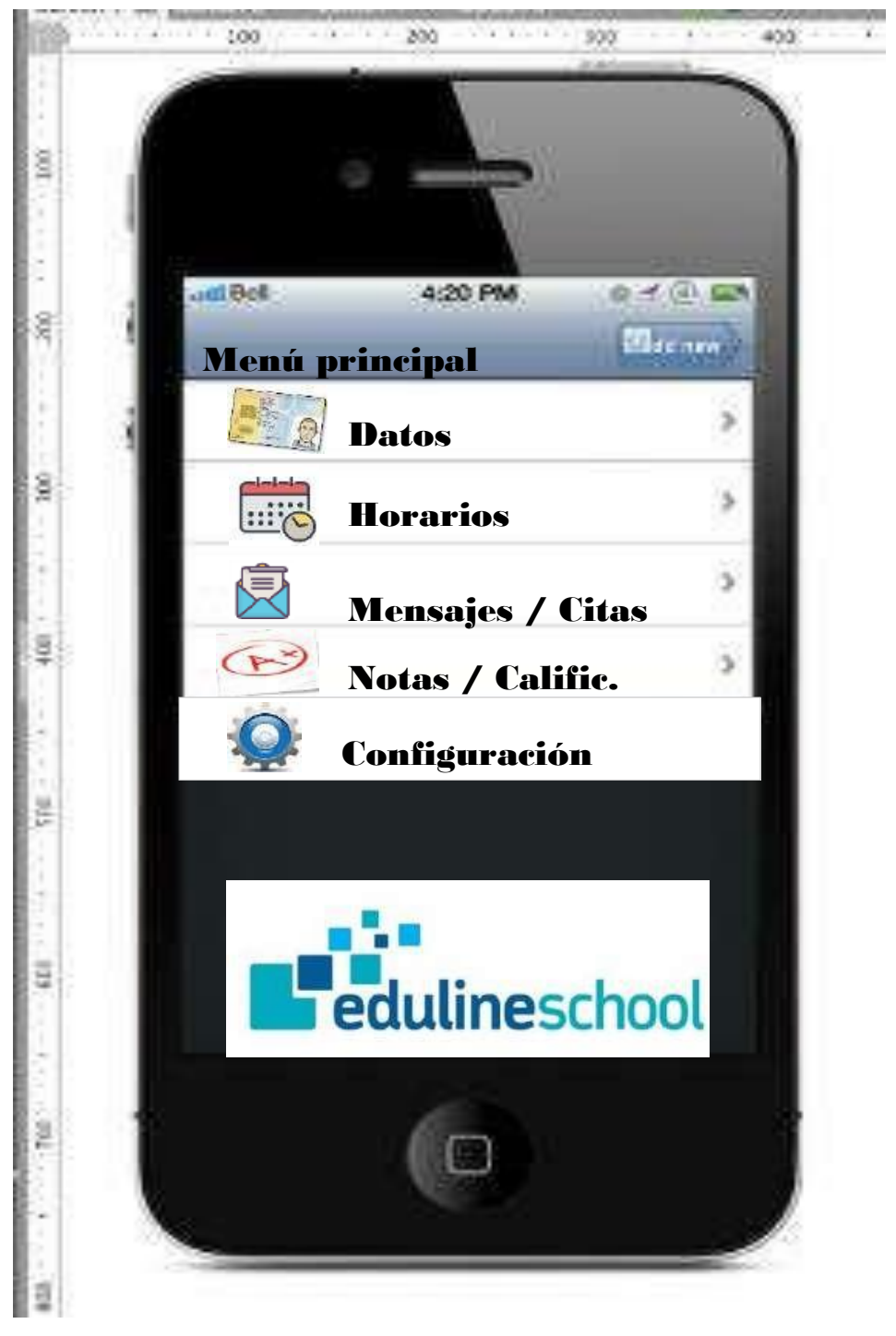

Figura 32. Diseño aplicación menú principal. Elaboración Propia. 
En esta segunda pantalla se visualiza el formulario donde estarán los datos de cada alumno, incluye los contados de sus padres o apoderados

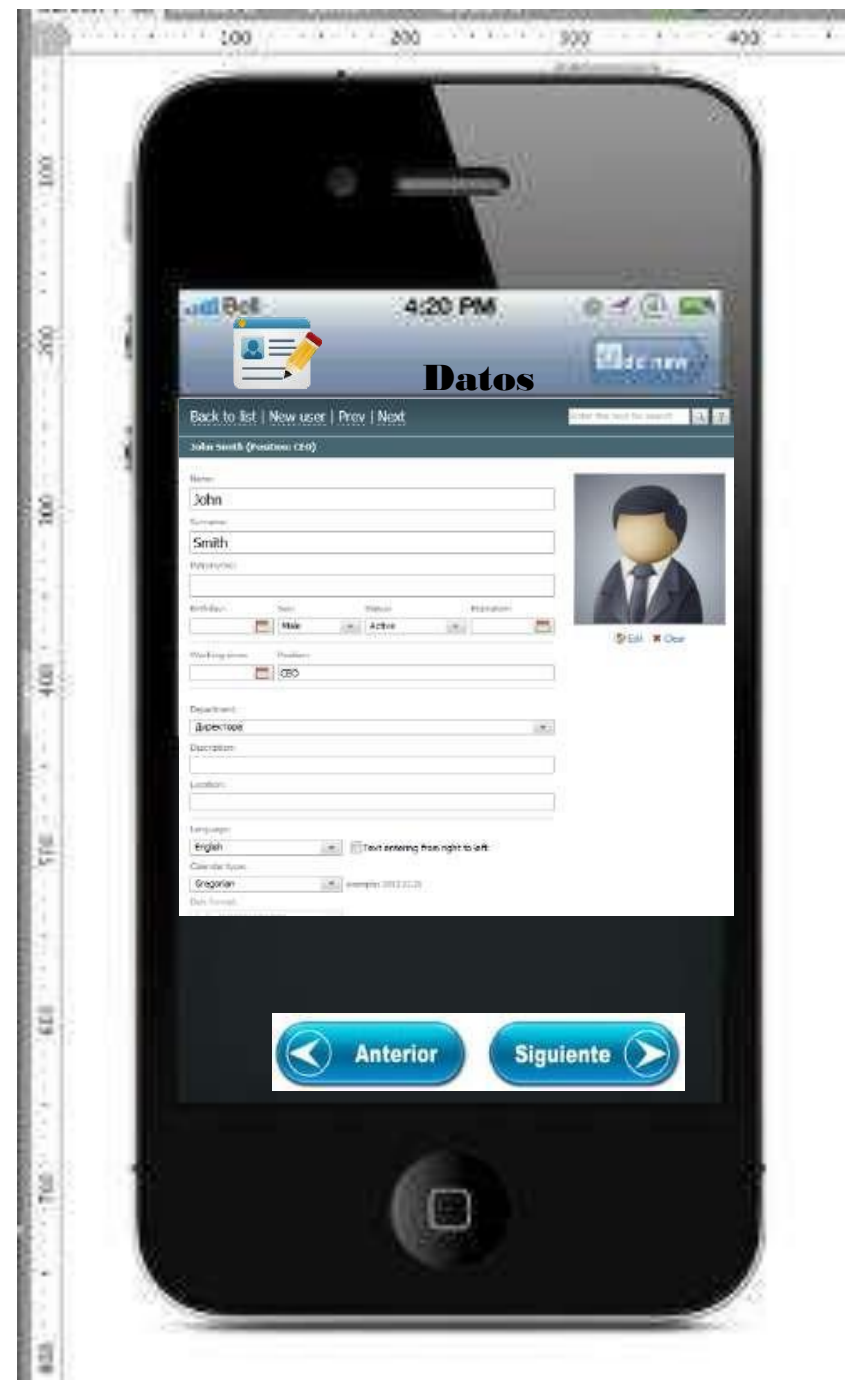

Figura 33. Diseño aplicación menú Datos. Elaboración Propia. 
En esta tercera pantalla se visualiza el horario de clases del alumno.

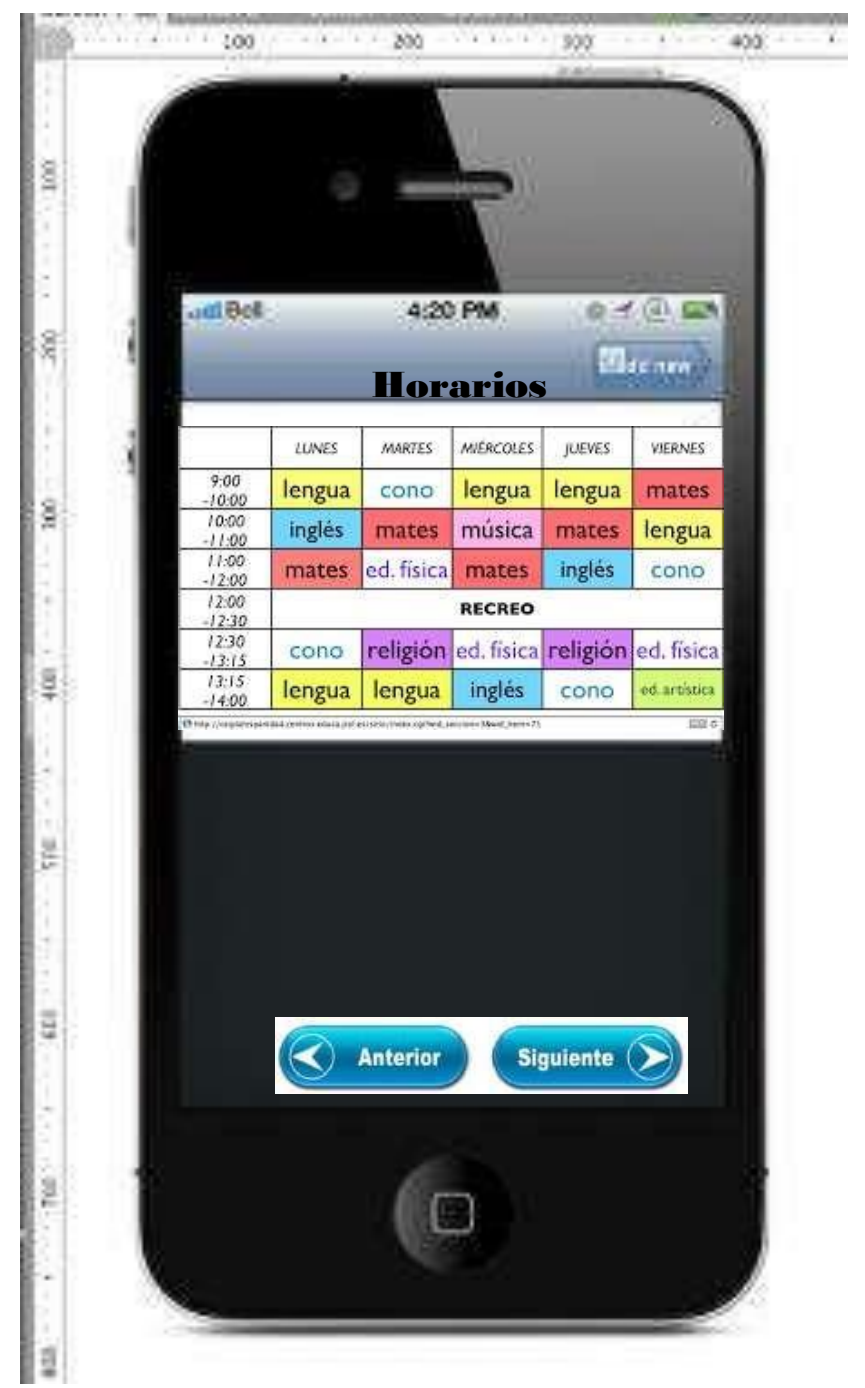

Figura 34. Diseño aplicación menú Datos. Elaboración Propia. 
En esta cuarta pantalla se visualiza la sección de mensajería.

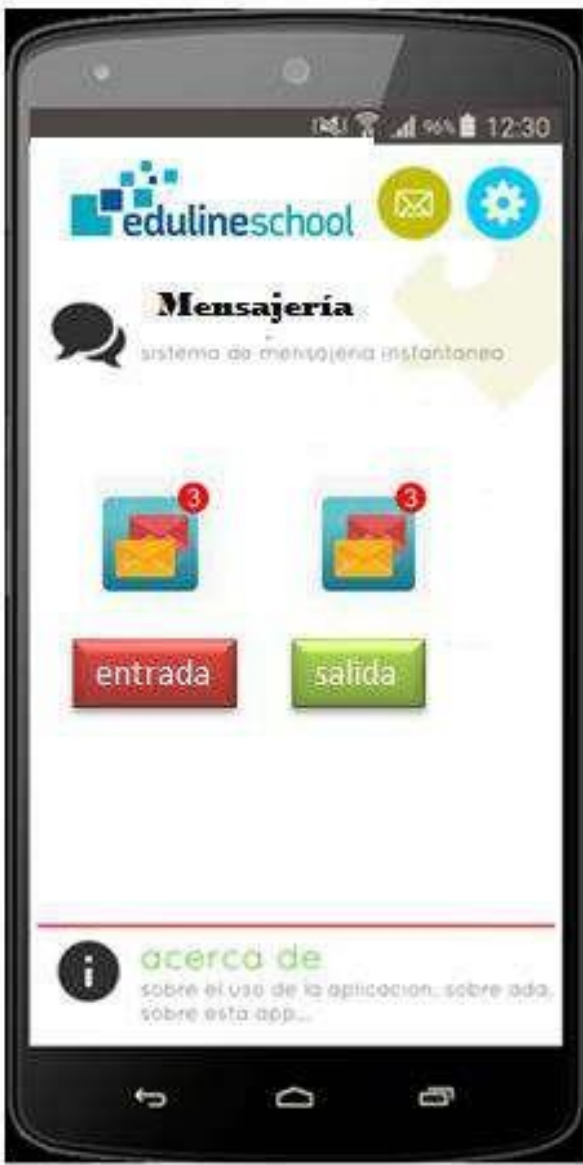

Figura 35. Diseño aplicación menú mensajería, donde se encuentra las mensajes enviados y recibidos. Elaboración Propia. 
En esta quinta pantalla se visualiza la sección de notas o calificaciones del alumno.

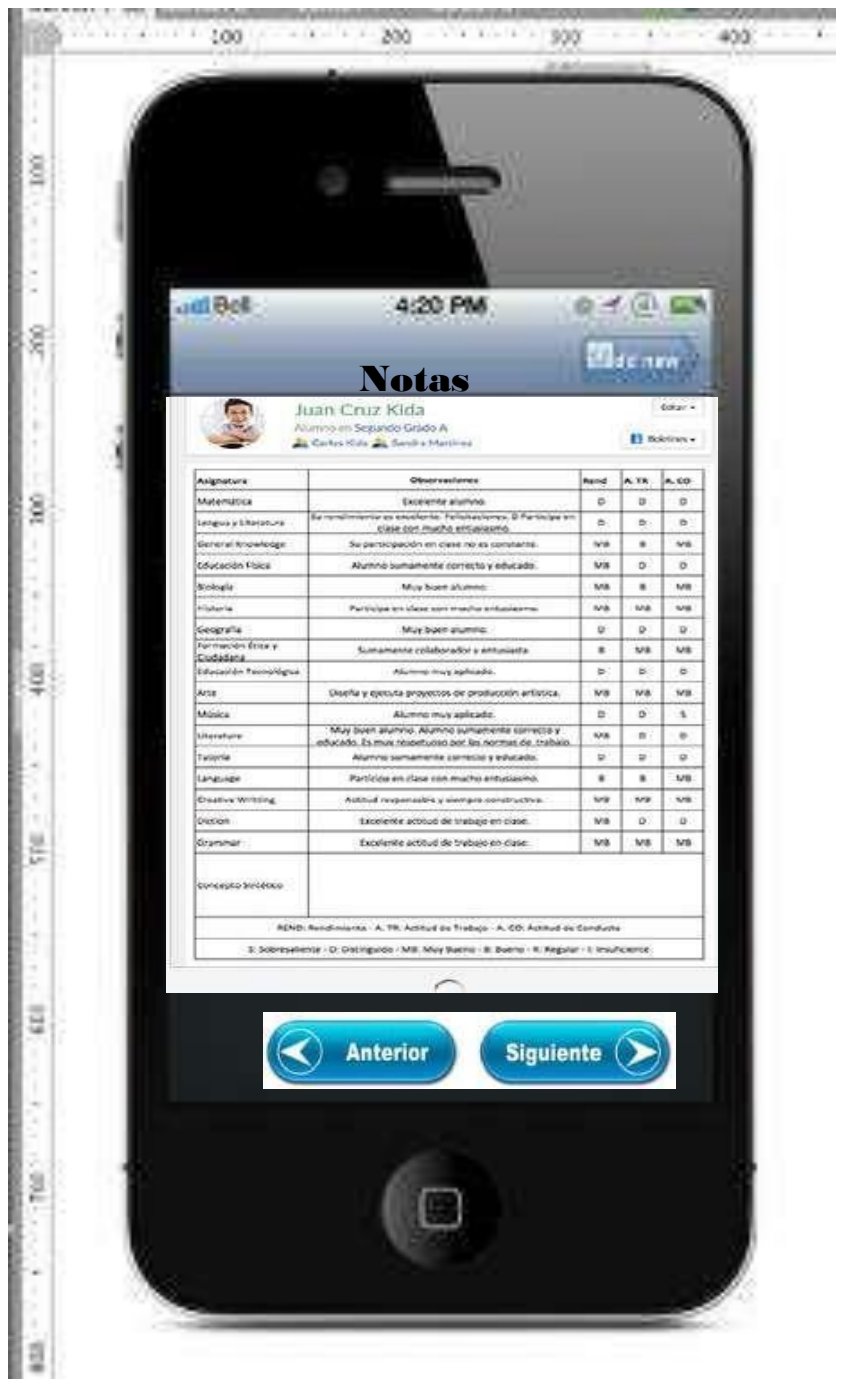

Figura 36. Diseño aplicación menú Notas o Calificaciones. Elaboración Propia.

Sabemos que la primera impresión es lo más importante hacia los usuarios en este caso los padres de familia, las pantallas son simples e intuitivas, se ha cuidado cada detalle con énfasis, la experiencia del usuario y la usabilidad son factores muy importantes que siempre deben ser considerados. La experiencia del padre de familia es un factor crítico y fundamental para que decida permanecer más tiempo en el sitio y pueda ver los beneficios que puede obtener. 


\subsubsection{Lay out}

Baca (2013) señala que es importante considerar la distribución de la planta ya que asegura que el trabajo se desarrolle de manera óptima y garantiza la seguridad y bienestar de los colaboradores.

El equipamiento a utilizar por la empresa para poder brindar el producto en línea, y adecuado para poder cumplir con los procesos productivos necesitaremos los siguientes equipamientos.

La distribución de áreas para el proyecto, contempla las áreas externas e internas para poder brindar el servicio de venta y post-venta del producto de comunicación en línea entre la comunidad educativa. Las áreas internas deben albergar espacio para las oficinas administrativas e ingeniería, el área exterior contempla un espacio para estacionamiento de un vehículo. 


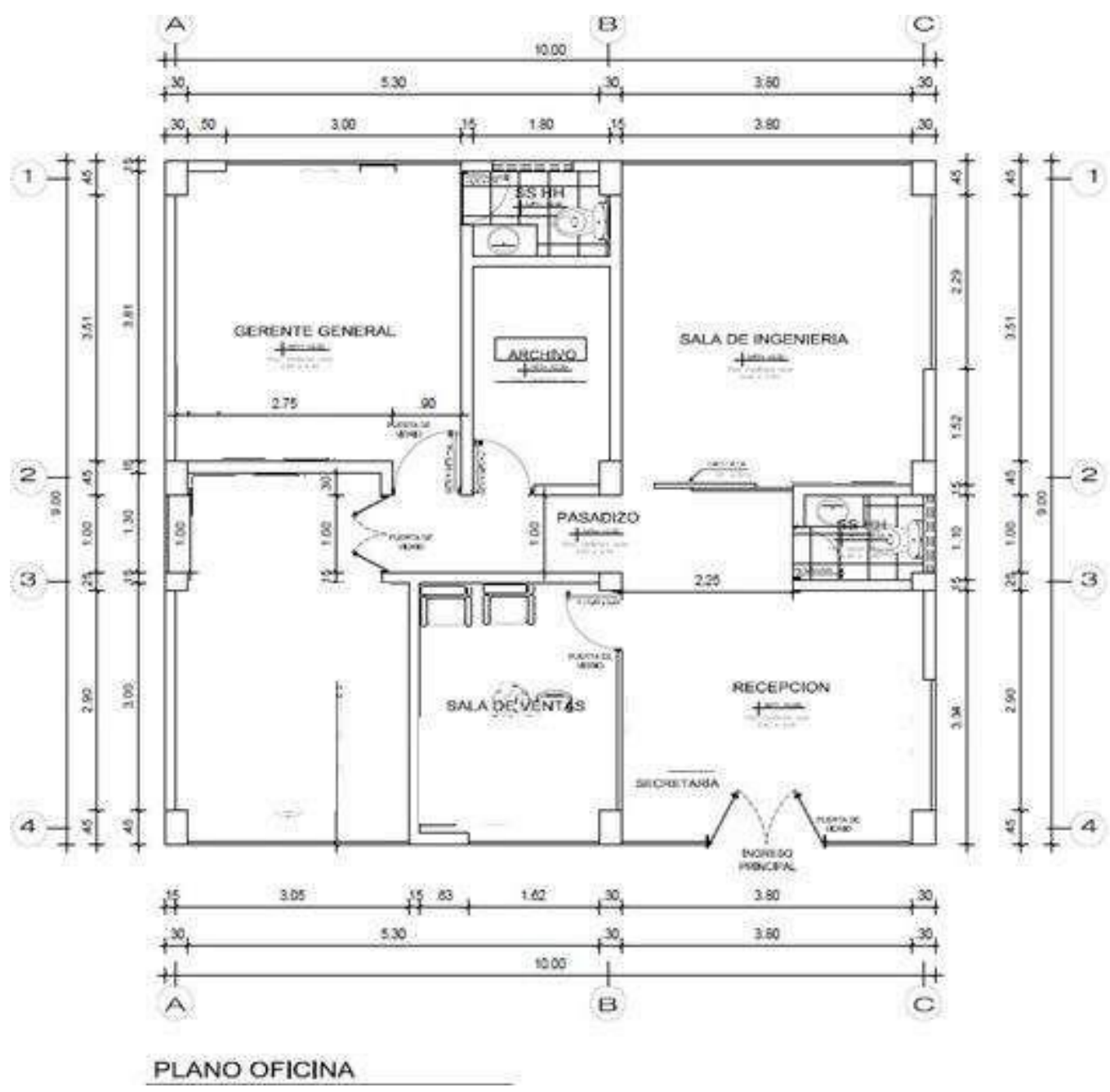

Figura 37. Plano de Oficina. Elaboración Propia.

Tabla 29

Distribución

Cantidad

Descripción

Mt2

\begin{tabular}{lcc}
\hline 1 & Oficina para gerencia general & $3.80 * 3.81$ \\
1 & Oficina ingeniería & $3.80 * 3.81$ \\
1 & Oficina de ventas & $2.25 * 3.45$ \\
1 & Sala de reuniones & $3.05 * 4.85$ \\
1 & Recepción & $3.80 * 3.34$
\end{tabular}




\subsubsection{Distribución de equipos y maquinarias}

De acuerdo a Baca (2013), señala que para que el trabajo se realice de manera óptima y se asegure una operación eficiente que resguarde la seguridad y salud de los colaboradores, es imprescindible tomar en cuenta la distribución de la planta.

Asimismo, Baca indica que la distribución de la planta generalmente se determina por lo siguiente:
a. Tipo de producto (bien o servicio):
b. Tipo de proceso productivo (tecnología empleada).
c. Volumen de producción.(tipo y nivel de producción)

De igual forma el mismo autor hace mención de una serie de principios básicos sumamente importantes:

a. Integración total.: se compila la totalidad de principios que tienen un efecto en la delimitación de los ambientes de la planta con la finalidad de saber cómo afectan a la misma y tener una visión general de cada factor involucrado.

b. Mínima distancia de recorrido: poseer una perspectiva amplia ayudará a disminuir costos de materiales.

c. Utilización del espacio cúbico: importante tomar en cuenta el espacio vertical ya que esto permitirá utilizar eficientemente espacios reducidos.

d. Seguridad y bienestar para el trabajador: es vital que en la determinación de los espacios de la planta, este principio o factor sea visualizado como una meta prioritaria.

e. Flexibilidad: es necesario que la distribución sea capaz de reajustarse a los cambios que se puedan hacer, esto ayudara a reducir costos. 
De acuerdo a como se detalla en el Layout, el ambiente se ha dividido en tres áreas:

gerencia general, sala de reuniones, ingeniería más espacios para recepción y asistente de gerencia. A continuación se muestra la distribución final.

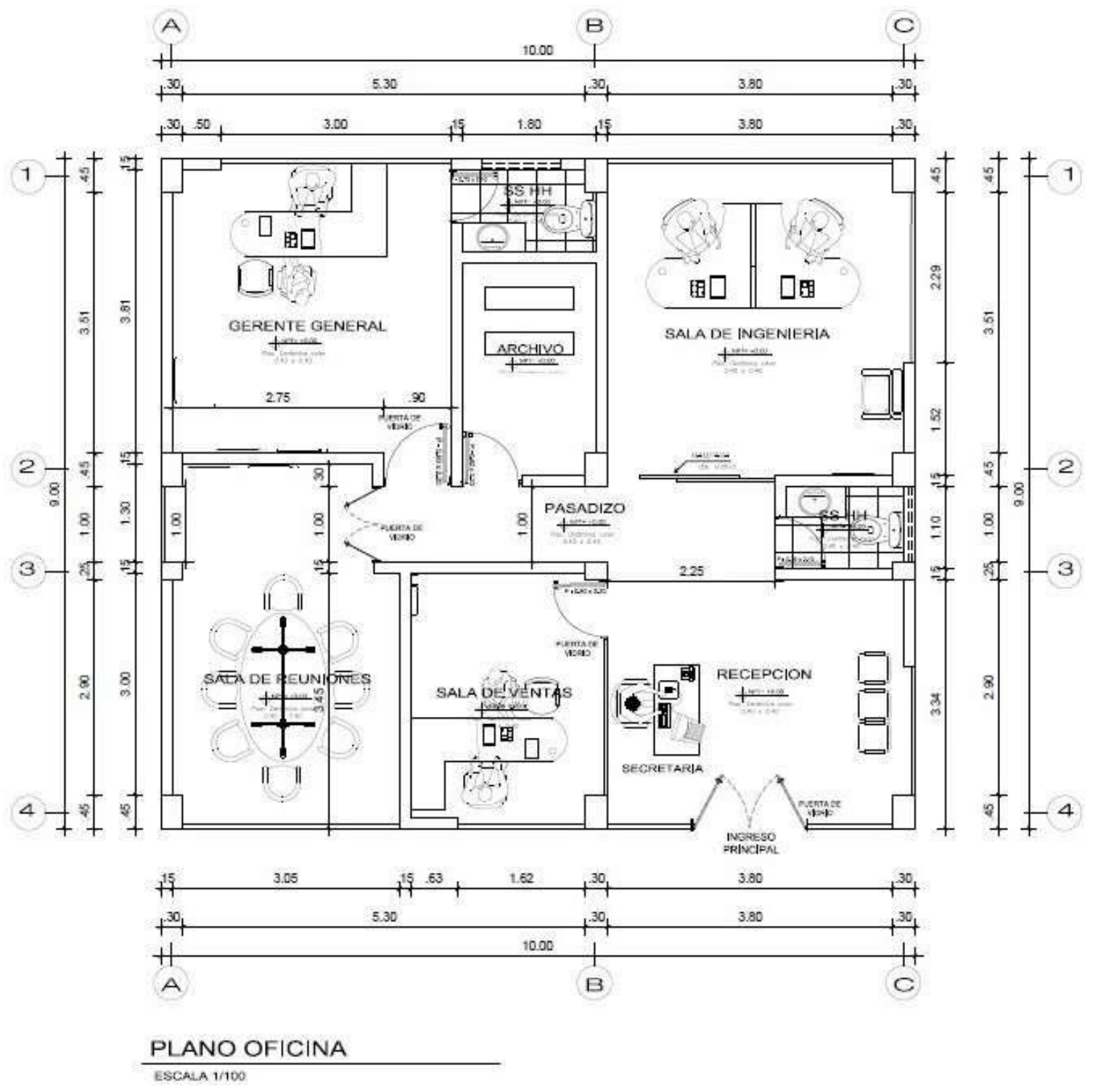

Figura 38. Plano oficina detallado. Elaboración Propia. 


\subsection{Determinación del Tamaño}

Según Sapag (2014), señala que es sumamente importante determinar el tamaño que tendrá el proyecto en lo que respecta a su capacidad de producción ya que esto repercutirá directamente en las inversiones, costos y futura rentabilidad.

Los factores que determinan el tamaño del proyecto son:

a. La cantidad demandada, proyectada a futuro es el factor más importante.

b. La localización del proyecto, cuanto más lejos se esté de las fuentes de insumos, más alto será el costo de abastecimiento.

c. La estrategia de crecimiento, más rentable o segura para el proyecto.

d. La distribución geográfica del mercado, conduce a seleccionar diferentes tamaños para cada locación.

\subsubsection{Proyección de crecimiento}

De acuerdo a Sapag (2014), destaca que se debe de elegir entre dos estrategias alternativas (satisfacer por exceso o por defecto la demanda al momento de proyectar el crecimiento del tamaño del proyecto ya que la demanda se incrementa a tasas que son distintas a las del incremento en las capacidades de la planta.

Los clientes acceden al producto como un servicio brindado en la nube de internet, por lo que la proyección debe orientarse a la capacidad de brindar un servicio post-venta adecuado y oportuno y velocidad de respuesta del producto. 
Para el servicio de post-venta se han determinado horarios de atención de:

\section{Turno Horario}

$1 \quad$ 7:00 a.m. a 3:00 p.m.

$2 \quad$ 3:00 p.m. a 11.00 p.m.

\section{Frecuencia}

Lunes a Sábado

Lunes a Viernes

Estos horarios serán cubiertos por una persona por cada turno, si la demanda crece o los tiempos de respuesta definidos de 2 horas no son cubiertos, se debe incrementar a dos recursos de técnicos de soporte por turno. Este incremento de recurso no afecta a los espacios considerados en la capacidad del área de ingeniería. Con las estadísticas de los tres primeros meses se determinará los recursos a incrementar.

\subsubsection{Recursos}

Como indica Baca (2013), la clave para la consecución de un proyecto es satisfacer ampliamente las necesidades de cantidad y calidad de los elementos extraídos de la naturaleza que se modifican en bienes de consumo y que permiten la elaboración de los productos que se desea fabricar. Es importante registrar en un listado a los posibles proveedores que suministrarán la materia prima e insumos y calificar su capacidad para abastecer.

Los recursos humanos a ser utilizados para brindar el producto y servicio son:

a. Gerente General de profesión de administración o afines.

b. Gerente de Sistemas de profesión de ingeniero de sistemas, cumplirá labores propias de la gerencia, analista funcional y supervisor de proyectos.

c. Gerente de Comercial, de profesión de administración o afines.

d. Dos analistas de informática para brindar soporte post-venta. 
e. Secretaria general.

\subsubsection{Tecnología}

Según Baca (2013), la tecnología y los equipos determinarán que la magnitud del plan de negocio posee una meta mínima de producción necesaria a ser alcanzada. Cabe señalar, que el mismo autor, señala que las relaciones entre tamaño, inversiones y costos de producción se verán afectados por las relaciones entre tamaño del proyecto y tecnología.

Las características propias del servicio brindado y el soporte post-venta que usan como medio de comunicación el internet y telefonía se debe tener en consideración los siguientes elementos:

a. Internet de alta velocidad en el local de la empresa.

b. Conexión a WI-FI de alta velocidad.

c. Servidor virtual privado de 2 GB RAM 2 Cores CPu y 1.5 TB ancho de banda, con soporte a Linux, Base de Datos MY SQL y lenguaje de programación libre: java y php.

d. Central telefónica y telefonía para móvil para soporte post-venta.

e. Hardware y software para laptops.

f. Entornos de desarrollo de programación Netbeans., no tienen costos.

Las características tecnológicas de la aplicación instalada en los smartphones deben considerar los siguientes elementos:

a. $\quad$ Smartphone Apple Sistema Operativo IOS versión 7,8,9 y 10 .

b. Smartphone con Sistemas Operativo Android versiones 4.1 hacia adelante

c. Lenguaje de programación Objetive C, C o C++ para Smartphone IOS

d. Lenguaje de programación Java y XML para Smartphone Android 
Las características tecnológicas de la configuración del sistema Back End, que permite configurar y poner los parámetros del sistema son:

a. Navegadores de Internet: Explorer versión 9 o superior, Mozilla Firefox versión 50.0 o superior, Google Chrome

b. $\quad$ Lenguaje de programación PHP 5.0 o superior con Java Script

c. Responsive Web Desing con HTML 5

d. La presentación de estilos debe usar lenguaje CCS.

e. $\quad$ Base de Datos My SQL

Los mecanismos de seguridad que debe manejar el sistema son:

a. Configuración de Roles de Usuario.

b. Asignación de Roles a Perfiles.

c. El usuario debe siempre ingresar una clave para ingresar a la aplicación móvil y al ambiente de configuración del Sistema EDULINE

Procesamiento

a. Soporte a múltiple instancias de colegios configurables.

b. Capacidad de respuesta menor a 2 segundos antes requerimientos.

Seguridad de la Plataforma:

La seguridad de nuestra plataforma en tiempo real, va estar garantizada en todos los puntos donde puede exista exposición a vulnerabilidad, desde el viaje de información a través de la nube de internet, el almacenamiento en la base de datos así como la protección de virus en los smartphones o pcs de acceso vía browser. 
Por lo tanto, se ha determinado que el desarrollo de la aplicación debe tener como guía el estándar mundial OWASP y las mejores prácticas en un entorno seguro para aplicaciones móviles así tenemos:

Almacenamiento de Información

a. Identificar los datos sensibles: Nombres y datos de alumnos menores de edad, padres de familia, profesores, calificaciones de los alumnos, mensajes privados intercambiados entre la comunidad educativa.

b. No debe registrarse información sensible que no sea necesaria en la aplicación.

c. Guardar la información sensible de forma encriptada con algoritmo TDES.

d. Desactivar el cache en el teclado de ingreso del smartphone o web browser para información sensible.

Gestión de Sesiones

a. Validar solo una sesión por usuario a la vez.

b. Invalidar una sesión activa después de un tiempo determinado o periodo de inactividad.

Control de Acceso

a. Los usuarios (comunidad educativa) solo pueden acceder a la información y opciones para la cual fue configurado, basado en perfiles y roles.

b. Cada usuario solo puede acceder a su información y no de otro usuario.

Validación de Información

a. La información a ser ingresada por los usuarios debe ser validada en la aplicación móvil antes de enviarla al servidor, datos numéricos, datos tipo carácter o alfa numéricos

Comunicación 
a. La información intercambiada entre el servidor de aplicaciones y el dispositivo móvil debe ser usando protocolo TLS.

\subsubsection{Flexibilidad}

Para el servicio que se ofrecerá en la empresa, tendremos las siguientes consideraciones que se han manejado para ser flexibles en el tiempo ante un incremente de clientes:

a. El tamaño de la oficina, para el área de ingeniería se ha acondicionado para dos personas de ingeniería una exclusiva para soporte post venta por turno en caso aumente la demanda de post-venta, puede acondicionarse un escritorio compartido adicional para dos personas más.

b. La capacidad del servidor virtual puede hacer un escalamiento inmediato en espacio en disco, capacidad de procesador o memoria por lo que un aumento necesario puede ser rápidamente cubierto.

\subsubsection{Selección del tamaño ideal}

Baca (2013) “para estimar los espacios adecuados del piso se necesita realizar un estudio minucioso del tiempo y fluctuaciones de movimiento del proceso. Cabe señalar, que el autor considera que determinar el tamaño óptimo es un arte y que se requiere de una gran cantidad de ingenio y técnicas. El mismo autor considera que el tamaño óptimo de la planta se correlaciona con su potencial de producción.

Para determinar la capacidad instalada que permita atender la demanda proyectada se ha considerado las siguientes variables:

RAM, la aplicación desarrollada necesitará como mínimo 2 GB de RAM 
Espacio en disco, el requerido para cada cliente se ha calculado en base a un promedio de 400 alumnos por colegio, más un espacio asignado como repositorio de comunicados u otros archivos, por lo que se le asigna en promedio 1.5 GB de espacio.

\begin{tabular}{cccccc}
\hline $\begin{array}{c}\text { Espacio } \\
\text { asignado por } \\
\text { colegio en GB }\end{array}$ & $\begin{array}{c}\text { Número de } \\
\text { colegios }\end{array}$ & $\begin{array}{c}\text { Espacio } \\
\text { Necesario en GB }\end{array}$ & $\begin{array}{c}\text { Espacio } \\
\text { contratado en } \\
\text { GB }\end{array}$ & $\begin{array}{c}\text { Espacio de } \\
\text { reserva en } \\
\text { GB (25\%) }\end{array}$ & $\begin{array}{c}\text { Máxima número } \\
\text { de colegios que } \\
\text { pueden ser } \\
\text { atendidos }\end{array}$ \\
\hline 1.5 & 60 & 90 & 165 & 41 & 82 \\
\hline
\end{tabular}

Para poder atender la demanda proyectada se ha considerado la contratación de un servicio de almacenamiento Hosting con las siguientes características: CPU: 2 Cores, RAM: 4GB, espacio en disco: $165 \mathrm{~GB}$, ancho de banda de 2TB

\subsection{Estudio de localización}

Según Sapag (2014), el estudio de la localización es fundamental ya que supone una decisión que involucre la estrategia, la parte emocional, la tecnología y sobretodo que garantice la rentabilidad del negocio. Asimismo, el mismo autor señala que dicho estudio supone un análisis minucioso de diferentes alternativas de localizaciones y que debe de darse prioridad a la que genere mayor ganancia a futuro.

\subsubsection{Definición de factores locacionales}

Sapag (2014) señala que las fuerzas locacionales típicas de los proyectos generalmente son empleadas para evaluar la elección de las diferentes alternativas de instalación de la planta. Dichas fuerzas son consideradas como un punto de referencia importante y es por ello que se encuentra en la literatura diferentes listas y clasificaciones. De acuerdo a Sapag (2014), la clasificación de esta fuerza debe de contener al menos los siguientes factores globales: 
a. La demanda y sus áreas de influencia.

b. Medios y costos de transporte.

c. Disponibilidad y costo de mano de obra.

d. Cercanía de las fuentes de abastecimiento.

e. Factores ambientales.

f. Cercanía del mercado.

g. Costo y disponibilidad de terrenos.

h. Topografía de suelos.

i. Estructura impositiva legal.

j. Disponibilidad de agua, energía y otros suministros.

k. Comunicaciones.

1. Posibilidad de desprenderse de desechos

Las localizaciones elegidas son en Lima Metropolitana que es el área geográfica donde están los clientes. Los distritos a considerar en la evaluación para implementar la oficina son Miraflores, Surquillo y Lince en base a los siguientes factores locacionales:
a. Acceso a mercado objetivo
b. Costo de alquiler
c. Seguridad
d. Imagen empresarial

El resultado de la valoración nos indica que el distrito seleccionado es Lince. 
Tabla 30

Matriz de decisión de localización

\begin{tabular}{|c|c|c|c|c|c|c|c|c|}
\hline & \multirow[b]{2}{*}{$\mathrm{E} C \mathrm{~F}$} & \multirow[b]{2}{*}{$\begin{array}{c}\text { Ponderac } \\
\text { ión }\end{array}$} & \multicolumn{2}{|c|}{ Miraflores } & \multicolumn{2}{|c|}{ Surquillo } & \multicolumn{2}{|c|}{ Lince } \\
\hline & & & $\begin{array}{c}\text { Califica } \\
\text { ción }\end{array}$ & Duntais & $\begin{array}{l}\text { Califica } \\
\text { ción }\end{array}$ & Duntria & $\begin{array}{c}\text { Calificac } \\
\text { ión }\end{array}$ & Duntais \\
\hline 1 & Acceso & 0.3 & 4 & 1.2 & 5 & 1.5 & 6 & 1.8 \\
\hline 2 & Costo & 0.3 & 2 & 0.6 & 6 & 1.8 & 5 & 1.5 \\
\hline 3 & Seguridad & 0.2 & 7 & 1.4 & 4 & 0.8 & 4 & 0.8 \\
\hline 4 & Imagen & 0.1 & 7 & 0.7 & 4 & 0.4 & 5 & 0.5 \\
\hline 5 & $\begin{array}{l}\text { Disponibil } \\
\text { idad }\end{array}$ & 0.1 & 4 & 0.4 & 4 & 0.4 & 5 & $\begin{array}{l}0.5 \\
0.5\end{array}$ \\
\hline & & 1.0 & & 4.3 & & 4.9 & & 5.1 \\
\hline
\end{tabular}

Nota: Elaboración propia

Características de la Oficina en alquiler

a) Área $90 \mathrm{mt}^{2}$

b) Costo mensual $\mathrm{S} / 3,250$

\subsubsection{Consideraciones legales}

Es imprescindible realizar un análisis de la normatividad alusiva a la descentralización como también revisar los beneficios legales y tributarios que poseen las diferentes opciones de locaciones como de las recomendaciones y prohibiciones para la implementación de determinadas industrias en ciertas localizaciones. Asimismo, dicho autor enfatiza que existen países que motivan el desarrollo (Sapag, 2014) 
Actualmente en el Perú, no existen regulaciones por servicios o productos brindados con acceso virtual, sin embargo debemos regirnos a la ley de régimen tributario de acuerdo al tipo de empresa elegida en base al estudio realizado en los puntos posteriores.

\subsubsection{Identificación del marco legal}

Se deben de cumplir y respetar fielmente las actuales directrices y disposiciones jurídicas previamente a implementar un proyecto. (Baca, 2013)

Cuando se pone en marcha un proyecto la primera actividad es la estructuración en términos legales de la organización. La normatividad estipula las formas de sociedad viables, su actividad y sus parámetros. Uno de los primeros pasos que debe seguir una empresa es tomar una determinación legal de la clase de sociedad que regirá, el tipo de administración y su alcance.

En lo que respecta a la localización Baca (2013), menciona los siguientes aspectos relacionados con la empresa los cuales determinan el aprovechamiento de los recursos si y solo si se conoce a profundidad el marco legal:

a. Estudios de posesión y vigencia de los títulos de bienes raíces.

b. Litigios, prohibiciones, contaminación ambiental, uso intensivo de agua en determinadas zonas.

c. Apoyos fiscales a través de exención de impuestos, en lugar de establecerse en determinada zona.

d. Gastos notariales, transferencias, inscripción en el Registro Público de la Propiedad y el Comercio.

e. Establecimiento de los honorarios de los especialistas o profesionales que efectúen todos los trámites necesarios. 
Realizado el registro en SUNARP como empresa jurídica como Sociedad Anónima Cerrada, con la escritura de la constitución debemos realizar el trámite en SUNAT para obtener el número de RUC.

Los requisitos necesarios solicitados por la SUNAT se detallan específicamente en el Anexo $\mathrm{N}^{\circ}$ 2. (Orientacion.sunat.gob.pe, 2017)

Asimismo, en el Anexo $\mathrm{N}^{\circ} 3$ se especifica los diferentes requisitos para la solicitud de registro de marcas de productos y/o servicios, ante Indecopi.(indecopi.gob.pe)

\subsubsection{Ordenamiento jurídico de la empresa}

Tiene como función formalizar y regular leyes o normas que limitan la operatividad de los proyectos e impulsan al emprendedor a analizar primero las prohibiciones y reglamentaciones legales para encontrar la mejor manera de optimizar su inversión maximizando así como su rentabilidad. (Sapag, 2014)

La razón social de la empresa será "Eduline School”, se ha escogido el tipo de sociedad de Sociedad Anónima Cerrada, debido a los beneficios que otorga para el tipo de empresa pequeña. (Proinversion.gob.pe, 2017)

En el Anexo $N^{\circ} 4$ se detalla específicamente el tipo de Sociedad elegida.

\section{Marco Legal Municipal}

De acuerdo a la Ley $\mathrm{N}^{\circ} 28976$ para el otorgamiento de la licencia de funcionamiento se señalan ciertos requisitos que se especifican en el Anexo $N^{\circ} 5$.

En el Anexo 6 , se toma como referencia la Municipalidad del Distrito de Lince para detallar los requisitos que solicita para la gestion de la licencia de funcinamiento para llevar a cabo desarrollo de su actividad económica. 


\section{Marco Legal Laboral}

Una forma que propicia un mayor compromiso y fomenta la atención en los colaboradores es incorporando dentro de las empresas decisiones relacionadas a incrementos en los sueldos , incentivos, ascensos, encargaturas , premios y reconocimientos los cuales son vistos como un recurso importante. (Thompson, 2014)

En el Perú, la normatividad que rige la Jornada de Trabajo son las siguientes: Artículo 24º de la Constitución Política del Perú; el Decreto Legislativo № 854 (01.10.1996) modificado por la Ley No 27671 (21.02.2002), el Texto Único Ordenado de la Ley de Jornada de Trabajo, Decreto Supremo No 007-2002-TR (04.07.2002) y su Reglamento el Decreto Supremo No 008-2002-TR. (Mintra.gob.pe, 2014)

a) Vacaciones:

De acuerdo al artículo $10^{\circ}$ el Decreto Legislativo 713, una vez que el colaborador cumpla con ciertos requisitos podrá gozar del derecho vacacional el cual consiste en que será acreedor de 30 días calendario de descanso físico remunerado de forma continua por cada año completo de servicio. El empleador deberá depositar la remuneración vacacional al comenzar el descanso vacacional del colaborador, lo cual se evidenciará en la Planilla y Boleta de Pago.

b) Gratificaciones

El artículo 1 de la Ley No. 27735 y el artículo $1^{\circ}$ del Decreto Supremo No. 0052002-TR señala que la gratificación es un derecho que puede ser percibido tanto por los trabajadores que se encuentran sujetos al régimen laboral privado (considerando los tipos de contratos a plazo indeterminado o a la modalidad o a tiempo parcial) como para las cooperativas especialmente los socios trabajadores. 
El artículo anterior menciona que los colaboradores tienen derecho a recibir dos gratificaciones anuales, una por motivos de Fiestas Patrias (28 de Julio)y otra por la celebración de Navidad (25 de Diciembre).

c) Compensaciones por tiempo de servicio

De acuerdo al Artículo $1^{\circ}$ del Decreto Supremo Nº01-97-TR, la CTS es un beneficio social que permite satisfacer las necesidades del colaborador y de los miembros de su círculo familiar cuando el trabajador es cesado (desempleado) o promocionado. Es decir, ayuda a prever las situaciones anteriores. El artículo 21 del Decreto Supremo No 001-97TR. Señala que el trabajador recibirá un depósito en Mayo y otro en Noviembre.

\section{d) Seguro de Salud}

Se registrará a los nuevos empleados en Es-salud y se cancelará un porcentaje del sueldo de los trabajadores como aporte para que ellos puedan posteriormente acceder a la atención médica.

La ley de Creación del seguro Social de Salud, Ley No 27056 señala que la remuneración mínima mensual de los trabajadores será siempre mayor a la Remuneración Mínima Vital. Además, es importante resaltar que para los trabajadores que se encuentren en actividad se aplica una tasa de $9 \%$ sobre la remuneración.

Se contará con la posibilidad de que el trabajador pueda afiliarse a una Entidad Prestadora de Salud (EPS), la cual es complementa al servicio otorgado por ESSALUD. Si así lo decidiera, el empleador debe pagar el costo del servicio de la EPS el cual es de 6,75\% de la remuneración mensual a ESSALUD. 
e) Horas extras

De acuerdo al artículo 9 del Decreto Supremo No. 007-2002-TR, las horas extras pueden llevarse a cabo antes del inicio de la hora de ingreso o después de la hora de salida. Viene a ser el trabajo voluntario que el colaborador realiza fuera de la jornada diaria o semanal.

En el anexo 7 se detalla información alusiva a las horas extras referida al artículo 9 del Decreto Supremo No. 007-2002-TR.

f) Descansos remunerados

El Convenio Internacional de Trabajo No. $52^{\circ}$, Artículo $25^{\circ}$ de la Constitución y Artículo $1^{\circ}$ y $2^{\circ}$ del Decreto Legislativo No. 713 señala que Los descansos remunerados permiten a los colaboradores proveerse de energía después de una semana laborada. Se reconocen algunos días que son establecidos como festividades por feriados. Estos días son remunerados como un día de trabajo cualquiera.

g) Subsidio por maternidad

De acuerdo a la LEY No 28791Articulo 12, para que la colaboradora sea acreedora del subsidio es necesario que tenga vínculo laboral al momento del goce de la prestación (al inicio y durante el periodo de subsidio).

En el anexo 8 se especifica información alusiva al subsidio de maternidad.

h) Asignación Familiar

De acuerdo a la Ley N25129, todo colaborador que tenga uno o más hijos menores de 18 años percibirá esta asignación familiar.

Se amplifica información referente a la asignación familiar en el Anexo 9. 
i) Lactancia

De acuerdo al artículo 1 de la Ley $\mathrm{N}^{\circ} 27591$ señala que una madre que trabaja al culminar su periodo post natal tiene derecho a una hora diaria de permiso por lactancia materna, hasta que el hijo tenga como mínimo 6 (seis) meses de edad.

En el anexo $\mathrm{N}^{\circ} 10$ se amplifica información referente a la lactancia considerando el artículo único de la Ley $\mathrm{N}^{\circ} 27403$.

\section{Marco legal tributario}

Según la SUNA, existen 3 trámites que la persona jurídica debe de realizar antes de dar inicio de sus actividades.

i. Inscripción en el Registro único de Contribuyentes- ruc

ii. Autorización de impresión de comprobantes de Pago

iii. Legalizar los libros de contabilidad

A continuación, en el anexo 11 se especifican dichos trámites previos que debe de realizar la persona jurídica de acuerdo a SUNAT.

\subsection{Determinación de la localización óptima}

De acuerdo a Baca (2013), para lograr un nivel elevado en la tasa de rentabilidad sobre el capital (criterio privado) y conseguir el costo unitario mínimo (criterio social), es imprescindible tener una óptima localización del proyecto.

De acuerdo a la literatura de Baca (2013) existen dos métodos para poder determinar la localización adecuada del proyecto : el método cualitativo por puntos y el método 
cuantitativo de Vogel. El primero considera a un conjunto de factores relevantes a los cuales les atribuye factores cuantitativos y el segundo realiza un estudio o análisis minucioso de los costos de transporte como de los productos finales y de las materias primas necesarias.

La localización óptima del proyecto, basado en la valoración cualitativa es ubicar e implementar la oficina en el distrito de Lince, provincia de Lima. 


\section{Capítulo VI: Aspectos Organizacionales}

\subsection{Caracterización de la cultura organizacional deseada}

Como señala la revista Mal-Estar E Subjetividade / Fortaleza / V. Ii / N. 2 / P. 86 -

122 / Set. 2002, la empresa es una cultura sustantivo y no adjetiva. La cultura de una empresa se forma cuando tanto los miembros como el líder tratan de solucionar los problemas que pueden presentarse y luchan por alcanzar la meta principal que propició la agrupación de los miembros.

La cultura organizacional es un sistema donde intervienen cada uno de los individuos que conforman la empresa, cada cultura se diferencia de las otras porque sus características principales son diferentes. (Robbins, 2013)

i. Innovación y toma de riesgos.- Se estimula a los trabajadores a para que le den importancia a la innovación y a establecer riesgos.

ii. Atención a los detalles.- Nivel en que se anhela que los trabajadores exterioricen precisión, reflexión, un mayor estudio y minuciosidad por los pormenores.

iii. Orientación a los resultados.- nivel en que la dirección se focaliza únicamente en el rendimiento.

iv. Orientación a las personas.- nivel en que la dirección de la empresa considera el rendimiento de sus trabajadores para tomar una determinación.

v. Orientación a los equipos.- tipo de cultura que se enfoca en dar prioridad al trabajo en equipo .

vi. Agresividad/Dinamismo.- cultura que fomenta que sus trabajadores tomen la iniciativa, sean dinámicas y que les guste la competencia.

vii. Estabilidad.- tipo de cultura que prefiere no arriesgarse hacia lo novedoso sino más bien que mantiene un alto interés por preservar practicas previamente implementadas que en su momento han tenido efecto positivo (Robbins , 2013) 


\subsubsection{Visión}

Es una representación de como deseamos que sea el futuro de la empresa, las proyecciones de la empresa en el tiempo y el espacio, se resaltan los stakeholders, clientes, empleados, accionistas y demás grupos de interés a los que desea llegar.

Las aspiraciones de la empresa se traducen en la visión estratégica que decide tomar y realizarlo en un plazo mayor a tres años (Thompson, 2012)

"Liderar el mercado peruano, siendo una empresa que otorgue tecnologías en innovación útiles y de gran impacto para la mejora de la comunicación de la comunidad educativa y por ende de la educación, comprometiéndonos fielmente con nuestros clientes, los colegios, y convirtiéndonos en su socio de confianza que camina con los cambios de la tecnología, la sociedad y la educación"

\subsubsection{Misión}

La misión desde el enfoque del cliente debe responder a que segmento queremos satisfacer, como el producto va a satisfacer al cliente y que necesidad.

Como indica Thompson (2012) una declaración de misión bien planteada comunica el fin y propósito de una compañía en un leguaje bastante descriptivo con la finalidad de que empresa forje su propia identidad.

"Eduline school ofrece a las instituciones educativas escolares, tecnologías de innovación de alta calidad y eficiencia para la mejora de la comunicación entre los colegios y familias, a través de nuevas soluciones creativas, plasmadas en aplicaciones móviles, satisfaciendo la necesidad de interrelación entre la comunidad educativa y contribuyendo al progreso educativo del país." 


\subsubsection{Principios}

Los principios o valores de una compañía es la ideología de sus miembros, la valoración, la conducta que toman en el día a día como organización que se traduce en las acciones de cada miembro. Es lógico que cada compañía persiga cumplir con la visión y misión que se hayan trazado (Thompson, 2012)

a. Trato justo, se refiere a apreciar a los empleados y promover la diversidad, fomentar la percepción de justicia en los diversos procesos de la empresa.

b. Integridad, se refiere a que el trabajo realizado dentro de la institución laboral se efectúa con honestidad, eficiencia como también con confiabilidad.

c. Ética, es cuando los trabajadores desempeñan sus funciones siendo responsables, demostrando seriedad y compromiso y apegándose a la normatividad laboral actual. Cuando las empresas se enfocan en darle suma prioridad a que sus trabajadores asuman sus funciones laborales regulando sus acciones siendo sumamente honestos, justos, con responsabilidad y compromiso. Lo anterior, quiere decir que para esas empresas es vital la inserción de la ética profesional la cual es una rama inmersa en la ética.

d. Sentido innovador, es introducir cambios positivos en la propuesta de negocio emprendida que involucren una mejora en la tecnología, en la producción y en la organización del negocio, con la intención de posicionarlo en el mercado de modo más eficiente.

e. Trabajo en equipo, es cuando se fomenta que los colaboradores realicen sus actividades laborales en equipo lo cual promueve un ambiente en donde reina la colaboración, responsabilidad y relaciones armoniosas.

f. Calidad, permite que el negocio mejore sus resultados y que prevalezca en el tiempo ya que generalmente al orientarse a la calidad los negocios se apegan a la 
normatividad y por ende satisfacen a sus consumidores. La calidad de estar presente en todos los negocios.

g. Atención al cliente, es cuando se promueve que el cliente obtenga una adecuada atención en donde prime el acceso inmediato, la información y uso adecuado del producto. Se coloca a los clientes en el corazón de todo lo que hace la compañía.

h. Responsabilidad social, es cuando los personas de una sociedad al ser vistas como individuales o dentro de un grupo tiene a cuestas un peso o deber que sobresale cuando toman decisiones que tienen un efecto o impacto en la sociedad. Involucra contenido ética y legal en las valoraciones que pueden ser positivas y negativas. ( Thompson, 2012 )

\subsection{Formulación de Estrategias del Negocio}

Una estrategia es idear "como" se resuelven los incidentes, problemas y restos en la organización, desde la atención a los clientes, pasando por los proveedores y todos los interesados. El plan estratégico que haya decidido tomar la organización debe tener como propósito cumplir las metas y objetivos trazados. (Thompson ,2012)

Thompson (2012) sostiene una compañía manifiesta un propósito estratégico cuando persigue sin descanso un objetivo estratégico excepcionalmente ambicioso y se compromete a hacer todo lo necesario para alcanzarlo. (p. 25)

Para poder asegurar que la estrategia se llevara a cabo de forma correcta, la compañía debe asegurarse de:

a. Contratar personal con las habilidades y experiencia necesarias.

b. Construir y fortalecer las competencias y capacidades competitivas que beneficien a la estrategia. 
c. Tomar en cuenta las mejores prácticas al momento de organizar el esfuerzo laboral.

d. Atribuir amplios recursos a las actividades críticas para alcanzar el éxito estratégico.

e. Asegurarse que las políticas y procedimientos faciliten la ejecución, en lugar de obstaculizarla.

f. Instalar sistemas operativos y de información que ayuden que el personal efectúe sus funciones de manera eficiente y eficaz.

g. Motivar al personal y conectar las recompensas e incentivos directamente la consecución de las metas de cumplimiento.

h. Generar en el negocio una cultura y un clima laboral que propicien una buena ejecución de la estrategia.

i. Profesar un liderazgo interno con el objeto de promover un continuo perfeccionamiento al ejecutar la estrategia.

Thompson (2012, p. 32)

Como se menciona en la teoría, al implementar el negocio se considerará como puntos importantes la contratación del personal con los perfiles adecuados para el correcto desarrollo de los procesos productivos, comerciales y tecnológicos que se necesite.

Al ser una empresa nueva tenemos el compromiso de organizar los procesos aplicando las mejores prácticas, no sólo en la construcción del producto de la plataforma de comunicación entre colegios y padres si no en todas las áreas de la empresa: comercial y administrativa.

También aplicaremos lo que lleva a identificar errores para corregirlos, la mejora continua. 


\subsection{Determinación de las ventajas competitivas críticas}

Como menciona David (2013) El proceso para lograr una ventaja competitiva en una empresa es:

Debilidades -> Fortalezas -> Competencias distintivas -> Ventaja competitiva

Todas la organizaciones deben trabajar por superar sus debilidades y estas transfórmalas en fortalezas, todo ello a través del desarrollo de diferentes competencias que harán que la organización este en ventaja contra sus competidores. (David, 2013)

La ventaja competitiva que se aplicará es Liderazgo en Costo, lo que se busca es ingresar al mercado con un precio inferior.

Este tipo de estrategia requiere una atención prioritaria enfocada a reducir los costos de producción. En el caso en estudio el servicio a diferencia de los ya existentes en el mercado local, hace uso de Teléfonos Inteligentes (Smartphones) mediante una Aplicación Móvil (App), busca satisfacer a las instituciones educativas que no pueden acceder a una plataforma integral de gestión educativa y que buscan una alternativa que les permita acceder a herramientas de comunicación en línea, haciendo uso de la tecnología móvil entre los integrantes del ámbito educativo.

El posicionamiento de acuerdo a la propuesta de valor, teniendo en cuenta el factor precio-beneficio mencionado por Kotler y Armstrong (2012), la marca buscaría como estrategia en su etapa de introducción brindar los mismos beneficios por menos precio para luego en su etapa de crecimiento en el mediano plazo llegar a ofrecer más beneficios por menos. Fijar un precio bajo para un producto nuevo, busca cautivar un elevado número de posibles clientes y posicionarse en el mercado obteniendo una considerable porción. 
Se aplicará una estrategia de precios bajos, tratando de cubrir la mayor cantidad de beneficios básicos inicialmente, con la finalidad de obtener una mayor participación de mercado.

6.4. Diseño de la estructura organizacional deseada

La configuración "ideal” de la organización depende sobre todo de garantizar que se tengan los recursos y capacidades suficientes que sean el soporte de la estrategia. La ejecución competente de la estrategia depende en gran medida del personal capacitado de todo tipo. ( Thompson , 2014, p. 327-328).

Es importante tomar tres tipos de acciones: dotar al personal adecuado, acumular competencias esenciales y capacidades para competir, estructurar la organización adecuadamente y del esfuerzo laboral. (Thompson, 2014)

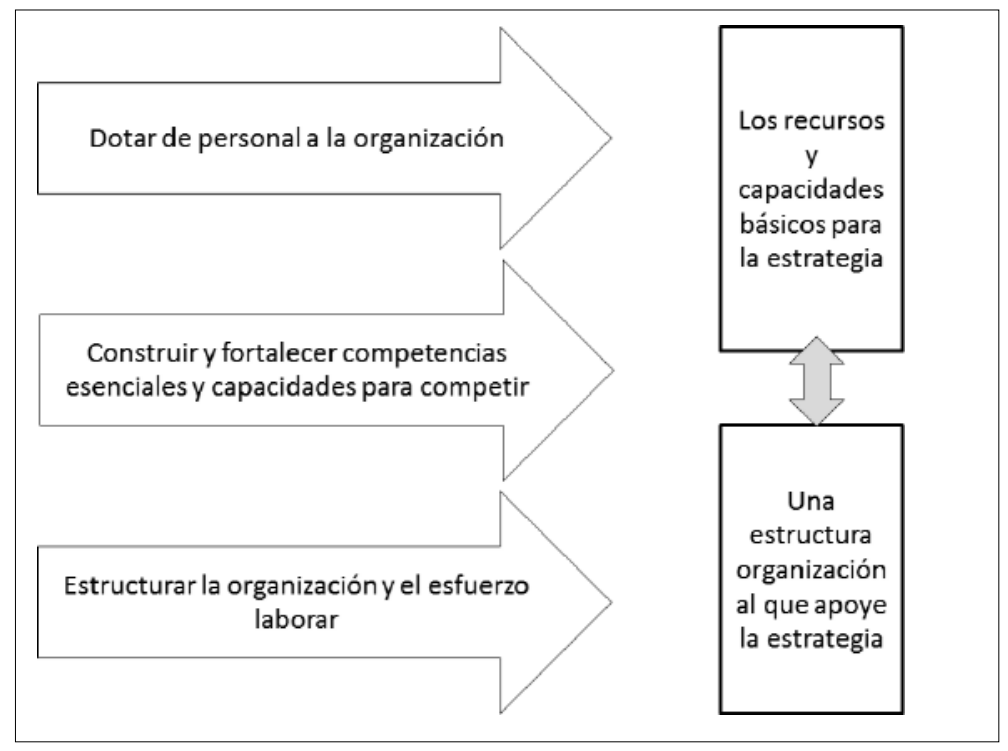

Figura 39. Pasos para crear una organización capaz de ejecutar bien una estrategia. Adaptado de "Administración estratégica" Thompson (2015). 
La organización estará compuesta por:
a) Gerente General
b) Gerente de TI
c) Gerente Comercial
d) 02 Analistas
e) Asistente de Gerencia

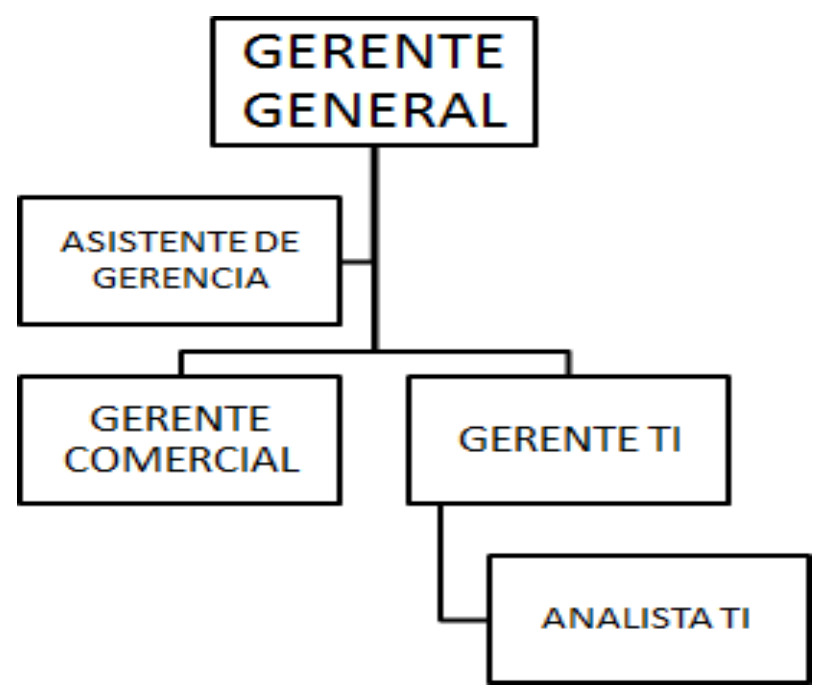

Figura 40. Organigrama de la empresa. Elaboración Propia.

\subsection{Diseño de los perfiles de puestos clave}

Lo correcto es la combinación entre el individuo y el puesto de trabajo, el sentirse a gusto en el puesto genera una baja rotación que trae beneficios a la organización, lo más importante es satisfacer a los clientes internos para que los clientes externos se beneficien. (Thompson, 2014).

A continuación lo perfiles del personal que requerirá la empresa ver Anexo 12 


\subsection{Remuneraciones, compensaciones e incentivos}

Una manera de atraer la atención y propiciar un nivel elevado de compromiso en las empresas y que al mismo tiempo es visto como un recurso clave, es el emplear incrementos en los sueldos, incorporar incentivos, ascensos, asignaciones importantes y premios y reconocimiento. (Thompson, 2014)

A continuación, se muestra las tablas con los datos de las remuneraciones del personal de la empresa. 
Tabla $\mathrm{N}^{\circ} 31$

Sueldos

\begin{tabular}{|c|c|c|c|c|c|c|c|c|}
\hline \multicolumn{2}{|c|}{$\begin{array}{c}\text { COSTO LABORAL PERSONAL } \\
\text { AÑO } 2017\end{array}$} & \multicolumn{4}{|c|}{$\begin{array}{c}\text { Q REMUNERACIÓN GRATIFICACIÓN ES SALUD } \\
9 \%\end{array}$} & \multirow{2}{*}{$\begin{array}{r}\begin{array}{c}\text { ASIGNACIÓN } \\
\text { FAMILIAR }\end{array} \\
85.00\end{array}$} & \multirow{2}{*}{$\begin{array}{r}\begin{array}{c}\text { PLANILLA } \\
\text { MOVILIDAD }\end{array} \\
300.00\end{array}$} & \multirow{2}{*}{$\begin{array}{l}\text { CTS } \\
364.94\end{array}$} \\
\hline Administración & Gerente General & 1 & $3,680.80$ & 613.47 & 331.27 & & & \\
\hline Administración & $\begin{array}{l}\text { Asistente de } \\
\text { Gerencia }\end{array}$ & 1 & $1,200.00$ & 200.00 & 108.00 & - & - & 116.67 \\
\hline Comercial & Gerente Comercial & 1 & $1,500.00$ & 250.00 & 135.00 & 85.00 & 150.00 & 152.92 \\
\hline Comercial & Gerente TI & 1 & $1,491.50$ & 248.58 & 134.24 & - & - & 145.01 \\
\hline \multirow[t]{2}{*}{ Comercial } & Analista TI & 2 & $2,000.00$ & 333.33 & 180.00 & - & - & 194.44 \\
\hline & & & $\mathbf{9 , 8 7 2 . 3 0}$ & $1,645.38$ & 888.51 & 170.00 & 450.00 & 973.97 \\
\hline
\end{tabular}

\begin{tabular}{lllrrrr}
\hline $\begin{array}{l}\text { COSTO LABORAL PERSONAL } \\
\text { AÑO 2017 }\end{array}$ & Q & $\begin{array}{c}\text { PLANILLA } \\
\text { MENSUAL }\end{array}$ & $\begin{array}{c}\text { DEPOSITO } \\
\text { CTS MAYO }\end{array}$ & $\begin{array}{c}\text { CTS } \\
\text { NOVIEMBRE } \\
\text { DEPOSITO }\end{array}$ & CTS ANUAL \\
\hline Administración & Gerente General & 1 & $5,375.48$ & $2,189.63$ & $2,189.63$ & $4,379.27$ \\
Administración & Asistente de & 1 & $1,624.67$ & 700.00 & 700.00 & $1,400.00$ \\
& Gerencia & 1 & $2,272.92$ & 917.50 & 917.50 & $1,835.00$ \\
Comercial & Gerente Comercial & 1 & $2,019.33$ & 870.04 & 870.04 & $1,740.08$ \\
Comercial & Gerente TI & 1 & $2,707.78$ & $1,166.67$ & $1,166.67$ & $2,333.33$ \\
Comercial & Analista TI & 2 & $\mathbf{1 4 , 0 0 0 . 1 6}$ & $\mathbf{5 , 8 4 3 . 8 4}$ & $\mathbf{5 , 8 4 3 . 8 4}$ & $\mathbf{1 1 , 6 8 7 . 6 8}$ \\
& & & & & & \\
\hline
\end{tabular}




\subsection{Política de recursos humanos}

Las políticas y prácticas de recursos humanos de una organización representan fuerzas importantes que dan forma al comportamiento y actitudes de los empleados.

a) Prácticas de Selección

Si las practica se selección se diseñan de manera correcta se puede lograr identificar a los candidatos competentes y que se ajustaran bien al puesto y a la organización.

b) Capacitación

Los programas de capacitación es una mejora directa a las habilidades necesarias para que el empleado realice con éxito su trabajo. Una mejora en las habilidades incrementa el potencial, pero el hecho de que ese potencial se desarrolle depende en gran parte de la motivación. La capacitación aumenta la autoeficacia del trabajador.

c) Evaluación de desempeño

Las evaluaciones de desempeño es calificar con exactitud el rendimiento de un individuo como base para asignar las recompensas.

Las evaluaciones de desempeño tienen como objetivo ayudar a la dirección a que tome decisiones de recursos humanos sobre ascensos, transferencias y despidos. También las evaluaciones detectan necesidades de capacitación y desarrollo, ya que identifican con precisión las habilidades y competencias de los trabajadores para los cuales se pueden desarrollar programas correctivos. (Robbins 2013) 


\section{Capítulo VII: Plan de Marketing}

\subsection{Estrategias de marketing}

El producto a desarrollarse consiste en la creación de una Aplicación Móvil (App) para usuarios de la comunidad educativa (colegios, profesores, padres de familia y alumnos) al ser lanzado se encontrará en la etapa de introducción, según Kotler y Armstrong (2012) la fase de introducción es un ciclo de incremento pausado de las ventas. En esta fase no hay ganancias, ya que se gasta en introducir el bien o servicio, hasta lograr un portafolio de clientes.

Para reconocer oportunidades de desarrollo una de las herramientas que se usa es la matriz de Ansoff. Esta matriz muestra combinaciones producto mercado en que la empresa puede basar su crecimiento.

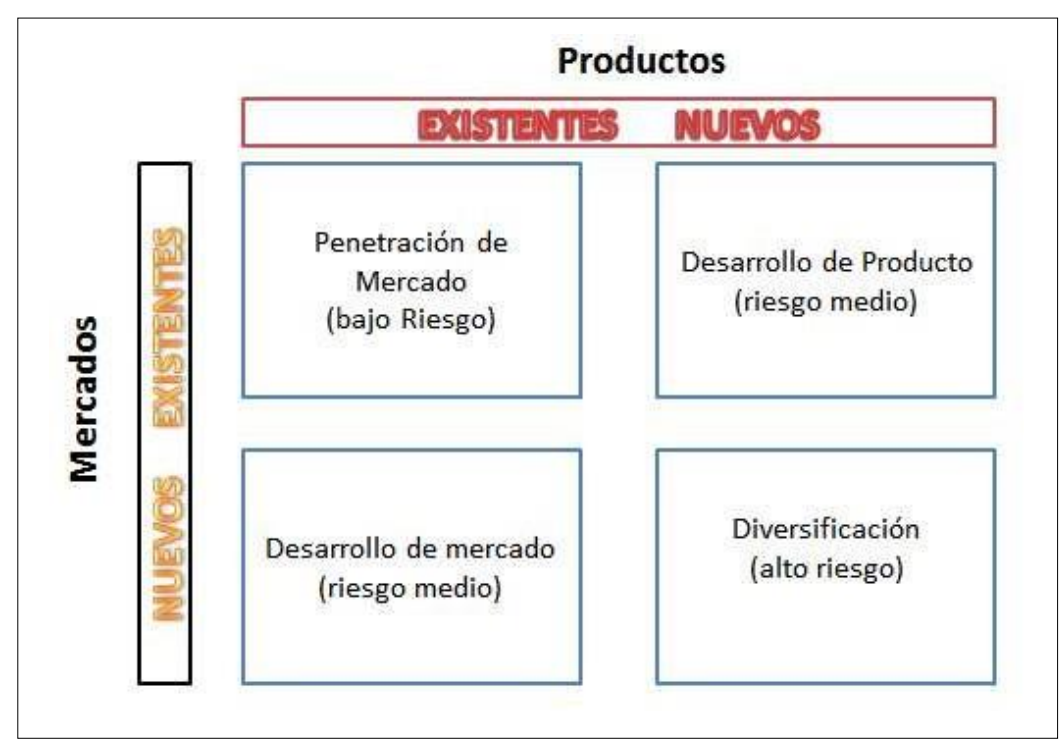

Figura 41. Matriz Ansoff. Tomado de "Estrategias para la Diversificación en Harvard Business Review”, 1952. Recuperado de http://www.grandespymes.com.ar/2014/04/26/estrategia-la-matriz-de-ansoff-deproductomercado-o-vector-de-crecimiento-2/ 
Desarrollando la matriz de ANSOFT, el producto se ubica en el cuadro superior derecho que corresponde a un producto nuevo en un mercado existente, definiéndose la estrategia de desarrollo de producto. Las estrategias seleccionadas para el desarrollo de producto son las siguientes:

- El desarrollo de un nuevo producto innovador que se distingue de la competencia, con características deseadas por los consumidores, recogidas en las entrevistas cualitativas y cuantitativas.

- Un servicio de post-venta que ofrece a los clientes un nivel de calidad adicional.

\subsubsection{Estrategia de producto}

El producto es un bien brindado para su consumo, atención o uso, y que podría complacer una necesidad o un anhelo, por otra parte, un servicio es una tarea, complacencia que se propone por una venta y no tiene como resultado la tenencia de algo, Kotler y Armstrong (2012).

El producto ofrecido clasifica según Kotler y Armstrong (2012) como un producto no buscado que corresponden a bienes de consumo que el consumidor conoce, pero casi siempre no considera comprar, por lo que requerirá una venta personal enérgica y mucha publicidad.

De acuerdo a Macia (2016) recomienda que, para enfrentar el gran reto de educación, tanto la familia y la escuela deben crear un lazo estrecho de comunicación fuerte y eficaz. Para entablar un vínculo más cercano entre la familia y colegio que genere un incremento en el sentido de pertenencia y confianza entre estos dos agentes esenciales, es fundamental contar con un canal de comunicación bidireccional que ofrezca posibilidad de tener acceso a información transparente, actualizada y clara y en que se puedan intercambiar diferentes datos para propiciar una mejor dinámica entre la familia y escuela. 
El beneficio principal es mejorar la comunicación entre familias y colegios, logrando un mayor nivel de involucramiento de los padres en el desarrollo académico de sus hijos y el mejor rendimiento escolar de estos últimos.

Se buscará el beneficio principal para obtener el producto real a corto plazo para brindarle al cliente un buen servicio de calidad y fidelizar la marca. Se tiene que tener en cuenta las características de las funcionalidades a ofrecerse, lo cual es un punto importante para diferenciarse de la competencia.

El producto a diferencia de los ya existentes en el mercado local, hace uso de Teléfonos Inteligentes (Smartphones) mediante una Aplicación Móvil (App).

El producto busca satisfacer a las instituciones educativas que no pueden acceder a una plataforma integral de gestión educativa y que buscan una alternativa que les permita acceder a herramientas de comunicación en línea, haciendo uso de la tecnología móvil entre el personal docente $\mathrm{u}$ administrativo de los colegios, los padres de familia y alumnos. 
Factores de calidad de la aplicación, Pressman (2010):

a) Funcional: la aplicación realizará las funciones para las que fue creada.

i. Idoneidad. - la aplicación proporcionara funciones apropiadas en función a las necesidades de los usuarios (colegios, profesores, padres de familia y alumnos).

ii. Precisión. - La aplicación proporcionara los resultados esperados.

iii. Seguridad. - Característica de la aplicación que busca proteger información de agentes no autorizados.

b) Fiable. - La aplicación podrá mantenerse operativo (funcionando) dentro de condiciones normales.

i. Madurez. - La aplicación tendrá la capacidad de evolucionar para ser más robusta.

ii. Tolerancia a fallos. - La aplicación deberá siempre estar en la capacidad de continuar con su operación.

c) Usable. - Es la habilidad de la aplicación para que el usuario invierta el mínimo esfuerzo.

i. Facilidad de aprendizaje. - Uso intuitivo de la aplicación.

ii. Operabilidad. - Permitir su operación y control.

iii. Atractividad. - Amigable para el usuario.

d) Eficiencia. - Habilidad de la aplicación para responder a una petición de usuario con velocidad apropiada.

i. Recursos. - uso óptimo de los recursos.

ii. Eficiencia. - uso de directivas sobre eficiencia.

e) Mantenimiento óptimo. - Habilidad de la aplicación para que el usuario invierta el mínimo esfuerzo para mantenerlo o mejorarlo. 
i. $\quad$ Fácil de Cambiar. - Realizar cambios con poco esfuerzo.

ii. Aplicación Estable - Evitar comportamientos no esperados al realizar cambios.

f) Portabilidad: la aplicación estará disponible para diversas plataformas como Android, IOS, Windows. Tendrá la habilidad para ser transferido de un ambiente a otro y funcionar es este.

i. Adaptable. - Capacidad de la aplicación de funcionar en ambientes variados.

ii. Facilidad de instalación. - Capacidad de la aplicación para ser instalado en un entorno especificado.

g) Pruebabilidad. - facilidad de realizar pruebas sobre el sistema.

(Pressman Roger, 2010, pág. 342)

Los siguientes atributos son los que se han recogidos de las entrevistas cualitativas pregunta numero 11 ¿Cuáles son los atributos o características que le gustaría que tenga esta plataforma de comunicación móvil para la comunidad educativa? Y en la encuesta cuantitativas pregunta numero 19 ¿Qué otro factor es importante para adquirir una plataforma de comunicación online?

Atributos de la aplicación

a) Personalizable: se puede cambiar la presentación con el logo y los colores institucionales del centro educativo.

b) Calidad: se debe buscar una calidad inherente a las aplicaciones móviles, que permita darle valor a los compradores, agregándole valor a la compra y entregando un servicio post-venta superior a los clientes. Los factores clave del servicio es la seguridad, confidencialidad y que el producto cumpla con su funcionalidad sin algún defecto.

c) El diseño: el producto debe de contemplar la funcionabilidad ofrecida, atractivo visual, fácil acceso y debe ser intuitivo. 
d) Control de asistencia: desde sus dispositivos móviles los profesores podrán tomar la asistencia y esta se podrá consultar por los padres de familia.

e) Control de tareas: los profesores pueden programar los trabajos a entregarse para que estos puedan ser consultados por padres de familia y alumnos

f) Notas de alumnos: las notas de las prácticas, trabajos y exámenes podrán ser consultadas por cursos o por periodo para que los padres puedan realizar seguimiento del rendimiento académico de sus hijos.

g) Publicaciones: el área administrativa del colegio podrá actualizar el calendario académico, enviar avisos y noticias. Los comunicados podrán ser enviados mediante sms, correo o como comunicados push (es una forma de comunicación en la que una aplicación servidora envía un mensaje a un cliente-consumidor) a la Aplicación Móvil (App).

La marca de la "Plataforma de Comunicación En Tiempo Real Entre Colegio Padres de Familia y Alumnos" será:

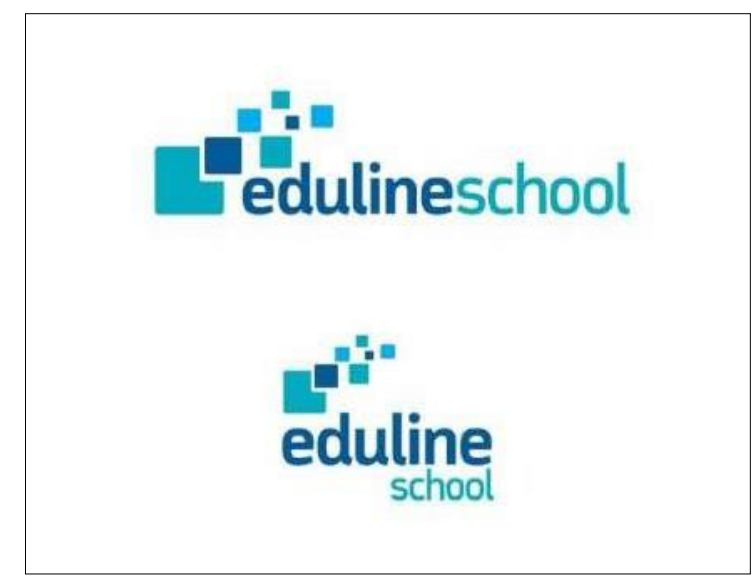

Figura 42. Logotipo de la empresa Eduline School. Elaboración propia.

Aplicación Móvil (App) para usuarios de la comunidad educativa (colegios, profesores, padres de familia y alumnos) 
De acuerdo a Kotler y Amstrong ( 2012 ), la propuesta de valor es el posicionamiento total de una marca : el mix de beneficios con los cuales la marca se distingue y posiciona. Existen diferentes propuestas de valor con las cuales una empresa puede posicionar sus productos. Propuestas de valor ganadoras ( 5 ), propuestas de valor perdedoras ( 3 ) y propuesta marginal (1)

Para poder conocer la mezcla integra de beneficios que permita posicionar a la empresa Eduline School a través de su servicio de plataforma de comunicación en tiempo real para colegios, padres de familia y alumnos se elabora la propuesta de valor y para lograrlo se sigue una serie de pasos.

a) En primer lugar, se elabora un FODA para poder conocer a detalle cómo se encuentra la industria en el que se considera las fortalezas, debilidades, oportunidades y amenazas. Dicho FODA se adjunta en los Anexos. Todo ello, permite un análisis exhaustivo de la industria.

b) En segundo lugar, se realiza un análisis detenido de las empresas que son consideradas competencia. En este caso, se analiza a la empresa Netschool $360^{\circ}, \mathrm{H} \& \mathrm{O}$ System S.A.C (Sia Web), Sistemas Integrales empresariales S.A.C (Sia Net) . La comparación entre las propuestas de servicio de las diferentes empresas mencionadas se encuentra en la Tabla 11 Semejanzas y diferencias entre la propuesta de servicio y los competidores y en la figura 11 Mapa de posicionamiento de los diferentes competidores.

c) En tercer lugar, realiza un análisis de las respuestas obtenidas a las preguntas que se enfocan en investigar al mercado efectivo. En dicha pregunta se investiga sobre las diferentes características que los encuestados desean que tenga el servicio que propone la empresa Edulineschool. En dichas respuestas los encuestados valoran que el servicio tenga 
un excelente servicio de postventa y que posea un nivel de personalización que responda con la imagen del colegio en relación a colores y logos.

d) Finalmente, con todo lo antes detallado se tiene el insumo para poder definir adecuadamente la propuesta de valor que permita diferenciar y posicionar al servicio que brinda EdulineSchool.

En relación al posicionamiento de acuerdo a la propuesta de valor, teniendo en cuenta el factor precio-beneficio mencionado por Kotler y Armstrong (2012), la marca buscaría como estrategia en su etapa de introducción brindar menos beneficios que la competencia por menos precio.

Cabe señalar, que lo anterior hace alusión a la teoría de Kotler quien menciona la existencia de una serie de propuestas de valor ganadoras en las cuales se encuentra la propuesta de valor menos por menos. Dicha propuesta de valor "menos por menos" es la que más se ajusta de acuerdo al análisis realizado previamente.

Los competidores ofrecen un servicio parecido “ entre comillas” al que propone Eduline School ya que generalmente los competidores ofrecen suits mucho más completas que incluyen módulos que gestionan todos los procesos que se realizan dentro del colegio pero a un precio mucho más elevado. En cambio, Eduline School ofrece un servicio de plataforma que solo gestiona la comunicación y por el cual pueden acceder a un precio módico y al mismo tiempo contar con diversas funcionalidades básicas requeridas para afianzar los lazos en la comunidad escolar y mejorar por ende la comunicación.

La serie de beneficios que brinda el servicio de plataforma de comunicación en tiempo real que se traduce en la propuesta de valor son los siguientes: 
Eduline se caracteriza por brindar el servicio de plataforma de comunicación en tiempo real para colegios, padres de familia y alumnos en donde se resalta su excelente servicio de post venta, nivel de personalización básico, seguridad en su comunicación y precio razonable.

La declaración de posicionamiento deseado de la marca se define en la figura 43 Figura 43. Declaración de posicionamiento. Tomado de Marketing, p. No, Kotler, Peter;

"Para quienes deseen mejorar la comunicación entre los miembros de su comunidad educativa nuestra plataforma de comunicación móvil en línea entre familias y colegio Eduline School los acerca mucho más, en un entorno seguro y a un precio accesible." Armstrong, Gary, 2012. México: Pearson Education. Elaboración propia.

\subsubsection{Estrategia de precio}

Según Kotler y Armstrong (2012), el precio es el conjunto de los valores que los clientes dan por la satisfacción de poseer o usar el bien o servicio.

Como indica Kotler y Armstrong (2012), las empresas que presentan nuevos productos tienen que asumir el trabajo de establecer por primera vez el precio, y pueden utilizar dos opciones: establecer el precio alto para captar el sector más exclusivo del mercado existente, con menos ventas y mayor margen de beneficios y la de fijar un precio bajo para entrar en el mercado. Establecer un precio bajo para un producto nuevo, busca atraer un número importante de clientes y conseguir una significativa participación de mercado, reduciendo costos debido al alto volumen de ventas.

De acuerdo a los instrumentos cuantitativos aplicados a los directores de colegios el $53 \%$ pagaría entre S/ 640 y S/ 960 soles mensuales (pregunta $\mathrm{N}^{\circ} 18$ herramienta cuantitativa US \$200 - US \$300). 
Se ha considerado como primer criterio para establecer el precio inicial, la comparación de precios tomando como referencia productos similares disponibles en el mercado local, como SiaNet el cual es el más representativo localmente. Este producto tiene como una de sus características una plataforma de comunicación similar al producto, más un módulo de gestión educativa.

Tabla 32

Competidores

\begin{tabular}{lc}
\hline Producto & $\begin{array}{c}\text { Plataforma de Comunicación } \\
\text { completa S/ }\end{array}$ \\
NetShool & 1,500 \\
SiaNet & 2,000 \\
SieWeb & 2,500
\end{tabular}

Se aplicará la estrategia de fijación de precios basados en la competencia. Se procede a analizar minuciosamente los precios que ofrece la competencia y se decide mantener una diferencia por debajo. Se opta por esta estrategia debido a que evita los costos de prueba y error del proceso de establecimiento de precios.

Asimismo, unido a esta estrategia de fijación de precios basados en la competencia Eduline pretende emplear el método de fijación de precios por penetración en el cual se establece el precio por debajo de la competencia con la finalidad de introducir el nuevo servicio y ganar rápidamente mayor participación en el mercado.

El medio de pago, será al contado mediante abono en cuenta bancaria local en soles la cual será proporcionada a la firma del contrato. 
Además, se utilizará una estrategia de precios psicológica, impactando en la percepción del cliente: por ejemplo, en lugar de poner el precio a 750 soles se ofrece el producto a 749 soles mensuales.
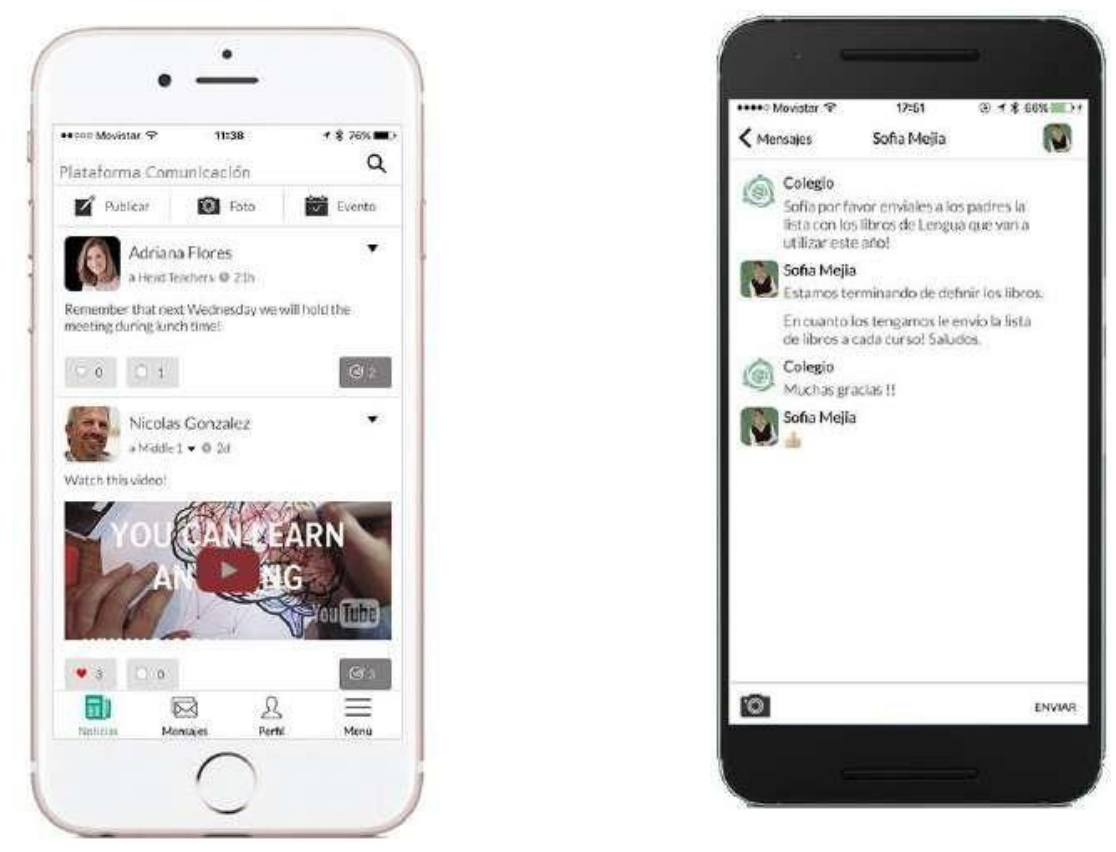

Figura 44. Ejemplos de aplicación de comunicación entre colegio y padres de familia. Adaptado de Programa Blended. Recuperado https://blended.com.ar/.

\subsubsection{Estrategia de distribución}

Como indica Kotler y Armstrong (2012), un canal de distribución es un grupo de agentes libres que hacen que un producto o servicio se encuentre disponible para el cliente.

El geomarketing es una disciplina que hace uso de la geolocalización y el internet para el crecimiento de los negocios, según Beltrán (2012)

Se aplicará el geomarketing para lo cual se deberá seguir los siguientes pasos

a. Identificar los distritos con mayor proporción de colegios. 
b. Identificar puntos de ventas cerca a escuelas primarias y secundarias.

c. Identificar los clientes con servicios similares los cuales son competencia y diseñar campañas más agresivas para ellos.

El sistema y la base de datos serán alojados en servidores hosting en la nube los cuales contarán con alta disponibilidad y seguridad. Los colegios no invertirán en infraestructura de hardware ni costos adicionales por soporte y mantenimiento.

Las oficinas administrativas y el personal de soporte y mantenimiento se encontrarán estratégicamente ubicadas dentro del área del proyecto, para poder atender los pedidos de soporte presencial; sin embargo, el soporte se establecerá en su mayoría de los casos de forma remota o virtual.

\subsubsection{Estrategia de promoción y publicidad}

Como indica Kotler y Armstrong (2012), se entiende por publicidad a la promoción y conceptualización sobre un producto e ideas por un patrocinador. Una estrategia publicitaria es la que usa la empresa para lograr sus metas de publicidad y consiste en dos elementos: la selección de los canales de comunicación publicitarios y la concepción de mensajes publicitarios

Selección de objetivos y público objetivo

Colegios particulares de Primaria y Secundaria de distritos de:

Barranco, Bellavista, Breña, Callao, Carmen de La Legua Reynoso, Chorrillos, Jesús María, La Molina, La Perla, La Punta, La Victoria, Lima, Lince, Los Olivos, Magdalena Del Mar, Miraflores, Pueblo Libre, Rímac, San Borja, San Isidro, San Luis, San Martin de Porres, San Miguel, Santiago de Surco y Surquillo. 
La estrategia a implementarse se centrará en el Marketing Digital, lo cual permitiría dentro de sus principales beneficios competir en iguales condiciones con empresas grandes y consolidadas que puedan ofrecer productos similares a un costo muy bajo en relación a la publicidad tradicional. Se debe buscar posicionar la marca en los principales buscadores como google, esto con la finalidad de que el producto sea percibido como una buena opción y genere confianza para los potenciales clientes y fidelice a los existentes.

El primer paso es implementar un sitio web cuyo contenido se encuentre alineado con los objetivos del negocio, el contenido debe ser en su mayor parte visual, con imágenes infografías, videos, con la finalidad de generar confianza, esto haciendo uso del marketing de contenido, logrando generar atracción hacia el producto. El sitio web debe ser adaptable a equipos móviles permitiendo un acceso amigable desde cualquier dispositivo móvil y no solo desde computadoras personales.

La principal red social a utilizarse debería ser Facebook en su versión pagada ya que está orientada al público objetivo, debido a que esta es usada en su mayoría por personas de edades en las que se encuentran los padres de familia y directores de colegios.

La empresa debe contar con un Fanpage de Facebook, enlazado a una herramienta que permita analizar indicadores de comportamiento de los usuarios y que permita determinar qué es lo que más buscan, determinar quienes buscan información sobre el producto, su edad, sexo, cuantas fotos y videos vieron, entre otros datos de interés para efectuar campañas enfocadas en sus preferencias.

Según Kotler (2010), los mercados son ahora más horizontales lo que permite a los potenciales clientes interactuar de una forma más dinámica con la sociedad, las opiniones y críticas, utilizando las redes sociales como herramientas que eliminan las barreras geográficas 
y demográficas; sin embargo el marketing digital no reemplazará totalmente al tradicional más deben converger ambas.

En relación al Marketing Directo, se recomienda el uso del correo electrónico para mediante una base de datos de Directores de colegios se pueda remitir, información de interés sobre el producto de forma rápida y a bajo costo, logrando captar nuevos clientes y fidelizar a los existentes, lo cual es muy importante para lograr los objetivos de venta.

La estrategia para llegar al público objetivo será del tipo publicidad sobre la línea o above the line ATL (actividades publicitarias relacionadas con medios masivos donde el objetivo es lograr números de impacto) con la finalidad de usar los medios de comunicación masivos como redes sociales pagadas para llegar al público objetivo. La finalidad es que los padres de familia conozcan los beneficios de plataforma propuesta y sus características ya que ellos mediante el comité de padres de familia pueden influir sobre su adquisición.

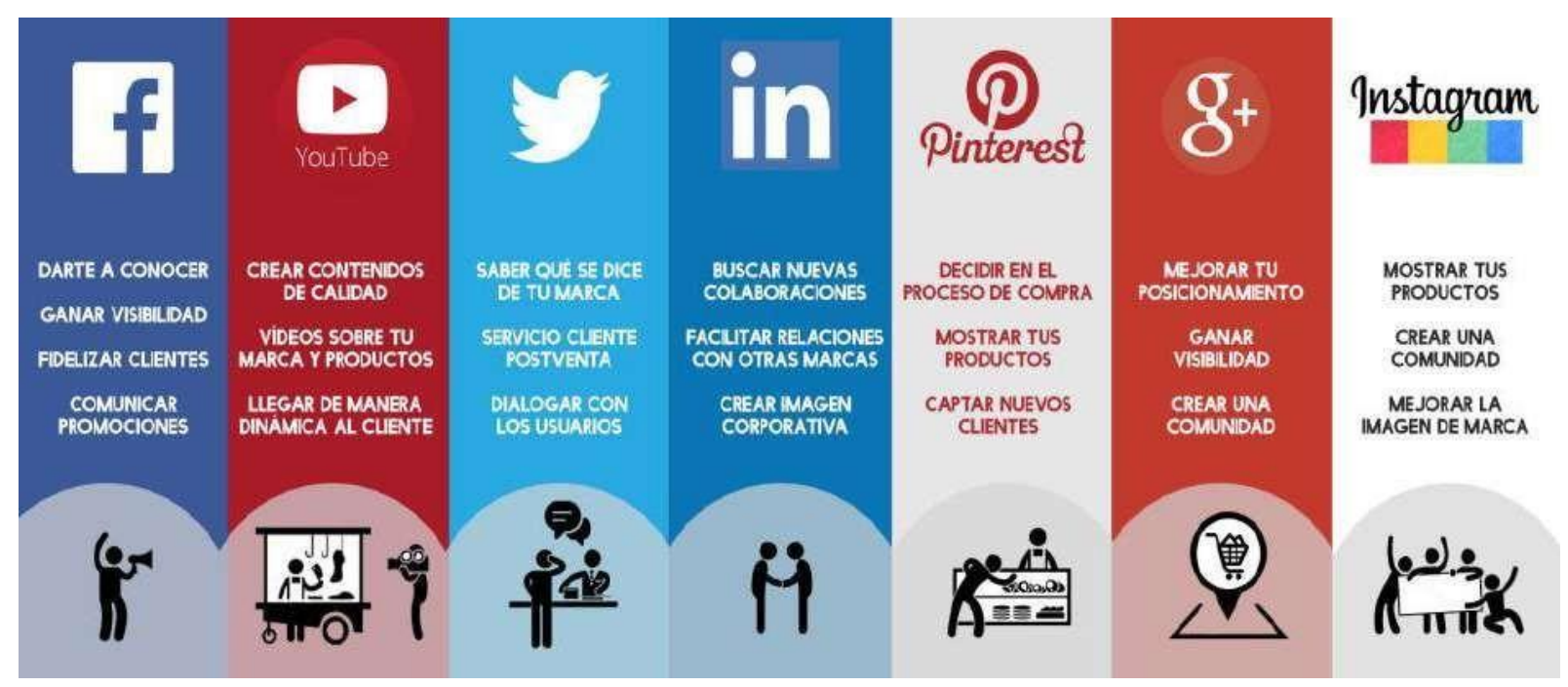

Figura 45. Tendencias Marketing Digital. Recuperado de Recuperado de http://www.expertosnegociosonline.com/tendencias-marketing-digital-2017/

El objetivo final es fidelizar a los clientes, mediante un producto de buena calidad que permita que este se quede grabado en la mente de los consumidores. 
Creación del mensaje

Para captar la atención de los colegíos, la estrategia estará enfocada en el mejoramiento de la imagen del colegio, al permitirle presentarse como una institución a la vanguardia de los cambios tecnológicos

Los spots publicados en las redes sociales deben ser de corte persuasivo ej: Familias más unidas, que comparten no solo las actividades de ocio, sino también las actividades académicas de sus hijos. Con esto se conseguirá captar el interés de colegios en invertir en la solución.

Selección de los canales

Los canales de marketing serán usando la estrategia multiplataforma:

Online: los canales seleccionados son redes sociales, como Google Adwords, YouTube, Facebook, y/o Twitter.

Offline: se entregarán brochures directamente a los colegios, adjuntos a cartas de presentación de la empresa 


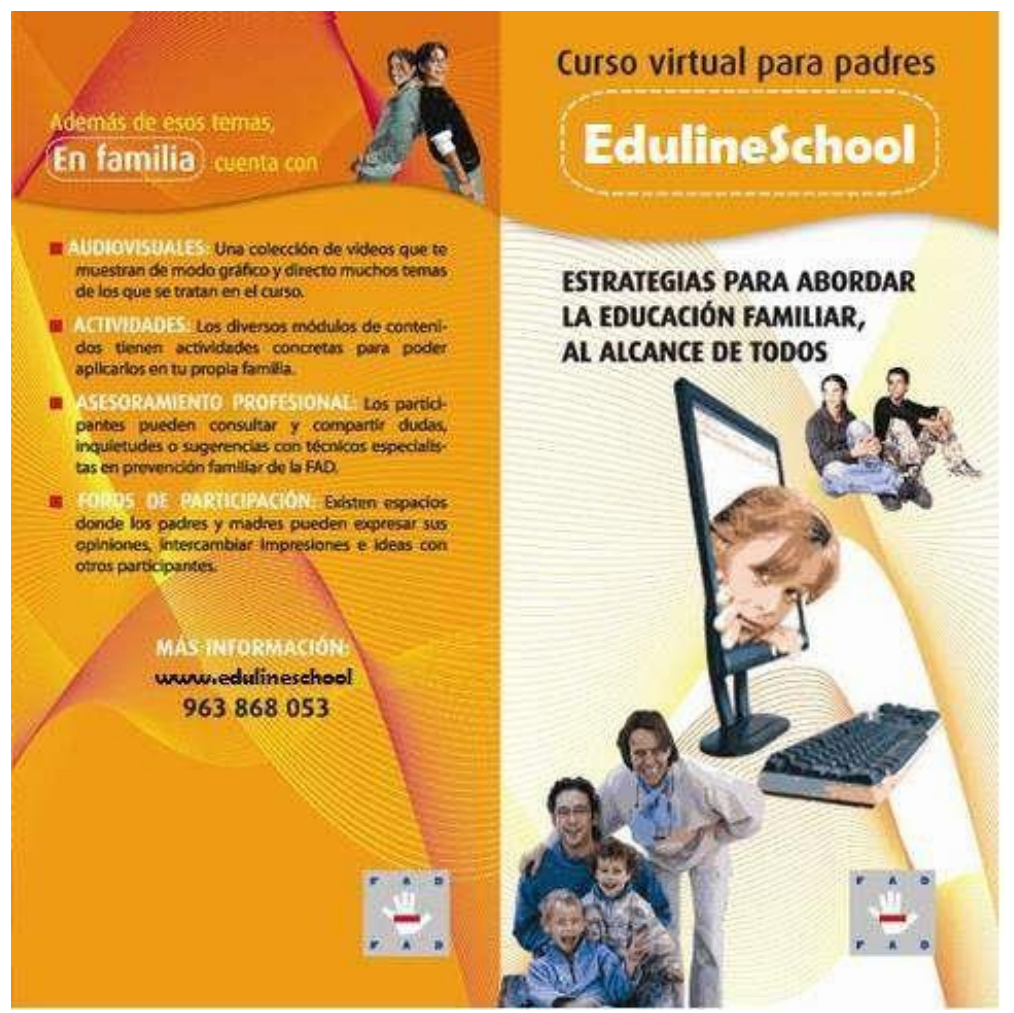

Figura 46. Brochure EdulineSchool. Adaptado de Portal de Xátiva. Recuperado http://portaldexativa.es/xativa/xativa-el-curso-virtual

Evaluación del efecto

El efecto deberá verse reflejado en las ventas, para lo cual se hará uso de herramientas de análisis de datos de redes sociales, para ver la preferencia del público objetivo, también se debe realizar el manejo de gestión de redes sociales en general.

La publicidad será mediante el uso de una página web en donde se brinde información sobre las características del producto, sus beneficios, demo de descarga gratuita por 30 días y un enlace al Facebook del producto.

La descarga de la demo gratuita será mediante suscripción lo que permite identificar potenciales clientes, contactarlos, solicitar una visita técnica, cotizar y posteriormente cerrar 
una posible venta. El producto a descargar corresponderá a una versión limitada del aplicativo de modo gratuito por 30 días.

\subsection{Estrategia de ventas}

\subsubsection{Plan de ventas}

Las ventas personales corresponden a la presencia personal de los vendedores de la empresa, con el objetivo de vender y crear relaciones con el consumidor, el vendedor es quien labora para una empresa y realizando lo siguiente: búsqueda de clientes potenciales, prestación de servicios, ventas, comunicación, recopilación de información y creación de las relaciones, Kotler y Armstrong (2012).

En relación otros aspectos de la estrategia y estructura de la fuerza de ventas, Kotler y Armstrong (2012), definen a la fuerza de ventas exterior o fuerzas de ventas de campo como vendedores externos que visitan a los clientes; asimismo, la fuerza de ventas interna la conforman los vendedores que hacen negocios desde sus oficinas, por teléfono, por internet o reciben visitas de los compradores potenciales.

Se considera el enlace telefónico y el correo electrónico herramientas fundamentales para contactar a los directores y/o promotores de colegios privados de Lima Metropolitana y Callao de los distritos definidos en este documento. La visita técnica por parte de especialistas para realizar demostraciones del software es también una herramienta que se utilizará para concretar las ventas. Además, se debe hacer uso de al menos un vendedor de campo que se entreviste con los potenciales clientes y realice el primer acercamiento.

Se planifica lograr una venta de 71 contratos anuales el primer año a un precio de S/ 749 soles mensuales con un incremento en el número de servicios vendidos de $5 \%$ anual. 


\subsubsection{Políticas de servicios y garantías}

Según Kotler y Armstrong (2012), el Marketing de valor para el cliente, es un principio sustentable según el cual la empresa debe destinar recursos en su mayoría sobre acciones de marketing que genere valor para los consumidores.

Considerando el principio de generación de valor para los consumidores mencionado por Kotler y Armstrong (2012), se brindará servicio de soporte mediante línea telefónica para personal de centros educativos usuarios. Se podrá acceder a manuales técnicos y de usuario desde el sitio web informativo de la aplicación mediante usuario y contraseña. Los interesados podrán realizar consultas mediante correo electrónico. Para brindar un mejor servicio de mantenimiento, se dispondrá de herramientas que agilicen las tareas del soporte técnico, diagnosticando fallas en menos tiempo. Los horarios de atención telefónica para consultas técnicas serán de lunes a viernes de 7:00 a 23:00 horas, sábados de 07:00 a 15:00 horas excepto domingos y feriados. Asimismo, la página web informativa del aplicativo contendrá un formulario virtual para consultas y/o comentarios.

La garantía del software incluye actualizaciones que contemplan mejoras en las funcionalidades, corrección de errores, mejoras en desempeño. 


\section{Capítulo VIII: Planificación Financiera}

La finalidad del presente capítulo, es mostrar el plan de donde se obtendrá el capital que el proyecto necesita para las inversiones que se ha identificado. La relación deuda/capital es de $40 \%$. En este capítulo se determinará el cronograma de la inversión que contempla adquisición de activo fijo, entre mobiliario, equipos de cómputo; así como los gastos para el capital de trabajo y los gastos para la puesta en marcha.

\subsection{La Inversión}

La evaluación y selección de las inversiones a largo plazo lleva a la elaboración del presupuesto que es congruente con la meta de maximizar la riqueza de los dueños de la compañía.

Las empresas realizan inversiones de capital por muchos motivos o razones. Los motivos fundamentales de las inversiones de capital son la sustitución o renovación de activos fijos, la expansión de operaciones o para tener algún otro beneficio menos tangible durante un periodo largo de tiempo.

La elaboración del presupuesto, tiene cinco pasos interrelacionados: elaborar propuestas, revisión y análisis, toma de decisiones, implementación y seguimiento. (Gitman \& Zutter, 2012).

En el proyecto la inversión será un porcentaje del capital propio, aporte de los inversionistas, los que tienen una esperanza de ganancia cuando asignan dinero para el financiamiento del proyecto; tienen conocimiento que el beneficio que obtendrán obedecerá a los resultados, es decir se convierte en un capital emprendedor o de riesgo.

Las compañías por la deuda asumen compromisos, obligaciones de pago, que deben ser honradas. Por el contrario, por el aporte de capital de los inversionistas, la compañía 
ofrece una expectativa de ganancia en la medida que los resultados; por lo que los socios inversionistas están directa o indirectamente relacionados en la gestión del proyecto o negocio, esto conlleva a que el éxito sea un compromiso en toda la empresa.

El capital que usa la compañía son los recursos que obtiene para financiar sus inversiones, de modo que el costo de capital será el retorno de porcentaje mínimo que exigen los inversionistas por financiar un proyecto o inversión. Santos, N. (2015).

\subsubsection{Inversión pre-operativa}

Como indica Gitman \& Zutter (2012, p. 361), inversión operativa es desembolso de fondos por parte de la firma que generará beneficios dentro del plazo de un año.

Como indica Baca la inversión inicial fija es la adquisición de los activos fijos o tangibles, que se necesitan para dar inicio a las operaciones, exceptuando el capital de trabajo.

1. El activo tangible o fijo, son bienes propiedad de la compañía, entre ellos terrenos, edificios, maquinarias, herramientas, vehículos de transporte, equipos, mobiliario y otros.

2. El activo intangible, son conjunto de bienes propiedad de la compañía, necesarios para su funcionamiento, y que incluyen: gastos pre operativos, diseños comerciales o industriales, nombres comerciales, marcas, contratos de servicios (como luz, teléfono, internet, agua y servicios notariales).

En la tabla 33 se muestra la inversión en intangibles que asciende a S/ 28,961. En esta sección de los activos intangibles se ha considerado las licencias de software, el desarrollo del software que será tercerizado, el diseño de la identidad de la empresa, los costos para la compra de dominio y el bosquejo de la web. También hemos incluido los gastos notariales, para constitución de la empresa, el gasto de los libros contables, la licencia municipal y los registros de marca ante Indecopi. 
Tabla 33

Inversión Intangible e Inversión Gastos Pre-Operativos montos en Soles sin IGV

\begin{tabular}{|c|c|c|c|}
\hline Concepto & Costo Unitario S/ & Cantidad & Total S/ \\
\hline Licencias Office & 700 & 5 & 3,500 \\
\hline Desarrollo de Software & 20,000 & 1 & 20,000 \\
\hline Diseño de identidad corporativa, logotipo y & 1,000 & 1 & 1,000 \\
\hline \multicolumn{4}{|l|}{ diseños } \\
\hline Dominio y página WEB Empresa & 3,000 & 1 & 1,000 \\
\hline Estudio de mercado & & & 2,000 \\
\hline Gastos Constitución Empresa & 1,461 & 1 & 1,461 \\
\hline Gastos notariales y registros públicos & 400 & & \\
\hline Compra y legalización de libros contables & 300 & & \\
\hline Licencia municipal de funcionamiento & 226 & & \\
\hline Registro de marca comercial Indecopi & 535 & & \\
\hline Total Activos Intangibles (sin IGV) & & & 28,961 \\
\hline Acondicionamiento local & 10,000 & 1 & 10,000 \\
\hline Marketing Lanzamiento & 3,000 & 1 & 3,000 \\
\hline Alquiles, Servicios (un mes pre-operativo) & 10,126 & 1 & 10,126 \\
\hline Planilla (un mes pre-operativo) & 14,000 & 1 & 14,000 \\
\hline Total Gastos Pre-Operativos (sin IGV) & & & 37,126 \\
\hline
\end{tabular}


En la tabla 34 muestra la inversión requerida de activo fijo, los escritorios y sillas para el personal. Lo equipos informáticos, los equipos de comunicación móviles y el equipo para telefónica fija que asciende S/ 35,811.

Tabla 34

Inversión Activo Fijo, montos en Soles sin IGV

\begin{tabular}{lccc}
\hline \multicolumn{1}{c}{ Concepto } & Costo & Cantidad & Total S/ \\
& Unitario S/ & & \\
\hline Escritorio Gerencia General & 2,475 & 1 & 2,475 \\
Escritorios Ingeniería & 2,100 & 2 & 4,200 \\
Escritorio Ventas & 2,100 & 1 & 2,100 \\
Escritorio Secretaria & 2,250 & 1 & 2,250 \\
Mesa de Reuniones & 2,700 & 1 & 2,700 \\
Sillas Escritorio & 351 & 18 & 6,311 \\
Sofá 3 piezas o tres sillas de espera escritorio & 527 & 1 & 527 \\
Laptops Lenovo Notebook 15,6" AMD A8 8 & 1,699 & 5 & 8,495 \\
GB 1 & & & 749 \\
Impresora Epson Multifuncional & 749 & 1 & 629 \\
Celular Galaxy J7 & 629 & 1 & 1,076 \\
Celular Galaxy J1 & 269 & 4 & 4,300 \\
Central Telefónica Intebral Pack Impacta 8, & 4,300 & 1 & 35,811 \\
8 anexos & & & \\
\hline Total Activo Fijo (sin IGV) & & & \\
\hline
\end{tabular}


La tabla 35 muestras la inversión pre operativa o nacimiento, en esta etapa se presenta los gastos antes del inicio de las operaciones, cuando aún no han comenzado las actividades principales para la que se constituyó la empresa. Esta etapa inicia desde el desembolso uno hasta que entre en funciones.

Tabla 35

Inversión Gastos Pre Operativos, montos en Soles sin IGV

\begin{tabular}{lccc}
\hline \multicolumn{1}{c}{ Concepto } & Costo Unitario S/ & Cantidad & Total S/ \\
\hline Acondicionamiento local & 10,000 & 1 & 10,000 \\
Marketing Lanzamiento & 3,000 & 1 & 3,000 \\
Servicios (un mes pre-operativo) & 10,126 & 1 & 10,126 \\
Planilla (un mes pre-operativo) & 14,000 & 1 & 14,000 \\
\hline Total Gastos Pre-Operativos (sin IGV) & & & 37,126 \\
\hline
\end{tabular}

\subsubsection{Inversión en capital de trabajo}

“El capital de trabajo o activo circulante, se denomina de esa manera ya que este es necesario para que siga manteniéndose activas las operaciones del día a día. Una gran parte del capital de trabajo la proporciona los inversionistas otra gran parte de préstamos suministrados por lo proveedores, empleados y gobierno”. Gitman \& Zutter (2012, pag. 47-48)

Para calcular el capital de trabajo que se necesita es a través del flujo de caja mensual, donde se estima las proyecciones de ingresos mensuales y las proyecciones de los egresos mensuales.

En el presente proyecto el capital de trabajo se necesita para los diferentes gastos mensuales que se realizan para el funcionamiento de la empresa, como los pagos de servicio (luz, agua, telefonía, alquiler, dominio, etc.) los sueldos, etc. 
A continuación en la Tabla 36 se muestra el capital de trabajo que asciende a

S/109,106.

Tabla 36

Capital de Trabajo montos en Soles sin IGV

\begin{tabular}{lc}
\hline \multicolumn{1}{c}{ Concepto } & Total S/ \\
\hline Caja & 1,000 \\
Capital de trabajo neto & 108,106 \\
\hline Total capital de trabajo & 109,106 \\
\hline
\end{tabular}

En la siguiente tabla se muestra la estructura de la inversión que asciende a S/ 213,689 Incluido IGV

Tabla 37

Estructura de Inversiones, montos en Soles sin IGV

\begin{tabular}{lcrr}
\hline \multicolumn{1}{c}{ Estructura de Inversiones } & Sin IGV S/ & IGV S/ & Con IGV S/ \\
\hline Activos Fijos & 35,811 & 6,446 & 42,257 \\
Activos Intangibles & 28,961 & 5,076 & 34,037 \\
Gastos Pre-Operativos & 37,126 & 4,163 & 28,289 \\
Capital de Trabajo & 109,106 & & 109,106 \\
\hline Valor total de la inversión & 211,005 & 15,685 & 226,689 \\
\end{tabular}


Tabla 38

Estructura de Flujo de caja mensual del año 2018, expresado en Soles

\begin{tabular}{|c|c|c|c|c|c|c|c|c|c|c|c|c|c|}
\hline & Ene & Feb & Mar & $\overline{\text { Abril }}$ & May & Jun & $\overline{\mathrm{Jul}}$ & Ago & Set & $\overline{\text { Oct }}$ & Nov & $\overline{\text { Dic }}$ & TOTAL \\
\hline Ingresos & 749 & 2,247 & 3,745 & 9,737 & 15,729 & 21,721 & 27,713 & 33,705 & 39,697 & 45,689 & 51,681 & 53,179 & 305,592 \\
\hline Egresos & 25,325 & 24,870 & 24,870 & 28,410 & 28,410 & 28,410 & 29,455 & 28,410 & 28,410 & 28,410 & 28,410 & 24,870 & 328,255 \\
\hline $\begin{array}{l}\text { Saldo de caja (ingresos - } \\
\text { egresos) }\end{array}$ & $-24,576$ & $-22,623$ & $-21,125$ & $-18,673$ & $-12,681$ & $-6,689$ & $-1,742$ & 5,296 & 11,288 & 17,280 & 23,272 & 28,310 & \\
\hline Saldo de caja final (acumulado) & $-24,576$ & $-47,198$ & $-68,323$ & $-86,995$ & $-99,676$ & $-106,364$ & $-108,106$ & $-102,811$ & $-91,523$ & $-74,244$ & $-50,972$ & $-22,663$ & \\
\hline
\end{tabular}

Como se aprecia en la tabla 38 el monto S/ 108,106 del mes de Julio es el Capital de Trabajo necesario como Inversión. 


\subsubsection{Costo del proyecto}

En los capítulos anteriores hemos revisado los rubros relacionados con los egresos para el presente proyecto, entre ellos estudios técnicos, estudios de mercado, legal y organizacional, se han determinado diferentes ítems relacionados con los egresos necesarios para producir el servicio, financiar y operar la actividad comercial. Esta sección mostrará lo que se hará, ordenar sistemáticamente estos valores para obtener los costos totales de operación y financiación de evaluación del negocio o proyecto.

"Costo es un desembolso en efectivo o en especie hecho en el pasado (costos hundidos), en el presente (inversión), en el futuro (costos futuros) o en forma virtual (costo de oportunidad)".

Baca,G. (2013).Evaluación de proyectos.(7a. ed.) McGraw-Hill Interamericana.

Página 184. Tomado de http://www.ebooks7-24.com

Para el desarrollo de la plataforma de comunicación iniciaremos como primer punto el Desarrollar el prototipo, que son las pantallas descritas en los capítulos anteriores, los menús a los que accederán los usuarios de la app. Este costo están contemplados en la línea de Desarrollo de software en la tabla de gastos pre operativos.

Como segundo punto está el estudio de mercado ya que siempre será requisito indispensable para la creación de un negocio. En este punto, se financiara la aplicación de las entrevistas a los expertos, las encuestas y los focus group, etc.

Como tercer punto se tiene los gastos para constituir la empresa, tramites notariales y en registros públicos, la legalización de libros contables, la obtención de las licencias municipales, y el registro de marca ante Indecopi. Estos primeros tres puntos se han visto en detalle en las tablas 32, 33, 34 y35.

Como cuarto punto se tiene que realizar los contratos de los suministros básicos como el eléctrico, Internet y teléfono. 
Como quinto punto se tiene los gastos de alquilar el local, con los montos de garantía que exija le contrato. Comprar el mobiliario y las herramientas de trabajo en este cado las computadores.

En la tabla 39 está el detalle de los gastos administrativo, donde se encuentra los gastos por los servicios de electricidad, agua, teléfono, internet, los sueldos del personal administrativo, etc.

En la tabla 40 se muestra los gastos de venta la personalización del producto, sueldos del área comercial y los gastos de publicidad. 
Tabla 39

Gastos Administrativos, montos en Soles sin IGV

Año

\begin{tabular}{|c|c|c|c|c|c|}
\hline & 2018 & 2019 & 2020 & 2021 & 2022 \\
\hline Conexión a internet/telefonía fija & 1,548 & 1,548 & 1,548 & 1,548 & 1,548 \\
\hline Conexión a red móvil / red móviles & 5,052 & 5,052 & 5,052 & 5,052 & 5,052 \\
\hline Servidor Virtual & 780 & 780 & 780 & 780 & 780 \\
\hline Oficina en Alquiler & 39,000 & 39,000 & 39,000 & 39,000 & 39,000 \\
\hline Mantenimiento y Limpieza & 14,400 & 14,400 & 14,400 & 14,400 & 14,400 \\
\hline Energía eléctrica & 3,600 & 3,600 & 3,600 & 3,600 & 3,600 \\
\hline Agua & 1,800 & 1,800 & 1,800 & 1,800 & 1,800 \\
\hline Sueldos Administración & 84,000 & 84,000 & 84,000 & 84,000 & 84,000 \\
\hline Servicio Dominio & 120 & 120 & 120 & 120 & 120 \\
\hline Servicios Contabilidad & 2,400 & 2,400 & 2,400 & 2,400 & 2,400 \\
\hline Arbitrios & 180 & 180 & 180 & 180 & 180 \\
\hline Útiles & 1,772 & 1,772 & 1,772 & 1,772 & 1,772 \\
\hline Total Egresos desembolsables (sin IGV) & 154,652 & 154,652 & 154,652 & 154,652 & 154,652 \\
\hline
\end{tabular}


Tabla 40

Gastos de Ventas, montos en Soles sin IGV

Año

\begin{tabular}{lccccc}
\hline & 2018 & 2019 & 2020 & 2021 & 2022 \\
\hline Personalización & 35,500 & 37,500 & 39,000 & 41,000 & 43,000 \\
Sueldos Comercial & 84,000 & 84,000 & 84,000 & 84,000 & 84,000 \\
Publicidad & 36,000 & 36,000 & 36,000 & 36,000 & 36,000 \\
\hline Total Egresos desembolsables (sin IGV) & & & & & \\
\end{tabular}

\begin{tabular}{|c|c|c|c|c|c|c|c|c|c|}
\hline $\begin{array}{c}\text { COSTO LABORAL } \\
\text { PERSONAL AÑO } 2017\end{array}$ & $\mathbf{Q}$ & $\begin{array}{c}\text { REMUNERACIÓ } \\
\mathbf{N}\end{array}$ & $\begin{array}{c}\text { GRATIFICACIÓ } \\
\mathbf{N}\end{array}$ & $\begin{array}{c}\text { ES SALUD } \\
9 \%\end{array}$ & $\begin{array}{l}\text { PLANILLA } \\
\text { MENSUAL }\end{array}$ & $\begin{array}{l}\text { Planilla año } \\
2018\end{array}$ & $\begin{array}{l}\text { Planilla año } \\
2019\end{array}$ & $\begin{array}{l}\text { Planilla año } \\
2020\end{array}$ & $\begin{array}{c}\text { Planilla año } \\
2021\end{array}$ \\
\hline $\begin{array}{ll}\text { Comercial } & \text { Gerente Comercial }\end{array}$ & 1 & $1,500.00$ & 250.00 & 135.00 & $2,272.92$ & $27,275.00$ & $27,275.00$ & $27,275.00$ & $27,275.00$ \\
\hline Comercial Gerente TI & 1 & $1,491.50$ & 248.58 & 134.24 & $2,019.33$ & $24,231.90$ & $24,231.90$ & $24,231.90$ & $24,231.90$ \\
\hline Comercial Analista TI & 2 & $2,000.00$ & 333.33 & 180.00 & $2,707.78$ & $32,493.33$ & $32,493.33$ & $32,493.33$ & $32,493.33$ \\
\hline & & 4,992 & 832 & 449 & 7,000 & 84,000 & 84,000 & 84,000 & 84,000 \\
\hline
\end{tabular}




\subsubsection{Inversiones futuras}

Al ser una empresa nueva aún no están planificadas las inversiones futuras para nuevos negocios. Lo que se evaluara es la reposición de equipos de cómputo en un lapso de cuatro años, ya que la ser herramientas tecnológicas están deberán ser reemplazadas por obsolescencia.

\subsection{Financiamiento}

Como indica Gitman la necesidad para el financiamiento permanente es Inversión constante en activos operativos como resultado de las ventas constantes a través del tiempo. El requisito de financiamiento estacional (o temporal), es inversión en activos operativos que varía con el paso del tiempo.

\subsubsection{Endeudamiento y condiciones}

Como indica Gitman \& Zutter (2012) el endeudamiento es un indicador de la cantidad de dinero de otras personas o instituciones usan, para que la empresa genere utilidades. El adeudo a largo plazo que comprometen al negocio o empresa son las que analiza la gerencia financiera, ya que, hay el riesgo que no se pueda cumplir con el pago de las obligaciones Para el desarrollo del proyecto el capital social (aporte de los accionistas) será el $60 \%$ de la inversión. La postura que se adopta el proyecto es conservadora. La estructura del capital se encuentra representada mediante la Tabla 41. 
Tabla 41

Estructura de la Inversión

\begin{tabular}{ccc} 
Inversión & Deuda 40\% & Capital Propio 60\% \\
\hline 226,689 & 90,676 & 136,014
\end{tabular}

Cronograma de Pago de Deuda, para conseguir el financiamiento de la inversión surgieron dos opciones, de las cuales por selección de beneficios obtenidos se escogió la opción del Banco Mi Banco, con una tasa efectiva anual de 24.00\% por tres años con cuotas mensuales fijas.

Se detallan los requisitos para el préstamo solicitado por el banco para pequeñas empresas:

Antigüedad de negocio mínima de tres meses

Copia de documento de identidad de titular y cónyuge de cada socio (en caso de ser casado o conviviente)

Copia de documento que sustente el funcionamiento de tu negocio (boletas de compra, licencia de funcionamiento, RUC, etc.)

Copia del documento que sustente tu vivienda. En caso de no tener casa propia, se solicitará aval.

En la Tabla 42 se muestran las opciones evaluadas.

Tabla 42

Relación de entidades financieras

\begin{tabular}{lccc}
\hline & TCEA & Monto & Tiempo \\
\hline Interbank & $47.50 \%$ & 90,676 & 36 meses \\
Mi Banco & $24.00 \%$ & 90,676 & 36 meses
\end{tabular}


El cronograma del pago del financiamiento se muestra en la Tabla 43, donde se visualiza el monto correspondiente a las cuotas, intereses, amortización y estado de la deuda.

Tabla 43

Datos préstamo bancario

$\begin{array}{lrr}\text { Préstamo: } & 90,676 & \\ \text { TCEA: } & 1.81 \% & 24.00 \% \\ \text { Plazo años } & 3 & \\ \text { Cuotas anuales } & 12 & \\ \text { Total Cuotas } & 36 & \\ \text { Valor Cuota } & 3,449 & \end{array}$

\begin{tabular}{cccccc}
\hline Periodo & \multicolumn{1}{l}{ Deuda } & Interés & Pago Amort. & Cuota \\
\hline & 1 & 90,676 & 17,386 & $24,003.54$ & 41,390 \\
& 2 & 66,672 & 11,625 & $29,764.40$ & 41,390 \\
& 3 & 36,908 & 4,482 & $36,907.85$ & 41,390 \\
& & & 33,493 & 90,676 & 124,169 \\
\hline
\end{tabular}


Tabla 44

Detalle Cronograma de pagos

\begin{tabular}{|c|c|c|c|c|c|}
\hline . & Fecha de Pago & Saldo & Interés & Capital & Cuota \\
\hline & & 85,476 & & & \\
\hline 1 & $02 / 02 / 2018$ & 83,771 & 1,546 & 1,705 & 3,251 \\
\hline 2 & $02 / 03 / 2018$ & 82,035 & 1,515 & 1,736 & 3,251 \\
\hline 3 & $02 / 04 / 2018$ & 80,267 & 1,484 & 1,768 & 3,251 \\
\hline 4 & $02 / 05 / 2018$ & 78,468 & 1,452 & 1,800 & 3,251 \\
\hline 5 & $04 / 06 / 2018$ & 76,635 & 1,419 & 1,832 & 3,251 \\
\hline 6 & $02 / 07 / 2018$ & 74,770 & 1,386 & 1,865 & 3,251 \\
\hline 7 & 02/08/2018 & 72,871 & 1,352 & 1,899 & 3,251 \\
\hline 8 & 03/09/2018 & 70,938 & 1,318 & 1,933 & 3,251 \\
\hline 9 & $02 / 10 / 2018$ & 68,970 & 1,283 & 1,968 & 3,251 \\
\hline 10 & $02 / 11 / 2018$ & 66,966 & 1,247 & 2,004 & 3,251 \\
\hline 11 & $03 / 12 / 2018$ & 64,926 & 1,211 & 2,040 & 3,251 \\
\hline 12 & $02 / 01 / 2019$ & 62,849 & 1,174 & 2,077 & 3,251 \\
\hline 13 & $04 / 02 / 2019$ & 60,734 & 1,137 & 2,115 & 3,251 \\
\hline 14 & 04/03/2019 & 58,582 & 1,099 & 2,153 & 3,251 \\
\hline 15 & $02 / 04 / 2019$ & 56,390 & 1,060 & 2,192 & 3,251 \\
\hline 16 & $02 / 05 / 2019$ & 54,158 & 1,020 & 2,231 & 3,251 \\
\hline 17 & 03/06/2019 & 51,887 & 980 & 2,272 & 3,251 \\
\hline 18 & 02/07/2019 & 49,574 & 939 & 2,313 & 3,251 \\
\hline 19 & 02/08/2019 & 47,219 & 897 & 2,355 & 3,251 \\
\hline 20 & 02/09/2019 & 44,822 & 854 & 2,397 & 3,251 \\
\hline 21 & $02 / 10 / 2019$ & 42,381 & 811 & 2,441 & 3,251 \\
\hline 22 & $04 / 11 / 2019$ & 39,897 & 767 & 2,485 & 3,251 \\
\hline 23 & $02 / 12 / 2019$ & 37,367 & 722 & 2,530 & 3,251 \\
\hline 24 & $02 / 01 / 2020$ & 34,791 & 676 & 2,575 & 3,251 \\
\hline 25 & $03 / 02 / 2020$ & 32,169 & 629 & 2,622 & 3,251 \\
\hline 26 & $02 / 03 / 2020$ & 29,500 & 582 & 2,669 & 3,251 \\
\hline 27 & $02 / 04 / 2020$ & 26,782 & 534 & 2,718 & 3,251 \\
\hline 28 & $04 / 05 / 2020$ & 24,015 & 484 & 2,767 & 3,251 \\
\hline 29 & $02 / 06 / 2020$ & 21,198 & 434 & 2,817 & 3,251 \\
\hline 30 & $02 / 07 / 2020$ & 18,330 & 383 & 2,868 & 3,251 \\
\hline 31 & 03/08/2020 & 15,410 & 332 & 2,920 & 3,251 \\
\hline 32 & $02 / 09 / 2020$ & 12,438 & 279 & 2,973 & 3,251 \\
\hline 33 & $02 / 10 / 2020$ & 9,412 & 225 & 3,026 & 3,251 \\
\hline 34 & $02 / 11 / 2020$ & 6,330 & 170 & 3,081 & 3,251 \\
\hline 35 & $02 / 12 / 2020$ & 3,194 & 115 & 3,137 & 3,251 \\
\hline \multirow[t]{2}{*}{36} & $04 / 01 / 2021$ & & 58 & 3,194 & 3,251 \\
\hline & & & 31,572 & 85,476 & 117,048 \\
\hline
\end{tabular}

Cabe señalar, que se adicionará para la obtención del crédito una garantía hipotecaria como una vivienda, que será proporcionada por uno de los socios. 


\subsubsection{Capital y costo de oportunidad}

Como indica Gitman el valor del dinero en el tiempo se refiere que es mejor recibir dinero ahora que luego en el tiempo. El efectivo o dinero que tenemos ahora en la mano podemos invertirlo para conseguir rendimiento positivo, generando más efectivo para el futuro.

Según Gitman, el costo de capital representa el costo del financiamiento de una empresa y es la tasa mínima de rendimiento que debe ganar un proyecto para incrementar el valor de la compañía. Se debe aceptar el proyecto con el costo de capital más bajo, lo que nos permita obtener un retorno de la inversión lo más alto posible.

En la tabla 45 se muestra el Costo de oportunidad del capital (COK), fue hallado mediante el beta apalancado a la empresa según el sector de Aplicaciones de software. La tasa libre de riesgo corresponde al promedio de bonos del tesoro promedio de los últimos años, rendimiento de los mercados, prima de riesgo del mercado y riesgo país, con lo cual se obtiene un COK igual al $15.10 \%$ según el modelo CAPM y $29.10 \%$ el COK del proyecto.

Cabe recalcar que de acuerdo a 50 minutos.es el modelo de valoración de activos financieros (CAPM ) es uno de los tipos de valoración riesgos de los activos financieros más conocidos que se emplea para solucionar inconvenientes financieros en las organizaciones como en los mercados financieros y ayuda a calcular la rentabilidad de un activo al comparándolo con su riesgo potencial. De manera prioritaria, dicho modelo permite averiguar el costo de oportunidad del capital (COK) y su cálculo se fundamenta sobre la clase de interés, rentabilidad que se espera y la medición del riesgo sistemático.

Además, provee a los inversionistas de contundente información acerca de la posible rentabilidad y riesgo que puede tener un activo financiero al cual podrían estar interesados en invertir. 
Tabla 45

Costo de oportunidad del capital (COK)

COK Modelo

CAPM

Tasa de rendimiento de activo de libre riesgo (Rf)

5.18\% Damodaran (10-year T. Bond 1928-2016)

Tasa de rendimiento del mercado ( $\mathrm{Rm})$

$11.42 \%$ Damodaran (S\&P 500 1928-2016)

Beta desapalancada $\mathrm{Bu}$

0.94 Damodaran Unlevered Beta (Software (System \& Application))

\%D Financiamiento bancario

$40 \%$

\%E Aporte de accionistas

$60 \%$

Riesgo país(Rp)

1.34\% Embi + JP Morgan

Impuesto a la renta

$29.5 \%$

Beta Apalancado

1.376

$\mathrm{B}=\mathrm{Bu} \times(1+(\% \mathrm{D} / \% \mathrm{E}) *(1-\mathrm{t}))$

COK (Modelo CAPM)

$15.10 \%$

$\mathrm{COK}=\mathrm{Rf}+\operatorname{Beta} \mathrm{x}(\mathrm{Rm}-\mathrm{Rf})+\mathrm{Rp}$

TIPMN (Tasa de Interés Pasiva de Mercado Moneda Nacional)

$2.70 \%$

SBS - Mayo 2017

TAMN (Tasa de Interés Activas de Mercado Moneda Nacional)

$16.70 \%$

Spread Bancario (FTAMN - FTIPMN)

$14.00 \%$

SBS - Mayo 2017

Tasa activa promedio de mercado de las operaciones realizadas en los últimos 30 días útiles Tasa pasiva promedio de mercado de las operaciones realizadas en los últimos 30 días útiles 
En la tabla 45 se menciona que el COK del proyecto es la suma del COK hallado bajo el modelo CAPM y la diferencia entre la tasa de interés pasiva y activa llamada Spread

El costo oportunidad del capital (COK) es la tasa de rendimiento que se le exige a un proyecto y que está en función directa a su riesgo y no al de la empresa que lo ejecuta. Para determinar el COK se emplea el modelo de la valoración de los activos financieros (CAPM)

A continuación, se detalla la obtención del costo de oportunidad del capital (COK)

$$
\mathrm{COK}=\mathrm{Rf}+\operatorname{Beta} \mathrm{x}(\mathrm{Rm}-\mathrm{Rf})+\mathrm{Rp}
$$

1. Rf: es la tasa de interés que paga el día de hoy un activo libre de riesgo, en el caso de este proyecto se ha tomado los datos de la base de datos del rendimiento anual de las inversiones en bonos del tesoro de la reserva federal de USA el promedio desde 1928 al 2016 (10-year T. Bond) el cual es 5.18\%

2. Rm: es el rendimiento del mercado. En el siguiente proyecto se ha considerado el promedio del índice de Standard \& Poor's 500, el cual es uno de los índices bursátiles más importantes de USA, contiene el listado de las 500 empresas más grandes que cotizan en la New York Exchange (NYSE), American Exchange (AMEX) y Nasdaq. Promedio de Damodaran S\&P 500 1928-2016) es $11.42 \%$.

3. Beta Bu: sensibilidad del activo al riesgo no-diversificable conocido también como riesgo del mercado o riesgo sistémico. Betas mayores a 1 significan que el activo tiene un riesgo mayor al promedio de todo el mercado. Para el caso del presente proyecto se ha tomado el Beta desapalancado de la industria del Software (System \& Application) que es 0.94 según la tabla Damodaran Unlevered Beta Software System \& Application. 
4. Rp: riesgo país señala las posibilidades de un país emergente pueda o no cumplir con el pago de su deuda externa, ya sea al capital o sus intereses; cuanto más mayor el nivel del "Riesgo País" de una nación, elevada es la probabilidad de que la misma ingrese en moratoria de pagos. Este dato los mide con el EMBI (Emerging Markets Bond Index), que fue creado por la firma internacional JP Morgan Chase, en junio del año 2017 fue de 1.34\%

5. Impuesto a la renta: de acuerdo a la Superintendencia Nacional de Administración Tributaria ( SUNAT) $29.50 \%$

6. Deuda financiera $40 \%$

7. Capital aportado por los cuatro accionistas $60 \%$, nivel de aporte de cada accionista $25 \%$

8. Para hallar el Beta apalancado $\mathrm{B}=\mathrm{Bu} \times(1+(\% \mathrm{D} / \% \mathrm{E}) *(1-\mathrm{t}))$

Es la multiplicación del Beta desapalancado con la división de la deuda financiera y el capital de los accionistas, multiplicado por el impuesto a la renta. En el siguiente proyecto esta operación resulta 1.376

Con los datos hallados se calcula el costo oportunidad del capital (COK)

$$
\mathrm{COK}=\mathrm{Rf}+\operatorname{Beta} \mathrm{x}(\mathrm{Rm}-\mathrm{Rf})+\mathrm{Rp}
$$

COK modelo CAPM $=5.18 \%+1.376 \times(11.42 \%-5.18 \%) 1.34 \%=15.10 \%$

El COK hallado a través del modelo CAPM es el rendimiento que le exigirá un inversionista americano, como el proyecto será ejecutado en el Perú, el COK se ajustará con el Spread Bancario (margen que existen entre los tipos de interés activos y pasivos)

- $\quad$ TIPMN $2.70 \%$

- $\quad$ TAMN $16.70 \%$

- $\quad$ Spread Bancario $($ FTAMN - FTIPMN $)=14.00 \%$ 
COK del proyecto $=(1+\mathrm{COK}) \times(1+\mathrm{SB})-1=(1+15.10 \%) \times(1+14.00 \%)-1=29.10 \%$ Flujo Financiero

Según León C. (2007), en mercados poco desarrollados, que tienen la capacidad de ingresar a fondos de mercados de otros países (del primer mundo), se incrementa el riesgo de los actores, es decir, de los inversionistas; sin embargo, cuando no se tiene la capacidad para obtener fondos, se tiene que requerir al mercado de capital local, este contiene riesgo, que es el sobre costo financiero, este compromete admitir el riesgo de tener fuentes de deuda que los costos distorsionan el costo de oportunidad del capital, medido a partir de mercados desarrollados. Para calcular este riesgo y corregir la distorsión, se recurre al análisis del spread o diferencial de tasas activas frente a las pasivas del mercado financiero local.

\subsubsection{Costo de capital promedio ponderado}

Como indica Gitman presenta el costo del financiamiento de una empresa y es la tasa mínima de rendimiento que debe ganar un proyecto para incrementar el valor de la compañía.

Las fuentes de capital a largo plazo son, las deudas de plazo largo, acciones preferentes, acciones comunes y ganancias retenidas. Para el proyecto como hemos indicado será deuda a largo plazo del $40 \%$ del monto de inversión.

El costo del déficit de plazo largo, es el valor del financiamiento que se encuentra asociado con los nuevos fondos recaudados con préstamos a plazo largo.

De acuerdo a Gitman \& Zutter, el costo de capital promedio ponderado (WACC), es un indicador financiero que resume en tal solo un dato, el costo de las diversas fuentes de financiamiento que se empleara para financiar el proyecto. 
WACC $=\mathrm{COK}$ del proyecto $\mathrm{x} \% \mathrm{E}+$ Costo efectivo de la deuda $\mathrm{x} \% \mathrm{D}$

El Costo efectivo de la deuda, es la multiplicación del costo de la deuda financiera 24 $\%$ (Tasa de Costo Efectivo Anual) por el impuesto a la renta $29.50 \%$

Costo efectivo de la deuda $=31.21 \%(1-29.50 \%)=16.92 \%$

Finalmente, una vez obtenido el costo efectivo de la deuda se procede a hallar el costo de capital promedio ponderado (WACC)

$\mathrm{WACC}=31.21 \% \times 60 \%+16.92 \% \times 40 \%=24.23 \%$ Flujo Económico 
Tabla 46

Costo de capital promedio ponderado (WACC)

\begin{tabular}{lll}
\hline \multicolumn{1}{c}{ WACC } & $29.10 \%$ & Flujo financiero \\
\hline & & \\
Costo de la deuda (Kd) TCEA & $24.00 \%$ & Tasa de Interés Préstamo \\
Costo efectivo de la deuda Kd (1-T) & $16.92 \%$ & \\
& & \\
Estructura de capital & $40 \%$ & \\
\%D Financiamiento bancario & $60 \%$ & \\
\%E Aporte de accionistas & & \\
& $24.23 \%$ & Flujo económico \\
\hline Costo promedio ponderado capital (WACC) $=$ &
\end{tabular}

En la Tabla 46 se muestran los cálculos realizados para obtener el costo de oportunidad y la tasa de descuento WACC igual al $29.10 \%$ de flujo financiero y $24.23 \%$ de flujo económico.

\subsection{Presupuestos Base}

Los estudios previos realizados en la presente investigación en relación a la definición de precios, pronóstico de ventas, costos y gastos han permitido formular una serie de presupuestos que permitirán posteriormente tener mayor claridad para poder formular una serie de estrategias para el arranque del servicio de plataforma de comunicación para alumnos, padres y docentes.

De acuerdo a Horngren, Datar \& Rajan (2012) el presupuesto es una propuesta que realiza el área de administración en la cual se plasma numéricamente el plan de acción y suele ser una herramienta que apoya en la implementación de dicho plan. Los mismos 
autores, señalan que el presupuesto es uno de los instrumentos más importantes en el momento de la planeación y desarrollo de estrategias permitiendo una mejor coordinación. Señalan que es importante hacer una integración tanto del presupuesto como de la estrategia.

\subsubsection{Presupuesto de ventas}

De acuerdo a Jobber y Lancaster (2012) el pronóstico de ventas es lo que se espera recibir por el total de productos vendidos y es catalogado como el punto de inicio para la elaboración del presupuesto ya que todas las actividades de la empresa se encuentran ligadas con las ventas y con el ingreso total anticipado. Los mismos autores señalan que el pronóstico de ventas antecede al presupuesto de ventas.

Cabe señalar, que según Jobber y Lancaster (2012) el presupuesto de ventas impacta directamente en otras áreas del negocio como en finanzas y producción.

El servicio de plataforma de comunicación a tiempo real entre colegios, padres de familia y alumnos generará ingresos esencialmente de la prestación de dicho servicio que constará de un pago mensual de S/749 por servicio prestado.

De acuerdo al estudio de mercado realizado previamente en la presente investigación, las ventas están direccionadas a determinada población de colegios privados de nivel primaria y secundaria con las siguientes características: Pertenecientes a los distritos de:

Barranco, Bellavista, Breña, Callao, Carmen de La Legua Reynoso, Chorrillos, Jesús María, La Molina, La Perla, La Punta, La Victoria, Lima, Lince, Los Olivos, Magdalena Del Mar, Miraflores, Pueblo Libre, Rímac, San Borja, San Isidro, San Luis, San Martin de Porres, San Miguel, Santiago de Surco y Surquillo.

Estos se encuentran interesados en adquirir dicho servicio con el finalidad de mejorar la comunicación entre padres, alumnos y docentes todo ello para fomentar una mejora en la comunicación. 
Se toma como referencia el mercado efectivo, mercado disponible y el pronóstico de venta que servirán como base para poder tener una aproximación de las ventas del primer año. Cabe señalar, que para estimar la proyección de ventas del segundo al quinto año se emplea un porcentaje de crecimiento del $5 \%$ anual lo cual equivale a la venta del servicio de plataforma de comunicación a tiempo real a 4 colegios más por cada año.

A continuación, se detalla en la tabla 47 y 48 la composición de los ingresos, los cuales constan de brindar el servicio de plataforma de comunicación en tiempo real de manera mensual y con una tarifa plana anual.

En las tablas 48 y 49 muestra los ingresos expresado en Soles desde el año 2018 al año 2022. 
Tabla 47

Detalle de servicios mensuales año 2018 expresado en Unidades

\begin{tabular}{|c|c|c|c|c|c|c|c|c|c|c|c|c|c|c|}
\hline $\begin{array}{l}\text { Detalle por } \\
\text { unidades }\end{array}$ & $\begin{array}{c}\text { Mercado } \\
\text { objetivo } \\
\text { Año } \\
2018\end{array}$ & Enero & Febrero & Marzo & Abril & Mayo & Junio & Julio & Agosto & Setiembre & Octubre & Noviembre & Diciembre & $\begin{array}{c}\text { Total Año } \\
2018\end{array}$ \\
\hline Clientes & 71 & 1 & 2 & 2 & 8 & 8 & 8 & 8 & 8 & 8 & 8 & 8 & 2 & 71 \\
\hline $\begin{array}{l}\text { Servicios } \\
\text { mensuales }\end{array}$ & & 1 & 3 & 5 & 13 & 21 & 29 & 37 & 45 & 53 & 61 & 69 & 71 & 408 \\
\hline
\end{tabular}

Tabla 48

Detalle de servicios anuales del año 2019 al 2022 expresado en Unidades

\begin{tabular}{|c|c|c|c|c|c|c|c|c|}
\hline $\begin{array}{l}\text { Detalle por } \\
\text { unidades }\end{array}$ & $\begin{array}{l}\text { Mercado objetivo } \\
\text { Año } 2019\end{array}$ & Total Año 2019 & $\begin{array}{l}\text { Mercado objetivo } \\
\text { Año } 2020\end{array}$ & $\begin{array}{l}\text { Total } \\
\text { Año } \\
2020\end{array}$ & $\begin{array}{l}\text { Mercado objetivo } \\
\text { Año } 2021\end{array}$ & $\begin{array}{l}\text { Total } \\
\text { Año } \\
2021\end{array}$ & $\begin{array}{l}\text { Mercado objetivo } \\
\text { Año } 2022\end{array}$ & $\begin{array}{l}\text { Total Año } \\
2022\end{array}$ \\
\hline $\begin{array}{l}\text { Servicios } \\
\text { mensuales }\end{array}$ & & 900 & & 936 & & 984 & & 1,032 \\
\hline
\end{tabular}


Tabla 49

Detalle del precio de venta de la aplicación desde el año 2018 al año 2022 expresado en Soles

\begin{tabular}{lccccc}
\hline Año & 2018 & 2019 & 2020 & 2021 & 2022 \\
\hline Valor venta & 634.75 & 634.75 & 634.75 & 634.75 & 634.75 \\
IGV & 114.25 & 114.25 & 114.25 & 114.25 & 114.25 \\
Precio venta & 749.00 & 749.00 & 749.00 & 749.00 & 749.00 \\
\hline
\end{tabular}

La Planificación Financiera del plan de negocios se ha considerado a precios constantes, sin considerar la inflación, el precio base se determina a partir del año cero.

Tabla 50

Detalle de servicios anuales del año 2018 expresado en Soles

\begin{tabular}{|c|c|c|c|c|c|c|c|c|c|c|c|c|c|}
\hline $\begin{array}{l}\text { Ventas } \\
(\mathrm{S} / .)\end{array}$ & Enero & Febrero & Marzo & Abril & Mayo & Junio & Julio & Agosto & Setiembre & Octubre & Noviembre & Diciembre & Año 2018 \\
\hline $\begin{array}{l}\text { Ventas } \\
(\sin I G V)\end{array}$ & $\mathrm{S} / .635$ & $\mathrm{~S} / .1,904$ & $\mathrm{~S} / .3,174$ & $\mathrm{~S} / .8,252$ & $\mathrm{~S} / .13,330$ & $\mathrm{~S} / .18,408$ & $\mathrm{~S} / 23,486$ & $\mathrm{~S} / 28,564$ & $\mathrm{~S} / 33,642$ & $\mathrm{~S} / 38,719$ & $\mathrm{~S} / .43,797$ & $\mathrm{~S} / .45,067$ & $\mathrm{~S} / 258,976$ \\
\hline IGV & $\mathrm{S} / .114$ & $\mathrm{~S} / .343$ & $\mathrm{~S} / .571$ & $\mathrm{~S} / .1,485$ & $\mathrm{~S} / 2,399$ & $\mathrm{~S} / 3,313$ & $\mathrm{~S} / .4,227$ & $\mathrm{~S} / .5,141$ & $\mathrm{~S} / .6,055$ & $\mathrm{~S} / .6,970$ & $\mathrm{~S} / .7,884$ & $\mathrm{~S} / .8,112$ & $\mathrm{~S} / .46,616$ \\
\hline $\begin{array}{l}\text { Ventas } \\
\text { (con IGV) }\end{array}$ & $\mathrm{S} / .749$ & $\mathrm{~S} / .2,247$ & $\mathrm{~S} / .3,745$ & $\mathrm{~S} / 9,737$ & $\mathrm{~S} / .15,729$ & $\mathrm{~S} / 21,721$ & $\mathrm{~S} / 27,713$ & $\mathrm{~S} / 33,705$ & $\mathrm{~S} / 39,697$ & $\mathrm{~S} / .45,689$ & $\mathrm{~S} / .51,681$ & $\mathrm{~S} / .53,179$ & $\mathrm{~S} / .305,592$ \\
\hline
\end{tabular}


Tabla 51

Detalle de servicios anuales del año 2019 al 2022 expresado en Soles

\begin{tabular}{|c|c|c|c|c|}
\hline Ventas (S/.) AÑO & 2019 & 2020 & 2021 & 2022 \\
\hline Ventas (sin IGV) & S/.571,271 & $\mathrm{S} / .594,122$ & $\mathrm{~S} / .624,590$ & $\mathrm{~S} / .655,058$ \\
\hline IGV & S/.102,829 & S/.106,942 & S/.112,426 & $\mathrm{S} / .117,910$ \\
\hline Ventas (con IGV) & S/.674,100 & $\mathrm{S} / .701,064$ & S/.737,016 & S/.772,968 \\
\hline
\end{tabular}

Las cinco últimas tablas muestras con detalle la evolución de las ventas, con ello se visualiza el presupuesto de ventas, el punto de partida para la planificación del proyecto. 


\subsubsection{Presupuesto de costos de producción}

Según Horngren, Datar \& Foster (2007) es cuando se procede a hacer un resumen de del costo que se visualiza en las cédulas de las mercancías fabricadas.

Existe un costo de implementación o de producción para la concretización del negocio de la venta del servicio de plataforma de comunicación a tiempo real para padres, docentes y alumnos. Debido a que la empresa que brindará este servicio aún no existe en el mercado se deberá de tener en cuenta el desembolso de dinero relacionado a costos de implementación.

En la tabla de Inversión Pre-operativa se detalló total de la inversión pre-operatoria necesaria que arroja los costos producción necesarios para el arranque del negocio.

Los siguientes meses los costos se traducen en los gastos administrativos, financieros y de ventas al ser un servicio que se entrega al cliente.

\subsubsection{Presupuesto de compras}

De acuerdo a Faga \& Ramos (2006) el presupuesto de compras está compuesto por materias primas y materiales y mercaderías con posibilidad de reventa tomando como referencia el presupuesto de ventas de estas mercadería y los presupuestos de niveles de inventario.

Las compras básicamente corresponden a artículos de consumo se considera como gastos directos para la realización del servicio. Dichos gastos poseen una frecuencia mensual y anual.

En el presente proyecto las compras están enfocadas a las suministros y útiles que se necesitan para el trabajo del día a día. Ya que al entregar un servicio no se necesita compra de materias primas ni otros para la transformación del servicio a entrega. En la siguiente tabla 52 se muestra las compras de materiales de oficina que se realizar 2 veces al año. 
Tabla 52

Detalle de compras realizadas 2 veces al año, expresado en Soles

\begin{tabular}{lccc}
\hline Materiales de Oficina & Cantidad & Costo Unitario & Total \\
\hline Archivadores & 5 & 20.00 & 100.00 \\
Bandejas para escritorios & 6 & 10.00 & 60.00 \\
Cartuchos de tinta & 2 & 120.00 & 240.00 \\
Clips \# 1 (Caja x100unid) & 3 & 5.00 & 15.00 \\
Clips Mariposa Wingo (Caja x 100unid) & 3 & 5.00 & 15.00 \\
Agendas & 6 & 5.00 & 30.00 \\
File Manila oficio (Pate 50 unid) & 3 & 10.00 & 30.00 \\
Grapas 23/6 (Caja x 5000unid) & 10 & 2.00 & 20.00 \\
Lapicero azul punta fina Faber Castell & 12 & 1.00 & 12.00 \\
Notas adhesivas 3"x3" (100hojas) Post it & 12 & 8.00 & 96.00 \\
Papel Bond 75gr. & 10 & 10.00 & 100.00 \\
Perforador & 3 & 15.00 & 45.00 \\
Porta clips cilíndrico & 3 & 2.00 & 6.00 \\
Resaltador 48 & 12 & 1.00 & 12.00 \\
Saca grapas & 3 & 3.00 & 9.00 \\
Sello fechador & 3 & 6.00 & 18.00 \\
Sello Trodat & 1 & 6.00 & 6.00 \\
Sobre Manila A4 (Pqte 50 unid) & 3 & 10.00 & 30.00 \\
Tachos de basura & 3 & 12.00 & 36.00 \\
Tampón & 1 & 6.00 & 6.00 \\
\hline TOTAL & & 886.00 \\
\hline
\end{tabular}

\subsubsection{Presupuesto de costo de ventas}

Faga \& Ramos (2006) señalan que el presupuesto de costo de ventas es un consolidado de todos los costos en los que se puede incurrir, los cuales pueden cambiar por la relación directa que existe con las ventas. Los costos que pueden varían son los siguientes: a) impuestos a los ingresos brutos y similares; b) fieles y acarreos, c) comisiones o cargan sociales de vendedores; d) otros costos variables de ventas. Los mismos autores señalan que 
para su elaboración se toman en cuenta los datos desarrollados en su respectivo presupuesto de ventas.

En la siguiente tabla 53 se visualiza el Presupuesto del costo de venta del servicio de plataforma de comunicación en tiempo real entre colegio, padres de familia y alumnos de ventas, que comprende el costo de la personalización del producto, pago único por cada cliente, costo de los trabajadores del área de administración, los gastos de publicidad.

Tabla 53

Detalle costos de ventas del año 2018 al 2022, expresado en Soles

\begin{tabular}{lccccc}
\hline Año & 2018 & 2019 & 2020 & 2021 & 2022 \\
\hline Personalización S/ 500 & 35,500 & 37,500 & 39,000 & 41,000 & 43,000 \\
Sueldos Área Comercial & 84,000 & 84,000 & 84,000 & 84,000 & 84,000 \\
Publicidad & 36,000 & 36,000 & 36,000 & 36,000 & 36,000 \\
Total Egresos & & & & & 163,000 \\
desembolsables (con IGV) & 155,500 & 157,500 & 159,000 & 161,000 & \\
IGV & 12,870 & 13,230 & 13,500 & 13,860 & 14,220 \\
\hline Total Egresos & & & & & \\
desembolsables (con IGV) & 168,370 & 170,730 & 172,500 & 174,860 & 177,220 \\
& & & & & \\
\hline
\end{tabular}

Se calcula el costo unitario del servicio en relación a los costos fijos y variables del proyecto y el total de servicios realizados obteniéndose como resultado un costo unitario de S/. 390.40 soles 


\subsubsection{Presupuesto de gastos administrativos}

De acuerdo a Tanaka (2005) el presupuesto de gastos administrativos es proyectar de manera anticipada todos los gastos en los que incurren las áreas administrativas.

A continuación en la tabla 54, se detalla los gastos administrativos relacionados a los siguientes cinco años. Se muestra el detalle de los servicios de internet, electricidad, agua, alquileres, sueldos del área administrativa y servicios de terceros.

Tabla 54

Detalle costos de administrativos del año 2018 al 2022, expresado en Soles

\begin{tabular}{|c|c|c|c|c|c|}
\hline Año & 2018 & 2019 & 2020 & 2021 & 2022 \\
\hline Conexión a internet/telefonía fija & 1,548 & 1,548 & 1,548 & 1,548 & 1,548 \\
\hline Conexión a red móvil / red móviles & 5,052 & 5,052 & 5,052 & 5,052 & 5,052 \\
\hline Servidor Virtual & 780 & 780 & 780 & 780 & 780 \\
\hline Oficina en Alquiler & 39,000 & 39,000 & 39,000 & 39,000 & 39,000 \\
\hline Mantenimiento y Limpieza & 14,400 & 14,400 & 14,400 & 14,400 & 14,400 \\
\hline Energía eléctrica & 3,600 & 3,600 & 3,600 & 3,600 & 3,600 \\
\hline Agua & 1,800 & 1,800 & 1,800 & 1,800 & 1,800 \\
\hline Sueldos Administración & 84,000 & 84,000 & 84,000 & 84,000 & 84,000 \\
\hline Servicio Dominio & 120 & 120 & 120 & 120 & 120 \\
\hline Servicios Contabilidad & 2,400 & 2,400 & 2,400 & 2,400 & 2,400 \\
\hline Arbitrios & 180 & 180 & 180 & 180 & 180 \\
\hline Útiles & 1,772 & 1,772 & 1,772 & 1,772 & 1,772 \\
\hline $\begin{array}{l}\text { Total Egresos desembolsables (sin } \\
\text { IGV) }\end{array}$ & 154,652 & 154,652 & 154,652 & 154,652 & 154,652 \\
\hline IGV & 5,233 & 5,233 & 5,233 & 5,233 & 5,233 \\
\hline $\begin{array}{l}\text { Total Egresos desembolsables (con } \\
\text { IGV) }\end{array}$ & 159,885 & 159,885 & 159,885 & 159,885 & 159,885 \\
\hline
\end{tabular}




\subsubsection{Presupuesto de marketing y ventas}

El presupuesto para marketing se traduce en un plan de acción en el que existe un compromiso para realizar un gasto que involucre una meta en relación a la venta de volúmenes de venta, cuota de mercado y una expectativa en cuanto a la rentabilidad y en relación a la posición con la competencia.

A continuación, se detalla el presupuesto destinado al marketing de la plataforma de comunicación en tiempo real.

Tabla 55

Presupuesto de Marketing

\begin{tabular}{llcc}
\hline Descripción & Detalle & Cantidad & Precio \\
\hline Campaña & Ads de manejo y creación de banner con texto & 1 & 500.00 \\
Facebook & por 100x72 píxeles & 1 & 500.00 \\
Adwords & Pauta en facebook por 3,000 clics & & 1000.00 \\
\cline { 2 - 4 } & Sub Total de campaña mensual & 1 & $2,000.00$ \\
Campaña Google & Keywords (anuncios de texto), 2000 clics & & $2,000.00$ \\
\hline & Sub Total de campaña mensual & & $3,000.00$ \\
\hline
\end{tabular}

Para publicitar la plataforma de comunicación será necesario realizar campañas que permitan generar en el público objetivo expectativas positivas en cuanto al servicio.

Se evaluó que la manera más ideal de llegar a ellos fue por medio de Facebook y del Google Adword.

El total de la campaña mensual tendrá un costo de $\mathrm{S} / 3,000$. 


\subsubsection{Presupuesto de gastos financieros}

Según Tanaka (2012) la estimación de gastos financieros ayuda a determinar cuánto es el costo de interés de las distintas fuentes de financiamiento empleadas por empresa para el periodo de proyección

Es preciso mencionar, que las condiciones para el financiamiento bancario serán las siguientes. Se financiará el $40 \%$ de toda la inversión con un préstamo a tres años.

Dentro de este presupuesto se debe contemplar los costos por préstamos como los intereses que están relacionados con el préstamo hecho a la institución financiera Interbank, como muestra la siguiente tabla.

Tabla 56

Gastos financieros

\begin{tabular}{ccc}
\hline Periodo Anual & Deuda & Interés \\
\hline Año 1 & 90,676 & 17,386 \\
Año 2 & 66,672 & 11,625 \\
Año 3 & 36,908 & 4,482 \\
\hline
\end{tabular}

\subsection{Presupuestos de Resultados}

Tiene que ver con la implementación de un enfoque que se orienta a los resultados y a la gestión de rendimiento en ambos ámbitos, trasladando el acento en la elaboración del presupuesto, la gestión y la rendición de cuentas desde los insumos a los resultados que pueden medirse. (La modernización del Estado: el camino a seguir. 2006.) 


\subsubsection{Estado de Resultados proyectado}

Según Gitman "el estado de pérdidas y ganancias, también llamado estado de resultados, proporciona un resumen financiero de los resultados de operación de la empresa durante un periodo específico" p.53 
Tabla 57

Estado de resultados proyectado del año 2018 al 2022

(Sin incluir Gastos Financieros) expresado en Soles

\begin{tabular}{|c|c|c|c|c|c|}
\hline & 2018 & 2019 & 2020 & 2021 & 2022 \\
\hline Ventas & 258,976 & 571,271 & 594,122 & 624,590 & 655,058 \\
\hline Costos de Operaciones & $(326,951)$ & $(328,951)$ & $(330,451)$ & $(332,451)$ & $(334,451)$ \\
\hline (-) Gastos Administrativos & $(154,652)$ & $(154,652)$ & $(154,652)$ & $(154,652)$ & $(154,652)$ \\
\hline (-) Gastos Ventas & $(155,500)$ & $(157,500)$ & $(159,000)$ & $(161,000)$ & $(163,000)$ \\
\hline (-) Depreciación & $(3,581)$ & $(3,581)$ & $(3,581)$ & $(3,581)$ & $(3,581)$ \\
\hline (-) Amortización & $(13,217)$ & $(13,217)$ & $(13,217)$ & $(13,217)$ & $(13,217)$ \\
\hline EBIT o Utilidad Operativa & $-67,974$ & 242,321 & 263,672 & 292,139 & 320,607 \\
\hline Utilidad neta antes de impuestos & $-67,974$ & 174,346 & 263,672 & 292,139 & 320,607 \\
\hline (-) Impuestos & 0 & $(51,432)$ & $(77,783)$ & $(86,181)$ & $(94,579)$ \\
\hline Utilidad Neta & $-67,974$ & 190,888 & 185,888 & 205,958 & 226,028 \\
\hline
\end{tabular}


Tabla 58

Estado de resultados proyectado del año 2018 al 2022

Estado de Resultados

(Incluyendo Gastos Financieros y Venta de Activos Fijos) expresado en Soles

\begin{tabular}{|c|c|c|c|c|c|}
\hline & 2018 & 2019 & 2020 & 2021 & 2022 \\
\hline Ventas Netas & 258,976 & 571,271 & 594,122 & 624,590 & 655,058 \\
\hline Costos De Operaciones & $(326,951)$ & $(328,951)$ & $(330,451)$ & $(332,451)$ & $(334,451)$ \\
\hline (-) Gastos Administrativos & $(154,652)$ & $(154,652)$ & $(154,652)$ & $(154,652)$ & $(154,652)$ \\
\hline (-) Gastos Ventas & $(155,500)$ & $(157,500)$ & $(159,000)$ & $(161,000)$ & $(163,000)$ \\
\hline (-) Depreciación & $(3,581)$ & $(3,581)$ & $(3,581)$ & $(3,581)$ & $(3,581)$ \\
\hline (-) Amortización & $(13,217)$ & $(13,217)$ & $(13,217)$ & $(13,217)$ & $(13,217)$ \\
\hline EBIT o Utilidad Operativa & $-67,974$ & 242,321 & 263,672 & 292,139 & 320,607 \\
\hline Ingresos por Venta Activos & & & & & 5,897 \\
\hline (-) Valor Libros & & & & & $(17,906)$ \\
\hline (-) Gastos Financieros & $(17,386)$ & $(11,625)$ & $(4,482)$ & & \\
\hline Utilidad Antes Impuestos & $-85,360$ & 230,695 & 259,190 & 292,139 & 308,598 \\
\hline (-) Impuestos & 0 & $(42,874)$ & $(76,461)$ & $(86,181)$ & $(91,037)$ \\
\hline Utilidad Neta & $-85,360$ & 187,822 & 182,729 & 205,958 & 217,562 \\
\hline Escudo Fiscal & - & 8,558 & 1,322 & & \\
\hline
\end{tabular}


Tabla 59

Detalle ingreso por venta de activos al finalizar el proyecto

\begin{tabular}{lrrr}
\hline & Precio & Porcentaje & Valor Mercado \\
& \multicolumn{1}{c}{ S/ } & & S/ (5 Años) \\
\hline Escritorio Gerencia General & 2,475 & $20 \%$ & 495 \\
Escritorios Ingeniería & 4,200 & $20 \%$ & 840 \\
Escritorio Ventas & 2,100 & $20 \%$ & 420 \\
Escritorio Secretaria & 2,250 & $20 \%$ & 450 \\
Mesa de Reuniones & 2,700 & $20 \%$ & 540 \\
Sillas Escritorio & $6,310.80$ & $20 \%$ & $1,262.16$ \\
Sofá 3 piezas o tres sillas de espera escritorio & 526.50 & $20 \%$ & 105.3 \\
Laptops Lenovo Notebook 15,6" AMD A8 8 GB 1 & 8,495 & $10 \%$ & 849.5 \\
Impresora Epson Multifuncional & 749 & $10 \%$ & 74.9 \\
Celular Galaxy J7 & 629 & $0 \%$ & 0 \\
Celular Galaxy J1 & 1,076 & $0 \%$ & 0 \\
Central Telefónica Intebral Pack Impacta 8, 8 anexos & 4,300 & $20 \%$ & 860 \\
\hline
\end{tabular}




\subsubsection{Estado de situación financiera proyectado}

De acuerdo a Faga \& Ramos es una estimación de la proyección de Estado de situación financiera que consiste mostrar la situación patrimonial de la empresa al finalizar el periodo en cuestión. Los mismos autores señalan que el balance proyectado es el resultado de realizar diferentes movidas presupuestales en diferentes cuentas. Es preciso mencionar, que de acuerdo a las NIIF ( Normas Internacionales de Información Financiera ) existen una serie de cambios en la nomenclatura de los estados financieros sugeridos que se toman en cuenta en el siguiente trabajo.

Tabla 60 ( falta cambiar tabla)

Estado de situacion Financiera proyectado

\begin{tabular}{|c|c|c|c|c|c|c|}
\hline & Año 0 & Año 1 & Año 2 & Año 3 & Año 4 & Año 5 \\
\hline \multicolumn{7}{|l|}{ Activo corriente } \\
\hline Caja & 109,106 & 109,106 & 522,781 & 934,940 & $1,417,657$ & $1,942,602$ \\
\hline Crédito fiscal (igv) & 15,685 & & & & & \\
\hline Total activo corriente & 124,791 & 109,106 & 284,311 & 448,461 & 670,451 & 921,950 \\
\hline \multicolumn{7}{|l|}{ Activo no corriente } \\
\hline Activo tangible & 35,811 & 35,811 & 35,811 & 35,811 & 35,811 & \\
\hline $\begin{array}{l}\text { (-) Depreciación } \\
\text { acumulada }\end{array}$ & & $-3,581$ & $-7,162$ & $-10,743$ & $-14,325$ & \\
\hline activo intangible & 53,087 & 53,087 & 53,087 & 53,087 & 53,087 & 53,087 \\
\hline $\begin{array}{l}\text { (-) Amortización } \\
\text { acumulada }\end{array}$ & & $-10,617$ & $-21,235$ & $-31,852$ & $-42,470$ & $-53,087$ \\
\hline Total activo no corriente & 88,898 & 74,700 & 60,501 & 46,303 & 32,104 & 0 \\
\hline Total activos & 213,689 & 183,806 & 344,812 & 494,764 & 702,555 & 921,950 \\
\hline \multicolumn{7}{|l|}{ Pasivos } \\
\hline Cuentas por pagar & 85,476 & 62,849 & 34,791 & 0 & 0 & 0 \\
\hline Total pasivos & 85,476 & 62,849 & 34,791 & 0 & 0 & 0 \\
\hline \multicolumn{7}{|l|}{ Patrimonio } \\
\hline Capital & 128,214 & 202,721 & 202,721 & 202,721 & 202,721 & 202,721 \\
\hline Utilidad acumulada & & & $-81,763$ & 107,300 & 292,043 & 499,834 \\
\hline Utilidad del ejercicio & & $-81,763$ & 189,063 & 184,743 & 207,791 & 219,395 \\
\hline Total patrimonio & 128,214 & 120,957 & 310,021 & 494,764 & 702,555 & 921,950 \\
\hline Total pasivos y patrimonio & 213,689 & 183,806 & 344,812 & 494,764 & 702,555 & 921,950 \\
\hline
\end{tabular}




\subsubsection{Flujo de caja proyectado}

En el flujo de caja se ha contado con la información sobre los ingresos y egresos de efectivo que haya tenido la compañía. Esta información la obtenemos de la contabilidad.

Una de los objetivos con esta información es adelantarnos a un futuro déficit si fuera el caso, y así, tomar la decisión de buscar financiamiento oportunamente. También podrá prever un excedente de efectivo para decidir si se vuelve a invertir.

La siguiente tabla 61 muestra el flujo de caja, que es el saldo que resulta de restar los ingresos menos los egresos generados por la inversión y actividad productiva del proyecto. Además, el horizonte de tiempo sobre el cual se preparan estos cálculos abarca cinco años.

En las tablas 61 y 62 se muestra el detalle de la liquidación del IGV y el detalle del valor de recuperación del activo fijo respectivamente. 
Tabla 61

Flujo de Caja proyectado del año 2018 al 2022, expresado en Soles

\begin{tabular}{|c|c|c|c|c|c|c|}
\hline Flujo de caja & 2017 & 2018 & 2019 & 2020 & 2021 & 2022 \\
\hline Ingresos por ventas & & 305,592 & 674,100 & 701,064 & 737,016 & 772,968 \\
\hline (-) Gastos Administrativos & & $-159,885$ & $-159,885$ & $-159,885$ & $-159,885$ & $-159,885$ \\
\hline (-) Gastos de Ventas & & $-168,370$ & $-170,730$ & $-172,500$ & $-174,860$ & $-177,220$ \\
\hline (-) Impuesto a la Renta & & - & $-51,492$ & $-77,783$ & $-86,181$ & $-94,579$ \\
\hline (-) Pago de IGV & & $-12,828$ & $-84,366$ & $-88,209$ & $-93,333$ & $-99,519$ \\
\hline (=) Flujo de Caja Operativo & & $-35,491$ & 207,687 & 202,687 & 222,757 & 241,765 \\
\hline Inversión en Activos Tangibles & $-42,257$ & & & & & \\
\hline Inversión en Activos Intangibles & $-34,037$ & & & & & \\
\hline Gastos Preoperativos & $-28,289$ & & & & & \\
\hline Inversión en Capital de Trabajo & $-109,106$ & & & & & \\
\hline Valor de Recuperación del Activo Fijo & & & & & & 10,501 \\
\hline Flujo de Capital o Inversión & $-226,689$ & $\mathbf{0}$ & $\mathbf{0}$ & $\mathbf{0}$ & $\mathbf{0}$ & 10,501 \\
\hline (=) Flujo de Caja Económico & $-226,689$ & $-35,491$ & 207,687 & 202,687 & 222,757 & 252,266 \\
\hline Préstamos & 90,676 & & & & & \\
\hline Cuotas & & $-41,390$ & $-41,390$ & $-41,390$ & & \\
\hline Escudo Fiscal & & - & 8,558 & 1,322 & & \\
\hline (=) Servicio de la deuda & 90,676 & $-41,390$ & $-32,831$ & $-40,067$ & 0 & 0 \\
\hline (=) Flujo de Caja Financiero & $-136,014$ & $-76,881$ & 174,856 & 162,619 & 222,757 & 252,266 \\
\hline
\end{tabular}

Elaboración propia 
Tabla 62

Liquidación de IGV del año 2018 al 2022, expresado en soles

\begin{tabular}{|c|c|c|c|c|c|c|}
\hline & 2017 & 2018 & 2019 & 2020 & 2021 & 2022 \\
\hline IGV Ventas netas & & $46,615.73$ & $102,828.81$ & $106,941.97$ & $112,426.17$ & $117,910.37$ \\
\hline IGV Valor de recupero activo fijo & & & & & & $1,061.43$ \\
\hline IGV Gastos de Ventas & & $-12,870.00$ & $-13,230.00$ & $-13,500.00$ & $-13,860.00$ & $-14,220.00$ \\
\hline IGV Inversión Activo Fijo & $-6,446.03$ & & & & & \\
\hline IGV Inversión Activo Intangible & $-5,076.00$ & & & & & \\
\hline IGV Neto & $-15,684.71$ & $28,512.77$ & $84,365.85$ & $88,209.01$ & $93,333.21$ & $99,518.85$ \\
\hline Crédito Fiscal & $-15,684.71$ & 0.00 & 0.00 & 0.00 & 0.00 & 0.00 \\
\hline Pago de IGV & 0.00 & $12,828.05$ & $84,365.85$ & $88,209.01$ & $93,333.21$ & $99,518.85$ \\
\hline
\end{tabular}

Tabla 63

Detalle Flujo de Capital o Inversión, expresado en Soles

\begin{tabular}{lc} 
Valor Mercado (Ingresos por Venta Activos) & 5,897 \\
Valor en Libros & $-17,906$ \\
Perdida de Capital & $-12,009$ \\
Ahorro Impuestos & 3,543 \\
Valor Residual & 9,439 \\
IGV Valor Mercado & 1,061 \\
\hline Valor Recupero con IGV & 10,501 \\
\hline
\end{tabular}




\section{Capítulo IX: Evaluación Económico Financiera}

De acuerdo a Sánchez y Tarodo (2015) señalan que tanto el análisis económico como el análisis financiero son estudios que nos permiten tener conocimiento sobre cómo se encuentra realmente una empresa en relación a un lapso de tiempo determinado.

Richards, Davies, Yaron \& Sanginés (2018) manifiestan que existe un aspecto que ayuda a diferenciarlos y este se relaciona con los precios empleados. El análisis financiero emplea los precios de mercado más importantes ya que son los precios que ayudan a incentivar económicamente. En cambio, el análisis económico hace referencia a la presencia de políticas y un mercado imperfecto que genera que los valores de disponibilidad a pagar sean diferentes a los precios reales.

De igual forma, los mismos autores señalan que la segunda diferencia es que el análisis económico toma en cuenta los costos y beneficios externos más no el análisis financiero.

López \& Nevado (2006) señalan que el análisis financiero y el análisis económico ayudan a formular criterios de decisión ya que se orientan a realizar un análisis y evaluación de flujos y estados económicos

Los mismos autores manifiestan que el análisis financiero es el estudio de la estructura financiera y de la forma como ha sido obtenido para que posibilite la inversión. Cabe señalar, que es un análisis que se orienta a las fuentes de información. En cambio el análisis económico es el estudio de cómo evolucionan los resultados de la empresa por medio de la visualización de los costos, ingresos y rentabilidad de la inversión de capital. 
De acuerdo a un estudio de investigación realizado por la ESAN (2016) señalan que para hacer una selección de proyectos, el principal criterio económico y financiero es la eficiencia.

\subsection{Evaluación Financiera}

La evaluación financiera es un instrumento básico que permite una correcta canalización del ahorro hacia la inversión. En este instrumento se encontrará las fallas existentes a distintos niveles de la compañía.

Para la correspondiente evaluación del desempeño del proyecto se usará una herramienta principal: el análisis de razones donde se determina la forma en que las partidas de los estados financieros se relacionan. (Bañol y Franco, Tesis Análisis financiero, 2009. javeriana.edu.co)

En las siguientes tablas 64 y 65 se muestra los Indicadores de Rentabilidad Económico y Financiero. 
Tabla 64

Indicadores de Rentabilidad Económico

\begin{tabular}{|c|c|c|c|c|c|c|}
\hline$\overline{\text { Año }}$ & 0 & 1 & 2 & 3 & 4 & 5 \\
\hline Flujo de caja eco nómico & $-226,689$ & $-35,491$ & 207,687 & 202,687 & 222,757 & 252,266 \\
\hline $\mathrm{WACC}=$ & $24.23 \%$ & & & & & \\
\hline Van económico $=$ & 163839.68 & & & & & \\
\hline TIR económica $=$ & $45.73 \%$ & & & & & \\
\hline Beneficio $/$ costo $=$ & 1.72 & & & & & \\
\hline \multicolumn{7}{|l|}{ Periodo de recupero descontado } \\
\hline Flujo de caja descontado & $-226,689$ & $-28,569$ & 134,578 & 105,724 & 93,532 & 85,265 \\
\hline Flujo de caja acumulado & $-226,689$ & $-255,259$ & $-120,681$ & $-14,957$ & 78,575 & 163,840 \\
\hline Periodo de recupero descontado económico & 3.16 & años & & & & \\
\hline
\end{tabular}

Tabla 65

Indicadores de Rentabilidad Financiero

\begin{tabular}{|c|c|c|c|c|c|c|}
\hline Año & 0 & 1 & 2 & 3 & 4 & 5 \\
\hline Flujo de Caja Fi nanciero & $-136,014$ & $-76,881$ & 174,856 & 162,619 & 222,757 & 252,266 \\
\hline $\mathrm{COK}=$ & $29.10 \%$ & & & & & \\
\hline VAN Financiero $=$ & 135467.398 & & & & & \\
\hline TIR financiera $=$ & $54.30 \%$ & & & & & \\
\hline Beneficio/Costo $=$ & 2.00 & & & & & \\
\hline \multicolumn{7}{|l|}{ Periodo de recupero descontado } \\
\hline Flujo de caja descontado & $-136,014$ & $-59,552$ & 104,914 & 75,579 & 80,193 & 70,346 \\
\hline Flujo de caja acumulado & $-136,014$ & $-195,565$ & $-90,651$ & $-15,072$ & 65,121 & 135,467 \\
\hline Periodo de recupero descontado financiero & 3.19 & años & & & & \\
\hline
\end{tabular}

En las siguientes secciones se evaluara con detalle los índices financieros, la tasa interna de retorno T I R, el valor actual neto V A N, la Return on Equity ROE y los principales ratios de rentabilidad y endeudamiento. 


\subsubsection{TIR}

Según Gitman \& Zutter (2012) la tasa interna de rendimiento (TIR) es una de las herramientas más empleadas para la elaboración de presupuesto de capital. De igual forma, los mismos autores señalan que es una tasa de descuento que iguala el V P N de una oportunidad de inversión con S/0. Es considerada una tasa de rendimiento que ganara la empresa si invierte en el proyecto y recibe las entradas de efectivo esperadas.

Las tablas 64 y 65 muestran una TIR económica de $45.73 \%$ y una TIR financiera de $54.30 \%$ lo que significa que la tasa de rendimiento es mayor a la tasa que ofrecen las instituciones financieras, las cuales tienen una tasa pasivas anuales en promedio de 5\% anual. También muestra que el retorno de la inversión es mayor a la exigida por los accionistas WACC $24.23 \%$

\subsubsection{VAN}

Según Gitman \& Zutter (2012) el valor presente neto o valor actualizado neto (V P N/ V AN) siendo una de las herramientas más elaboradas, permite la construcción del presupuesto de capital. El VPN se obtiene al restar la inversión del inicio de un proyecto del valor actual de los flujos de entrada de efectivo descontados a una tasa que posee un equivalente al costo de capital de la empresa.

El valor actual neto VAN se ha calculado mediante la siguiente fórmula:

$$
\begin{aligned}
& \text { VAN }=\sum_{t=1}^{n} \frac{V_{t}}{(1+k)^{t}}-I_{0} \\
& V_{t} \text { representa los flujos de caja en cada periodo t. } \\
& I_{0} \text { es el valor del desembolso inicial de la inversión. } \\
& n \text { es el número de períodos considerado. } \\
& k \text { es el tipo de interés. }
\end{aligned}
$$

El Valor Actual Neto es uno de los métodos básicos, que consiste en encontrar la diferencia entre el valor actualizado de beneficios futuros, menos el valor actualizado de los costos futuros. La tasa que se utiliza para reducir los flujos es el rendimiento mínimo aceptable de la compañía, por debajo de la cual los proyectos de inversión no deben 
realizarse. Si el Valor Actual Neto de un proyecto es positivo, la inversión deberá realizarse y si es negativo deberá rechazarse, las inversiones con VAN positivo tienen una rentabilidad mayor que la rentabilidad mínima aceptable.

Las tablas 64 y 65 muestras una VAN económica de S/ 163,840 y una VAN financiera de S/ 135,467 lo que significa que el proyecto es viable.

\subsubsection{ROE}

De acuerdo Pampillón, De la Cuesta \& Ruza (2012) al hacer la multiplicación de la rentabilidad del activo con el factor del apalancamiento financiero es equivalente al ROE, es decir la rentabilidad financiera o rentabilidad de capital.

Tabla 66

\section{Rentabilidad financiera}

\begin{tabular}{cccccc}
\hline \multicolumn{5}{c}{ ROE por años } \\
\hline \multirow{2}{*}{ Utilidad Neta } & 2018 & 2019 & 2020 & 2021 & 2022 \\
Total patrimonio & $-85,360$ & 187,822 & 182,729 & 205,958 & 217,562 \\
\hline ROE & 136,014 & 127,534 & 315,356 & 498,084 & 704,043 \\
\hline & $-67 \%$ & $60 \%$ & $37 \%$ & $29 \%$ & $24 \%$ \\
\hline
\end{tabular}

Este indicador mide el alcance que tiene la empresa de remunerar a sus accionistas, como se muestra en la tabla 66 a partir del segundo año este es $60 \%$.

\subsubsection{Ratios}

De acuerdo Aching \& Aching (2016) los ratios financieros permiten abastecer de información que finalmente ayuda a tomar decisiones acertadas para direccionar y dirigir la empresa durante un lapso de tiempo.

i) Índices de solvencia, apalancamiento y endeudamiento: evalúa y mide que tan capaz es la empresa para generar riqueza. 
ii) Índices de liquidez: realizan una evaluación y análisis de los compromisos que posee la empresa a corto plazo.

iii) Índices de gestión de calidad: Realizan una medición del empleo del activo y hacen una comparación de la cifra de ventas con el activo total, el material movilizado y el activo circulante.

Tabla 67

Margen Operativo

\begin{tabular}{lccccc}
\hline Año & $\mathbf{2 0 1 8}$ & $\mathbf{2 0 1 9}$ & $\mathbf{2 0 2 0}$ & $\mathbf{2 0 2 1}$ & $\mathbf{2 0 2 2}$ \\
\hline EBIT o Utilidad Operativa & $-67,974$ & 242,321 & 263,672 & 292,139 & 320,607 \\
Ventas Netas & 258,976 & 571,271 & 594,122 & 624,590 & 655,058 \\
\hline Margen Operativo & $-26 \%$ & $42 \%$ & $44 \%$ & $47 \%$ & $49 \%$ \\
\hline
\end{tabular}

Este indicador calcula el \% que queda de casa Sol de ventas, después de que se opera todos los costos y gastos, a partir del segundo año del proyecto este indicador esta sobre el $40 \%$.

Tabla 68

Margen Neto

\begin{tabular}{|c|c|c|c|c|c|}
\hline Año & 2018 & 2019 & 2020 & 2021 & 2022 \\
\hline Utilidad Neta & $-85,360$ & 187,822 & 182,729 & 205,958 & 217,562 \\
\hline Ventas Netas & 258,976 & 571,271 & 594,122 & 624,590 & 655,058 \\
\hline Margen Neto & $-33 \%$ & $33 \%$ & $31 \%$ & $33 \%$ & $33 \%$ \\
\hline
\end{tabular}

Este indicador evalúa el porcentaje que queda de cada Sol de ventas después que se dedujeron todos los costos y gastos, a partir del segundo año del proyecto este indicador esta sobre el $30 \%$. 
Tabla 69

Retorno de la Inversión

\begin{tabular}{cccccc}
\hline & $\mathbf{2 0 1 8}$ & $\mathbf{2 0 1 9}$ & $\mathbf{2 0 2 0}$ & $\mathbf{2 0 2 1}$ & $\mathbf{2 0 2 2}$ \\
\hline Utilidad Neta & $-85,360$ & 187,822 & 182,729 & 205,958 & 217,562 \\
Total activos & 226,689 & 194,206 & 352,263 & 498,084 & 704,043 \\
\hline ROA & $-44 \%$ & $53 \%$ & $37 \%$ & $29 \%$ & $24 \%$ \\
\hline
\end{tabular}

Este indicador mide la eficacia de la administración para generar utilidades con los activos disponibles, como se muestra en la tabla 69 a partir del segundo año este es $53 \%$.

Tabla 70

Deuda / Capital

\begin{tabular}{lccccc}
\hline & $\mathbf{2 0 1 8}$ & $\mathbf{2 0 1 9}$ & $\mathbf{2 0 2 0}$ & $\mathbf{2 0 2 1}$ & $\mathbf{2 0 2 2}$ \\
\hline Total pasivos & 90,676 & 66,672 & 36,908 & 0 & 0 \\
Total patrimonio & 136,014 & 127,534 & 315,356 & 498,084 & 704,043 \\
\hline \multicolumn{1}{c}{ Deuda / Capital } & 0.52 & 0.12 & 0.00 & 0.00 & 0.00 \\
\hline
\end{tabular}

Este indicador mide la cantidad de deuda que está usando la empresa para financiar los activos, la tabla 70 muestra que el primer año este es un 0.52 y el segundo año 0.11 .

Tabla 71

Grado de Propiedad

\begin{tabular}{lccccc}
\hline & 2018 & 2019 & 2020 & 2021 & 2022 \\
\hline Total patrimonio & 136,014 & 127,534 & 315,356 & 498,084 & 704,043 \\
Total activos & 226,689 & 194,206 & 352,263 & 498,084 & 704,043 \\
\hline Grado de Propiedad & $66 \%$ & $90 \%$ & $100 \%$ & $100 \%$ & $100 \%$ \\
\hline
\end{tabular}

Mide el nivel de compromiso del patrimonio para los acreedores de la empresa, a partir del tercer año este indicador es $100 \%$. 
Tabla 72

Cobertura de Gastos Financieros

\begin{tabular}{lccccc}
\hline & 2018 & 2019 & 2020 & 2021 & 2022 \\
\hline EBIT o Utilidad Operativa & $-67,974$ & 242,321 & 263,672 & 292,139 & 320,607 \\
(-) Gastos Financieros & $-17,386$ & $-11,625$ & $-4,482$ & & \\
\hline Cobertura de Gastos Financieros & -3.91 & 20.84 & 58.83 & & \\
\hline
\end{tabular}

Este indicador mide la capacidad de utilizar capital de terceros.

\subsection{Análisis de Riesgo}

Gitman \& Zutter (2012) manifiestan que el análisis de riesgos consiste en medir y evaluar si el rendimiento supera a la inversión. Los mismos autores indican que el concepto anterior es cuando se analiza el nivel en el que varía los rendimientos comparándolo con un activo específico.

\subsubsection{Análisis de punto de equilibrio}

Los autores Gitman \& Zutter (2012) señalan que el análisis de punto de equilibrio es llamado también análisis de costo, calidad y volumen; realiza una evaluación de la rentabilidad de los diferentes niveles de ventas y señala que nivel de operación es necesario para cubrir todos los costos.

Keat \& Young (2004) señalan que el análisis del equilibrio entre ingresos y egresos es una versión reducida del análisis económico que mide el impacto que se genera en la empresa al hacer un cambio de la cantidad de un producto sobre las ganancias o utilidades de la empresa. 
Tabla 73

Análisis Punto de Equilibrio en número de Clientes y en Soles

Años

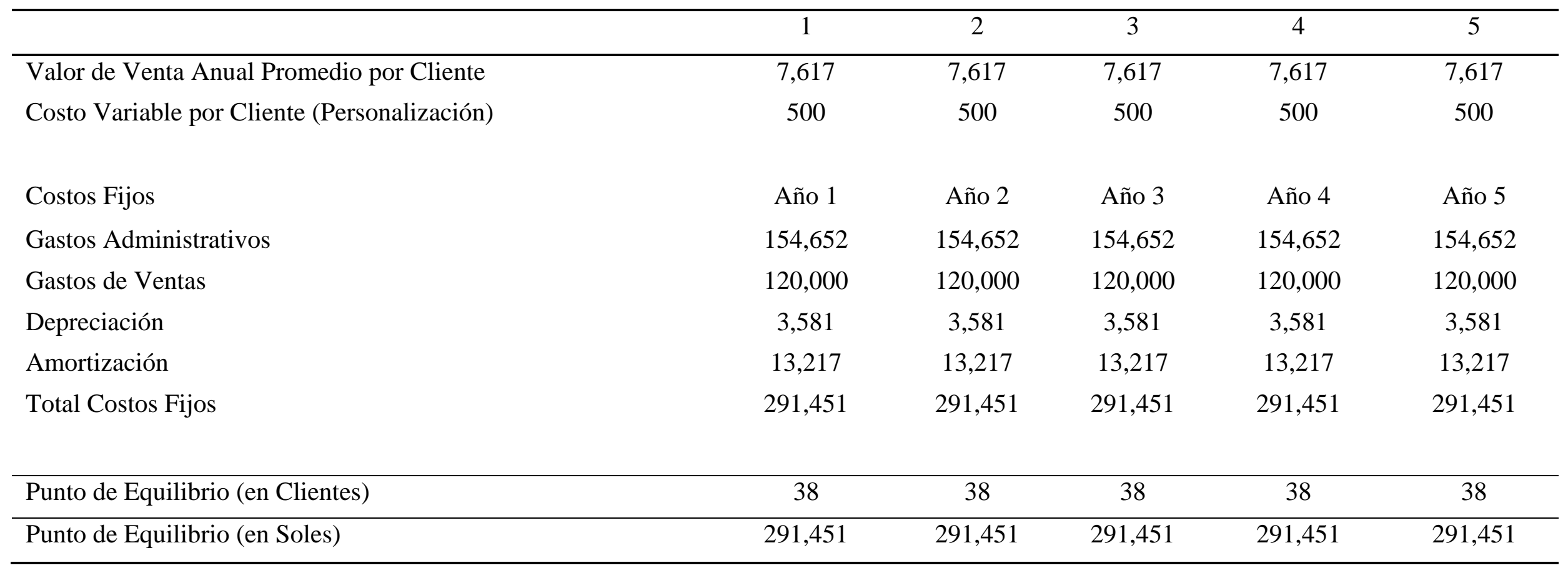

En la tabla 73 se muestra que son 38 clientes necesarios para llegar al punto de equilibrio, que significa S/ 291,451 


\subsubsection{Análisis de sensibilidad}

De acuerdo a Gitman \& Zutter (2012) el análisis de sensibilidad permite hacer una evaluación del riesgo ya que toma en cuenta diversas opciones de escenarios con el objetivo de conocer el nivel que varían entre los rendimientos.

El análisis de sensibilidad es definido por Mochón y Aparicio (2014), como una técnica que permite estimar impacto de las variaciones de los factores importantes en los beneficios, en la tasa de rendimiento, de forma tal que podamos conocer el impacto en dicha tasa de una variación de ventas, costes.

\section{Tabla 74}

Análisis de sensibilidad en Soles

\begin{tabular}{ccc}
\hline \multicolumn{2}{c}{ Variable de entrada - Precios expresado en Soles } \\
\hline Normal & VANE $=0$ \\
Disminución máxima de precios & $-15.44 \%$ \\
Precio mensual de licencia & 749.00 & 633.34 \\
\hline Variables de salida & & \\
\hline VANE & 163,840 & 0.00 \\
TIRE & $45.73 \%$ & $24.23 \%$ \\
WACC & $24.23 \%$ & $24.23 \%$ \\
\hline
\end{tabular}

El máximo porcentaje es de $15.44 \%$ que el precio puede disminuir, manteniendo sin variaciones las demás variables. 
Tabla 75

Análisis de sensibilidad en cantidades

Variable de entrada - Cantidad de Clientes

\begin{tabular}{|c|c|c|}
\hline & Normal & $\mathrm{VANE}=0$ \\
\hline Disminución máxima de la demanda & & $-16.20 \%$ \\
\hline Año 1 & 71 & 60 \\
\hline Año 2 & 75 & 62 \\
\hline Año 3 & 78 & 66 \\
\hline Año 4 & 82 & 69 \\
\hline Año 5 & 86 & 72 \\
\hline \multicolumn{3}{|c|}{ Variables de salida } \\
\hline VANE & 163,840 & 0 \\
\hline TIRE & $45.73 \%$ & $24.23 \%$ \\
\hline WACC & $24.23 \%$ & $24.23 \%$ \\
\hline
\end{tabular}

La demanda puede disminuir en un máximo de $16.20 \%$, manteniendo sin variaciones las otras variables. 


\subsubsection{Análisis de escenarios}

Como indica Gitman \& Zutter (2012), las distribuciones de probabilidad permiten obtener un conocimiento más cuantitativo del riesgo de un activo.

Tabla 76

Análisis de escenarios

\begin{tabular}{lccc}
\hline & Pesimista & Normal & Optimista \\
\hline Variables de entrada & & & $10 \%$ \\
Precios & $-10 \%$ & $0 \%$ & $10 \%$ \\
$\quad$ Demanda & $-10 \%$ & & \\
Variables de Salida & & 163,840 & 353,693 \\
$\quad$ VANE & $-29,518$ & $45.73 \%$ & $68.10 \%$ \\
TIRE & $20.23 \%$ & $24.23 \%$ & $24.23 \%$ \\
WACC & $24.23 \%$ & $60 \%$ & $25 \%$ \\
Escenarios Probabilidades & $15 \%$ & & \\
& & & \\
\hline Van Económico Esperado & S/ 182,299 & & \\
\hline
\end{tabular}

En un escenario pesimista el proyecto no sería rentable, genera un V A N negativo.

En los escenarios normal y optimista el proyecto es rentable, genera V A N positivos.

Si es que se considera las probabilidades de ocurrencia de cada escenario, el V A N Económico esperado es positivo, por lo tanto es viable. 
Tabla 77

Probabilidad de éxito, montos expresados en Soles

\begin{tabular}{|c|c|c|c|c|}
\hline Escenario & Probabilidad & VANE & Prob. $\mathrm{x}$ VANE & $\begin{array}{c}\text { Prob } x \text { (VANE - VANE } \\
\text { esperado })^{\wedge} 2\end{array}$ \\
\hline Pesimista & $15 \%$ & $-29,518$ & $-4,428$ & $6,730,011,371$ \\
\hline Base & $60 \%$ & 163,840 & 98,304 & $204,452,710$ \\
\hline \multirow[t]{2}{*}{ Optimista } & \multirow[t]{2}{*}{$25 \%$} & 353,693 & 88,423 & $7,343,934,313$ \\
\hline & & & 182,299 & $14,278,398,394$ \\
\hline VANE esperado = & & S/ 182,299 & & \\
\hline Desviación estándar = & & S/ 119,492 & & \\
\hline Probabilidad de no éxi & $(\mathrm{VANE}<=0)$ & $6.36 \%$ & & \\
\hline Probabilidad de éxito & $\mathrm{ANE}>0)$ & $93.64 \%$ & & \\
\hline
\end{tabular}

Con la conjugación de las probabilidades del escenario pesimista al 15\%, el escenario normal al $60 \%$ y el escenario optimista al 25\%, las probabilidades de éxito del proyecto es de casi $94 \%$ un indicador alentador para los socios inversionistas. 
Conclusiones

\section{Conclusiones y Recomendaciones}

La elaboración del plan de negocios realizado para la implementación de una apps para aplicaciones móviles que permita la comunicación real entre padres, colegios y alumnos en el mercado peruano nos ha permitido evaluar e identificar las oportunidades y limitaciones en el entorno del mercado objetivo y poder afirmar la viabilidad del servicio.

a) El entorno macro, por la coyuntura del país favorable, la creciente mejoras en los servicios de educación y la preocupación de los padres por una mejor calidad en la educación contantes nos resulta favorable el entorno económico, político y social

b) Identificamos el mercado objetivo y considerando el continuo crecimiento del uso de teléfonos inteligentes y la continua busca de mejoras en la educación, por lo que podemos afirmar que para el segmento identificado es de gran interés el negocio del servicio de comunicación en línea en la educación a través de una app para aplicaciones móviles.

c) Se identificaron los principales competidores de la industria de TI aplicada a la educación, su tipo y nivel de participación, se ha hallado que el servicio online de comunicación es una oportunidad de negocio que no está cubierta en el mercado y tendrá gran aceptación en el mercado. Si bien este servicio online no será el único por las características que se han definido resulta ser un producto diferenciado.

d) La ingeniería de producto, nos ha permitido identificar que una buena distribución del equipamiento y recursos incide directamente en la mejor calidad en el servicio, por lo que se ha determinado que un proveedor de Hosting Virtual y un soporte post-venta eficiente nos va a ser diferenciar de otros competidores. 
e) La evaluación económica y financiera arrojaron resultados positivos y rentables para el inversionista, con una TIR y tasa de rentabilidad atractiva, por lo que podemos decir el proyecto económicamente es viable.

\section{Recomendaciones}

a) La rápida implementación nos permitiría ser una opción novedosa en el mercado y permitiría posicionarnos como la empresa con un servicio especializado en herramientas de comunicación en línea para la comunidad educativa.

b) Por la amplia variedad de colegios privados en Lima Metropolitana y Callaos deben implementarse estrategias de marketing de acuerdo a las necesidades particulares de cada colegio o grupos de colegios segmentados por cantidad de alumnos para establecer un nivel de precio acorde.

c) Establecer líneas de comunicación efectivas con los clientes, para solución de posibles inconvenientes nos hará tener una diferenciación especial en el mercado.

d) Establecer políticas de actualización de la aplicación en los clientes para que tengan la última versión de la aplicación. 


\section{Índice de gráficos}

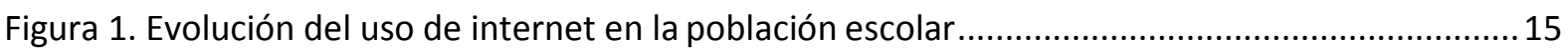

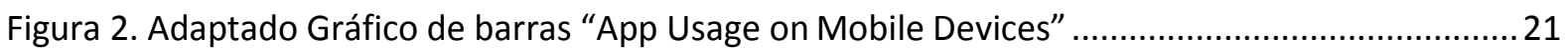

Figura 3. Composición y crecimiento del mercado de software en América Latina .............................24

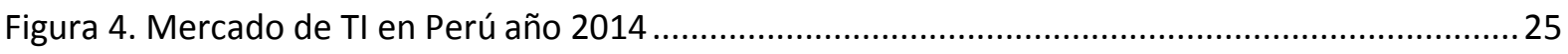

Figura 5. Según Denniss Carranza, gerente de desarrollo de negocios para +1 los rubros que se desarrollan son Retail, Banca, Finanzas, Televisión, Medios de comunicación, Educación y Otros ..... 26

Figura 6. Factores de la Estructura Industrial del Sector............................................................... 30

Figura 7. .Empresas que ofrecen un servicio de cierta manera a fin al que otorga Eduline School. .... 50

Figura 8. Características del servicio que ofrece NetSchool $360^{\circ}$. Recuperado de

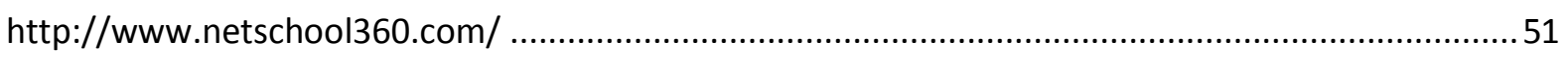

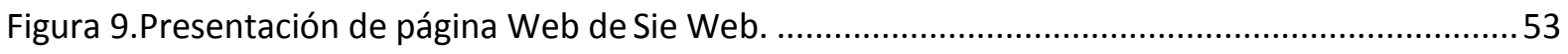

Figura 10.Módulos del servicio otorgado por SieNet ....................................................................5

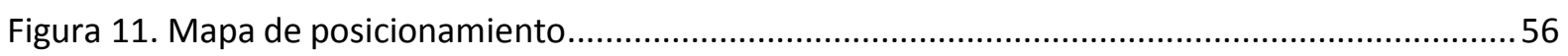

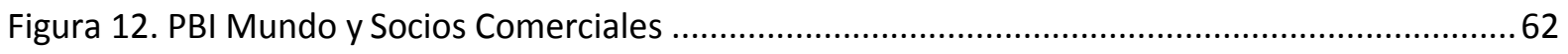

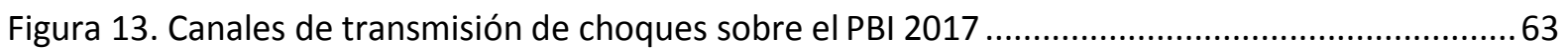

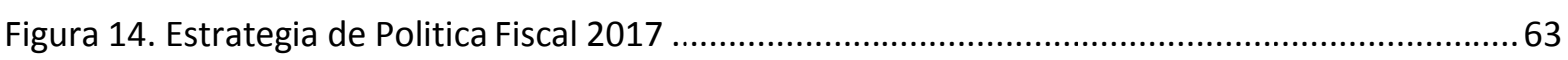

Figura 15. PBI por Sectores. Tomado de "Informe de actualización de proyecciones macroeconómicas," por el Ministerio de Economía y Finanzas MEF, 2017 .........................................65

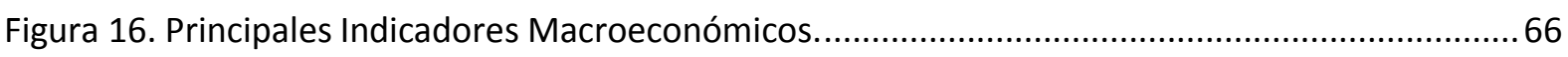

Figura 17. Inflación de alimentos y bebidas y Confianza del consumidor por componentes...............67

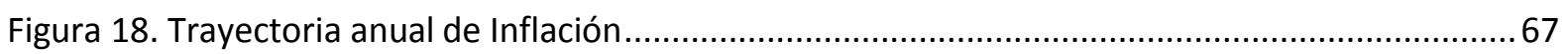

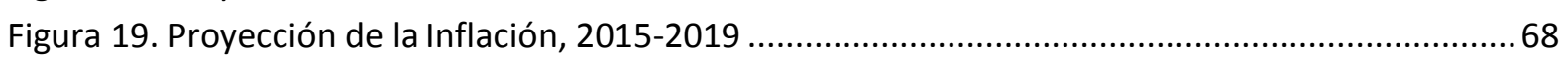

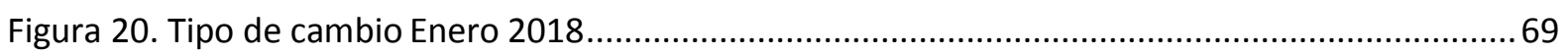

Figura 21. Número de aplicaciones descargadas por usuarios de SmartPhone en el Perú .................. 70

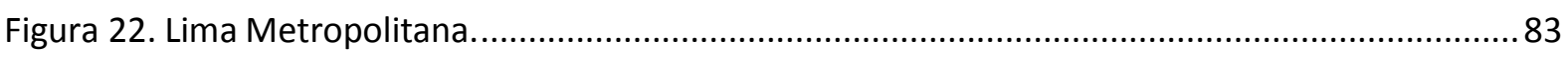

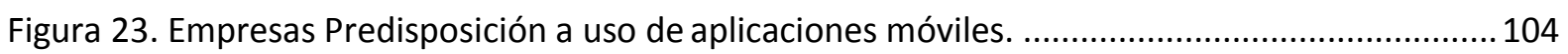

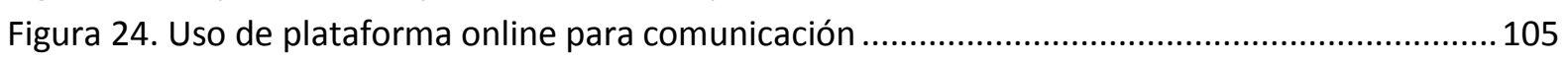

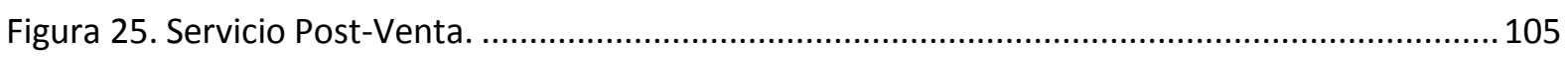

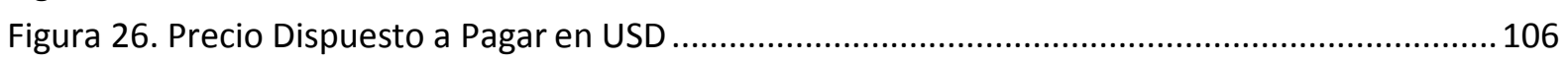

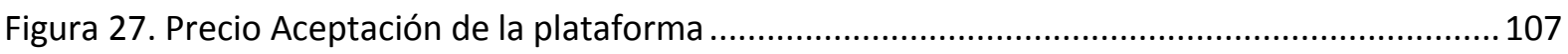

Figura 28. Proceso diseño de software. Adaptado de "Diseñando apps para móviles" por Cuello y

Vittone (2013). Recuperado de https://es.wikipedia.org/wiki/Aplicaci\%C3\%B3n_m\%C3\%B3vil ..... 122

Figura 29. Flujo de actividades proceso Soporte Post Venta......................................................... 125

Figura 30. Flujo de actividades proceso Instalación y personalización de software............................127

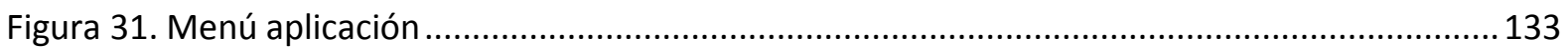

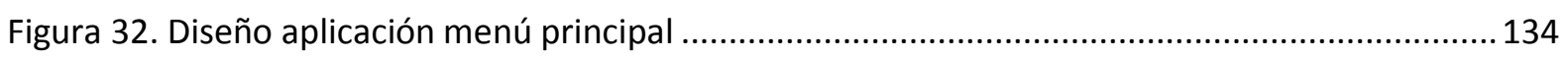

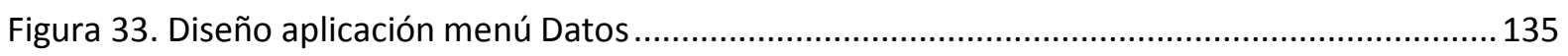

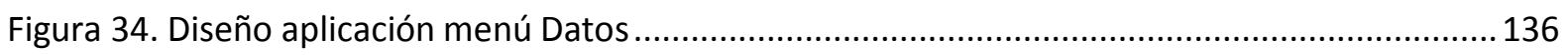

Figura 35. Diseño aplicación menú mensajería, donde se encuentra las mensajes enviados y recibidos

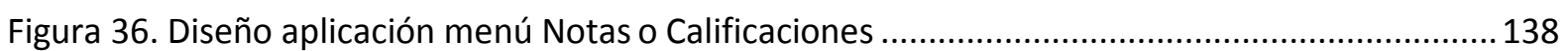

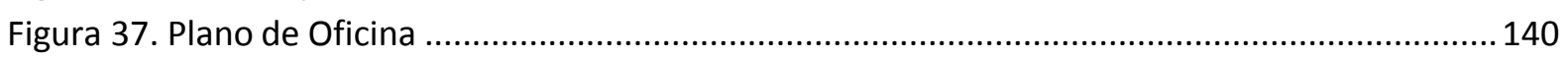




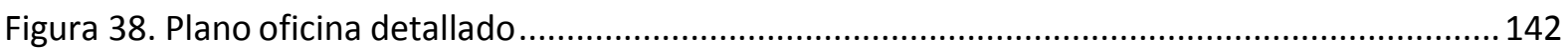

Figura 39. Pasos para crear una organización capaz de ejecutar bien una estrategia. .......................165

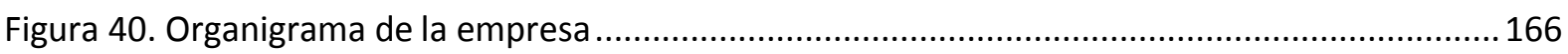

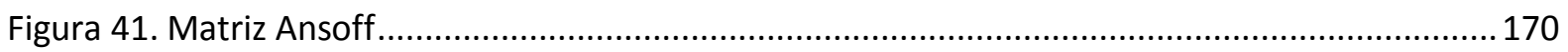

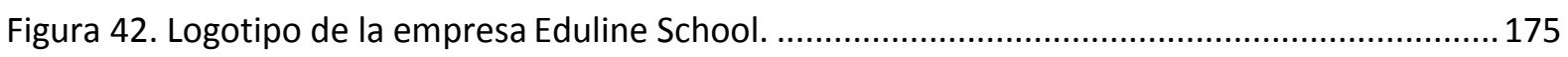

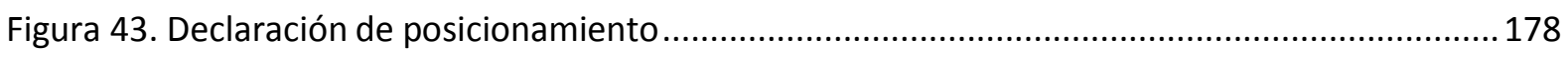

Figura 44. Ejemplos de aplicación de comunicación entre colegio y padres de familia...................... 180

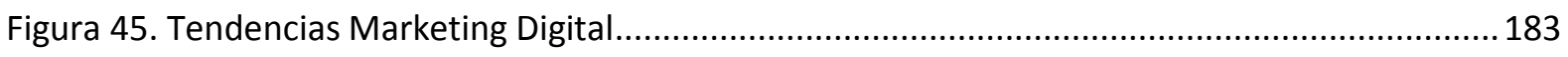

Figura 46. Brochure EdulineSchool. Adaptado de Portal de Xátiva. Recuperado

http://portaldexativa.es/xativa/xativa-el-curso-virtual .............................................................. 185 


\section{Índice de tablas}

Tabla 1 Población que accede a internet de 6 años a más .15

Tabla 2 Crecimiento de mercado de software año 2014 en América Latina ..........................................2 24

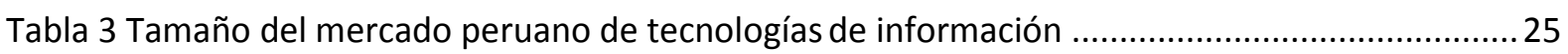

Tabla 4 Principales empresas desarrolladoras de Apps en Perú...........................................................26

Tabla 5 Matriz de Atractividad amenaza de ingreso de nuevos competidores......................................35

Tabla 6 Matriz de Atractividad para la rivalidad entre competidores actuales .................................... 41

Tabla 7 Matriz de Atractividad para la amenaza de productos o servicios sustitutos.......................... 44

Tabla 8 Matriz de Atractividad para el poder de negociación de los clientes ......................................46

Tabla 9 Matriz de Atractividad para el poder de negociación de los proveedores ............................... 48

Tabla 10 Empresas que ofrecen servicio de cierta manera a fin al que otorga Eduline School............ 49

Tabla 11 Semejanzas y diferencias entre la propuesta de servicio y los competidores .......................55

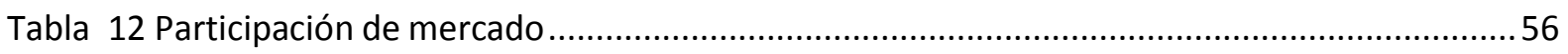

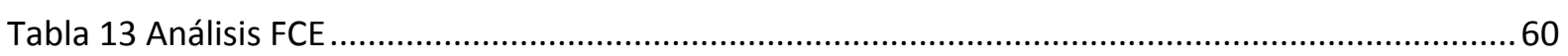

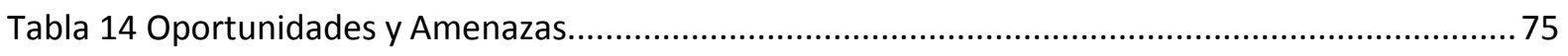

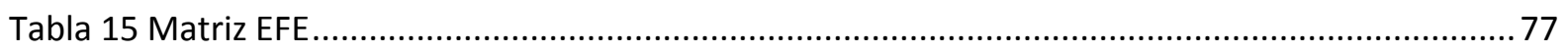

Tabla 16 Colegios privados escolarizados en la Lima Metropolitana y Callao ........................................98

Tabla 18 Muestra de Colegios privados escolarizados en la Lima y Callao Metropolitano .................101

Tabla 19 Distribución de Colegios por distrito y número de alumnos............................................111

Tabla 20 Guía de Aproximaciones de Porcentaje de Participación de Mercado .................................114

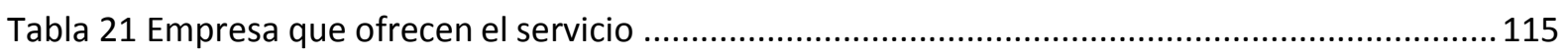

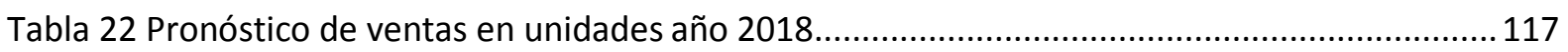

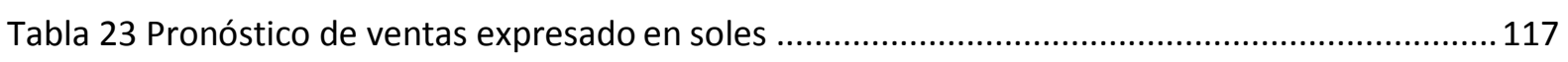

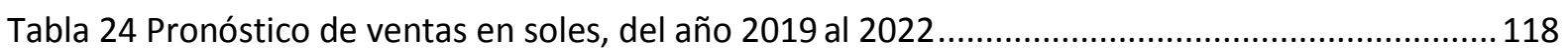

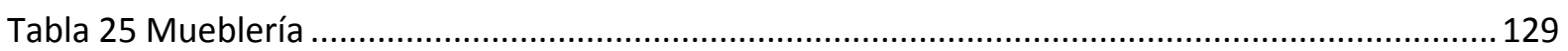

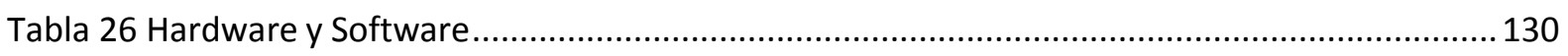

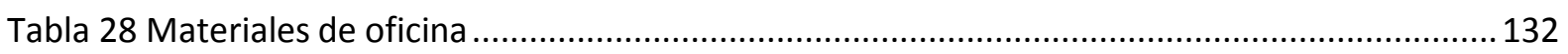

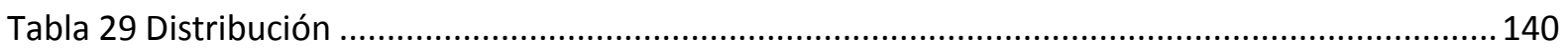

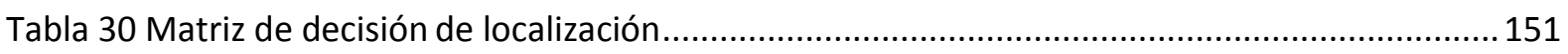

Tabla 31 Sueldo personal ..................................................................... jError! Marcador no definido.

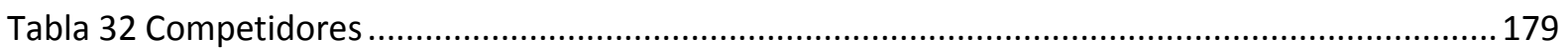

Tabla 33 Inversión Intangible e Inversión Gastos Pre-Operativos montos en Soles sin IGV............... 191

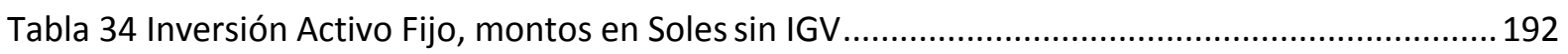

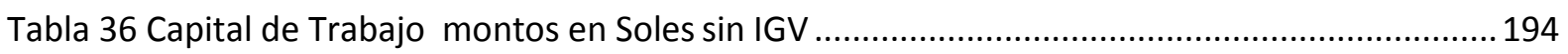

Tabla 37 Estructura de Inversiones, montos en Soles sin IGV .................................................... 194

Tabla 38 Estructura de Flujo de caja mensual del año 2018, expresado en Soles..............................195

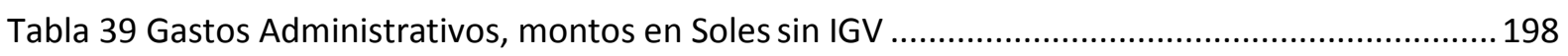

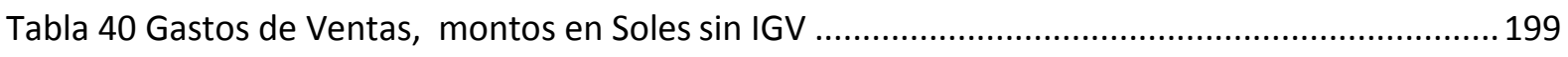

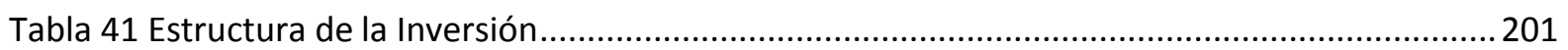

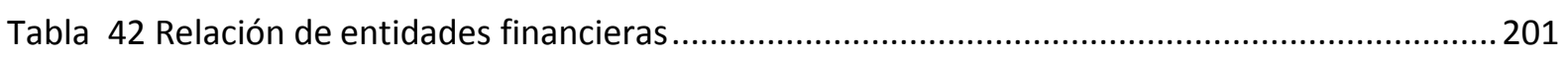

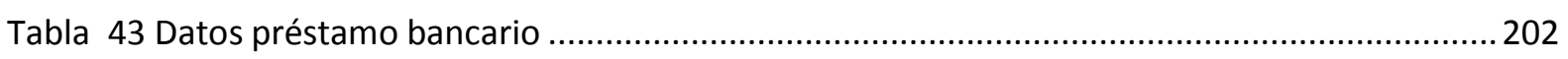

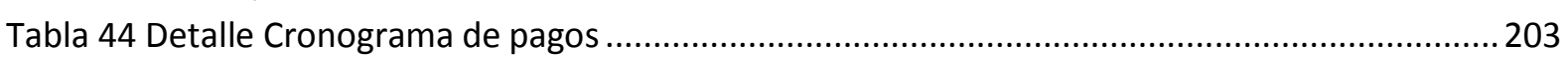

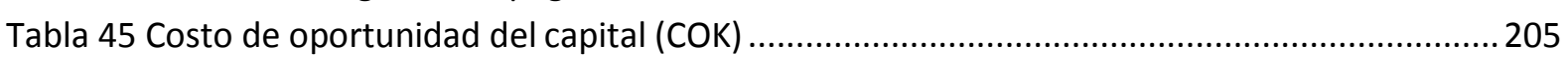




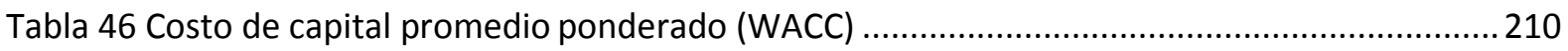

Tabla 47 Detalle de servicios mensuales año 2018 expresado en Unidades.......................................213

Tabla 48 Detalle de servicios anuales del año 2019 al 2022 expresado en Unidades .........................213

Tabla 49 Detalle del precio de venta de la aplicación desde el año 2018 al año 2022 expresado en

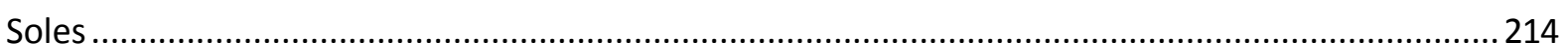

Tabla 50 Detalle de servicios anuales del año 2018 expresado en Soles..............................................214

Tabla 51 Detalle de servicios anuales del año 2019 al 2022 expresado en Soles ..............................215

Tabla 52 Detalle de compras realizadas 2 veces al año, expresado en Soles .....................................217

Tabla 53 Detalle costos de ventas del año 2018 al 2022, expresado en Soles.....................................218

Tabla 54 Detalle costos de administrativos del año 2018 al 2022, expresado en Soles .................... 219

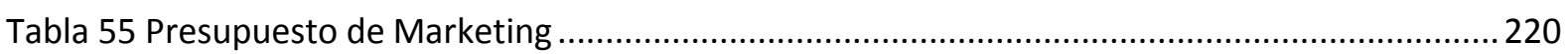

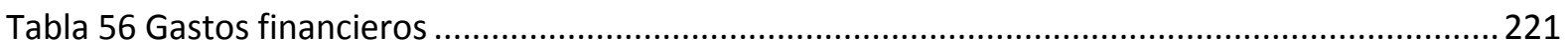

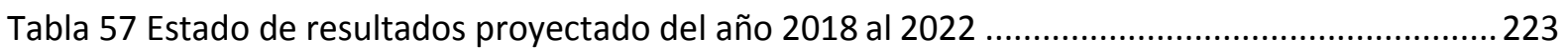

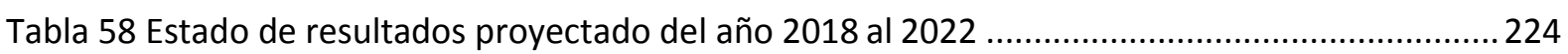

Tabla 59 Detalle ingreso por venta de activos al finalizar el proyecto ..............................................225

Tabla 60 Estado de situacion financiera proyectado, expresado en Soles......................................226

Tabla 61 Flujo de Caja proyectado del año 2018 al 2022, expresado en Soles....................................228

Tabla 62 Liquidación de IGV del año 2018 al 2022, expresado en soles..........................................229

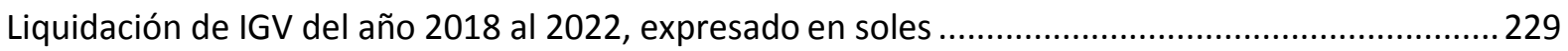

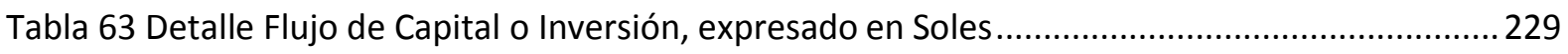

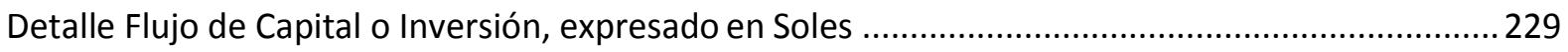

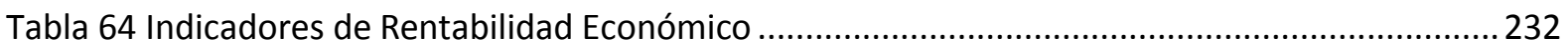

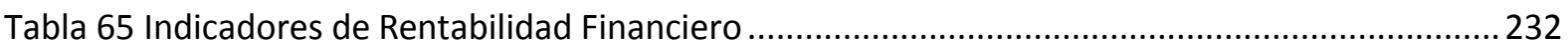

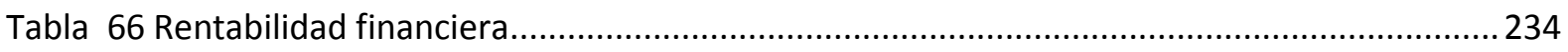

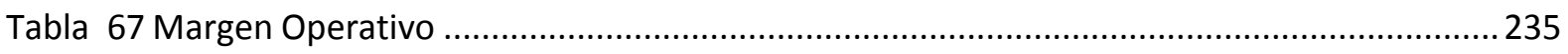

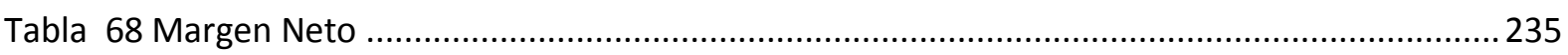

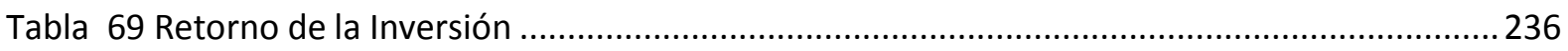

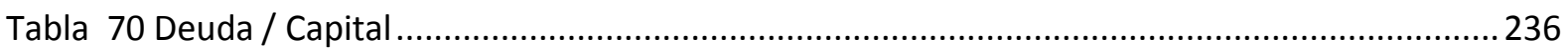

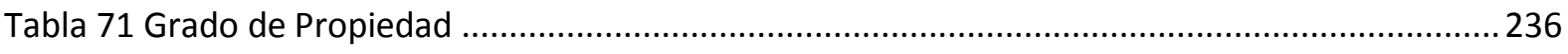

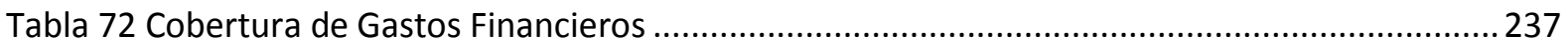

Tabla 73 Análisis Punto de Equilibrio en número de Clientes y en Soles..........................................238

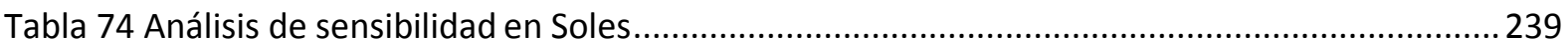

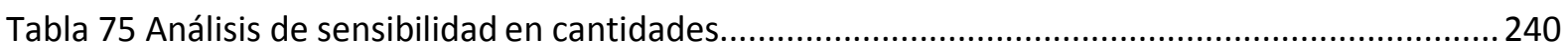

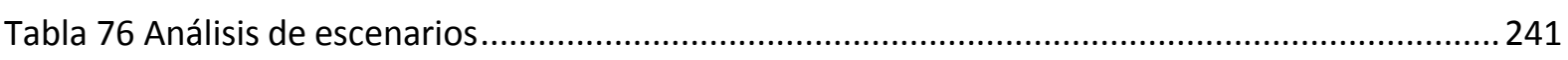

Tabla 77 Probabilidad de éxito, montos expresados en Soles ......................................................... 242 


\section{Anexos}

\section{Anexo $\mathbf{N}^{\circ} 2$}

Requisitos necesarios solicitados por la SUNAT. (Orientacion.sunat.gob.pe, 2017)

a) DNI del representante legal.

b) Ficha o partida electrónica certificada por Registros Públicos con una antigüedad no mayor a 30 días calendario.

c) Cualquier documento privado o público en el que conste una dirección del domicilio fiscal que se declara. (Orientacion.sunat.gob.pe, 2017) 


\section{Anexo N’3}

Requisitos de INDECOPI para la solicitud de registro de marcas de productos y/o servicios. (Pg152) (indecopi.gob.pe/web/signos-distintivos/registro-de-marca-y-otros-signos)

a) Llenar y presentar tres juegos del formato de la solicitud de marcas de productos y/o servicios (2 para la Autoridad y uno para el administrado).

b) Indicar los datos de identificación del(s) solicitante(s):

a. Para personas naturales: indicar el número del Documento Nacional de Identidad (DNI), Carné de Extranjería (CE) Pasaporte y consignar el número del Registro Único de Contribuyente (RUC), de ser necesario.

b. Para personas jurídicas: indicar el número del Registro Único de Contribuyente (RUC), de ser necesario.

c. Si cuenta con un representante, tendrá que consignar sus datos de identificación y será obligado presentar el documento de poder.

c) Indicar su dirección de domicilio para que puedan remitirle notificaciones en el Perú (incluir referencias, de ser necesario)

d) Indicar el signo que tiene intención de registrar (denominativo, mixto, tridimensional, figurativo u otros).

a. Si la marca es mixta, figurativa o tridimensional tendrá que adjuntar su reproducción (tres copias de aproximadamente $5 \mathrm{~cm}$ de largo y $5 \mathrm{~cm}$ de ancho en blanco y negro o a colores si se desea resguardar los colores).

b. Se aconseja enviar una copia exacta del mismo logotipo al correo electrónico: logos-dsd@ indecopi.gob.pe (Formato sugerido: JPG o TIFF, a 300 dpi y bordes entre 1 a 3 pixeles).

c. Indicar expresamente los productos y/o servicios que se desea diferenciar con el signo solicitado, así como la clase y/o clases a la que forman parte. Es 
necesario, entrar al buscador Peruanizado para saber exactamente las clases a las cuáles pertenecen los productos o servicios a diferenciar.

d. En caso de una solicitud multiclase, los productos y/o servicios se deben consignar agrupados por la clase, considerando el número de clase correspondiente de manera precedente y en el orden estipulado por la Clasificación Internacional de Niza.

e. Si se diera el caso de reivindicarse prioridad extranjera sobre la base de una solicitud de registro presentada en otro país, indicarse el número de solicitud cuya prioridad se reivindica, así como el país en la cual se presentó . En esta situación, tendrá que adjuntar copia certificada emitida por la autoridad competente de la primera solicitud de registro, o certificado de la fecha de presentación de esa solicitud, y traducción al español, de ser el necesario.

f. Firmar la solicitud por el solicitante o su representante.

g. Adjuntar la constancia de pago del derecho de trámite, cuyo costo es equivalente al $13.90 \%$ de la Unidad Impositiva Tributaria (UIT) por una clase solicitada, es de S/ 534.99 Soles. El importe podrá pagarse en la sucursal del Banco de la Nación localizado en el Indecopi-Sede Sur, Calle De La Prosa N ${ }^{\circ}$ 104-San Borja, o podrá realizar el pago por medio de una de las modalidades que se especifican. 


\section{Anexo $N^{\circ} 4$}

Se detalla específicamente el tipo de Sociedad elegida. (Proinversion.gob.pe, 2017)

\section{Características De 2 a 20 accionistas.}

Denominación La denominación es seguida de las palabras sociedad anónima cerrada, o de las siglas S.A.C.

Órganos Junta general de accionistas, directorio (opcional) y gerencia

Capital social Aportes en moneda nacional y/o extranjera y en contribuciones tecnológicas intangibles.

Duración Determinado o indeterminado 


\section{Anexo $\mathbf{N}^{\circ} 5$}

Otorgamiento de la licencia de funcionamiento de acuerdo a la Ley $\mathrm{N}^{\circ} 28976$

a) Solicitud de Licencia de Funcionamiento, con carácter de declaración jurada, que incluya:

1. Número de R.U.C. y D.N.I. o Carné de Extranjería del solicitante, tratándose de personas jurídicas o naturales, según corresponda.

2. D.N.I. o Carné de Extranjería del representante legal en caso de personas jurídicas, o tratándose de personas naturales que actúen mediante representación.

b) Vigencia de poder de representante legal, en el caso de personas jurídicas u otros entes colectivos. Tratándose de representación de personas naturales, se requerirá carta poder con firma legalizada.

c) Declaración Jurada de Observancia de Condiciones de Seguridad o Inspección Técnica de Seguridad en Defensa Civil de Detalle o Multidisciplinaria, según corresponda.

d) Adicionalmente, de ser el caso, serán exigibles los siguientes requisitos:

d.1) Copia simple del título profesional en el caso de servicios relacionados con la salud.

d.2) Informar sobre el número de estacionamientos de acuerdo a la normativa vigente, en la Declaración Jurada. 
d.3) Copia simple de la autorización sectorial respectiva en el caso de aquellas actividades que conforme a Ley la requieran de manera previa al otorgamiento de la licencia de funcionamiento.

d.4) Copia simple de la autorización expedida por el Instituto Nacional de Cultura, conforme a la Ley N² 28296, Ley General del Patrimonio Cultural de la Nación. Verificados los requisitos señalados, se procederá al pago de la Tasa a que hace referencia el artículo $15^{\circ}$ de esta Ley. 


\section{Anexo $N^{\circ} 6$}

Se detalla los requisitos que solicita la Municipalidad Distrital de Lince para la gestion de la licencia de funcinamiento para llevar a cabo desarrollo de su actividad económica.

a) Solicitud de licencia de funcionamiento para el desarrollo de actividades económicas en establecimiento.

b) Contar con la vigencia de poder de representante legal, en el caso de personas jurídicas u otros entes colectivos. Tratándose de personas naturales se requerirá carta poder con firma legalizada.

c) Posteriormente, Defensa Civil realizará una inspección técnica a detalle

d) Se exigirán los siguientes requisitos: copia simple del título profesional en caso de servicios relacionados con la salud, copia simple de la autorización respectiva en el caso de aquellas actividades que conforme a Ley la requieran de manera previa al otorgamiento de la autorización.

e) Pago del derecho correspondiente a $\mathrm{S} / 40.70$ soles

Cabe señalar, que por cada $50 \mathrm{~m} 2$ se requiere de un estacionamiento, dentro de los 300mt. Lineales a la redonda del local. 


\section{Anexo No7}

\section{Normas Laborales}

Se detalla información alusiva a las horas extras referida al artículo 9 del Decreto Supremo No. 007-2002-TR.

El trabajo en sobretiempo es voluntario tanto en su otorgamiento como en su realización, sólo es obligatorio en casos justificados por hecho fortuito o de fuerza mayor, que pongan en peligro las personas, los bienes del centro de trabajo o la continuidad de la actividad productiva. La hora extra se entenderá otorgada tácitamente, cuando el trabajador acredite haber laborado en sobretiempo, aún sin autorización expresa del empleador. Cuando el sobretiempo es anterior o posterior a la jornada de trabajo en horario nocturno, la hora extra se calcula en base al valor de la remuneración ordinaria para la jornada nocturna.

Las horas extras se pagan con un recargo a convenir del $25 \%$ adicional del valor hora para las dos primeras horas y un 35\% adicional del valor hora a partir de la tercera hora en adelante.

Se detallará información alusiva al subsidio de maternidad en el siguiente anexo haciendo referencia a la Ley $\mathrm{N}^{\circ}$ 28791Articulo 12

Adicionalmente, la asegurada regular en actividad debe haber tenido vínculo laboral en el mes de la concepción; asimismo, la asegurada de régimen especial y la pescadora y procesadora pesquera artesanal independiente deben haber pagado el aporte del mes de la concepción antes de presentar la solicitud.

Se otorga por 98 días, iniciándose regularmente 49 días antes de la fecha probable de parto, la madre podrá diferir el inicio del descanso con autorización del médico tratante. 
El subsidio se extenderá por 30 días adicionales en caso de parto múltiple o niño con discapacidad.

Se detalla información sobre la Asignación Familiar haciendo alusión a artículos $\mathrm{N}^{\circ} 2$ y $\mathrm{N}^{\circ} 5$ de la ley Ley $\mathrm{N}^{\circ} 25129$.

En el caso de que el hijo al cumplir la mayoría de edad se encuentre efectuando estudios superiores o universitarios, este beneficio se extenderá hasta que termine dichos estudios, hasta un máximo de 6 años posteriores al cumplimiento de dicha mayoría de edad. Referencia: Artículo 2º de la Ley No. 25129.

Los requisitos para tener derecho a percibir la asignación familiar, es tener vínculo laboral vigente y mantener a su cargo uno o más hijos menores de dieciocho años y hasta los veinticuatro si se encuentra cursando estudios superiores o técnicos, en este caso el trabajador deberá comunicar al empleador adjuntando el documento que acredita la minoría de edad o el respectivo certificado de estudios. Referencia: Artículo $5^{\circ}$ del Decreto Supremo No. 035-90-TR.

Información referente a la lactancia considerando el artículo único de la Ley $\mathrm{N}^{\circ} 27403$.

Este permiso podrá ser fraccionado en dos tiempos iguales y será otorgado dentro de su jornada laboral.” De conformidad con el Artículo único de la Ley No 27403 publicada el 20-01-2001 se precisa que la hora diaria de permiso por lactancia materna se considera como efectivamente laborada para todo efecto legal, incluyéndose el goce de la remuneración correspondiente. La madre trabajadora y su empleador podrán convenir el horario en que se ejercerá el derecho establecido en el párrafo precedente. El derecho que por la presente Ley se otorga no podrá ser compensado ni sustituido por ningún otro beneficio. 


\section{Anexo $N^{\circ} 8$}

Se especifican dichos trámites previos que debe de realizar la persona jurídica de acuerdo a SUNAT.

Los trámites que realiza previamente la persona jurídica al inicio de las actividades son:

1. Inscripción en el Registro Único de Contribuyentes - RUC

El representante legal exhibirá:

a) Original de su DNI

b) Original de uno de los siguientes documentos: recibo de agua, telefonía fija, luz, televisión por cable cuya fecha de vencimiento de pago se encuentre comprendida en los últimos dos meses; o la última declaración jurada o autovalúo del local donde funcionará el establecimiento.

c) Original o copia simple del Testimonio de Escritura Pública de Constitución inscrita en los Registros Públicos.

Si el trámite lo realiza una persona autorizada será necesario que muestre su DNI original y, presentare una carta poder con firma legalizada notarialmente o autenticada por fedatario de la SUNAT y los siguientes formularios:

a) Formulario $\mathrm{N}^{\circ}$ 2119: Firmado por el representante legal.

b) Formulario $\mathrm{N}^{\circ}$ 2054: Solicitud de inscripción del Gerente General y los representantes legales de la sociedad, de acuerdo con lo establecido en su Estatuto.

c) Formulario $\mathrm{N}^{\circ}$ 2046: Siempre y cuando tuviera locales adicionales al domicilio fiscal.

2. Autorización de impresión de Comprobantes de Pago. 
Luego que la SUNAT le ha proveído su número de RUC y de la verificación de su domicilio fiscal, solicitará la autorización para imprimir sus comprobantes de pago con el Formulario $\mathrm{N}^{\circ} 806$ en las oficinas de SUNAT o con el Formulario $\mathrm{N}^{\circ} 816$ en las imprentas conectadas en línea y autorizadas por la SUNAT.

Si va a emitir tickets o cintas de máquina registradora, debe solicitar la inscripción de la máquina con el Formulario $\mathrm{N}^{\circ} 809$.

3. Para legalizar los libros de contabilidad

Según el Régimen tributario al cual se haya inscrito, será necesario adquirir y legalizar ante Notario Público o Juez de Paz los libros.

Sunat.gob.pe/institucional/publicaciones/revista_tributemos/tribut100/procedimient 


\section{Anexo No 9}

A continuación lo perfiles del personal que requerirá la empresa

\section{Perfil Gerente General}

Misión: Planificar, Administrar, Gestionar los proyectos externos e internos de la organización de los distintos segmentos de mercado, garantizando el correcto desarrollo del proyecto en tiempos, calidad, costes, funcionalidad y satisfacción del cliente.

Sexo F-M

Profesión Administrador, Ing. Industrial, Ing. Sistemas o

Experiencia afines

tres años en cargos similares

\section{Conocimientos}

Ingles $\quad$ Intermedio

MS Office

Avanzado

Herramientas de Programación

Avanzado

Competencias

Poder de negociación

Visión estratégica

Liderazgo

Planificación y organización

Solución de Problemas

Elevada capacidad de comunicación

Orientación al cliente

Orientación a los objetivos

Capacidad de negociación

Trabajo en equipo

Liderazgo 
Planificar, organizar, dirigir y verificar las labores de la empresa

Captar clientes nuevos

Autorizar las compras a proveedores

Elaborar presupuesto anual 
Perfil Gerente Comercial

Misión: Gestionar los proyectos comerciales externos e internos de la organización de los distintos segmentos de mercado, garantizando el correcto desarrollo del proyecto en tiempos, calidad, costes, funcionalidad y satisfacción del cliente.

Sexo F-M

Profesión Administrador, Ing. Industrial, Ing. Sistemas o

Experiencia afines

tres años en cargos similares

Conocimientos

Ingles $\quad$ Intermedio

MS Office Avanzado

Competencias

Poder de negociación

Liderazgo

Capacidad de relacionarse a todo nivel.

Funciones

Planificar, organizar, dirigir y verificar las labores de la empresa

Captar clientes nuevos

Autorizar las compras a proveedores

Elaborar presupuesto anual 
Perfil Gerente TI

Misión: Gestionar los proyectos externos e internos de la organización de los distintos segmentos de mercado, garantizando el correcto desarrollo del proyecto en tiempos, calidad, costes, funcionalidad y satisfacción del cliente. Reportando en todo momento el estado del proyecto.

Sexo

Profesión

\section{F-M}

Licenciado (a) de las carreras de Ingeniería de Sistemas, Industrial, Electrónica y Administración. Maestría en Proyectos de preferencia. Certificación en PMI

Experiencia tres años en cargos similares

\section{Conocimientos}

Dominio del idioma inglés avanzado

Conocimientos avanzados de ofimática, bases de datos e Internet

Conocimientos funcionales de productos interactivos (e-learning, aplicaciones para marketing interactivo u otro tipo de soluciones tecnológicas en internet).

\section{Competencias}

Visión estratégica

Planificación y organización

Solución de Problemas

Elevada capacidad de comunicación

Orientación al cliente

Orientación a los objetivos

Capacidad de negociación 
Trabajo en equipo

Liderazgo

Funciones

Planificar el proyecto para la correcta consecución del mismo en los plazos establecidos con el cliente.

Preparar y organizar las especificaciones e información del proyecto de manera conveniente y exhaustiva para la posterior comunicación de la misma al equipo de proyecto.

Gestionar los costes del proyecto tanto internos como externos, comunicando las posibles desviaciones.

Servir de eje de comunicación del equipo de trabajo hacia los responsables de la cuenta y viceversa, garantizando la rápida toma de decisiones de manera acertada en caso de desviaciones. 
Perfil Asistente de gerencia

Misión: Recepcionar llamadas relacionadas a reclamos, dar seguimiento a reclamos para luego derivarlos a los analistas. Asimismo, se encargará de la gestión de documentos de las distintas gerencias, administración y arqueo de caja chica y atención al cliente externo.

Sexo F-M

Profesión Universitaria completa de las carreras de Contabilidad, Administración, Ingeniería.

Experiencia dos años en cargos similares

\section{Conocimientos}

Dominio del idioma inglés a nivel avanzado.(fluidez, escritura y lectura)

Conocimientos avanzados de ofimática, bases de datos e Internet

Conocimiento en sistemas, servicio al cliente y demás normas de aplicación para atención al usuario.

\section{Competencias}

Orientación al cliente

Alta capacidad para solución de problemas

Alto nivel de comunicación

Capacidad de negociación

Planificación y Organización

Empatía

\section{Funciones}

Recepción de facturas y Letras de Proveedores, pago de proveedores. (asesoría contable, empresa desarrolladora, empresa de limpieza). Recepción y envío de documentación. 
Recepcionar reclamos (llamadas telefónicas) de parte del cliente. Derivar reclamos a Área de TI. Realizar seguimiento de los reclamos asegurándose de que el cliente logre solucionar su problema. Elaborar el cierre quincenal de caja, arqueos y el informe correspondiente.

Elaborar requerimiento de útiles de oficina. Mantener actualizados controles y archivos variados relacionados con la actividad a su cargo.

Atender al público y evaluar consultas relacionadas con procedimientos de trabajo. 


\section{Perfil del participante}

- Director de colegio

- Experiencia: en puesto de Director de Colegios particulares que posea los dos niveles de educación (Primaria y Secundaria) / Experiencia como docente.

\begin{tabular}{|l|l|}
\hline Nombre & SILVIO CESAR AYLAS GONZALES \\
\hline Edad & 59 años \\
\hline Profesión & Ingeniero Químico y Licenciado en Educación \\
\hline Cargo & Director del Colegio Salesiano Parroquial Don Bosco - Callao \\
\hline Reseña & \\
\hline
\end{tabular}




\section{FICHA TECNICA ENTREVISTA A PROFUNDIDAD: EXPERTOS DEL SECTOR}

\section{Objetivo de la investigación}

El objetivo de este estudio es de nutrirnos de la experiencia de expertos relacionados en el sector educación de nivel primario y secundario sobre la aceptación de una plataforma de comunicación entre padres, alumnos y colegios y el aporte de las Tecnologías de Información y Comunicación TIC en este rubro.

Estamos desarrollando una aplicación para teléfonos móviles inteligentes, que permitirá mejorar la comunicación entre las familias y el colegio. Desde esta aplicación los padres de familia podrán mantenerse informados sobre las actividades del colegio mediante SMS, emails, mensajes internos, avisos. La APP (aplicación móvil) permitirá realizar seguimiento de las tareas, notas de los alumnos, de su asistencia, gestionar citas, bajo un entorno seguro. El producto podrá ser adaptado a las necesidades de la Organización, pudiéndose elegir entre opciones estándar y funcionalidades adicionales. La aplicación será ofrecida mediante la modalidad de pago mensual diferenciada por número de usuarios que incluye su alojamiento en la nube (modelo de almacenamiento de datos basado en redes de computadoras, donde los datos están alojados en espacios de almacenamiento virtualizados), por lo que el colegio no necesita de inversión en infraestructura de hardware y software, mantenimiento y soporte. El servicio post-venta incluirá un servicio de soporte a la plataforma bajo la modalidad 16x5. Finalmente consideramos importante mencionar que nuestra propuesta contribuye a la protección del medio ambiente, reduciendo considerablemente el uso del papel, tinta y/o tóner.

\section{Contenido}

Los temas de interés que deseamos investigar son:

- Conocer la experiencia de los involucrados sobre la importancia de la comunicación entre la comunidad educativa.

- Los aportes que puede hacer las tecnologías de información y comunicación en el sector educación y el mejoramiento de la comunicación.

- Las plataformas de comunicación en educación usadas actualmente con el apoyo de las tecnologías de información TI. 
- La aceptación de una plataforma de comunicación en línea frente a productos que ofrecen una suite completa de gestión educativa.

\section{Cuestionario}

\section{Presentación:}

Buenos días, actualmente nos encontramos realizando una investigación acerca de las tecnologías de información, su aporte y uso como plataforma de comunicación para colegios de nivel primario y secundario. Agradecemos que pueda brindarnos su experiencia la cual significa un gran aporte a nuestro estudio.

A continuación, le haremos unas preguntas que nos permitirán tener mayor información y que ayudarán a esclarecer ciertos temas que consideramos importantes para poder concretar esta investigación. Desde ya le agrademos el apoyo.

Comunidad educativa: compuesto por profesores, APAFA, administración de colegio, padres de familia y alumnos de un determinado colegio.

\section{Pregunta sobre experiencia:}

¿Podría por favor comentarnos acerca de su experiencia en el sector educativo?

TENGO 32 AÑOS EN EL SECTOR EDUCACIÓN, COMO PROFESOR, COORDINADOR, ASESOR Y DIRECTOR DESDE HACE 17 AÑOS, PROMOTOR DE UN COLEGIO PRIVADO Y ASESOR DE COLEGIOS DE OTRAS CONGREGACIONES.

\section{a) Comunicación entre miembros de comunidad educativa}

1. Desde su punto de vista y su experiencia ¿Qué tan importante es para usted establecer comunicación en tiempo real entre la comunidad educativa? 
AHORA ES FUNDAMENTAL, ES NECESARIO, PADRES Y MADRES TRABAJAN Y LA MEJOR FORMA DE COMUNICACIÓN YA NO ES LA AGENDA ESCRITA SINO EL CAMBIO HACIA LA VIRTUALIZACIÓN EN TIEMPO REAL, SIN NECESIDAD DE ENTERARSE DE LAS NOTIFICACIONES RECIEN CUANDO EL ALUMNO LLEGA A CASA.

2. ¿Qué herramientas utiliza actualmente su institución para establecer la comunicación entre la comunidad educativa? ¿Cuáles son esas herramientas?

ESTAMOS UTILIZADO EL SOFTWARE SENSOFT, AHORA LOS SALESIANOS ESTAMOS UTILIZANDO DIFERENTES HERRAMIENTAS, EN AREQUIPA UN INGENIERO AREQUIPEÑO PROVEE AL COLEGIO ROSENTAL DE LA PUENTE DE UNA PLATAFORMA, EN BREÑA, PIURA Y HUANCAYO UTILIZAMOS EL SIEWEB, PERO CUESTA MUCHO PARA EL DON BOSCO DEL CALLAO DEBIDO A QUE NUESTRAS PENSIONES SON MUY COMODAS, POR LO QUE HEMOS DECIDIDO IMPLEMENTAR UNA PLATAFORMA MUY PARECIDA A UN PRECIO MAS ACCESIBLE.

3. ¿Qué barreras usted podría identificar en la actual comunicación entre la comunidad educativa?

LA BARRERA ES QUE LOS PADRES DE FAMILIA, SOBRE TODO LAS MADRES NO ESTAN AL DIA EN TECNOLOGÍA, MANEJAN EL WHATSAPP Y EL FACEBOOK, PERO CUANDO SE TRATA DE OTRAS HERRAMIENTAS MAS ESPECIALIZADAS NO LAS USAN, CREO QUE ES TAMBIEN ALGO PSICOLOGICO, PREFIEREN NO APRENDER PARA EVITAR LA RESPONSABILIDAD.

¿Usted percibe una diferencia en el rendimiento académico de los escolares cuyos padres se involucran en su desarrollo académico?

POR SUPUESTO, HAY TREMENDA DIFERENCIA, PADRE QUE NO SE INVOLUCRA EN EL DESARROLLO ACADEMICO IMPLICA UN ALUMNO QUE RENDIRA A LO QUE EL CREA CONVENIENTE, PERO CUANDO EL PADRE SE INVOLUCRA Y CONOCE EL POTENCIAL DE SU HIJO BUSCA NUEVAS ESPECTATIVAS, SI VEO QUE MI HIJO ES HABIL PARA LAS MATEMATICAS EN VACACIONES LO INSCRIBO EN UN CURSO EN LA UNI, SI UN PADRE NO ES CAPAZ DE 
RECONOCER LAS HABILIDADES DE SUS HIJO POSIBLEMENTE TRATE DE LLENAR SU TIEMPO LIBRE CON OTRAS DICIPLINAS YA QUE NO ESTA INVOLUCRADO EN EL TEMA ACADEMICO. SI EL PADRE SABE QUE SU HIJO ESTA FALLANDO EN ALGO BUSCA UN APOYO, SI EL NO PUEDE, BUSCA UN TERCERO O HERRAMIENTAS. UN ALUMNO PODRIA LLEGAR A RENDIR UN 70\% PERO CON LA AYUDA DE SUS PADRES PODRIA RENDIR UN 110\%. POCOS SON LOS QUE LO LOGRAN SOLOS, NO ES INDISPENSABLE, PERO SI MUY FAVORABLE.

Las tecnologías de la información y comunicación en la educación

4. ¿Considera importante el uso de las Tecnológicas de Información aplicadas en la educación escolar? ¿Por qué?

HOY EN DIA YA NO ES IMPORTANTE, ES FUNDAMENTAL, EL MODELO EDUCATIVO QUE SE ESTA IMPONIENDO EN NUESTRA CURRICULA NACIONAL, EXIGE QUE LAS TICS SEAN TRANSVERSALES EN TODOS LOS CURSOS, YA NO SE PUEDE HABLAR DE UN CURSO DE COMPUTACIÓN EN PRIMARIA, AQUÍ EN NUESTRA REALIDAD AÚN TENEMOS COMPUTACIÓN EN PRIMARIA, POR LA REALIDAD SOCIOECONÓMICA, ES UN COMPLEJO QUE TENEMOS TAMBIEN A NIVEL INSTITUCIÓN QUE NO QUIERE DAR EL PASO. UN PUNTO DEBIL ES QUE NUESTRAS PROFESORAS NO ESTAN CAPACITADAS AÚN EN TEMAS DE TECNOLOGÍA, DE FORMA QUE ELLAS ASUMAN ESE PESO Y NO ESTEN DESARROLLADO UNICAMENTE LOS LIBROS, REPITIENDO LO MISMO SIEMPRE.

5. Actualmente, podría comentarme ¿cuáles son las tecnologías de la información y comunicación que se emplean en su institución?

UTILIZAMOS PRESENTADORES VIRTUALES Y ORGANIZADORES DE INFORMACIÓN COMO POR EJEMPLO EL POWER POINT, EMAZE, PREZI COMO SOFTWARE DE LA WEB 2.0, PERO DEBEMOS PASAR A LA 2.1 Y 2.2, ENTONCES HEMOS PUESTO LA MIRA EN EDUCAPLAY, QUE YA NO CORRESPONDE A LAS TIC SINO A LAS TAC, LAS TAC SON LAS TECNOLOGÍAS DEL APRENDIZAJE Y EL CONOCIMIENTO, PARA LAS ESCUELAS DEBERÍA SER TAC, PARA LA SOCIEDAD TIC, UNA TAC ES COMO ESTAR CON UN PROFESOR, TE HACE PREGUNTAS, TU RELACIONAS, NO SON ESTATICOS, TE DA PAUTAS Y VAS APRENDIENDO 
6. ¿Cómo ve el futuro de las tecnologías de la información y comunicación en la educación?

LAS TIC EN EDUCACION VAN A DESAPARECER PARA ABRIR PASO A LAS TAC. YA NO TIENE SENTIDO HACER TIC'S EN EDUCACIÓN, PODRIAN USARSE A NIVEL DE PADRES DE FAMILIA PARA LA PARTE INFORMATIVA Y COMUNICACIONAL EN CAMBIO LOS CHICOS NECESITAN UTILIZAR LOS RECURSOS TECNOLÓGICOS PARA LAS MATEMATICAS, HERRAMIENTAS PARA APRENDER. POR EJEMPLO.

\section{Plataforma de comunicación en la educación}

7. ¿Actualmente usted conoce o ha tenido alguna experiencia con una herramienta de TI que facilite la comunicación en tiempo real entre los miembros de la comunidad educativa? Detalle su experiencia

CONOZCO EL SIAWEB, EL SIANET Y AHORA EL SENSOFT, LA PLATAFORMA QUE UTILIZA LA UNIVERSIDAD CATOLÍCA (MOODEL) Y LA UNIVERSIDAD CESAR VALLEJO.

La aceptación de una plataforma de comunicación en línea, frente a productos que ofrecen una suite completa de gestión educativa. Leer el siguiente concepto, antes de continuar:

"Si tuviese una plataforma de comunicación, que permita desde su celular Smartphone establecer comunicación en tiempo real entre la comunidad educativa, que sea inmediata y que posibilite obtener información actualizada en relación a avisos, reuniones, mensajes, fotos intercambiadas entre los padres, alumnos, profesores, así como revisar el estado de las notas y asistencias".

8. ¿Qué beneficios y limitaciones implicaría el uso de esta plataforma de comunicación móvil en tiempo real, entre la comunidad educativa?

OPTIMIZA EL SERVICIO, EL SISTEMA DEBE SER NETAMENTE UTILIZANDO LOS TELEFONOS MÓVILES Y ADICIONALMENTE TENER LA OPCION WEB PARA COMPUTADORAS, ACTUALMENTE ES LO INVERSO. 
9. ¿Cuáles son los atributos o características que le gustaría que tenga esta plataforma de comunicación móvil para la comunidad educativa?

PRIMERO SEGURIDAD, LUEGO FLUIDEZ Y POR ULTIMO AMIGABLE, INTUITIVA CON EL TUTORIAL INMERSO, ¿QUE DESEAS HACER?, Y TE MUESTRA LAS OPCIONES

10. ¿Conoce usted de alguna plataforma de comunicación móvil en tiempo real para la comunidad educativa?

MOVIL NO, LAS QUE TE HE MENCIONADO SON WEB PARA USARSE EN PC'S

11. ¿Ustedes usan actualmente una plataforma de comunicación móvil en tiempo real?

SI SIEWEB

MOVIL NO, EL SENSOFT ES WEB PARA PC

12. ¿Qué ventajas y desventajas usted encuentra en esta solución frente a plataformas que ofrecen toda una gestión educativa incluyendo las comunicaciones?

PUEDE SER BUENO PARA INVESTIGAR, PERO PUEDE SER REPRESENTAR UNA PERDIDA DE TIEMPO AL TENER TANTAS OPCIONES, PODRIA SER MAS UTIL AL CENTRO DE EDUCACION SUPERIOR, PODRIAN NO USARSE TODAS LAS OPCIONES, LOS JOVENES NO UTILIZAN LAS BIBLIOTECAS VIRTUALES, POR EJEMPLO.

13. ¿Cree usted desde su experiencia que los colegios estarían dispuestos a adquirir esta plataforma de comunicación? ¿Por qué?

CASI TODOS LOS COLEGIOS TIENEN UNA PLATAFORMA SIMILAR, HACE 15 AÑOS ERA UN MERCADO VIRGEN, POR EJEMPLO, EN MI OTRO COLEGIO DISEÑAMOS NUESTRO PROPIO SISTEMA, PERO LUEGO CAMBIAMOS AL SIAGIE DEL MINISTERIO DE EDUCACION, LA CUAL ES UNA PLATAFORMA INMENSA, PERO NO TENEMOS A TODO EL PERSONAL CAPACITADO PARA SU USO EN TODA SU DIMENSIÓN, POR EJEMPLO, PARA MENSAJERIA Y COMUNICACIÓN NO SE EXPLOTA, SOLO SE USA PARA REGISTRO DE ASISTENCIA Y NOTAS. EL MERCADO ESTA CADA VEZ MAS SOFISTICADO Y COPADO PARA ENTRAR AL MERCADO TIENES QUE BAJAR TUS COSTOS Y OFRECER MAS SERVICIOS. EL 
COSTO VA DESDE 250 A 2,500 SOLES MENSUALES. PARA UN COLEGIO DE 1,200 ALUMNOS PODRIA PAGAR POR UNA PLATAFORMA MAS O MENOS ESTABLE ENTRE 1,500 Y 1,800 SOLES, SI MI PENSION ESTA ENTRE 380 Y 400 SOLES, SI MI PENSION ESTA MAS DE 1,000 PODRIA ADQUIRIR UNA PLATAFORMA MAS COMPLETA CON FOTOS Y OTRAS OPCIONES.

14. ¿En qué medio publicitario prefiere enterarse de la plataforma de comunicación propuesta?

MEDIANTE BROCHURES ENTREGADOS PERSONALMENTE O MEDIANTE LLAMADAS TELEFÓNICAS.

MEDIO DE COMUNICACIÓN MASIVOS, VISUALES, REVISTAS

15. ¿Qué rango de precio mensual estaría dispuesto a invertir? (300 a 400, 401 a 500, 501 a 600, 601 a 700, 701 a más US\$ dólares)

PARA EL DON BOSCO DEL CALLAO NO PODRIA APLICAR A ESE RANGO, TENDRIA QUE SER HASTA 250 SOLES, QUE ES LO QUE ACTUALMENTE PAGAMOS Y ESTO ES DEBIDO A LA RELACIÓN QUE TENEMOS CON LOS DESARROLLADORES DEL SOFTWARE COMO APOYO MUTUO. EL PADRE DE FAMILIA AQUÍ SOLO SE PREOCUPA POR LA PENSION, NO VE MAS ALLA, EL MUNDO SE MUEVE DE FORMA DIFERENTE, PARECEMOS UNA ISLA. A NIVEL CORPORACIÓN DEBERIAMOS YA TENER NUESTRO SALESIAN INFORMATION Y NUESTRA BASE DE DATOS A NIVEL CORPORATIVO, UN SOLO DATA CENTER Y UN SOLO SOPORTE, PERO NO LO VEN AÚN LOS PROMOTORES.

16. ¿Usted estaría dispuesto a adquirir el servicio de plataforma en tiempo real para la comunicación entre familias, colegio y alumnos?

PARA ESTE COLEGIO POR UN TEMA DE COSTOS ME GUSTARIA, PERO CREO QUE NO PODRÍA ADQUIRIRLA, A MENOS QUE EL COSTO MENSUAL SEA DE MAXIMO 250 SOLES. SIN EMBARGO CONSIDERO QUE HAY COLEGIOS QUE SI PAGARIAN PARA DIFERENCIARSE A NIVEL INSTIUCIONAL, ESTO ES LO QUE SE DEBERÍA VENDER, AQUÍ NUESTRA POLITICA ES HACIA LOS MAS NECESITADOS.

SI ESTARIA DISPUESTO. 
17. ¿Quién es el decisor de las inversiones tecnológicas en la institución? ¿Ud. Influye en las decisiones de compra tecnológica?

COMO CUALQUIER EMPRESA SE CONSULTA CON EL DIRECTORIO, LAS

DECISIONES SIMPLES SON DIRECTAS, LAS TECNOLOGICAS SON

CONSULTADAS AL DIRECTORIO

Gracias por su colaboración en nuestro trabajo de investigación. 


\section{Perfil del participante}

- Director de colegio

- Experiencia: en puesto de Director de Colegios particulares que posea los dos niveles de educación (Primaria y Secundaria) / Experiencia como docente.

\begin{tabular}{|l|l|}
\hline Nombre & PAOLA DIAZ \\
\hline Edad & 42 años \\
\hline Profesión & Licenciada en Educación \\
\hline Cargo & Directora del Colegio SS. CC Belén \\
\hline Reseña & Colegio de los Sagrados Corazones Belen ( San Isidro) \\
\hline
\end{tabular}




\section{FICHA TECNICA ENTREVISTA A PROFUNDIDAD: EXPERTOS DEL SECTOR}

\section{Objetivo de la investigación}

El objetivo de este estudio es de nutrirnos de la experiencia de expertos relacionados en el sector educación de nivel primario y secundario sobre la aceptación de una plataforma de comunicación entre padres, alumnos y colegios y el aporte de las Tecnologías de Información y Comunicación TIC en este rubro.

Estamos desarrollando una aplicación para teléfonos móviles inteligentes, que permitirá mejorar la comunicación entre las familias y el colegio. Desde esta aplicación los padres de familia podrán mantenerse informados sobre las actividades del colegio mediante SMS, emails, mensajes internos, avisos. La APP (aplicación móvil) permitirá realizar seguimiento de las tareas, notas de los alumnos, de su asistencia, gestionar citas, bajo un entorno seguro. El producto podrá ser adaptado a las necesidades de la Organización, pudiéndose elegir entre opciones estándar y funcionalidades adicionales. La aplicación será ofrecida mediante la modalidad de pago mensual diferenciada por número de usuarios que incluye su alojamiento en la nube (modelo de almacenamiento de datos basado en redes de computadoras, donde los datos están alojados en espacios de almacenamiento virtualizados), por lo que el colegio no necesita de inversión en infraestructura de hardware y software, mantenimiento y soporte. El servicio post-venta incluirá un servicio de soporte a la plataforma bajo la modalidad 16x5. Finalmente consideramos importante mencionar que nuestra propuesta contribuye a la protección del medio ambiente, reduciendo considerablemente el uso del papel, tinta y/o tóner.

\section{Contenido}

Los temas de interés que deseamos investigar son:

- Conocer la experiencia de los involucrados sobre la importancia de la comunicación entre la comunidad educativa.

- Los aportes que puede hacer las tecnologías de información y comunicación en el sector educación y el mejoramiento de la comunicación.

- Las plataformas de comunicación en educación usadas actualmente con el apoyo de las tecnologías de información TI. 
- La aceptación de una plataforma de comunicación en línea frente a productos que ofrecen una suite completa de gestión educativa.

\section{Cuestionario}

\section{Presentación:}

Buenos días, actualmente nos encontramos realizando una investigación acerca de las tecnologías de información, su aporte y uso como plataforma de comunicación para colegios de nivel primario y secundario. Agradecemos que pueda brindarnos su experiencia la cual significa un gran aporte a nuestro estudio.

A continuación, le haremos unas preguntas que nos permitirán tener mayor información y que ayudarán a esclarecer ciertos temas que consideramos importantes para poder concretar esta investigación. Desde ya le agrademos el apoyo.

Comunidad educativa: compuesto por profesores, APAFA, administración de colegio, padres de familia y alumnos de un determinado colegio.

\section{Pregunta sobre experiencia:}

¿Podría por favor comentarnos acerca de su experiencia en el sector educativo?

TENGO 20 AÑOS DE EXPERIENCIA COMO DOCENTE, EN EL COLEGIO SS.CC BELEN TENGO 7 AÑOS TRABAJANDO COMO COORDINADORA DE PRIMARIA Y ESTE AÑO ASUMIENDO LA DIRECCION DEL COLEGIO.

b) Comunicación entre miembros de comunidad educativa

18. Desde su punto de vista y su experiencia ¿Qué tan importante es para usted establecer comunicación en tiempo real entre la comunidad educativa? 
CONSIDERO IMPORTANTE EL QUE EL COLEGIO HOY EN DIA ESTE EN LA VANGUARDIA CON LA TECNOLOGIA. LA TECNOLOGIA NOS AYUDA A MANTENER UNA COMUNICACIÓN RAPIDA Y DIRECTA CON EL PADRE DE FAMILIA . EL USO DE UNA PLATAFORMA NO SOLO NOS AYUDARIA EN CUANTO A LOS MENSAJES SINO EN LA NOMINA DE MATRICULAS, EN CUANTO A INGRESO DE CALIFICACION, TODO EN LO QUE REFIERE A TEMA DE GESTION TANTO ADMINISTRATIVA COMO LA RELACIO N O CONTACTO QUE TENDRIAMOS QUE TENER CON EL PADRE DE FAMILIA. POR ELLO CONSIDERO IMPORTANTE CONTAR CON ESTE TIPO DE PLATAFORMAS.

19. ¿Qué herramientas utiliza actualmente su institución para establecer la comunicación entre la comunidad educativa? ¿Cuáles son esas herramientas?

NOSOTROS TRABAJAMOS CON INTRANET QUE ES UN SISTEMA INTEGRAL Y EL SERVICIO BASICAMENTE ES DE COMUNICACIÓN CON TODOS LOS MIEMBROS D ELA COMUNIDAD EDUCATIVA. INTRANET ES A TRAVES DE SIEWEB NOS BRINDA EL SERVICIO DE LO QUE ES MENSAJERIA Y LO QUE ES ACADEMICO. LO QUE ES ACADEMICO NOSOTROS A TRAVES DE ESTA PLATAFORMA PODEMOS INGRESAR NOTAS, SACAR PROMEDIOS, TENEMOS EL SERVIICO DE SALUD QUE A TRAVES DEL MESAJE QUE BRINDA LOS ESPECIALISTAS ( PERSONAL DE SALUD) AL PADRE DE FAMILIA LE LLEGA ESA INFORMACION Y TAMBIEN TENEMOS EL TEMA DE LA MENSAJERIA CON LOS PAPAS.

ESTA INFORMACION LE LLEGA AL CORREO .

20. ¿Qué barreras usted podría identificar en la actual comunicación entre la comunidad educativa?

SI BIEN NOSOTROS ESTAMOS A LA VANGUARDIA CON UNA PLATAFORMA QUE ES LA INTRANET , NO TODOS LOS PAPAS LAMENTABLEMENTE INGRESAN A ESTA PPLATAFORMA. ES MAS HACE DOS AÑOS, LES LLEGA A LOS CORREOS PERSONALES DE LOS PADRES DE FAMILIA INVITANDOLOS A REVISAR SU INTRANET. A PESAR DE QUE NOSOTROS PODEMOS BRINDAR ESTE SERVICIO NO TODOS LOS PADRES LLEGAN A VECES A REVISAR DE FORMA 
PERMANENTE ESTE SISTEMA. CONSIDERO QUE NOSOTROS NECESITARIAMOS SACARLE MUCHO MAS PROVECHO A LA PLATAFORMA, HAY HERRAMIENTAS QUE QUIZAS LAS TENEMOS AHÍ Y QUE AUN NO LA UTILIZAMOS.

¿Usted percibe una diferencia en el rendimiento académico de los escolares cuyos padres se involucran en su desarrollo académico?

DEFINITIVAMENTE, YO PIENSO QUE EL TRABAJO ES UN TRABAJO EN EQUIPO, EL COLEGIO Y EL PADRE DE FAMILIA. PARA QUE UN ALUMNO PUEDA SALIR BIEN NECESITA UN ACOMPAÑAMIENTO POR PARTE DE LOS PADRES DE FAMILIA ( PRIMEROS EDUCADORES DE SUS HIJOS) . LA PLATAFORMA SI BINE NOS AYUDA A MANTENER UNA COMUNICACIÓN, YO PIENSO QUE TIENE QUE HABER UN ACOMPAÑAMIENTO PERMANENTE POR PARTE DE LOS PADRES.

Las tecnologías de la información y comunicación en la educación

21. ¿Considera importante el uso de las Tecnológicas de Información aplicadas en la educación escolar? ¿Por qué?

LAS TECNOLOGIAS DE LA INFORMACION AYUDAN MUCHO, ES UNA HERRAMIENTA COMO MAESTROS QUE NOSOTROS UTILIZAMOS PARA PODER TRABAJAR CON LOS ALUMNOS. EL TEMA DE LAS MULTIMEDIA, LAS APLICACIONES, HOY EN DIA TENEMOS MUCHA INFORMACION EN EL USO DE LAS TICS. ES PARA NOSOTROS UNA HERRAMIENTA QUE LA UTILIZAMOS EN EL MOMENTO DE L AMOTIVACION, EN EL PROCESO DE ENSEÑANZA APRENDIZAJE EN NUESTROS ALUMNOS . POR ELLO CADA AULA CUENTA CON UN MULTIMEDIA Y HACEMOS MUCHO ENFASIS EN EL TEMA DE LAS TICS.

22. Actualmente, podría comentarme ¿cuáles son las tecnologías de la información y comunicación que se emplean en su institución?

EL SISTEMA MULTIMEDIA( MULTIMEDIA AUDIOVISUAL) QUE ESTAN FORMA PERMANENTE EN LAS AULAS Y QUE NOSOTROS UTILIZAMOS ESO COMO UN MATERIAL DE REFUERZO Y MOTIVACION PARA NUESTROS ALUMNOS. TENEMOS TAMBIEN ESTA PLATAFORMA ( LA INTRANET) . 
23. ¿Cómo ve el futuro de las tecnologías de la información y comunicación en la educación?

YO PIENSO QUE LAS TICS HOY EN DIA, TENEMOS QUE ESTAR A LA VANGUARDIA Y CADA VEZ TIENEN QUE AYUDARNOS A QUE LA EDUCACION SEA MAS EFECTIVA. NO RESPLAZANDO AL MAESTRO PERO SI QUE SEA UN MEDIO PARA PODERNOS COMUNICAR CON EL PADRE DE FAMILIA Y PODER GENERAR MOTIVACION EN NUESTRAS CLASES Y GENERAL PARA PODER TRABAJAR CON NUESTROS ALUMNOS.

\section{Plataforma de comunicación en la educación}

24. ¿Actualmente usted conoce o ha tenido alguna experiencia con una herramienta de TI que facilite la comunicación en tiempo real entre los miembros de la comunidad educativa? Detalle su experiencia

SI, NOSOTROS TENEMOS EL SIEWEB ( EL INTRANET) PARA NOSOTROS SI ES UNA GRAN AYUDA Y CONSIDERO QUE DE TODAS MANERAS QUE TENDRIAMOS QUE IR MEJORANDOLA E IMPLEMENTANDOLA .

SI HUBIERA UNA PLANTAFORMA QUE SUPERE A LA SIEWEB SI ESTARIA INTERESADA EN CAMBIARLA, TENDRIA QUE VER BIEN CUALES SON LAS CARACTRISTICAS, QUE LOS QUE OFRECE AL COLEGIO Y TENEMOS QUE ESTAR A LA VANGUARDIA DE ESTAR CONECTADOS. EL USO DE LAS REDES SOCIALES NOS AYUDA A CONTACTARNOS CON LOS PADRES DE FAMILIA PERO YO CONSIDERO QUE ESTA PLATAFORMA SI BIEN ES UNA HERRAMIENTA PODRIAMOS MEJORARLA CON OTRAS OPCIONES.

\section{La aceptación de una plataforma de comunicación en línea, frente a productos que} ofrecen una suite completa de gestión educativa. Leer el siguiente concepto, antes de continuar:

"Si tuviese una plataforma de comunicación, que permita desde su celular Smartphone establecer comunicación en tiempo real entre la comunidad educativa, que sea inmediata y que posibilite obtener información actualizada en relación a avisos, 
reuniones, mensajes, fotos intercambiadas entre los padres, alumnos, profesores, así como revisar el estado de las notas y asistencias".

SERIA IDEAL TENER UNA PLATAFORMA DE ESA INDOLE PORQUE NECESITAMOS CONECTARNOS Y ESTAR AL TANTO CON LOS PADRES DE FAMILIA Y TAMBIEN ES NECESARIO QUE TENGAMOS UNA AULA VIRTUAL NO SOLAMENTE PARA PODER TRABAJAR EL TEMA DE MENSAJERIA SINO A TRAVES DE ESTA PLATAFORMA PODER TOMAR EXAMENES , TENER UNA BIBLIOTECA VIRTUAL Y DARLE MUCHO MAS USO A TEMA DE LA TECNOLOGIA . ES MAS HACER LAS CLASES MAS INTERACTIVA, MANDAR POR SKYPE ALGUNAS SESIONES, ALGUNOS TUTORIALES Y SI ES EN UN TELEFONO MOVIL AHÍ NO HABRIA NINGUN TIPO DE EXCUSA QUE NO TENGAN UNA COMPUTADORA.

25. ¿Qué beneficios y limitaciones implicaría el uso de esta plataforma de comunicación móvil en tiempo real, entre la comunidad educativa?

LAS LIMITACIONES QUE ENCUETRO O CONSIDERO QUE SI NOS COMUNICAMOS TODO EL TIEMPO POR ESO MEDIO YA LOS PADRES NO VENDRIAN AL COLEGIO . ENTONCES YO PIENSO QUE HAY MOMENTOS QUE NOSOTROS NECESITAMOS TENER UN ESPACIO CON EL PADRE DE FAMILIA Y NO PODER PERDER ESA COMUNICACIÓN DIRECTA CON EL PAPA. ENTONCES ESTA PLATAFORMA ES UNA HERRAMIENTA QUE NOS AYUDA PERO TAMPOCO NO TE QUITA ESE CONTACTO CON LA COMUNIDAD.

26. ¿Cuáles son los atributos o características que le gustaría que tenga esta plataforma de comunicación móvil para la comunidad educativa?

QUE SEA UNA PLATAFORMA ABIERTA, QUE SE TRABAJE EL TEMA DEL AULA VIRTUAL, QUE PODAMOS REGISTRAR NOTAS , PODAMOS INCLUIR EL TEMA DE LA MATRICULA, QUE PODAMOS TRABAJAR TUTORIALES , DE REPENTE QUE NOS PUEDA AYUDAR CON TEMA DE LOS HORARIOS, QUE NOS AYUDE EN ESTA LABOR. 
27. ¿Conoce usted de alguna plataforma de comunicación móvil en tiempo real para la comunidad educativa?

LA UNICA QUE CONOZCO ES LA SIEWEB QUE SI NOS LLEGA LOS MENSAJES AL TELEFONO MOVIL PERO NO LOS PODEMOS ABRIR SOLO NOS SEÑALA UNA ALERTA PERO CONSIDERO QUE TODAVIA SE DEBE TRABAJAR MAS EN SU TOTALIDAD. SI LES LLEGA LOS MENSAJITOS PERO NO PODEMOS RESPONDER POR MEDIO DE ESE MEDIO SOLO NOS MANDA MENSAJE DE ALERTA.

28. ¿Ustedes usan actualmente una plataforma de comunicación móvil en tiempo real?

\section{SI SIEWEB}

"Plataformas de gestión educativa completa: plataformas que incluyen funcionalidades como aula virtual, biblioteca en línea, agenda inteligente, matricula, gestión de notas, personalizar barra de herramientas".

29. ¿Qué ventajas y desventajas usted encuentra en esta solución frente a plataformas que ofrecen toda una gestión educativa incluyendo las comunicaciones?

COMO VENTAJA QUE NOS FACILITA UNA COMUNICACIÓN MAS RAPIDA Y DIRECTA CON EL PADRE DE FAMILIA, QUE NOS AYUDA Y AGILIZA ESTE TIPO DE PROCEDIMIENTO (NOTAS, ASISTENCIA, HORARIOS) , COMPARTIR BIBLIOTECA VIRTUAL Y LAS LIMITACIONES DE ESTA PLATAFORMA YO PIENSO

UNA PLATAFORMA MAS INTEGRAL SE PODRIA AÑADIR MAS COSAS ( TUTORIALES, EXAMENES, BIBLIOTECA VIRTUAL, TENER COMUNICACIÓN POR EL SKYPE ) ( SERIA MAS COMPLETA]) EN EL SIEWEB SOLO SE TRABAJA CON EL INTRANET ( MUY LIMITADA.

30. ¿Cree usted desde su experiencia que los colegios estarían dispuestos a adquirir esta plataforma de comunicación? ¿Por qué?

SI , PORQUE TENEMOS QUE ESTAR MAS ACTUALIZADO. HOY EN DIA LA EDUCACION TIENE QUE ESTAR ACUTALIZADA Y TIENE QUE ESTAR A LA PAR CON TODO ESTE TEMA DE LA CONECTIVIDAD. ENTONCES NO PODEMOS 
ESTAR AJENOS A ESTO, YO PIENSO QUE LAS TICS NOS AYUDAN MUCHO A NOSOTROS Y ES UNA HERRAMIENTA PARA OPTIMIZAR NUESTRO TRABAJO Y MANTENER UNA COMUNICACIÓN MUCHO MAS RAPIDA Y DIRECTA CON EL PADRE DE FAMILIA.

31. ¿En qué medio publicitario prefiere enterarse de la plataforma de comunicación propuesta?

MEDIO DE COMUNICACIÓN MASIVOS, VISUALES, REVISTAS

32. ¿Qué rango de precio mensual estaría dispuesto a invertir? (300 a 400, 401 a 500, 501 a 600, 601 a 700, 701 a más US\$ dólares)

600 A 700 DOLARES. EL SIEWEB ESTA ENTRE 500 Y 600

33. ¿Usted estaría dispuesto a adquirir el servicio de plataforma en tiempo real para la comunicación entre familias, colegio y alumnos?

SI ESTARIA DISPUESTO.

34. ¿Quién es el decisor de las inversiones tecnológicas en la institución? ¿Ud. Influye en las decisiones de compra tecnológica?

NOSOTROS DECIDIMOS EN EL CONSEJO ADMINISTRATIVO QUE ESTA COMPUESTO POR MI PERSONA, MADRE ASESORA, MADRE PROMOTORA Y PROMOTORA. SI INFLUYO EN LAS DECISIONES DE COMPRA TECNOLOGICA.

Gracias por su colaboración en nuestro trabajo de investigación. 


\section{Perfil del participante}

- Director de colegio

- Experiencia: en puesto de Director de Colegios particulares que posea los dos niveles de educación (Primaria y Secundaria) / Experiencia como docente.

\begin{tabular}{|l|l|}
\hline Nombre & Guido Andrade Arangüena \\
\hline Edad & 59 años \\
\hline Profesión & Psicólogo con especialización en psicología educativa \\
\hline Cargo & $\begin{array}{l}\text { Director nivel secundaria } \\
\text { Reseña }\end{array}$ \\
$\begin{array}{l}\text { Trilce La Molina, Nivel Secundaria. Avenida Javier Prado } 5840 \\
\text { La Molina }\end{array}$ \\
\hline
\end{tabular}




\section{FICHA TECNICA ENTREVISTA A PROFUNDIDAD: EXPERTOS DEL SECTOR}

\section{Objetivo de la investigación}

El objetivo de este estudio es de nutrirnos de la experiencia de expertos relacionados en el sector educación de nivel primario y secundario sobre la aceptación de una plataforma de comunicación entre padres, alumnos y colegios y el aporte de las Tecnologías de Información y Comunicación TIC en este rubro.

Estamos desarrollando una aplicación para teléfonos móviles inteligentes, que permitirá mejorar la comunicación entre las familias y el colegio. Desde esta aplicación los padres de familia podrán mantenerse informados sobre las actividades del colegio mediante SMS, emails, mensajes internos, avisos. La APP (aplicación móvil) permitirá realizar seguimiento de las tareas, notas de los alumnos, de su asistencia, gestionar citas, bajo un entorno seguro. El producto podrá ser adaptado a las necesidades de la Organización, pudiéndose elegir entre opciones estándar y funcionalidades adicionales. La aplicación será ofrecida mediante la modalidad de pago mensual diferenciada por número de usuarios que incluye su alojamiento en la nube (modelo de almacenamiento de datos basado en redes de computadoras, donde los datos están alojados en espacios de almacenamiento virtualizados), por lo que el colegio no necesita de inversión en infraestructura de hardware y software, mantenimiento y soporte. El servicio post-venta incluirá un servicio de soporte a la plataforma bajo la modalidad 16x5. Finalmente consideramos importante mencionar que nuestra propuesta contribuye a la protección del medio ambiente, reduciendo considerablemente el uso del papel, tinta y/o tóner.

\section{Contenido}

Los temas de interés que deseamos investigar son:

- Conocer la experiencia de los involucrados sobre la importancia de la comunicación entre la comunidad educativa.

- Los aportes que puede hacer las tecnologías de información y comunicación en el sector educación y el mejoramiento de la comunicación.

- Las plataformas de comunicación en educación usadas actualmente con el apoyo de las tecnologías de información TI. 
- La aceptación de una plataforma de comunicación en línea frente a productos que ofrecen una suite completa de gestión educativa.

\section{Cuestionario}

\section{Presentación:}

Buenos días, actualmente nos encontramos realizando una investigación acerca de las tecnologías de información, su aporte y uso como plataforma de comunicación para colegios de nivel primario y secundario. Agradecemos que pueda brindarnos su experiencia la cual significa un gran aporte a nuestro estudio.

A continuación, le haremos unas preguntas que nos permitirán tener mayor información y que ayudarán a esclarecer ciertos temas que consideramos importantes para poder concretar esta investigación. Desde ya le agrademos el apoyo.

Comunidad educativa: compuesto por profesores, APAFA, administración de colegio, padres de familia y alumnos de un determinado colegio.

\section{Pregunta sobre experiencia:}

¿Podría por favor comentarnos acerca de su experiencia en el sector educativo?

SOY PSICÓLOGO, CON ESPECIALIDAD EN PSICOLOGÍA EDUCATIVA, SIEMPRE HE TRABAJADO EN EL SECTOR EDUCACIÓN DESDE EL AÑO 1989, ESTOY A CARGO DE LA DIRECCIÓN DEL NIVEL SECUNDARIO DEL COLEGIO TRILCE LA MOLINA HACE 13 AÑOS.

\section{c) Comunicación entre miembros de comunidad educativa}

35. Desde su punto de vista y su experiencia ¿Qué tan importante es para usted establecer comunicación en tiempo real entre la comunidad educativa? 
MUY IMPORTANTE ES LA COMUNICACIÓN EN TODO NIVEL, VERBAL, ESCRITO, TELEFONICO, VIA AGENDA.

36. ¿Qué herramientas utiliza actualmente su institución para establecer la comunicación entre la comunidad educativa? ¿Cuáles son esas herramientas?

PARA USO INTERNO ADMINISTRATIVO SE USA EL CORREO ELECTRONICO, PARA LA COMUNICACIÓN DEL DIA A DIA CON LOS PADRES EN VIA AGENDA, Y PARA LA COMUNICACIÓN A NIVEL DE TODO SECUNDARIA EL FACEBOOK

37. ¿Qué barreras usted podría identificar en la actual comunicación entre la comunidad educativa?

BARRERA DE INDOLE GENERACIONAL, LOS ESTUDIANTES DE SECUNDARIA EN SU MAYORIA MANEJAN UN TELEFONO CON REDES SOCIALES, LOS ASISTENTES DE ACULA TAMBIEN, PERO NO NECESARIAMENTE PASA ESTO CON LOS PROFESORES

38. ¿Usted percibe una diferencia en el rendimiento académico de los escolares cuyos padres se involucran en su desarrollo académico?

NO AL 100\% PERO UN ALTO PORCENTAJE DE ALUMNOS CUYOS PADRES ESTAN AL TANTO DE LA AGENDA, REUNIONES Y TAREAS DE SUS HIJOS TIENEN UN MAYOR RENDIMIENTO

Las tecnologías de la información y comunicación en la educación

39. ¿Considera importante el uso de las Tecnológicas de Información aplicadas en la educación escolar? ¿Por qué?

SI PORQUE TODO ALUMNO DEBE MANEJAR HERRAMIENTAS DE TECNOLOGIA COMO OFFICE O PROGRAMAS QUE LE AYUDEN AL DESARROLLO DE SUS ASIGNATURAS, TRABAJOS GRUPALES, INVESTIGACIONES, ETC.

40. Actualmente, podría comentarme ¿cuáles son las tecnologías de la información y comunicación que se emplean en su institución? 
CONTAMOS CON 02 LABORATORIOS DE COMPUTO DONDE LOS ALUMNOS LLEVAN 03 HORAS ACADEMICAS DE CLASE A LA SEMANA DE

41. ¿Cómo ve el futuro de las tecnologías de la información y comunicación en la educación?

EL FUTURO EN EL PERU LO VEO COMO EN LOS PAISES DEL PRIMER MUNDO, LO QUE NO SE SABE CUANDO SUCEDERA ESTO, EN EL MINISTERIO DE EDUCACION ESTA PLANIFICADO QUE EN 05 AÑOS SE SUPERE LA ENORME BRECHA QIE EXISTE Y ESTO DESDE LOS MAESTROS. EN LAS INSTITUCIONES PRIVADAS COMO LA QUE DIRIJO ESTO ES MÁS INMEDIATO, DESDE HACE 03 AÑOS TODAS LA CORPORACION TRILCE ENTREGA A CADA ALUMNO DEL NIVEL SECUNDARIO UNA TABLET CON TODO EL MATERIAL QUE SE USARA EN EL AÑO ESCOLAR, ESTO PERMITE AL ALUMNO DESARROLLAR SUS HABILIDADES CON LAS HERRAMIENTAS TECNOLOGICAS, NO ES UNA NOVEDAD SI NO UNA HERRAMIENTA MÁS COMO EL CUADERNO O EL LAPICERO.

Plataforma de comunicación en la educación

42. ¿Actualmente usted conoce o ha tenido alguna experiencia con una herramienta de TI que facilite la comunicación en tiempo real entre los miembros de la comunidad educativa?

NO, SOLO LA PAGINA OFICIAL EN FACEBOOK, PERO NO ESTA EN TIEMPO REAL, TENEMOS EN NUESTRA PAGINA WEB PUBLICADO LA CALENDARIZACIÓN DEL AÑO ESCOLAR Y OTROS TEMAS DE INTERES DE LOS ALUMNOS Y PADRES DE FAMILIA

43. Detalle su experiencia

La aceptación de una plataforma de comunicación en línea, frente a productos que ofrecen una suite completa de gestión educativa. Leer el siguiente concepto, antes de continuar: 
"Si tuviese una plataforma de comunicación, que permita desde su celular Smartphone establecer comunicación en tiempo real entre la comunidad educativa, que sea inmediata y que posibilite obtener información actualizada en relación a avisos, reuniones, mensajes, fotos intercambiadas entre los padres, alumnos, profesores, así como revisar el estado de las notas y asistencias”.

44. ¿Qué beneficios y limitaciones implicaría el uso de esta plataforma de comunicación móvil en tiempo real, entre la comunidad educativa?

LOS BENEFICIOS ESTARIAN EN EL MEJOR CONTROL DE LSO ALUMONSO DE PARTE DE SUS PADRES, EL MAESTRO Y LOS PADRES TRABAJARIAN EN EQUIPO. LAS LIMITACIONES ESTARIAN EN LAS FACILIDADES DEL INTERNET O DEL LOS TELEFONOS INTELIGENTES AL ALCANCE DE LOS PORFESORES

45. ¿Cuáles son los atributos o características que le gustaría que tenga esta plataforma de comunicación móvil para la comunidad educativa?

USARLO COMO UNA AGENDA ELECTRONICA, QUE SEA FACIL DE MANEJAR

46. ¿Conoce usted de alguna plataforma de comunicación móvil en tiempo real para la comunidad educativa?

SOLO COMUNICACIÓN NO. HAY PROGRAMAS PILOTOS EN OTROS TRILCE QUE ESTAN USANDO LA APLICACIÓN DEL WHATSAPP , INTRANET PARA LA COMUNICACIÓN ENTRE MAESTROS, PADRES DE FAMILIA Y ALUMNOS

47. ¿Ustedes usan actualmente una plataforma de comunicación móvil en tiempo real?

"Plataformas de gestión educativa completa: plataformas que incluyen funcionalidades como aula virtual, biblioteca en línea, agenda inteligente, matricula, gestión de notas, personalizar barra de herramientas".

NO

48. ¿Qué ventajas y desventajas usted encuentra en esta solución frente a plataformas que ofrecen toda una gestión educativa incluyendo las comunicaciones? 
LA VENTAJA SERIA QUE LAS PREGUNTAS, CONSULTAS Y LAS REPUSTAS

LLEGUEN A SU DESTINO EN EL TIEMPO MAS CORT. DESVENTAJAS EN

NUESTRO CASO NO TENEMOS UNA PERSONA DEDICADA TODO EL TIEMPO A

ELLO, PODRIAMOS ASIGNARLE LA TAREA A LAS SEÑORITAS DEL COUNTER

DE RECEPCION.

49. ¿Cree usted desde su experiencia que los colegios estarían dispuestos a adquirir esta plataforma de comunicación? ¿Por qué?

SI, ESO DEPENDE DEL ALCANCE DEL PRODUCTO, EL PRECIO Y EL ANALISIS BENEFICIO Y COSTO QUE DEBERIAMOS ESTUDIAR

50. ¿En qué medio publicitario prefiere enterarse de la plataforma de comunicación propuesta?

EN LAS REDES SOCIALES

51. ¿Qué rango de precio mensual estaría dispuesto a invertir? (300 a 400, 401 a 500, 501 a 600, 601 a 700, 701 a más US\$ dólares)

DE 400 A500

52. ¿Usted estaría dispuesto a adquirir el servicio de plataforma en tiempo real para la comunicación entre familias, colegio y alumnos?

SI AUNQUE EL COLEGIO SIEMPRE EVALUA VARIAS OPCIONES DEL MERCADO

53. ¿Quién es el decisor de las inversiones tecnológicas en la institución? ¿Ud. Influye en las decisiones de compra tecnológica?

LAS GRANDES DECISIONES ESTAN A CARGO DE ING. JULIO RIVERO EL ESTA A CARGO DE LOS COLEGIOS DE LA MOLINA, SANTA ANITA, SALAMANCA, TRUJILO Y PIURA. TODOS LOS DIRECTORES INFLUIMOS EN LAS DECISONES PERO NO HAY UNA CABEZA QUE TIENE LA ULTIMA PALABRA.

Gracias por su colaboración en nuestro trabajo de investigación. 


\section{Perfil del participante}

- Director de colegio

- Experiencia: en puesto de Director de Colegios particulares que posea los dos niveles de educación (Primaria y Secundaria) / Experiencia como docente.

\begin{tabular}{|l|l|}
\hline Nombre & María Esther Tapia Rivera \\
\hline Edad & 45 años \\
\hline Profesión & $\begin{array}{l}\text { Administradora con Postgrado en Administración de la Educación, } \\
\text { (especialización de gerencia, administración y dirección para } \\
\text { orientar a las instituciones hacia el logro de la calidad, } \\
\text { estableciendo un sistema de gestión de calidad basado en la } \\
\text { planificación e investigación). }\end{array}$ \\
\hline Cargo & Directora \\
\hline Reseña & $\begin{array}{l}\text { Colegio Corazón Inmaculado de María, Educación Primaria } \\
\text { Avenida Santa Teodosio 333 Lima }\end{array}$ \\
\hline
\end{tabular}




\section{FICHA TECNICA ENTREVISTA A PROFUNDIDAD: EXPERTOS DEL SECTOR EDUCACION}

\section{Objetivo de la investigación}

El objetivo de este estudio es de nutrirnos de la experiencia de expertos relacionados en el sector educación de nivel primario y secundario sobre la aceptación de una plataforma de comunicación entre padres, alumnos y colegios y el aporte de las Tecnologías de Información y Comunicación (TIC) en este rubro.

Estamos desarrollando una aplicación para teléfonos móviles inteligentes, que permitirá mejorar la comunicación entre las familias y el colegio. Desde esta aplicación los padres de familia podrán mantenerse informados sobre las actividades del colegio mediante SMS, emails, mensajes internos, avisos. La APP (aplicación móvil) permitirá realizar seguimiento de las tareas, notas de los alumnos, de su asistencia, gestionar citas, bajo un entorno seguro. El producto podrá ser adaptado a las necesidades de la Organización, pudiéndose elegir entre opciones estándar y funcionalidades adicionales. La aplicación será ofrecida mediante la modalidad de pago mensual diferenciada por número de usuarios que incluye su alojamiento en la nube (modelo de almacenamiento de datos basado en redes de computadoras, donde los datos están alojados en espacios de almacenamiento virtualizados), por lo que el colegio no necesita de inversión en infraestructura de hardware y software, mantenimiento y soporte. El servicio post-venta incluirá un servicio de soporte a la plataforma bajo la modalidad 16x5. Finalmente consideramos importante mencionar que nuestra propuesta contribuye a la protección del medio ambiente, reduciendo considerablemente el uso del papel, tinta y/o tóner.

\section{Contenido}

Los temas de interés que deseamos investigar son:

- Conocer la experiencia de los involucrados sobre la importancia de la comunicación entre la comunidad educativa.

- Los aportes que puede hacer las tecnologías de información y comunicación TIC en el sector educación y el mejoramiento de la comunicación.

- Las plataformas de comunicación en educación usadas actualmente con el apoyo de las tecnologías de información TI.

- La aceptación de una plataforma de comunicación en línea frente a productos que ofrecen una suite completa de gestión educativa. 


\section{Cuestionario}

\section{Presentación:}

Buenos días, actualmente nos encontramos realizando una investigación acerca de las tecnologías de información, su aporte y uso como plataforma de comunicación para colegios de nivel primario y secundario. Agradecemos que pueda brindarnos su experiencia la cual significa un gran aporte a nuestro estudio.

A continuación, le haremos unas preguntas que nos permitirán tener mayor información y que ayudarán a esclarecer ciertos temas que consideramos importantes para poder concretar esta investigación. Desde ya le agrademos el apoyo.

Comunidad educativa: compuesto por profesores, APAFA, administración de colegio, padres de familia y alumnos de un determinado colegio.

Pregunta de control/verificación de experiencia:

¿Podría por favor comentarnos acerca de su experiencia en el sector educativo?

Trabajo hace 12 años en el colegio Corazón Inmaculado de María, cuatro años como docente y 8 como directora. Adicionalmente dentro del estudio de la Maestría en Administración de la Educación se investigaron v confeccionaron numerosos provectos destinados a la productividad (auto generación de ingresos) v a la comunicación dentro de la comunidad educativa.

d) Comunicación entre miembros de comunidad educativa

54. Desde su punto de vista y su experiencia ¿Qué tan importante es para usted establecer comunicación en tiempo real entre la comunidad educativa?

\section{$\underline{\text { Muv importante }}$}


55. ¿Qué herramientas utiliza actualmente su institución para establecer la comunicación entre la comunidad educativa? ¿Cuáles son esas herramientas?

\section{$\underline{\text { Actualmente ninguna }}$}

56. ¿Qué barreras usted podría identificar en la actual comunicación entre la comunidad educativa?

\section{Falta de expertos en la creación de TIC}

\section{Directores con pocos conocimientos sobre el tema IT}

57. ¿Usted percibe una diferencia en el rendimiento académico de los escolares cuyos padres se involucran en su desarrollo académico?

\section{$\underline{\text { Totalmente }}$}

\section{e) Las TIC en la educación}

58. ¿Considera importante el uso de las Tecnológicas de Información aplicadas en la educación escolar? ¿Por qué?

Muv importante porque es de respuesta rápida, muv dinámico para poder tener mucha comunicación con la institución educativa.

59. Actualmente, podría comentarme ¿Cuáles son las TIC que se emplean en su institución?

\section{Actualmente ninguna}

60. ¿Cómo ve el futuro de las TIC en la educación?

Como una realidad de uso común, al parecer en los colegios de las ciudades esto se usará en un primer momento y los colegios de zonas rurales tendrán poco 
acceso, con muchas limitaciones para poder implementar de manera adecuada una plataforma virtual, por ejemplo.

f) Plataforma de comunicación en la educación

61. ¿Actualmente usted conoce o ha tenido alguna experiencia con una herramienta de TI que facilite la comunicación en tiempo real entre los miembros de la comunidad educativa?

\section{$\underline{\text { Actualmente ninguna }}$}

62. Detalle su experiencia

g) La aceptación de una plataforma de comunicación en línea, frente a productos que ofrecen una suite completa de gestión educativa. Explicar el siguiente concepto, antes de continuar:

"Si tuviese una plataforma de comunicación, que permita desde su celular Smartphone establecer comunicación en tiempo real entre la comunidad educativa, que sea inmediata y que posibilite obtener información actualizada en relación a avisos, reuniones, mensajes, fotos intercambiadas entre los padres, alumnos, profesores, así como revisar el estado de las notas y asistencias".

63. ¿Qué beneficios y limitaciones implicaría el uso de esta plataforma de comunicación móvil en tiempo real, entre la comunidad educativa?

Entre los beneficios está el tener a mano una herramienta que muchos padres va usan, también el tener notificaciones, archivos, etc., haría que la comunicación sea acertiva y oportuna. 
Entre las limitaciones pueden existir padres renuentes al uso de tecnología lo que haría que se pierda en el tiempo la comunicación con ellos.

64. ¿Cuáles son los atributos o características que le gustaría que tenga esta plataforma de comunicación móvil para la comunidad educativa?

Notificaciones de recordatorios, actualizaciones permanentes, videos en línea de actividades especiales, chats con las autoridades del colegio

65. ¿Conoce usted de alguna plataforma de comunicación móvil en tiempo real para la comunidad educativa?

$\underline{\text { No }}$

66. ¿Ustedes usan actualmente una plataforma de comunicación móvil en tiempo real?

\section{Actualmente ninguna}

67. ¿Qué ventajas y desventajas usted encuentra en esta solución frente a plataformas que ofrecen toda una gestión educativa incluyendo las comunicaciones?

Ventajas, rapidez, actualidad, orden. Desventajas, personas que no les agrada el uso de la tecnología

68. ¿Cree usted desde su experiencia que los colegios estarían dispuestos a adquirir esta plataforma de comunicación? ¿Por qué?

\section{Sí, porque estaría a la vanguardia del desarrollo tecnológico}

69. ¿En qué medio publicitario prefiere enterarse de la plataforma de comunicación propuesta? 


\section{Diarios, TV, diarios digitales, Redes sociales}

70. ¿Qué rango de precio mensual estaría dispuesto a invertir? (300 a 400, 401 a 500, 501 a 600, 601 a 700, 701 a más US\$ dólares)

\section{$\underline{300 \text { a } 400}$}

71. ¿Usted estaría dispuesto a adquirir el servicio de plataforma en tiempo real para la comunicación entre familias, colegio y alumnos?

SI

72. ¿Quién es el decisor de las inversiones tecnológicas en la institución? ¿Ud. Influye en las decisiones de compra tecnológica?

\section{El promotor, Si influvo}

Gracias por su colaboración en nuestro trabajo de investigación. 


\section{Perfil del participante}

- Director de colegio

- Experiencia: en puesto de Director de Colegios particulares que posea los dos niveles de educación (Primaria y Secundaria) / Experiencia como docente.

\begin{tabular}{|l|l|}
\hline Nombre & CARMEN NAVARRO ESPELUCIN \\
\hline Edad & 57 años \\
\hline Profesión & Licenciada en Educación \\
\hline Cargo & Directora del Colegio Parroquial SS.CC Reina de la Paz \\
\hline Reseña & Colegio Parroquial SS. CC Reina de la Paz ( San Isidro) \\
\hline
\end{tabular}




\section{FICHA TECNICA ENTREVISTA A PROFUNDIDAD: EXPERTOS DEL SECTOR}

\section{ii. Objetivo de la investigación}

El objetivo de este estudio es de nutrirnos de la experiencia de expertos relacionados en el sector educación de nivel primario y secundario sobre la aceptación de una plataforma de comunicación entre padres, alumnos y colegios y el aporte de las Tecnologías de Información y Comunicación TIC en este rubro.

Estamos desarrollando una aplicación para teléfonos móviles inteligentes, que permitirá mejorar la comunicación entre las familias y el colegio. Desde esta aplicación los padres de familia podrán mantenerse informados sobre las actividades del colegio mediante SMS, emails, mensajes internos, avisos. La APP (aplicación móvil) permitirá realizar seguimiento de las tareas, notas de los alumnos, de su asistencia, gestionar citas, bajo un entorno seguro. El producto podrá ser adaptado a las necesidades de la Organización, pudiéndose elegir entre opciones estándar y funcionalidades adicionales. La aplicación será ofrecida mediante la modalidad de pago mensual diferenciada por número de usuarios que incluye su alojamiento en la nube (modelo de almacenamiento de datos basado en redes de computadoras, donde los datos están alojados en espacios de almacenamiento virtualizados), por lo que el colegio no necesita de inversión en infraestructura de hardware y software, mantenimiento y soporte. El servicio post-venta incluirá un servicio de soporte a la plataforma bajo la modalidad 16x5. Finalmente consideramos importante mencionar que nuestra propuesta contribuye a la protección del medio ambiente, reduciendo considerablemente el uso del papel, tinta y/o tóner.

\section{iii. Contenido}

Los temas de interés que deseamos investigar son:

- Conocer la experiencia de los involucrados sobre la importancia de la comunicación entre la comunidad educativa.

- Los aportes que puede hacer las tecnologías de información y comunicación en el sector educación y el mejoramiento de la comunicación.

- Las plataformas de comunicación en educación usadas actualmente con el apoyo de las tecnologías de información TI. 
- La aceptación de una plataforma de comunicación en línea frente a productos que ofrecen una suite completa de gestión educativa.

\section{iv. Cuestionario}

\section{Presentación:}

Buenos días, actualmente nos encontramos realizando una investigación acerca de las tecnologías de información, su aporte y uso como plataforma de comunicación para colegios de nivel primario y secundario. Agradecemos que pueda brindarnos su experiencia la cual significa un gran aporte a nuestro estudio.

A continuación, le haremos unas preguntas que nos permitirán tener mayor información y que ayudarán a esclarecer ciertos temas que consideramos importantes para poder concretar esta investigación. Desde ya le agrademos el apoyo.

Comunidad educativa: compuesto por profesores, APAFA, administración de colegio, padres de familia y alumnos de un determinado colegio.

\section{Pregunta sobre experiencia:}

¿Podría por favor comentarnos acerca de su experiencia en el sector educativo?

LLEVO 10 AÑOS COMO DIRECTORA ACA EN EL COLEGIO PARROQUIAL SS.CC REINA DE LA PAZ . TENGO 30 AÑOS DE EXPERIENCIA EN LA EDUCACION. DESDE QUE EMPECE MI ESPECIALIDAD ES PRIMARIA, SIEMPRE HE TRABAJADO CON LOS NIÑOS DE 3 ER GRADO HASTA 6 TO. LO LA GESTION ES UNA NUEVA EXPERIENCIA MUY AMPLIA QUE ABARCA TODA LA COMUNIDAD EDUCATIVA. 
h) Comunicación entre miembros de comunidad educativa

73. Desde su punto de vista y su experiencia ¿Qué tan importante es para usted establecer comunicación en tiempo real entre la comunidad educativa?

DEFINITIVAMENT ELA COMUNICACIÓN ES BASICA A TODO NIVEL Y QUIZAS TIENE SUS PRO Y TIENE SUS CONTRA . A TIEMPO REAL SIGNIFICA ESTAR PENDIENTE D ELA TECNOLOGIA QUE TE PUEDE HACER PERDER DE VISTA O DESCUIDAR UN POCO LA PARTE PEDAGOGICA QUE ES LA ATENCION AL ALUMNO. JUSTAMENTE UNO TIENE QUE APRENDER A SEPARAR ESO. SABER ORGANIZAR EL TIEMPO PARA PODER ATENDER LAS DOS COSAS A LA VEZ . TE CUENTO QUE CONTAMOS COMO UNA PLATAFORMA ACA EN EL COLEGIO, EFECTIVAMENTE UN SIEWEB QUE NOS PERMITE COMUNICAR A LOS PAPAS A TIEMPO REAL . LA PLATAOFRMA EMITE LOS COMUNICADOS TODOS EN FORMA VITUAL NO LLEGAN POR AGENDA. LA AGENDA ESTA MAS BIEN PRSONALIZADA PARA EL ALUMNO, PARA QUE EL APRENDA A ORGANIZAR SU TIEMPO, SUS TAREAS MAS QUE LA PROFESORA SEA LA QUE REALMENTE COMUNIQUE. DEFINITIVAMENTE HAY UN CONTROL DE AGENDA PARA EL ALUMNO SEPA SI ES QUE REALMENTE A HECHO LA TAREA, A CUMPLIDO CON COMUNICAR . LA AGENDA ES MAS PERSONALIZADA, MAS PARA EL ESTUDIANTE, PARA QUE NO PIERDA DE VISTA TAMBIEN DE QUE EXISTE UNA FORMA PARA ORGANIZAR SU TIEMPO. AHORA EL TIEMPO REAL DE COMUNICACIÓN CON EL PADRE DE FAMILIA, LO TECNOLOGICO YO DIRIA, NO NOS PUEDE HACER PERDER DE VISTA ESA PARTE MUY PERSONALIZADA QUE PODEMOS TENER CON LOS PADRES ( FRENTE A FRENTE). POR ESO ES QUE CONTINUAMOS TENIENDO LAS ENTREVISTAS CON ELLOS CADA SEMANA, CADA MAESTRO TIENE SUS HORAS DE ATENCION PARA MIRAR AL PADRE DE 
FAMILIA, PARA PODER CONVERSAR CON EL . SI EFECTIVAMENTE TE AYUDA MUCHO A CUIDAR EL PLANETA , ESO ES INCUESTIONABLE.

74. ¿Qué herramientas utiliza actualmente su institución para establecer la comunicación entre la comunidad educativa? ¿Cuáles son esas herramientas?

EL SIEWEB, LAS ENTREVISTAS PERSONALIZADAS, LAS REUNIONES DURANTE EL AÑO, TAMBIEN PARA FORMAR PADRES DE FAMILIA. ( ESCUELA DE PADRES)

75. ¿Qué barreras usted podría identificar en la actual comunicación entre la comunidad educativa?

LA FALTA DE DISPONIBILIAD DE TIEMPO DEL PADRE DE FAMILIA. NO CONCIBO QUE EL PADRE DE FAMILIA NO TENGA TIEMPO.

76. ¿Usted percibe una diferencia en el rendimiento académico de los escolares cuyos padres se involucran en su desarrollo académico?

. DEFINITIVAMENTE, NO SOLO EN EL RENDIMIENTO SINO TAMBIEN EN EL ESTADO DE ANIMO. ( ESTO SE DIFERENCIA EN AUTOESTIMA Y AUTOCONCEPTO)

Las tecnologías de la información y comunicación en la educación

77. ¿Considera importante el uso de las Tecnológicas de Información aplicadas en la educación escolar? ¿Por qué?

HOY EN DIA VITALE SPOR QUE ES LA GENERACION DE NUESTROS CHICOS, ELLOS SON LOS NATIVOS DIGITALES NOSOTROS LOS MIGRANTES DIGITALES . EL NATIVO DIGITAL PRACTICAMENTE NACE CON SU TABLET Y SU CELULAR EN LA MANO Y NO PODEMOS NEGARLES ESO. LA TECNOLOGIA ES BASICA PARA ELLOS. TAMPOCO PUEDE SER LO UNICO HAY QUE BALANCEARLO. LA TECNOLOGIA ES BASICA Y YO PIESNO QUE COLEGIO QUE NO TRABAJE CON ELLA TIENDE A DESAPARECER Y TIENES QUE DAR Y PERFECCIONAR Y OPTIMIZAR . 
78. Actualmente, podría comentarme ¿cuáles son las tecnologías de la información y comunicación que se emplean en su institución?

SE TRABAJA OCN UNA EDITORIAL QUE TRAE PLATAFORMA PARA TODAS LAS AREAS. TRABAJA NO SOLO EL PROFESOR, EL ALUMNO Y EL PADRE DE FAMILIA. HEMOS EMPEZADO CON AREA BASICAS.

79. ¿Cómo ve el futuro de las tecnologías de la información y comunicación en la educación?

EL FUTURO DE LAS TICS LO VEO MUY PROMETEDOR. TENEMOS QUE ESTAR A LA VANGUARDIA, PIENSO QUE LA TECNOLOGIA ES UNA BUENA HERRAMIENTA DE CONFORMOR PARA EL SER HUMANO PERO IGUAL REQUIERE DE MUCHO APRENDIZAJE.

Plataforma de comunicación en la educación

80. ¿Actualmente usted conoce o ha tenido alguna experiencia con una herramienta de TI que facilite la comunicación en tiempo real entre los miembros de la comunidad educativa? Detalle su experiencia

SOLO SKYPE Y LA PLATAFORMA SIEWEB.

La aceptación de una plataforma de comunicación en línea, frente a productos que ofrecen una suite completa de gestión educativa. Leer el siguiente concepto, antes de continuar:

"Si tuviese una plataforma de comunicación, que permita desde su celular Smartphone establecer comunicación en tiempo real entre la comunidad educativa, que sea inmediata y que posibilite obtener información actualizada en relación a avisos, reuniones, mensajes, fotos intercambiadas entre los padres, alumnos, profesores, así como revisar el estado de las notas y asistencias".

81. ¿Qué beneficios y limitaciones implicaría el uso de esta plataforma de comunicación móvil en tiempo real, entre la comunidad educativa? 
LIMITACIONES: CUANDO NO SE UTILICE RESPONSABLEMENTE, CUANDO SE HABLA MAL DE LOS ALUMNOS Y PROFESOR, QUIZAS QUE SE PUEDA DESVIRTUAR LA COMUNICACIÓN ( NECESARIO PARAMETROS), PODRIA FALLAR TECNOLOGIA.

BENEFICIOS: GANAR TIEMPO, LOGRAR QUE LA COMUNICACIÓN SE DE.

HACE TIEMPO NOS OFRECIERON UNA PLATAFORMA DE ASISTENCIA (COSTO MUY ELEVADO) EL ALUMNO MARCABA SU HUELLA PERO ERA ELEVADO.

82. ¿Cuáles son los atributos o características que le gustaría que tenga esta plataforma de comunicación móvil para la comunidad educativa?

QUE SEA ABIERTA, FACIL ACCESO, QUE SE VEA EN UN IPHONE Y SMARTPHONE, DEBE LLEVAR UN MONITOREO.

Y ESA NUEVE NO PUEDE SER VIOLADA O CAPTURAR DATOS $i$

83. ¿Conoce usted de alguna plataforma de comunicación móvil en tiempo real para la comunidad educativa?

LA UNICA SIEWEB O SIENET

84. ¿Ustedes usan actualmente una plataforma de comunicación móvil en tiempo real?

SI SIEWEB

"Plataformas de gestión educativa completa: plataformas que incluyen funcionalidades como aula virtual, biblioteca en línea, agenda inteligente, matricula, gestión de notas, personalizar barra de herramientas".

85. ¿Qué ventajas y desventajas usted encuentra en esta solución frente a plataformas que ofrecen toda una gestión educativa incluyendo las comunicaciones?

EL SIEWEB TAMBIEN TIENE ESA POSIBILIDAD, ES UN EXTRA MAS , E SUN SISTEMA INTEGRADO PERO PUEDES DESISTIR EN CUANTO A ESE ADICIONAL. VENTAJAS : AYUDARIA MUCHO EN GESTIONAR UNA COMPETENCIA DE GESTION MAS AMPLIA, 
DESVENTAJA.: DESPERSONALIZA CONTACTO CON ALUMNOS, PERSONAL Y PADRES DE FAMILIA

86. ¿Cree usted desde su experiencia que los colegios estarían dispuestos a adquirir esta plataforma de comunicación? ¿Por qué?

YO CREO QUE SI SIEMPRE Y CUANDO VIENDO LOS RECURSOS DEL COLEGIO, SI ES UN COLEGIO GRANDE SEGURO VA PODER ADQUIRIR. PERO ESTE COLEGIO ES PARROQUIAL Y ESTAMOS ALIADOS CON EL ESTADO Y PODER ENTRAR A ESTOS PROGRAMAS NOS FRUSTA YA QUE GENERALMENTE LOS COSTOS DE ESTAS PLATAFORMAS SON MUY ELEVADOS.( COSTOS ANUALES Y POR ALUMNO)

VAMOS A CAER EN LO MISMO, LOS RECURSO ECONOMICOS SON BAJOS.

87. ¿En qué medio publicitario prefiere enterarse de la plataforma de comunicación propuesta?

MEJOR ES CON UN PROMOTOR DE VENTA ( ALGO MAS DIRECTO Y QUE TRAIGA UN DEMO PARA QUE LO PUEDA MIRAR)

88. ¿Qué rango de precio mensual estaría dispuesto a invertir? (300 a 400, 401 a 500,501 a 600, 601 a 700, 701 a más US\$ dólares)

BUENO LO MAS BAJO 300 a 400

89. ¿Usted estaría dispuesto a adquirir el servicio de plataforma en tiempo real para la comunicación entre familias, colegio y alumnos?

SI ESTARIA DISPUESTA MIRANDO CON LO QUE TENGO, SI ES LO MISMO QUE YO TENGO NO TIENE SENTIDO SI ME DA MAS CLARO QUE SI

90. ¿Quién es el decisor de las inversiones tecnológicas en la institución? ¿Ud. Influye en las decisiones de compra tecnológica?

SI NUESTRO ENCARGADO DE SISTEMA. YO SOY LA MAXIMA AUTORIDAD, SOY LA REPRESENTANTE LEGAL PERO SIEMPRE HAY CONSEJO DIRECTIVO QUE ME APOYA EN DICHAS DECISIONES..

Gracias por su colaboración en nuestro trabajo de investigación. 


\section{Perfil del participante}

- Docente de colegio

- Experiencia: en puesto de Docente de Colegios particulares que posea los dos niveles de educación (Primaria y Secundaria)

\begin{tabular}{|l|l|}
\hline Nombre & Carlos Farías Hurtado \\
\hline Edad & 52 años \\
\hline Profesión & Licenciado en Informática y computación \\
\hline Cargo & Profesor de Computación e Informática \\
\hline Reseña & Colegio Sagrados Corazones Belén ( San Isidro) \\
\hline
\end{tabular}




\section{FICHA TECNICA ENTREVISTA A PROFUNDIDAD: EXPERTOS DEL SECTOR}

\section{Objetivo de la investigación}

El objetivo de este estudio es de nutrirnos de la experiencia de expertos relacionados en el sector educación de nivel primario y secundario sobre la aceptación de una plataforma de comunicación entre padres, alumnos y colegios y el aporte de las Tecnologías de Información y Comunicación TIC en este rubro.

Estamos desarrollando una aplicación para teléfonos móviles inteligentes, que permitirá mejorar la comunicación entre las familias y el colegio. Desde esta aplicación los padres de familia podrán mantenerse informados sobre las actividades del colegio mediante SMS, emails, mensajes internos, avisos. La APP (aplicación móvil) permitirá realizar seguimiento de las tareas, notas de los alumnos, de su asistencia, gestionar citas, bajo un entorno seguro. El producto podrá ser adaptado a las necesidades de la Organización, pudiéndose elegir entre opciones estándar y funcionalidades adicionales. La aplicación será ofrecida mediante la modalidad de pago mensual diferenciada por número de usuarios que incluye su alojamiento en la nube (modelo de almacenamiento de datos basado en redes de computadoras, donde los datos están alojados en espacios de almacenamiento virtualizados), por lo que el colegio no necesita de inversión en infraestructura de hardware y software, mantenimiento y soporte. El servicio post-venta incluirá un servicio de soporte a la plataforma bajo la modalidad 16x5. Finalmente consideramos importante mencionar que nuestra propuesta contribuye a la protección del medio ambiente, reduciendo considerablemente el uso del papel, tinta y/o tóner.

\section{Contenido}

Los temas de interés que deseamos investigar son:

- Conocer la experiencia de los involucrados sobre la importancia de la comunicación entre la comunidad educativa.

- La aceptación de smartphones y aplicaciones para teléfonos inteligentes y el grado de conexión a internet.

- La aceptación de una plataforma de comunicación en línea 


\section{Cuestionario}

\section{Presentación:}

Buenos días, actualmente nos encontramos realizando una investigación acerca de las tecnologías de información, su aporte y uso como plataforma de comunicación para colegios de nivel primario y secundario. Agradecemos que pueda brindarnos su experiencia la cual significa un gran aporte a nuestro estudio.

A continuación, le haremos unas preguntas que nos permitirán tener mayor información y que ayudarán a esclarecer ciertos temas que consideramos importantes para poder concretar esta investigación. Desde ya le agrademos el apoyo.

Comunidad educativa: compuesto por profesores, APAFA, administración de colegio, padres de familia y alumnos de un determinado colegio.

\section{Pregunta sobre experiencia:}

¿Podría por favor comentarnos acerca de su experiencia en el sector educativo?

TENGO UNA EXPERIENCIA ALREDEDOR DE 25 A 26 AÑOS COMO DOCENTE .

\section{i) Comunicación entre miembros de comunidad educativa}

91. Desde su punto de vista y su experiencia ¿Qué tan importante es para usted establecer comunicación en tiempo real entre la comunidad educativa?

BUENO PONIENDO COMO EJEMPLO MI EXPERIENCIA YO RECUERDO QUE ANTES ERA UN POCO COMPLICADO PARA TENER COMUNICACIÓN EN ESTE CASO CON LOS PADRES DE FAMILIA. HOY EN DIA SABERMOS QUE LA COMUNICACIÓN ES INMEDIATA Y ES IMPORTANTE SI PORQUE SE NECESITA UNA COMUNICACIÓN ABIERTA CON LOS PADRES DE FAMILIA 
DE TAL MANERAQUE ELLOS ESTEN PENDIENTE CON LOQUE SUCEDE CON SUS HIJOS EN EL COLEGIO.

a) Uso de smartphones y conectividad

1. ¿Actualmente podría comentarme si usted usa un Smartphone y que tipo de beneficios o desventajas usted encuentra?

SI USO UN SMARTPHONE. TENGO LAS APLICACIONES NECESARIAS, SI LO USO MUCHO SOBRE TODO EN EL COLEGIO TENEMOS ALGUNAS INDICACIONES Y SI TENEMOS ALGUNA LABOR NOS COMUNICAMOS INMEDIATAMENTE. (USO DE SIEWEB) A VECES TAMBIEN UTILIZAMOS EL WHAT APP.

LA DESVENTAJA SERIA A VECES ES NECESARIO TENER AL PADRE DE FAMILIA FRENTE A UNO Y ESTO FOMENTARIA QUE EL PADRE YA NO VENGA MUCHO.

2. ¿Encuentra necesaria la comunicación en tiempo real en la comunidad educativa vía dispositivos móviles?

SI ENCUENTRO NECESARIO, ES MUY RAPIDA. LOS CHICOS AHORA ESTAN MUY INTERADOS DE LOS SUCEDE. CON LA PLATAFORMA QUE TENEMOS PODRIA EL PADRE ENTERARSE.

3. Usted ha tenido experiencia con aplicaciones de google play o play store, por favor explíquenos.

SI SOBRE TODO PARA BAJAR APLICACIONES. APLICACIONES SOBRE TODO PARA MOVILIZARME, PARA SOLICITAR TAXIS. 
4. ¿Usted tienen conexión a internet en su celular, podría detallarnos por favor si tiene internet ilimitado, accede a través de wi-fi en su casa, trabajo?

SI TENGO ACCESO LIMITADO EN MI CELULAR. MUY POCO USO LA DEL COLEGIO. EN MI CASA TAMPOCO USO MUCHO PERO MAYORMENTE USO MIS MEGAS COMO ES ILIMITADO, NO NECESITO ACTIVARLA EN MI CASA PERO SI LO HAGO CUANDO TENGO QUE VER VIDEOS O BAJAR APLICACIONES QUE SON MUY PESADAS.

SI HE TENIDO EXPERIENCIA CON UNA APLICACIÓN EDUCATIVA. PREVIAMENTE EN EL COLEGIO NOS HAN VENIDO A OFRECER DIVERSAS APLICACIONES Y PROPUESTAS INTERESANTES Y VEO QUE ES MUY INTERESANTE YA QUE LO QUE SE BUSCA CON ELLAS ES MEJORAR LA COMUNICACIÓN PARA QUE SEA DIDACTICA.

b) La aceptación de una plataforma de comunicación. Por favor, explicar el siguiente concepto, antes de continuar:

"Si tuviese una plataforma de comunicación, que permita desde tan solo su celular Smartphone establecer comunicación en tiempo real entre la comunidad educativa, que posibilite el tener información actualizada en relación a avisos, reuniones, mensajes, fotos intercambiadas entre los padres, alumnos, profesores, así como revisar el estado de las notas y asistencias".

ANTES LA COMUNICACIONES NO ERAN INMEDIATAS, ANTES CUANDO SE MANDABAN LAS CITACIONES LOS PADRES NO SE ENTERABAN, HOY EN DIA CON ESTO SERIA MUCHO MAS FACIL . POR EJEMPLO NOSOTROS USAMOS EL SIEWEB Y MANDAMOS UN CORREO PARA CONFIRMAR QUE LA CITACION LE 
HAYA LLEGADO DE CIERTA FORMA TRATAMOS DE ASEGURARNOS POR CORREO.

5. ¿Qué beneficios y limitaciones implicaría el uso de esta plataforma de comunicación móvil en tiempo real, para su labor como docente?

EL BENEFICIO SERIA QUE LO TENDRIAMOS MAS ACCESIBLE EN EL SMARTPHONE Y YA SOLO EN EL CORREO O INTRANET. EL BENEFICIO SERIA QUE PODRIA COMUNICARME EN EL MOMENTO. Y LA LIMITACION SERIA EL NO TENER SEÑAL YA QUE ESTO INTERFERIRIA EN EL ENVIO DE LOS MENSAJES.

6. ¿Cuáles son los atributos o características que le gustaría que tenga esta plataforma de comunicación móvil desde su perspectiva?

LO QUE BUSCO ES QUE SEA LLAMATIVA QUE IMPRESIONE, QUE TENGA COLORES, QUE NO SEA ESTATICA. IMGENES QUE SE MUEVA, QUE SE INTERACTIVA. DE REPENTE QUE EL TEXTO TENGA UN BANER , QUE TENGA BOTONES O PESTAÑAS PARA QUE SEA MAS DIRECTO EL ACCESO A LA INFORMACION.

7. Considera necesaria esta plataforma o si es opcional para el desarrollo de sus labore

YO CREO QUE ES NECESARIA UNA PLATAFORMA DE COMUNICACIÓN A TIEMPO REAL QUE PUEDA UTILIZARSE DESDE EL SMARTPHONE YA QUE EN TODO MOMENTO USAMOS EL TELEFONO. 
8. ¿A qué tipos de colegios considera que sería más útil y/o necesaria este tipo de plataformas?

9. A VECES HACEMOS COMPARACIONES, PERO YO EMPEZARIA POR LOS COLEGIOS NACIONALES YA QUE SON LO QUE CARECEN Y NO TIENEN TODA LA INFORMACION REAL O INMEDIATA. SI EMPEZARIA POR LOS COLEGIOS QUE MAS SE NECESITARIA MAS COMUNICACIÓN CON LOS PADRES DE FAMILIA. MUCHOS VIVEN LEJOS , NO PUEDEN LLEGAR EN EL COLEGIO, TRABAJAN TODO EL DIA Y ESTO SERIA UNA SOLUCION.

10. ¿cuál considera que es el sustituto de este tipo de plataformas en la gestión educativa hoy?

LAS AGENDAS, CIRCULARES O APLICACIONES QUE NO TIENEN TODA LA HABILIDAD COMO LA QUE ESTA MENCIONANDO. BASICAMENTE AGENDAS. Muchas gracias por tu participación. 


\section{Perfil del participante}

- Docente de colegio

- Experiencia: en puesto de Docente de Colegios particulares que posea los dos niveles de educación (Primaria y Secundaria)

\begin{tabular}{|l|l|}
\hline Nombre & María del Rosario Bonifaz \\
\hline Edad & años \\
\hline Profesión & $\begin{array}{l}\text { Licenciado en Informática y computación (Universidad San } \\
\text { Ignacio de Loyola) Bachiller en Educación en Área Informática. 21 } \\
\text { años en la docencia. }\end{array}$ \\
\hline Cargo & Profesor de Computación e Informática \\
\hline Reseña & Colegio Sagrados Corazones Belén ( San Isidro) \\
\hline
\end{tabular}




\section{FICHA TECNICA ENTREVISTA A PROFUNDIDAD: EXPERTOS DEL SECTOR}

\section{Objetivo de la investigación}

El objetivo de este estudio es de nutrirnos de la experiencia de expertos relacionados en el sector educación de nivel primario y secundario sobre la aceptación de una plataforma de comunicación entre padres, alumnos y colegios y el aporte de las Tecnologías de Información y Comunicación TIC en este rubro.

Estamos desarrollando una aplicación para teléfonos móviles inteligentes, que permitirá mejorar la comunicación entre las familias y el colegio. Desde esta aplicación los padres de familia podrán mantenerse informados sobre las actividades del colegio mediante SMS, emails, mensajes internos, avisos. La APP (aplicación móvil) permitirá realizar seguimiento de las tareas, notas de los alumnos, de su asistencia, gestionar citas, bajo un entorno seguro. El producto podrá ser adaptado a las necesidades de la Organización, pudiéndose elegir entre opciones estándar y funcionalidades adicionales. La aplicación será ofrecida mediante la modalidad de pago mensual diferenciada por número de usuarios que incluye su alojamiento en la nube (modelo de almacenamiento de datos basado en redes de computadoras, donde los datos están alojados en espacios de almacenamiento virtualizados), por lo que el colegio no necesita de inversión en infraestructura de hardware y software, mantenimiento y soporte. El servicio post-venta incluirá un servicio de soporte a la plataforma bajo la modalidad 16x5. Finalmente consideramos importante mencionar que nuestra propuesta contribuye a la protección del medio ambiente, reduciendo considerablemente el uso del papel, tinta y/o tóner.

\section{Contenido}

Los temas de interés que deseamos investigar son:

- Conocer la experiencia de los involucrados sobre la importancia de la comunicación entre la comunidad educativa.

- La aceptación de smartphones y aplicaciones para teléfonos inteligentes y el grado de conexión a internet.

- La aceptación de una plataforma de comunicación en línea

\section{Cuestionario}




\section{Presentación:}

Buenos días, actualmente nos encontramos realizando una investigación acerca de las tecnologías de información, su aporte y uso como plataforma de comunicación para colegios de nivel primario y secundario. Agradecemos que pueda brindarnos su experiencia la cual significa un gran aporte a nuestro estudio.

A continuación, le haremos unas preguntas que nos permitirán tener mayor información y que ayudarán a esclarecer ciertos temas que consideramos importantes para poder concretar esta investigación. Desde ya le agrademos el apoyo.

Comunidad educativa: compuesto por profesores, APAFA, administración de colegio, padres de familia y alumnos de un determinado colegio.

\section{Pregunta sobre experiencia:}

¿Podría por favor comentarnos acerca de su experiencia en el sector educativo?

ESTUDIE INFORMATICA EN LA UNIVERSIDAD SAN IGNACIO DE LOYOLA Y

TENGO UNA SEGUNDA CARRERA QUE ESTOY POR CONCLUIR (CARRERA DE EDUCACION) . TENGO 21 AÑOS DE EXPERIENCIA COMO DOCENTE Y UNA EXPERIENCIA QUE CREO QUE HA SIDO SUFICIENTE PARA DARLE SENTIDO A LO HAGO.

\section{Comunicación entre miembros de comunidad educativa}

11. Desde su punto de vista y su experiencia ¿Qué tan importante es para usted establecer comunicación en tiempo real entre la comunidad educativa?

BUENO HOY VIVIMOS EN UN MUNDO TAN GLOBALIZADO EN EL QUE EL TIEMPO PASA TAN RAPIDO QUE EN REALIDAD ES UNA NECESIDAD PRMORDIAL QUE LOS PADRES Y TODA LA COMUNIDAD EDUCATIVA ESTE EN 
UNA COMUNICACIÓN A TIEMPO REAL PORQUE AHORA AMBOS PADRES (PAPA Y MAMA) TRABAJAN TODO EL DIA Y A VECES ESTUDIAN. ES PRIMORDIAL QUE ELLOS ESTEN AL TANTO EN EL MOMENTO OPORTUNO DE LO QUE SUCEDE CON SU NIÑOS EN EL COLEGIO. SUELE SUCEDER INCIDENCIAS DE SALUD , DE COMPORTAMIENTO, DE RENDIMIENTO ACADEMICO Y ESTO ES IMPORTANTE . Y A VECES NO PODEMOS PROLONGAR EL TIEMPO PARA VER QUE SUCEDE CON NUESTROS NIÑOS Y ES NECESARIA DICHA COMUNICACIÓN .

\section{c) Uso de smartphones y conectividad}

12. ¿Actualmente podría comentarme si usted usa un Smartphone y que tipo de beneficios o desventajas usted encuentra?

BUENO TENGO UN SMARTPHONE, EL BENEFICIO QUE TENGO ES QUE TENGO VARIAS APLICACIONES QUE ME AYUDAN, TENGO CALENDARIO, TENGO FECHA, TENGO PARA MENSAJEARME CON MI FAMILIA EN TIEMPO REAL, TENGO INTERNET SI QUIERO AVERIGUAR ALGO, QUIERO SABER UNA NOTICIA TODO LO TENGO AHÍ. LA VENTAJA ES LA ACCESIBILIDAD A TODO. EN CAMBIO, LA DESVENTAJA SERIA ES QUE TENGO QUE TENER UN PLAN DE DATOS Y ESE PLAN DE DATOS ME CUESTA.

ACTUALMENTE, CUENTO CON UN PLAN DE DATOS, CUANDO ESTOY EN MI CASA ME CUELGO A MI INTERNET QUE LO TENGO EN CASA PERO LA MAYOR PARTE DEL DIA QUE ESTOY FUERA, USO EL PLAN DE DATOS . EL INTERNET ES RESTRINGIDO PARA LOS DOCENTES ACTUALMENTE.

OTRA DESVENTAJA SON LOS VIRUS Y LOS FISHING EN LOS SMARTPHONE Y ESTO PUEDEGENERAR UN RIESGO QUE TE VIOLEN LA CUENTA. 
13. ¿Encuentra necesaria la comunicación en tiempo real en la comunidad educativa vía dispositivos móviles?

SI PARA MI SI, AHORA QUIEN NO TIENE UN SMARTPHONE CON LA VANGUARDIA DE LATENCOLOGIA. Y SI NOS ENFOCAMOS EN EL SECTOR PRIVADO CASI TODOS LOS PADRES Y DOCENTES LO TIENEN PERO SI NO ENFOCAMOS EN LOS COLEGIOS DEL ESTADO NO TODOS TIENEN EL ALCANCE. SI ENFOCAMOS EN TU MERCADO DEFINITIVAMENTE ES PRMORDIAL TODOS LOS PADRES MANEJAN EL SMARTPHONE.

14. Usted ha tenido experiencia con aplicaciones de google play o play store, por favor explíquenos.

BUENO SI, TENGO EN MI CELULAR GOOGLE PLAY Y ME SIRVE PARA DESCARGAR MIS APLICACIONES. INGAGANDO ENCONTRE ESTE MERCADO PARA BAJAR APLICACIONES Y HAY DIFERENTES TIPOS DE APLICACIONES. HAY DE TODO TIPO DE APLICACIONES.

15. ¿Usted tienen conexión a internet en su celular, podría detallarnos por favor si tiene internet ilimitado, accede a través de wi-fi en su casa, trabajo?

NO TENGO INTERNET LIMITADO. EN CASA SI PUEDO ACCEDER, TENGO MIS DATOS PERO LIMITADOS.

d) La aceptación de una plataforma de comunicación. Por favor, explicar el siguiente concepto, antes de continuar:

"Si tuviese una plataforma de comunicación, que permita desde tan solo su celular Smartphone establecer comunicación en tiempo real entre la comunidad educativa, que posibilite el tener información actualizada en relación a avisos, reuniones, mensajes, fotos 
intercambiadas entre los padres, alumnos, profesores, así como revisar el estado de las notas y asistencias”.

AHORA HAY CADA VEZ MAS PLATAFORMAS Y LO QUE VEO ES QUE ESTA PROPUESTA SERIA VIABLE YA QUE PERMITIRIA A LOS PADRES MODERNOS EL ESTAR INFORMADOS

16. ¿Qué beneficios y limitaciones implicaría el uso de esta plataforma de comunicación móvil en tiempo real, para su labor como docente?

BENEFICIOS: MEJORARIA LA COMUNICACIÓN ENTRE TODA LA COMUNIDAD DOCENTE Y EN REALIDAD ME AGILIZARIA MUCHAS COSAS EN LA COMUNICACIÓN CON LOS PADRES , COMPAÑEROS E INTERCAMBIAMOS INFORMACION , ASEGURARIAMOS ESA INFORMACION. BUENO EN CUANTO A LAS LIMITACIONES, ES EL GASTO EN PLAN DE DATOS , ESA SERIA UNA LIMITACION. NO TENGO INTERNET DE DONDE COLGARME.

17. ¿Cuáles son los atributos o características que le gustaría que tenga esta plataforma de comunicación móvil desde su perspectiva? ME GUSTARIA QUE SEA UNA APLICACIÓN MUY INTUTIVA PARA EL USUARIO QUE TAN SOLO CON UN TOUCH PUEDA ACCEDER FACILMENTE A LA PLATAFORMA Y QUE TODOS LO MENUS SEAN DESPLAYABLES ASI COMO PRESENTAN LAS APLICACIONES DE ANDROID ( INTUITIVO PARA EL USUARIO) UN DISEÑO AMENO QUE CAPTE LA ATENCION DE LOS PADRES DE FAMILIA, PADRES, ETC .. DEBE IMPACTAR. 
18. Considera necesaria esta plataforma o si es opcional para el desarrollo de sus labore

SI LA CONSIDERO NECESARIA, SI ES IMPORTANTE PARA EL DESARROLLO DE LABORES. PERO SOY DE LA IDEA DE QUE TAMPOCO TENEMOS QUE PRESCINDIR TENEMOS QUE BUSCAR UNA ALTERNATIVA, PLAN DE CONTINGENCIA PARA CUANDO NO HAYA INTERNET.

19. ¿A qué tipos de colegios considera que sería más útil y/o necesaria este tipo de plataformas?

DEFINITIVAMENTE, EL PUNTO DE INICIO LO VEO EN EL SECTOR PRIVADO. HAY UNA VISION DE QUE PUEDE LLEGAR AL ESTADO PERO DEBE SER POCO A POCO YA QUE MUCHOS NO TIENEN RECURSOS, CARECEN DE INFRAESTRUCTURA Y NO TODOS LOS PADRES DE FAMILIA CUENTAN CON UN SMARTPHONE . LO CONSIDERO ENFOCADO COMO PUNTO DE INICIO EN EL SECTOR PRIVADO

20. ¿cuál considera que es el sustituto de este tipo de plataformas en la gestión educativa hoy?

LA AGENDA EN FORMA FISICA Y EL SIEWEB . EN CAMBIO CON EL SMARTPHONE SERIA MAS A TIEMPO REAL. CONSIDERO QUE LOS DOCENTES REACCIONARIAN DE MANERA POSITIVA Y QUE SON BIEN PREPARADOS Y QUE NO RECHAZAN EL CAMBIO YA QUE TIENEN SUFICIENTE APERTURA.

Muchas gracias por tu participación. 


\section{Perfil del participante}

- Docente de colegio

- Experiencia: en puesto de Docente de Colegios particulares que posea los dos niveles de educación (Primaria y Secundaria)

\begin{tabular}{|l|l|}
\hline Nombre & Diana Ilizarbe Tito \\
\hline Edad & 32 años \\
\hline Profesión & Licenciada en Educación (Universidad Federico Villareal) \\
\hline Cargo & Profesora de Inglés del Nivel de Secundaria \\
\hline Reseña & Colegio Sebastián Salazar Bondy- San Borja (4 años) \\
\hline
\end{tabular}




\section{FICHA TECNICA ENTREVISTA A PROFUNDIDAD: EXPERTOS DEL SECTOR}

\section{Objetivo de la investigación}

El objetivo de este estudio es de nutrirnos de la experiencia de expertos relacionados en el sector educación de nivel primario y secundario sobre la aceptación de una plataforma de comunicación entre padres, alumnos y colegios y el aporte de las Tecnologías de Información y Comunicación TIC en este rubro.

Estamos desarrollando una aplicación para teléfonos móviles inteligentes, que permitirá mejorar la comunicación entre las familias y el colegio. Desde esta aplicación los padres de familia podrán mantenerse informados sobre las actividades del colegio mediante SMS, emails, mensajes internos, avisos. La APP (aplicación móvil) permitirá realizar seguimiento de las tareas, notas de los alumnos, de su asistencia, gestionar citas, bajo un entorno seguro. El producto podrá ser adaptado a las necesidades de la Organización, pudiéndose elegir entre opciones estándar y funcionalidades adicionales. La aplicación será ofrecida mediante la modalidad de pago mensual diferenciada por número de usuarios que incluye su alojamiento en la nube (modelo de almacenamiento de datos basado en redes de computadoras, donde los datos están alojados en espacios de almacenamiento virtualizados), por lo que el colegio no necesita de inversión en infraestructura de hardware y software, mantenimiento y soporte. El servicio post-venta incluirá un servicio de soporte a la plataforma bajo la modalidad 16x5. Finalmente consideramos importante mencionar que nuestra propuesta contribuye a la protección del medio ambiente, reduciendo considerablemente el uso del papel, tinta y/o tóner.

\section{Contenido}

Los temas de interés que deseamos investigar son:

- Conocer la experiencia de los involucrados sobre la importancia de la comunicación entre la comunidad educativa.

- La aceptación de smartphones y aplicaciones para teléfonos inteligentes y el grado de conexión a internet.

- La aceptación de una plataforma de comunicación en línea 


\section{Cuestionario}

\section{Presentación:}

Buenos días, actualmente nos encontramos realizando una investigación acerca de las tecnologías de información, su aporte y uso como plataforma de comunicación para colegios de nivel primario y secundario. Agradecemos que pueda brindarnos su experiencia la cual significa un gran aporte a nuestro estudio.

A continuación, le haremos unas preguntas que nos permitirán tener mayor información y que ayudarán a esclarecer ciertos temas que consideramos importantes para poder concretar esta investigación. Desde ya le agrademos el apoyo.

Comunidad educativa: compuesto por profesores, APAFA, administración de colegio, padres de familia y alumnos de un determinado colegio.

\section{Pregunta sobre experiencia:}

¿Podría por favor comentarnos acerca de su experiencia en el sector educativo?

YO HE COMENZADO DESDE MUY JOVEN A ENSEÑAR EN INICIAL . POSTULE A LA UNIVERSIDAD FEDERICO VILLAREAL, MI ALMA MATER. LUEGO, Y AHÍ ESTUVE COMO TUTORA DE PRIMARIA HASTA EL AÑO PASADO 2015.POSTERIORMENTE, CON LOS ESTUDIOS DE INGLES Y EL EXAMEN INTERNACIONAL, PARTO CON LO QUE ES EL NIVEL SECUNDARIA Y TAMBIEN HE DICTADO PREUNIVERSITARIO.

CONSIDERO IMPORTANTE LAS TIC COMO RECURSO FUNDAMENTAL, YA QUE DEBEMOS LOS MAESTROS RELACIONAR LO QUE A LOS ALUMNOS LES GUSTA COMPUTADORAS, SMARTPHONES, TABLET, SOFTWARE CON NUESTRAS 
CLASES. TODO ELLO PARA HACER LA EDUCACION MAS VIVENCIAL Y

RELACIONARLO CON LO QUE A ELLOS (ALUMNOS) LES AGRADA.

EN EL COLEGIO SEBASTIAN SALAZAR BONDY LLEVO 4 AÑOS COMO PROFESORA.

e) Comunicación entre miembros de comunidad educativa

21. Desde su punto de vista y su experiencia ¿Qué tan importante es para usted establecer comunicación en tiempo real entre la comunidad educativa?

BUENO EN LA PRAXIS PARA NOSOTROS ES IMPORTANTE SOBRETODO CUANDO TENEMOS ACTIVIDADES Y COSAS QUE COORDINAR CON LOS PADRES DE FAMILIAO DE REPENTE CUANDO HAY UNA EMERGENCIA O CUANDO TENEMOS UN TIPO DE SITUACION QUE ESURGENTE. ÁRA NOSOTROS COMO DOCENTES ES BASTANTE IMPORTANTE COMUNICARNOS EN TIEMPO REAL. DE REPENTE LA OPCION DE COMUNICARNOS VIA TELEFONO HACER UNA LLAMADA TELEFONICA, MANDARLES UN MENSAJE POR WHATAPP, PARTE DE NOSOTROS COMO UNA NECESIDAD INMEDIATA.

\section{f) Uso de smartphones y conectividad}

22. ¿Actualmente podría comentarme si usted usa un Smartphone y que tipo de beneficios o desventajas usted encuentra?

SI, DESDE HACE TRES AÑOS USO UN SMARTHPHONE, LO QUE PASA ES QUE USO UNO POR LA MISMA NECESIDAD DE ADAPTARME A LOS CHICOS. UNO 
TIENE QUE IRSE ADAPTANDO Y ACTUALIZANDOSE. TENGO UN EQUIPO UN POQUITO MAS ACTUALIZADO.

UNO TIENE QUE ESTAR A LA VANGUARDIA CON LA TECNOLOGIA Y ESTE EQUIPO ES UN POQUITO MAS RAPIDO, PUEDO DESCARGAR VIDEOS, IMÁGENES LO CUAL ME PERMITEMOSTRARLE ALGO A LOS CHICOS DE FORMA INMEDIATA, UTILIZAR UN DICCIONARIO ON LINE. PARA MI ES UNA HERRAMIENTA MUY IMPORTANTE.

PERO COMO TODO TIENE SU PRO TAMBIEN TIENE SU CONTRA. COMO UNA VISION DE DOCENTE EN GENERAL TAMBIEN TENER UN SMARTPHONE O TENER LACOMUNICACION DE LOS PAPAS INMEDIATA, A VECES TAMBIEN NO TE PERMITE ESTAR AL CIEN . COMO ADULTOSNOSOTROS PODEMOS REGULARLO. PERO DESDE LA VISION DE UN ALUMNO, TNER UN SMARTHPHONE Y EL NO TENER LA MADUREZ Y EL ESTAR EN UN PROCESO DE FORMACION ES UN POCODIFICIL PARA ELLOS. DE REPENTE DISCENIR EL MOMENTO PROPICIA PARA UTILIZAR ESTOS EQUIPOS. AVECES ELLOS NO SABES CUAL ES EL PRO Y EL CONTRA.

23. ¿Encuentra necesaria la comunicación en tiempo real en la comunidad educativa vía dispositivos móviles?

BUENO, PERSONALMENTE CREO QUE SI. EN REALIDAD, EN EL DIA A DIA SE DA UNA COMUNICACION EN TIEMPO REAL. LA NECESIDAD DEL DIA A DIA. POR EJEMPLO LO DE RETRASO DE LOS 7 DIAS SIN CLASE POR EL TEMA DE LOS HUAYCOS. HACE QUE NOS ADAPTEMOS , QUE NOS COMUNIQUEMOS, QUE PROGRAMEMOS ACTIVIDADES QUE A VECES NO PODEMOS MANEJAR. ALGUNOS TENEMOS SABER ADAPTARNOS A LO QUE TENEMOS Y POR EOS 
MISMO ESTAS CIRCUNTANCIAS NOS OBLIGAS A UTILIZAR ESTOS DISPOSITIVOS PARA REALIZAR UNA COMUNICACIÓN INMEDIATA CON LOS PADRES.

24. Usted ha tenido experiencia con aplicaciones de google play o play store, por favor explíquenos.

SI, MANEJO BASTANTE ESO. ME GUSTA MUCHO INVOLUCRAME EN ESTE TIPO DE TECNOLOGIA. TRATA DE BUSCAR NUEVAS APLICACIONES QUE PUEDEN SERVIR A LOS CHICOS. POR EJEMPLO APLICACIÓN DE AUDIOS QUE AHORA LOS CHICOS TIENEN QUE HACER POR EL TEMA DEL DIA DE LA MADRE. SE DESCARGAR APLICACIONES DEL PLAY STORE COMO TAMBINE DEL GOOGLE PLAY . ES ALGO DEL DIA A DIA QUE UNO DEBE DE SABER MANEJAR.

25. ¿Usted tienen conexión a internet en su celular, podría detallarnos por favor si tiene internet ilimitado, accede a través de wi-fi en su casa, trabajo?

SI TENGO CONEXIÓN A INTERNET. EN MI CASA NO TENGO ACCESO AL WI FI. EN EL TRABAJO ,EN CADA PISO HAY INTERNET PERO PARA LAS COMPUTADORAS. PERO ACCESO AL WI FI ES ALGO SOLO PARA LA PARTE DE COMPUTO PERO TODAVIA NO SE DA EN GENERAL. DE TENER INTERNET ILIMITADO EN MI CELULAR, NO LO TENGO POR UN TEMA ECONOMICOPERO SI TENGO UN PAQUETE DE DATOS QUE PUEDO MANEJAR PARA COMUNICARME CON MIS FAMILIARES CON LOS PAPAS DE MIS ALUMNOS.

g) La aceptación de una plataforma de comunicación. Por favor, explicar el siguiente concepto, antes de continuar: 
"Si tuviese una plataforma de comunicación, que permita desde tan solo su celular Smartphone establecer comunicación en tiempo real entre la comunidad educativa, que posibilite el tener información actualizada en relación a avisos, reuniones, mensajes, fotos intercambiadas entre los padres, alumnos, profesores, así como revisar el estado de las notas y asistencias".

BUENO PARA NOSOTROS LOS PROFESORES SERIA BUENISIMO Y MANEJAR UNA PLATAFORMA DE OCMUNICACION EN TIMEPO REAL Y CLARO TAMBIEN SE TENDRIA QUE PARA PODER ACCEDER OTROS QUE NO ESTAN TANTO CON ELLOS Y TIENEN UN TIEMPO. SERIA GENIAL QUE TENGAMOS UN TIPO DE COMUNICACIÓN MAS ABIERTA CON LOS PAPAS, SIEMPRE ES BUENO MANTENER LAS BUENAS RELACIONES, TENER UNA COMUNICACIÓN ABIERTA PORQUE ESO ES LO QUE BENEFICIA A LOS NIÑOS EN SU AVANCE Y NO SOLO EN LOS CURSO SINO LA PARTE ACTITUDINAL.

26. ¿Qué beneficios y limitaciones implicaría el uso de esta plataforma de comunicación móvil en tiempo real, para su labor como docente?

LOS BENEFICIOS ESTAN CLARISIMOS, TENER UNA COMUNICACIÓN SUPER FLUIDA CON LOS PAPAS, SOBRETODO LOS PAPAS QUE ESTAN EN CONSTATE VIAJE PORQUE TODO PAPA O FAMILIA TIENE UNA REALIDAD DIFERENTE. HAY ALGUNOS PADRES QUE STAN CERCA Y OTROS PAPAS QUE DE REPENTE ESTAN DE VIAJE O REALIDADES DE FAMILIA QUE NO ESTAN UNIDAS , OTRAS QUE ESTAN DISUELTAS, ETC. TENEMOS DIVERSOS TIPOS DE REALIDAD Y STE TIPO DE APLICACIONES PODRIA PERMITIRNOS COMO MAESTROS TENER UNA COMUNICACIÓN UN POCO MAS FLUIDA. 
POR PARTE FORMAL DE UN COLEGIO, YA DEJANDO DE LADO UNA OCMUNICACION DE WHATAPP O POR FACEBOOK QUE A VECES SE DA. Y LAS LIMITACIONESQUE PODRIA TENER ESTA APLICAICON, VEO QUE SERIA LA PARTE DE LOS TIEMPOS YA QUE NOSOSTROS LOS MAESTROS NOS AVOCAMOS A LOS CHICOS , PRACTICAMENTE DESDE QUE LLEGAMOSHASTA QUE SALIMOS PERO A VECES NO PODRIAMOS TENER EL TIEMPO INDICADO PARA PODER ENTABLAR UNA OCMUNICAICON A TIEMPO REAL . DE REPENTE NOS TENDRIAMOS QUE PONER DE ACUERDO CON LOS PAPAS , A TAL HORA Y TENER ESE ASPECTO MAS ORDENADO. DE REPENTE ESO PODRIA SER UNA LIMITACION. DE REPENTE UN PAPA O UNA MAMA QUIERA COMUNICARSE A UNA HORA Y NOSOTROS LOS MAESTROS TENEMOS OTROS TIPO DE ACTIVIDADES Y POR AHÍ ESA LIMITACION DEL TIEMPO DISPONIBLE PODRIA SER.

27. ¿Cuáles son los atributos o características que le gustaría que tenga esta plataforma de comunicación móvil desde su perspectiva?

\section{LA FLEXIBILIDAD DE HORAS PODRIA SER UN FACTOR Y QUIZAS SERIA} NECESARIO QUE HAYA UNA OPCION PARA QUE LOS PADRES PONGAN SUS SUGERENCIAS PERO SI DE MANERA ASERTIVA. QUE PUEDAN COLOCAR SUS OPINIONES COMO UN MEDIO DE MEJORA. QUIZASPODRIA SER POR GRUPO S DE PADRES.

28. Considera necesaria esta plataforma o si es opcional para el desarrollo de sus labores BUENO POR EL MOMENTO, YO CONSIDERO HONESTAMENTE QUE PARA MI ES ALGO OPCIONAL PORQUE AHORITA YO PUEDO RESOLVER LA NECESIDAD DE 
ADMINISTRACION CON LOS PADRES DE FAMILIA POR LO MEDIOS ACTUALES QUE TENGO PERO SI ESTO EN REALIDAD EXISTIERA DENTRO DEL COLEGIO YO NO TENDRIA NINGUN PROBLEMA EN PODER ADAPTARME O DE CAPACITARME PARA UTILIZAR ESTA PLATAFORMA . PARA NOSOSTROS SERIA GENIAL, PERO POR EL MOMENTO PARA MI SE PRESENTA COMO ALGO OPCIONAL.

29. ¿A qué tipos de colegios considera que sería más útil y/o necesaria este tipo de plataformas?

BUENO, YO CREO QUE PARA LOS COLEGIOS EN LOS CUALES TIENEN MAS ACCESO AL WI FI, AL INTERNET. DE REPENTE A LA CAPITAL O A LOS LUGARES QUE ESTAN MAS CERCA A LA CAPITAL DE REPENTE SERIA MAS DIFICIL EN PROVINCIAS, ZONAS NO URBANIZADAS, ETC

30. ¿cuál considera que es el sustituto de este tipo de plataformas en la gestión educativa hoy?

CONSIDERO QUE ESTOS SUSTITOS SERIAN LAS APLICACIONES DEL WHATAPP, (NO SOY LA UNICA PROFESORA QUE LO MANEJA, INCLUSO CON LOS CHICOS. YO TENGO UN GRUPO DE WHATAP CON ELLOS DESDE QUE NOS FUIMOS A UN PASEO , ERA MAS FACIL PORQUE TODOS LLEVABAN SUS TELEFONOS MOVILES Y A TRAVES DE ESE MEDIO ME COMUNICABA PARA INFORMARLES LA HORA DEL ALMUERZO, ERA MUCHO MAS FACIL MANTENERSE COMUNICADO)

SI NOS CAPACITAN CREO QUE SERIA DE MUCHA AYUDA ESTA PLATAFORMA DE COMUNICACIÓN EN EL SECTOR EDUCATIVO. 
Muchas gracias por tu participación. 
FICHA TECNICA ENTREVISTA A PROFUNDIDAD: EXPERTOS DEL SECTOR TI

\section{Objetivo de la investigación}

El objetivo de este estudio es de nutrirnos de la experiencia de expertos relacionados en el sector educación de nivel primario y secundario sobre la aceptación de una plataforma de comunicación entre padres, alumnos y colegios y el aporte de las Tecnologías de Información y Comunicación TIC en este rubro.

Estamos desarrollando una aplicación para teléfonos móviles inteligentes, que permitirá mejorar la comunicación entre las familias y el colegio. Desde esta aplicación los padres de familia podrán mantenerse informados sobre las actividades del colegio mediante SMS, emails, mensajes internos, avisos, web del centro, intranet. La APP permitirá realizar seguimiento de las tareas, notas de los alumnos, de su asistencia, gestionar citas, bajo un entorno seguro. El producto podrá ser adaptado a las necesidades de la Organización, pudiéndose elegir entre opciones estándar y funcionalidades adicionales. La aplicación será ofrecida mediante la modalidad de pago mensual diferenciada por número de usuarios que incluye su alojamiento en la nube, por lo que el colegio no necesita de inversión en infraestructura de hardware y software, mantenimiento y soporte. El servicio post-venta incluirá un servicio de soporte a la plataforma bajo la modalidad 16x5. Finalmente consideramos importante mencionar que nuestra propuesta contribuye a la protección del medio ambiente, reduciendo considerablemente el uso del papel, tinta y/o tóner.

\section{Contenido}

Los temas de interés que deseamos investigar son:

- Conocer la experiencia de los involucrados sobre el estado de aceptación de las aplicaciones móviles y servicios en la nube.

- Los aportes que puede hacer las TIC en el sector educación y el mejoramiento de la comunicación.

- Las plataformas de comunicación en educación usadas actualmente con el apoyo de TI.

- La aceptación de una plataforma de comunicación en línea.

\section{Perfil del participante}

- Experiencia: 5 años en puesto ingeniero de sistemas y de proyectos con en aplicaciones móviles. 
- Ingeniero de sistemas.

\section{Cuestionario}

\section{Presentación:}

Buenos días, actualmente nos encontramos realizando una investigación acerca de las tecnologías de información y su aporte y uso como plataforma de comunicación para colegios de nivel primario y secundario. Agradecemos que pueda brindarnos su experiencia la cual significa un gran aporte nuestro estudio.

A continuación, le haremos unas preguntas que nos permitirán tener mayor información y que ayudarán a esclarecer ciertos temas que consideramos importantes para poder concretar esta investigación. Desde ya le agrademos el apoyo.

Entrevista de Profundidad / Experto en TI

\begin{tabular}{|l|l|}
\hline Nombre & \\
\hline Edad & \\
\hline Profesión & \\
\hline Cargo & \\
\hline Reseña & \\
\hline
\end{tabular}

Comunidad educativa: compuesto por profesores, APAFA, administración de colegio, padres de familia y alumnos de un determinado colegio.

\section{Pregunta de control/verificación de experiencia:}

¿Podría por favor comentarnos acerca de su experiencia en sector educativo?

\section{h) Aplicaciones Móviles y Servicios en la Nube}

31. Desde su punto de vista y experiencia ¿Que tan aceptadas son las aplicaciones móviles en la actualidad? 
32. ¿Usted percibe alguna preferencia por los usuarios de aplicaciones móviles para Android o IOS?

33. ¿Podría detallarnos que características y de mayor aceptación en cuanto a diseño de aplicaciones móviles se están usando en las aplicaciones móviles y de mayor aceptación?

34. ¿Qué herramientas de seguridad están siendo usadas actualmente en las aplicaciones móviles en el sector educación?

35. ¿Qué ventajas o desventajas usted encuentra en los servicios de alojamiento de las soluciones de TI en la nube y su aceptación?

\section{i) Las TIC en la educación}

36. ¿Considera importante el uso de las Tecnológicas de Información aplicadas en la educación? ¿Por qué?

37. Actualmente, podría comentarme ¿Cuáles son las TIC que se emplean en su institución?

38. ¿Cómo ve el futuro de las TIC en la educación?

\section{j) Plataforma de comunicación en la educación}

39. ¿Actualmente usted conoce o ha tenido alguna experiencia con una herramienta de TI que facilite la comunicación en tiempo real entre los miembros de la comunidad educativa?

40. Detalle su experiencia

k) La aceptación de una plataforma de comunicación en línea. Por favor, explicar el siguiente concepto, antes de continuar:

"Si tuviese una plataforma de comunicación, que permita desde su celular Smartphone establecer comunicación en tiempo real entre la comunidad educativa, que sea inmediata y que posibilite obtener información actualizada en relación a avisos, 
reuniones, mensajes, fotos intercambiadas entre los padres, alumnos, profesores, así como revisar el estado de las notas y asistencias".

41. ¿Qué beneficios y limitaciones implicaría el uso de esta plataforma de comunicación móvil en tiempo real, entre la comunidad educativa?

42. ¿Cuáles son los atributos o características cree usted que deba tener esta plataforma de comunicación móvil para la comunidad educativa?

43. ¿Conoce usted de alguna plataforma de comunicación móvil en tiempo real para la comunidad educativa?

44. ¿Ustedes usan actualmente una plataforma de comunicación móvil en tiempo real en su institución?

\section{La aceptación de una plataforma de comunicación en línea, frente a productos} que ofrecen una suite completa de gestión educativa. Explicar el siguiente concepto, antes de continuar:

"Plataformas de gestión educativa completa: plataformas que incluyen funcionalidades como aula virtual, biblioteca en línea, agenda inteligente, matricula, gestión de notas, personalizar barra de herramientas".

45. ¿Qué ventajas y desventajas usted encuentra en esta solución frente a plataformas que ofrecen toda una gestión educativa incluyendo las comunicaciones?

46. ¿Cree usted desde su experiencia que los colegios estarían dispuestos a adquirir esta plataforma de comunicación? ¿Por qué?

47. ¿En qué medio publicitario usted sugiere usar para promocionar la plataforma de comunicación propuesta? 
48. ¿Qué rango de precio mensual cree que los colegíos estarían dispuestos a invertir? (300 a 400, 401 a 500, 501 a 600, 601 a 700, 701 a más US\$ dólares)

Gracias por su colaboración en nuestro trabajo de investigación. 
Tabulación de resultado de las encuestas - Gráficos

Pregunta $\mathrm{N}^{\circ} 1$

¿Su centro educativo brinda conexión a Internet inalambrica a la plana docente yadministrativa?

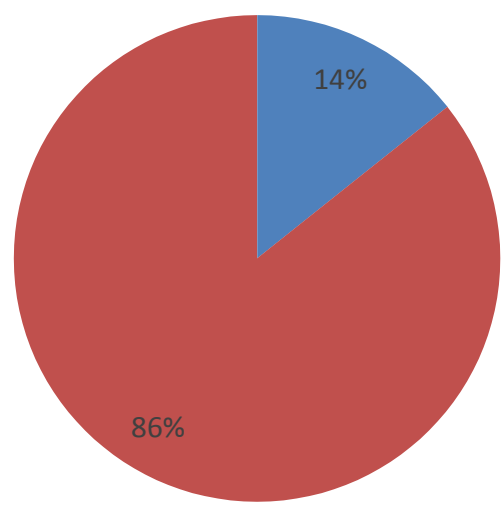

$\square \mathrm{NO} \square \mathrm{SI}$

Pregunta $\mathrm{N}^{\circ} 2$

¿Usted se siente familiarizado con el uso de aplicaciones móviles en su smartphone?

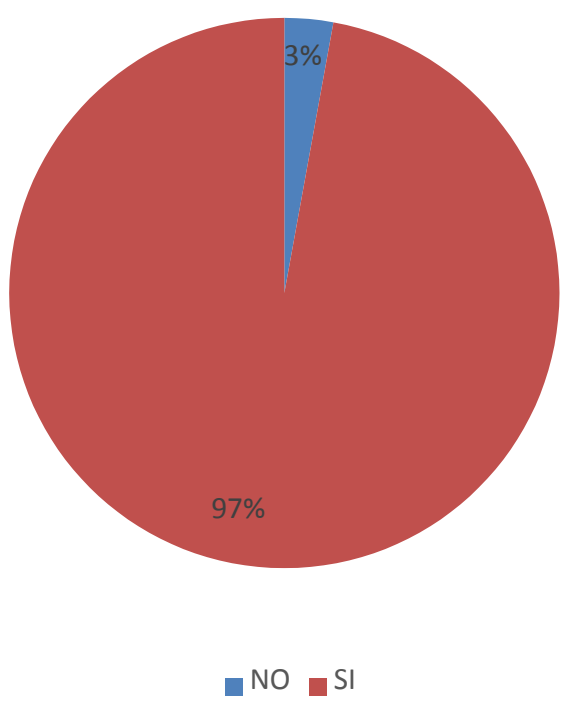


Pregunta $\mathrm{N}^{\circ} 3$

¿Cree usted que tiene aceptación el uso de smartphones en la plana docente y administrativa?

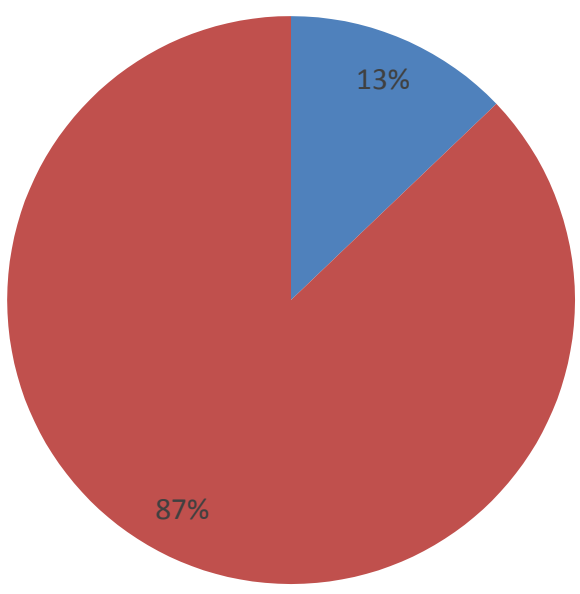

NO SI

Pregunta $\mathrm{N}^{\circ} 4$

$¿$ ¿Cree usted que la comunicación entre profesores, padres de familia y alumnos está directamente relacionadas con el rendimiento académico de los alumnos?

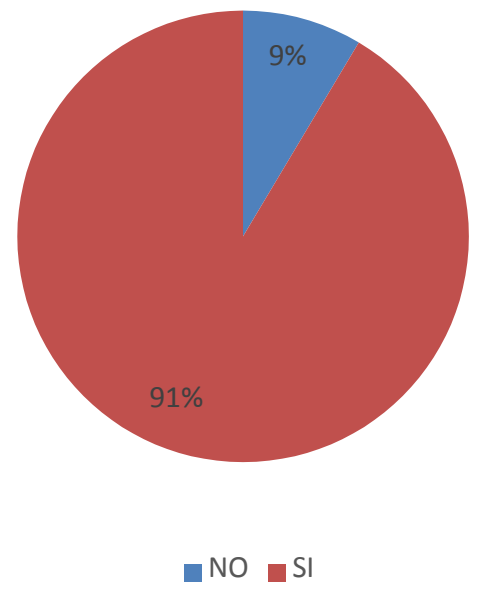


Pregunta $N^{\circ} 5$

¿Piensa que es importante la comunicación inmediata entre profesores, padres de familia y alumnos?

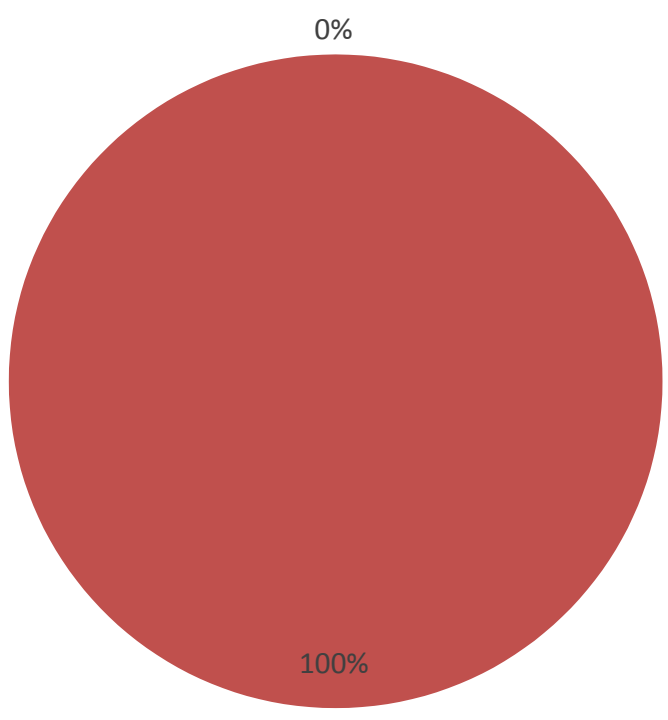

$\square$ NO SI

Pregunta $\mathrm{N}^{\circ} 6$

¿Cree usted que es efectivo el uso de una plataforma de comunicación online para la comunidad educativa a través de smartphones?

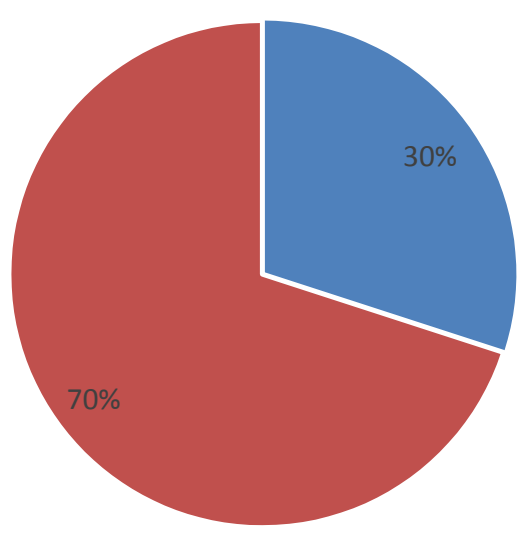

NO SI 


\section{Pregunta Nº}

\section{¿Actualmente ustedes usan alguna plataforma de} comunicación online?

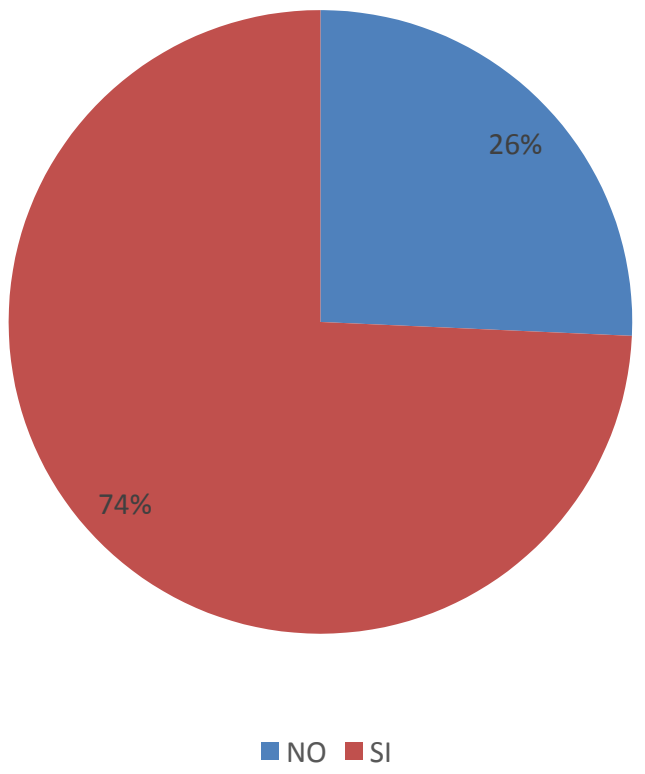

\section{Pregunta $\mathrm{N}^{\circ} 8$}

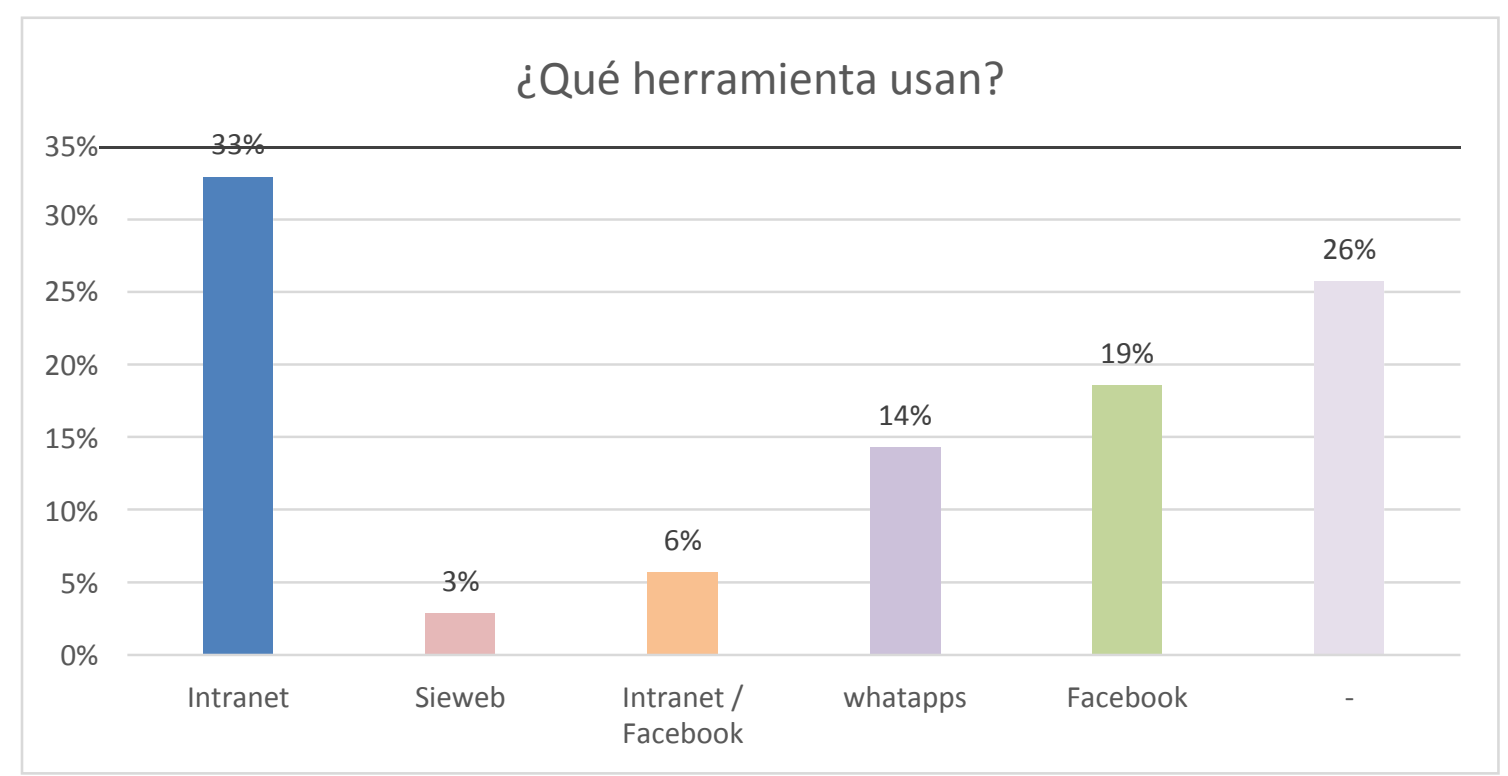


Pregunta $\mathrm{N}^{\circ} 9$

¿Se encuentran satisfechos con el servicio ofrecidocon la herramienta usada actualmente?

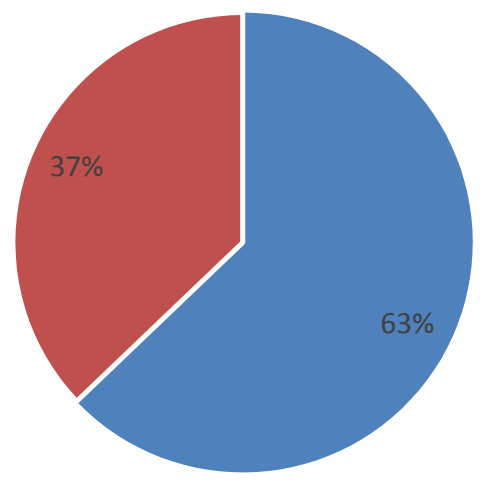

NO $\square \mathrm{SI}$

Pregunta $N^{\circ} 10$

¿Cómo considera usted la comunicación en tiempo real en la comunidad educativa?

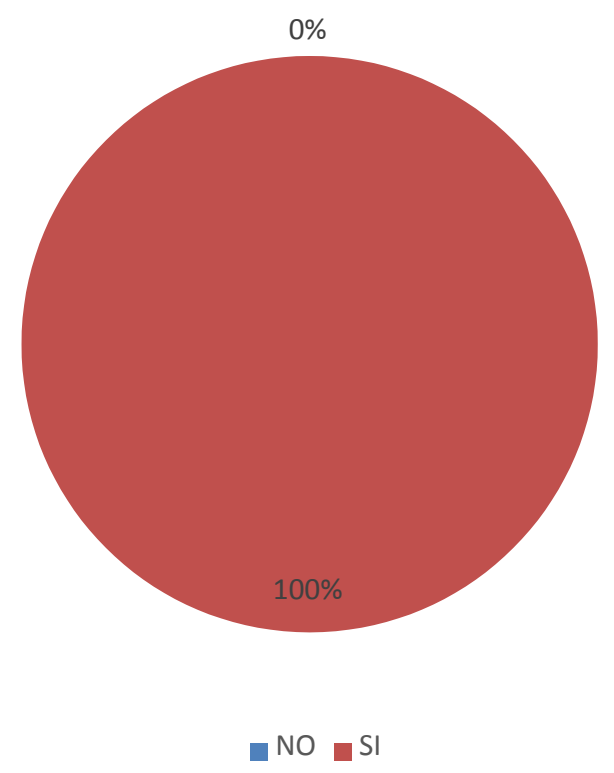


Pregunta $\mathrm{N}^{\circ} 11$

¿Considera que la visualización de las calificaciones es importante para los padres de familia?

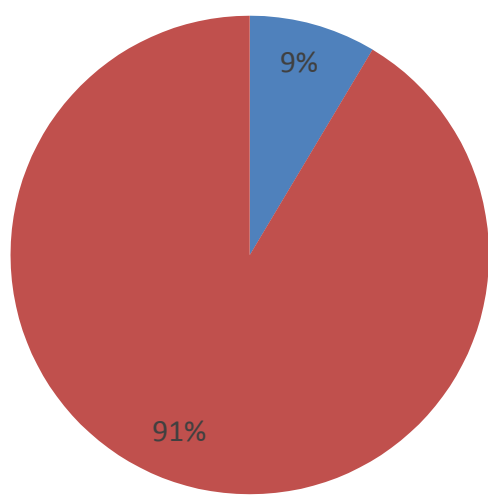

$\square \mathrm{NO}$ SI

Pregunta $\mathrm{N}^{\circ} 12$

¿Cómo considera la visualización por parte de los padres de familia de la lista de asistencia online?

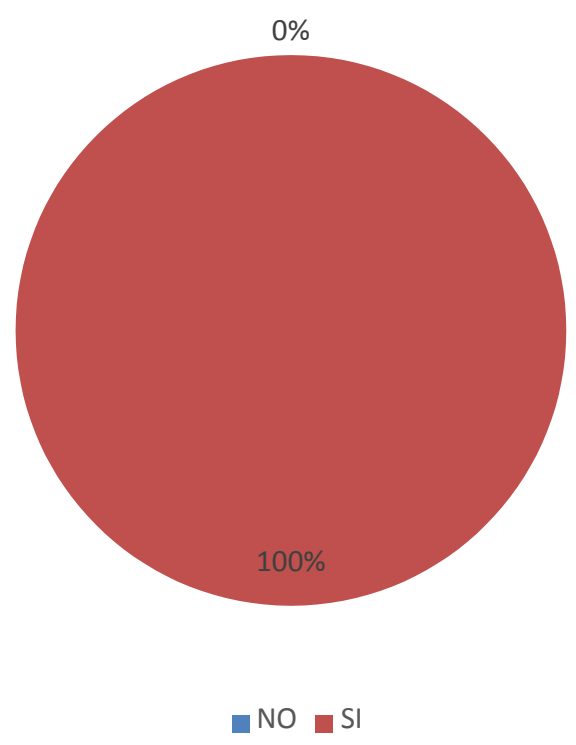


Pregunta $\mathrm{N}^{\circ} 13$

¿Cómo considera usted la seguridad en una aplicación que permita pagos online?

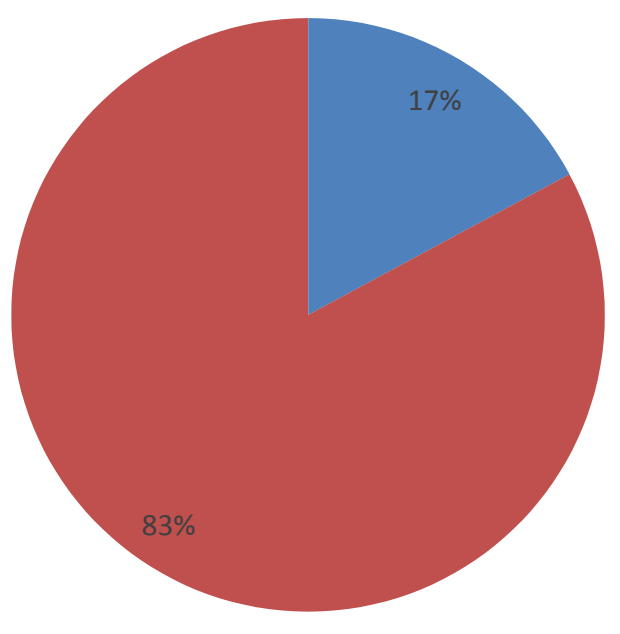

$\square \mathrm{NO} \square \mathrm{SI}$

Pregunta $\mathrm{N}^{\circ} 14$

¿Cómo considera usted, que una plataforma online tenga una presentación amigable y de fácil acceso?

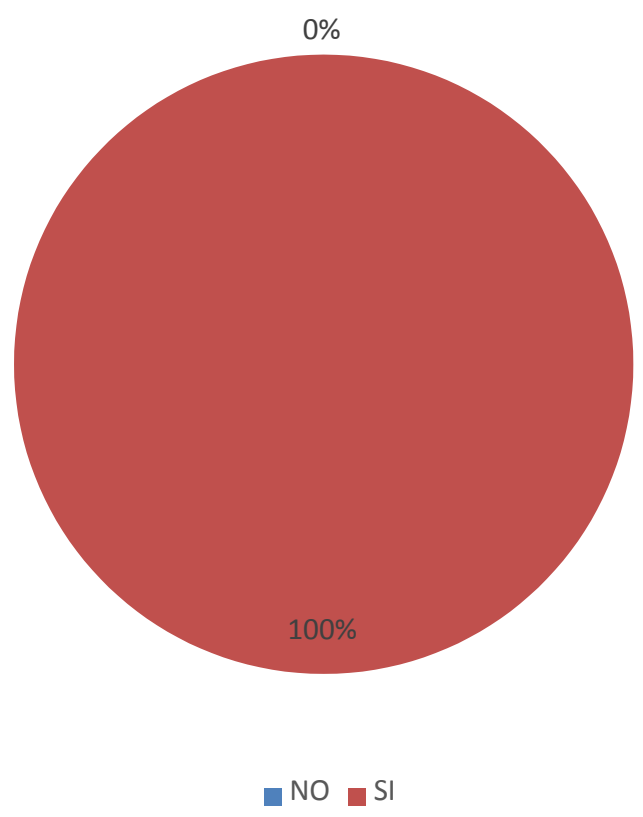


Pregunta $\mathrm{N}^{\circ} 15$

¿Qué tanto valora usted que la plataforma online tenga los colores, logos, escudos, etc. que identifiquen a su colegio?

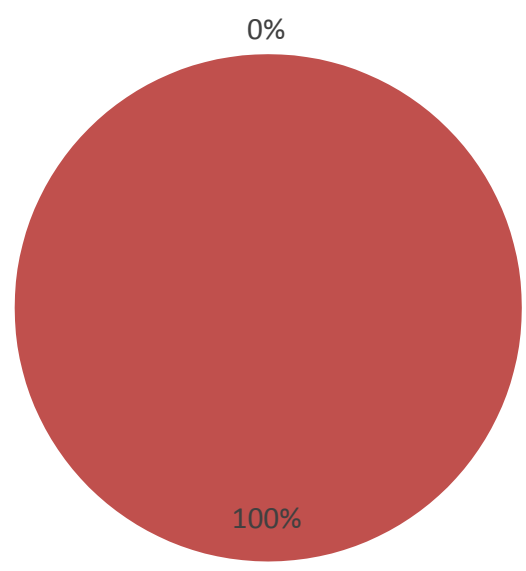

$\square \mathrm{NO} \square \mathrm{SI}$

Pregunta $N^{\circ} 16$

¿Qué tanto valora usted que la plataforma online tenga un servicio de postventa?

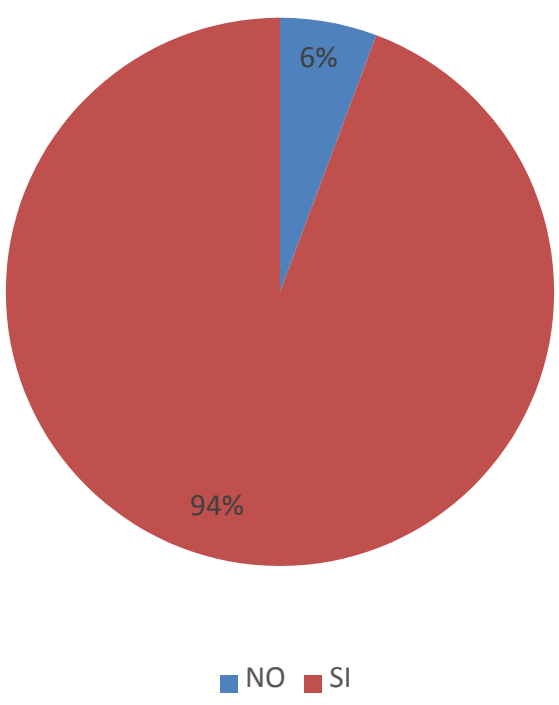




\section{Pregunta $\mathrm{N}^{\circ} 17$}

¿Considera usted que el precio es un factor importante para adquirir una plataforma de comunicación online?

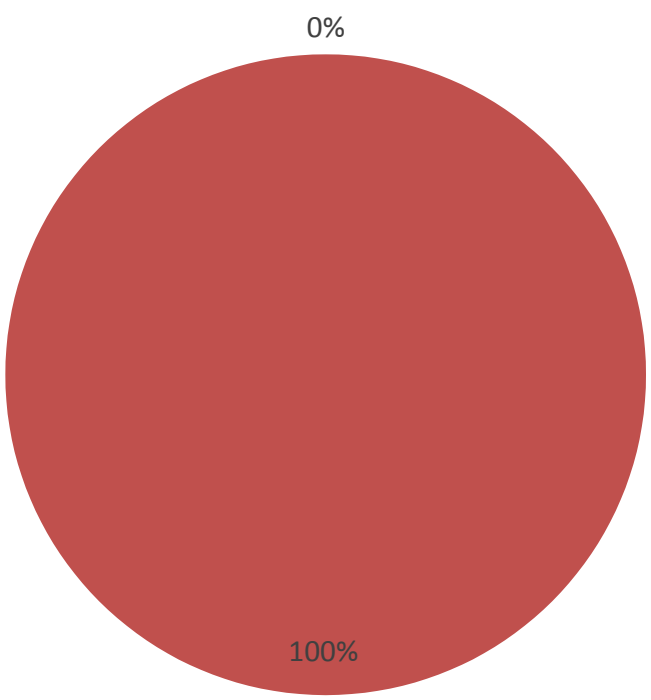

$\square \mathrm{NO} \square \mathrm{SI}$

Pregunta $\mathrm{N}^{\circ} 18$

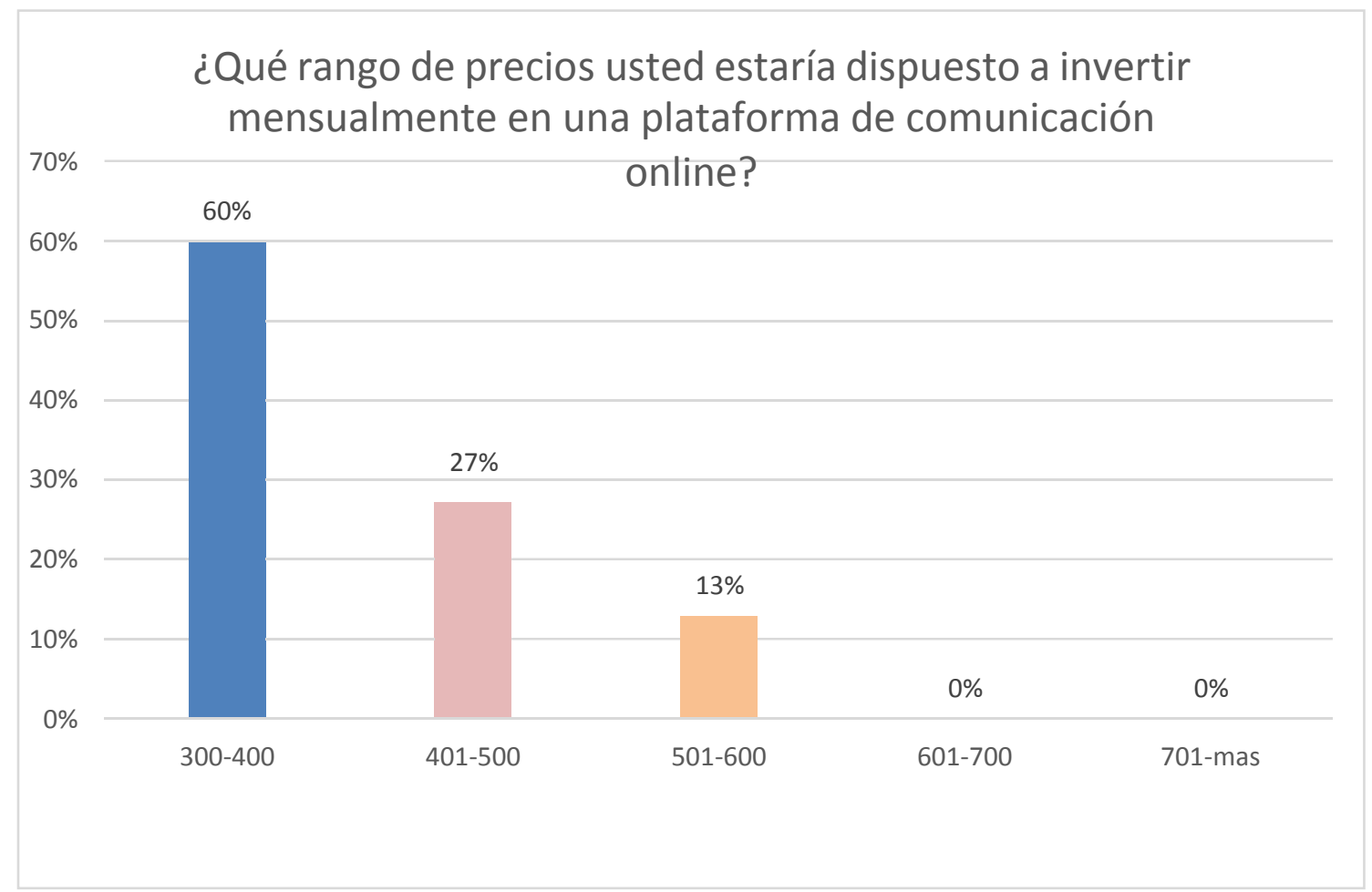


Pregunta $N^{\circ} 19$

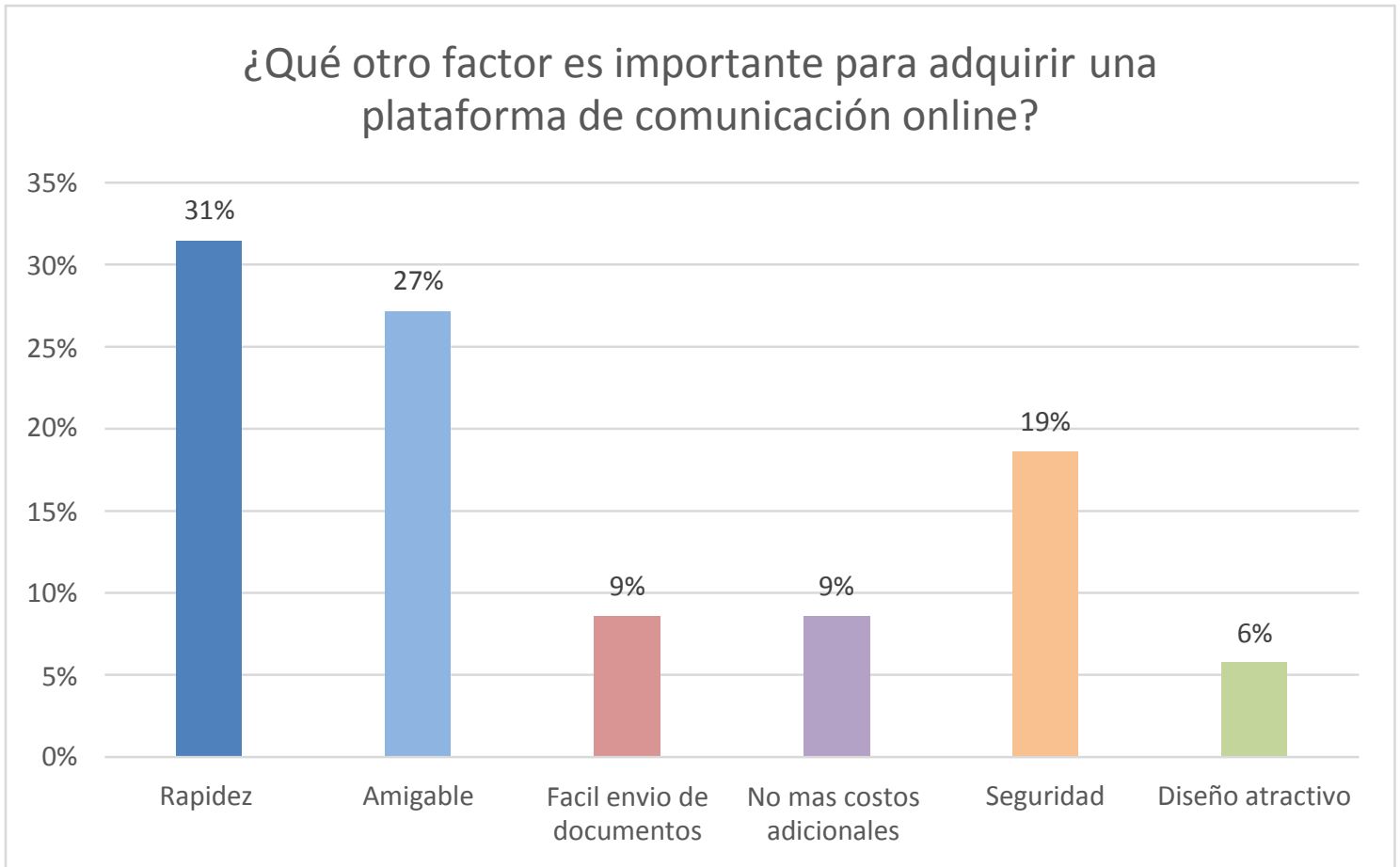

\section{Pregunta $\mathrm{N}^{\circ} 20$}

¿Usted estaría dispuesto a adquirir el servicio de plataforma en tiempo real para la comunicación entre familias, colegio y alumnos?

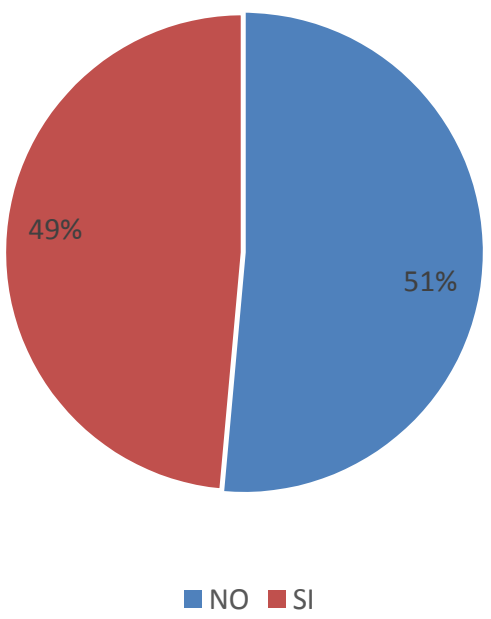


Pregunta $\mathrm{N}^{\circ} 21$

¿Estaría de acuerdo usted en realizar pagos mensuales por concepto de uso y servicio de la plataforma de comunicación online?

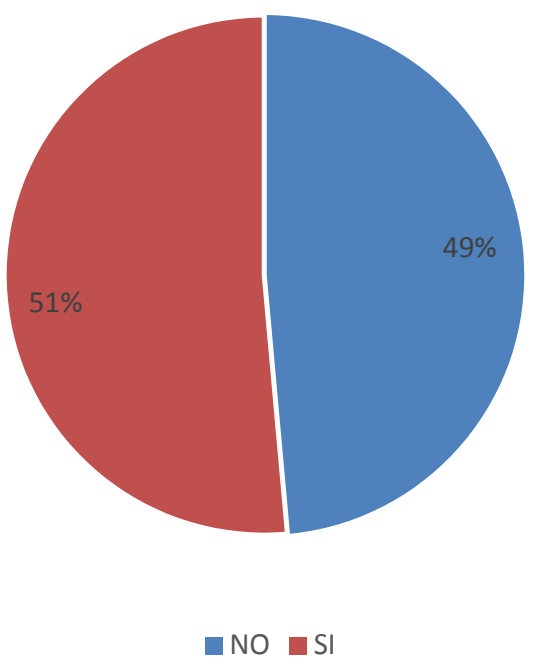


NOMBRE DEL DIRECTOR:

NOMBRE DEL COLEGIO:

DISTRITO:

COLEGIO: RELIGIOSO $\square$ LAICO $\square$

AÑOS DE ACTIVIDAD DEL COLEGIO:

TECNOLOGÍAS DE INFORMACIÓN, SU APORTE Y USO COMO PLATAFORMA DE COMUNICACIÓN PARA COLEGIOS DE NIVEL PRIMARIO Y SECUNDARIO

Queremos conocer cuál es su opinión sobre las siguientes preguntas

(Por favor marcar sólo una casilla por cada pregunta)

$1=$ Totalmente en desacuerdo

$2=$ En desacuerdo

$3=\mathrm{Ni}$ de acuerdo Ni en desacuerdo

$4=$ De acuerdo

$5=$ Totalmente de acuerdo

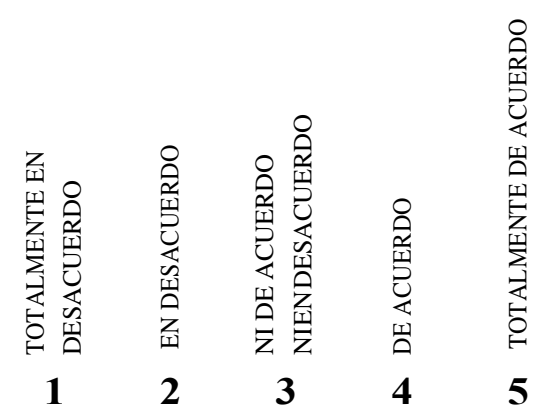

* Comunidad educativa: compuesto por profesores, APAFA, administración de colegio, padres de familia y alumnos de un determinado colegio.

\section{ACCESO A INTERNET Y ACTITUD HACIA USO DE SMARTPHONES}

1.- ¿Su centro educativo brinda conexión a Internet inalambrica a la plana docente y administrativa?

2- ¿Usted se siente familiarizado con el uso de aplicaciones móviles en su smartphone?

3.- ¿Cree usted que tiene aceptación el uso de smartphones en la plana docente y administrativa?

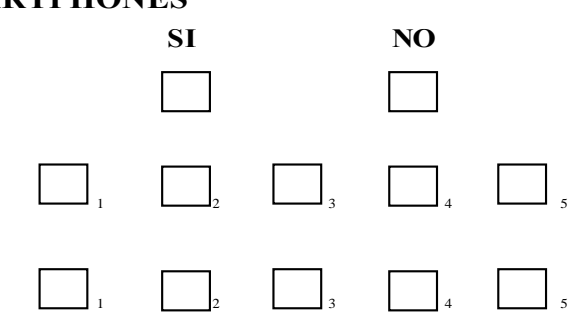

* Plataforma de comunicación online (tiempo real), permite desde un smartphone la comunicación (avisos, reuniones, mensajes, fotos intercambiadas entre los padres, alumnos, profesores) entre la comunidad educativa, pudiendo también revisar el estado de las notas, asistencias y pagos de pensiones.

\section{PREFERENCIA POR USO DE UNA PLATAFORMA COMUNICACIÓN ONLINE}

4.- ¿Cree usted que la comunicación entre profesores, padres de familia y alumnos está directamente relacionadas con el rendimiento académico de los alumnos?

5.- ¿Piensa que es importante la comunicación inmediata entre profesores, padres de familia y alumnos?

6.- ¿Cree usted que es efectivo el uso de una plataforma de comunicación online para la comunidad educativa a través de smartphones?

7.- ¿Actualmente ustedes usan alguna plataforma de comunicación online?

Si su respuesta fue NO pasar a la pregunta 10

8.¿Qué herramienta usan?

9.- ¿Se encuentran satisfechos con el servicio ofrecido con la herramienta usada actualmente? 


\section{TECNOLOGÍAS DE INFORMACIÓN, SU APORTE Y USO COMO PLATAFORMA DE COMUNICACIÓN PARA COLEGIOS DE NIVEL PRIMARIO Y SECUNDARIO}

Queremos conocer cuál es su opinión sobre las siguientes preguntas

(Por favor marcar sólo una casilla por cada pregunta)

$1=$ Nunca importante

$2=$ Casi nunca importante

$3=$ A veces importante

$4=$ Casi siempre importante

$5=$ Siempre importante

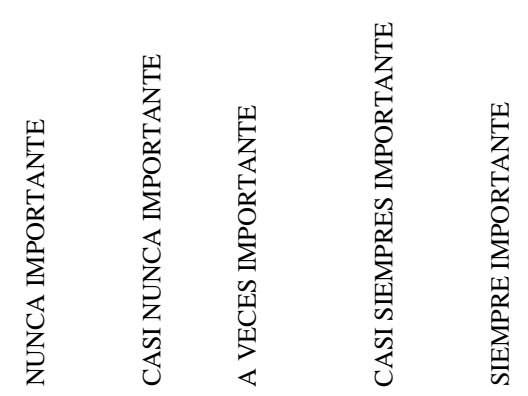

CARACTERÍSTICAS EN LA PLATAFORMA DE COMUNICACIÓN ONLINE

10.- ¿Cómo considera usted la comunicación en tiempo real en la comunidad educativa?

11.- ¿Considera que la visualización de las calificaciones es importante para los padres de familia?

12.- ¿Cómo considera la visualización por parte de los padres de familia de la lista de asistencia online?

13.- ¿Cómo considera usted la seguridad en una aplicación que permita pagos online?

14.- ¿Cómo considera usted, que una plataforma online tenga una presentación amigable y de fácil acceso?

15.- ¿Qué tanto valora usted que la plataforma online tenga los colores, logos, escudos, etc. que identifiquen a su colegio?

16.- ¿Qué tanto valora usted que la plataforma online tenga un servicio de postventa?

17.- ¿Considera usted que el precio es un factor importante para adquirir una plataforma de comunicación online?
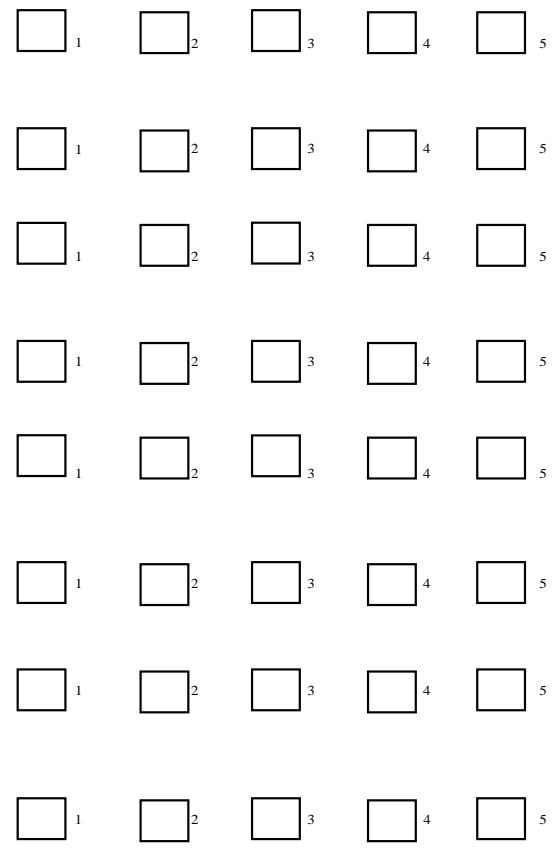

DOLARES

\begin{tabular}{|ccccc}
$300-400$ & $401-500$ & $501-600$ & $601-700$ & +701 \\
\hline
\end{tabular}

18.- ¿Qué rango de precios usted estaría dispuesto a invertir mensualmente en una plataforma de comunicación online?

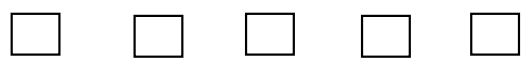

19.- ¿Qué otro factor es importante para adquirir una plataforma de comunicación online?

20.-

¿Usted estaría dispuesto a adquirir el servicio de plataforma en tiempo real para la comunicación entre familias, colegio y alumnos?

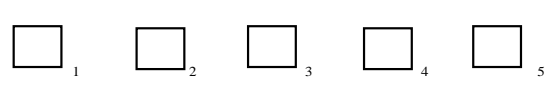

21.-

¿Estaría de acuerdo usted en realizar pagos mensuales por concepto de uso y servicio de la plataforma de comunicación online?

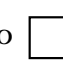




\section{CONCLUSIONES DEL FOCUS GROUP $\mathrm{N}^{\circ} 1$ y $\mathrm{N}^{\circ} 2$}

a) Sobre la experiencia de los involucrados o padres de familia sobre la importancia de la comunicación entre la comunidad educativa, les parece muy importante ya que pueden hacer seguimiento a sus hijos. Uno de ellos hizo hincapié en el seguimiento que puede realizar a su hijo adolecente.

b) Las aplicaciones que usan los padres son gratuititas, solo las de ocio o juegos son pagadas.

c) Los padres que participaron en el grupo de enfoque usan la apps para comprar en línea, realizar transacciones bancarias.

d) Sobre la experiencia de los involucrados o padres de familia con el uso de las Tecnologías de Información, todos ellos tienen experiencia en el manejo de aplicaciones, todos ellos cuentan con un Smartphone y están familiarizados desde aplicaciones de comunicación, pasando por compra y venta por aplicaciones móviles y también el manejo de aplicaciones bancarias.

e) Hay padres que usan la aplicación social del WhatsApp para comunicarse con grupos de padres del colegio.

f) Los entrevistados consideran que los aportes que puede hacer las TIC en el sector educación y el mejoramiento de la comunicación es muy alta cuando es bien empleada. Indican que han tenido experiencia negativas con aplicaciones pero que han sido muy pocas. (ejemplo, le cobraron una compra que página se Saga Falabella que ella no había realizado, hizo el trámite de anulación y la tienda la atendió).

g) La aceptación de una plataforma de comunicación en línea frente a productos que ofrecen una suite completa de gestión educativa, este punto fue muy receptivo ya que la suite completa en su caso está asociado a ingresar a una plataforma de pc, en 
cambio a tener un producto APP (aplicación móvil) siempre lo tienen activo en su Smartphone.

h) Características que debe tener la plataforma: diseño amigable, intuitivo, fácil de usar, fácil acceso sin password y claves.

i) Es necesario que tenga un buzón de sugerencias como medida de mejora de la plataforma

j) Padres considera que deberían enterarse del uso de esta plataforma por medio circulares, correos, reuniones explicativas ( funcionalidad, avance )

k) Desventajas ( no encuentran alguna) ventajas ( que puede ser usada por medio de smartphones, portabilidad, información y comunicación real inmediata,

1) Funcionalidades que añadirían: asistencias con huella, descargar clases ( si es que hijos no van a clases, *obviamente con políticas y normativa, límites y horarios; aula virtual, gps a movilidades para saber la ubicación de nuestros hijos )

m) Todos consideran importante y están de acuerdo en cuanto a emplear esta plataforma

n) Obstáculos que visualizan: tiempos, fijación de límites, disponibilidad de profesores, actualización de información y cuidado con errores en la subida de información.

o) Consideran que si podrían reemplazar la agenda pero que de alguna manera podrían quedarse como medio de organización del alumno. Si podría reemplazar la plataforma que se esté usando que no tenga acceso con su Smartphone. 
FODA

\begin{tabular}{|c|c|c|}
\hline & FORTALEZAS & DEBILIDADES \\
\hline & $\begin{array}{l}\text { * Plataforma amigable, intuitiva y atractiva } \\
\text { *Permite comunicación en tiempo real } \\
\text { dentro de la comunidad educativa } \\
\text { *Excelente servicio post venta } \\
\text { *Precios accesibles } \\
\text { *Única plataforma especializada en } \\
\text { comunicación en tiempo real en el sector } \\
\text { educativo }\end{array}$ & $\begin{array}{l}\text { *Empresa nueva y nueva marca } \\
\text { *Competencia con marcas posicionadas }\end{array}$ \\
\hline & OPORTUNIDADES & AMENAZAS \\
\hline & $\begin{array}{l}\text { *Reducción del IGV } \\
\text { *Crecimiento de la economía } \\
\text { *Crecimiento del PBI } \\
\text { *Tendencia a la baja del tipo de cambio } \\
\text { *Bajo nivel de inflación } \\
\text { *Ley de Promoción de la Investigación } \\
\text { científica, desarrollo tecnológico e } \\
\text { innovación tecnológica } \\
\text { *Crecimiento de la demanda de } \\
\text { Smartphones } \\
\text { *Gobierno impulsa iniciativas para reducir } \\
\text { el uso del papel } \\
\text { *Reducción de piratería de software }\end{array}$ & $\begin{array}{l}\text { *Crecimiento del número de empresas de } \\
\text { software en el Perú } \\
\text { *Incremento de investigaciones que } \\
\text { apoyan las desventajas de las TICS } \\
\text { *Vigencia y ciclo de los productos y } \\
\text { servicios tecnológicos es muy corto }\end{array}$ \\
\hline
\end{tabular}




\section{Bibliografía}

Aching C \& Aching J . (2016) Ratios financieros y matemática de la mercadotecnia (Capitulo 1)

Alvarez. D, Nuñez. J, Alvarez. L, Dobarro. A, Rodriguez. C (2011) Violencia a través de las tecnologías de la información y la comunicación en estudiantes de secundaria.

Belén, A., \& Sellers, R (2006). Dirección de Marketing: Teoría y Práctica. Barcelona España: Editorial Club Universitario

Cuello y Vittone (2013), Diseñando apps para móviles (ebook).

Faga. H \& Ramos.M. (2006). Como profundizar en el analisis de los costos para tomar las mejores decisiones empresariales. Ed Granica S.A. Buenos Aires.(Capitulo 7, pg196)

Hernandez, R., Fernandez, C \& Baptista, P (2010) Metodología de la investigación (5ta ed). Estado de México: Editorial Mcgraw-Hill /Interoamericana

Hitt, M.A., Ireland, A.D., \& Hoskisson, R.(2004). Administración Estratégica. Competitividad y conceptos de globalización, (5ta ed.). México

Horngren, C, Datar. S, \& Rajan. M. (2012). Contabilidad de Costos. Un enfoque gerencial, decimacuarta edición, México Pearson ( Capitulo 6 - pag 184)

Iborra, M., Dasí, A, Dolz. C., \& Ferre, C.(2014). Fundamentos de Dirección de Empresas. Conceptos y Habilidades directiva. (2da ed.).España, Madrid

Jaramillo. P , Castañeda. \& Pimienta. M. (2009) Que hacer con la tecnología en el aula: inventario de usos de las TICS para aprender y enseñar. P.161 
Jobber. D \& Lancaster. G. (2012) Administración de ventas. Octava edición. Pearson (capitulo 16, pag 458)

Keat y Young (2004) Economía de la empresa (pág. 448)

León, C. (2007) Evaluación de Inversiones. Un enfoque privado y social. Edición electrónica gratuita. www.eumed.net/libros/2007a/232/

Lopez Y Nevado (2006) Gestione y controle el valor integral de su empresa (Capitulo 3,pg. 39)

Macia.M. (2016). La comunicación Familia- escuela: el uso de las TIC en los centros de primaria. Revista Electrónica Interuniversitaria de Formación del Profesorado 19 (1), 73 83

Kotler, P., \& Armstrong, G. (2012). Marketing (12 va ed.). Naucalpan de Juárez, Estado de México: Editorial Pearson.

Aching. C y Aching. J (2016) Ratios financieros y matemática de la mercadotecnia.

Sanchez. O y Tarodo. C (2015) Gestión Contable UF0314. España.

Richards. M i. Davies. J, Yaron. G \& Sanginés. A (2002) Manejo forestal participativo. Entendiendo sus principios económicos. México

Lopez.R \& Nevado. D ( ) Gestione y controle el valor integral de sus empresas. Análisis integral, modelos, informes financieros y capital intelectual para rediseñar la estrategia. (4ta ed).México

Keat.P \& Young. P. Economía de empresa. España. 
Kotler, P., \& Keller, K. (2016). Dirección de Marketing (15va ed.).México: Pearson

Reyes, O.(2013). Nuevas tendencias de mercado electrónico. Estados Unidos:

Ediciones Palibrio.

David , F (2012). Administración estratégica. México

Llanos, J. (2005). Como entrevistar en la selección de personal. (1era ed ) Ciudad de México: Editorial Pax México

Merino, M. (2010). Introducción a la investigación de mercados. Madrid, España, Editorial Esic.

Michaux . S y Cadiat . A. Las 5 fuerzas de Porter: Cómo distanciarse de la competencia con éxito. Como distanciarse de la competencia con éxito. Economía y empresa en 50 minutos.

Mochon y Aparicio (2014)

Naresh K. \& Malhotra, (2008) Investigación de Mercados Quinta Edición. Pearson

Planificación aplicada a empresas asociativas rurales. Instituto Interamericano de Cooperación para la Agricultura (IICA). 2006.

Baca, G (2013). Evaluación de proyectos. McGraw Hill Inteamericana

Sapag, N \& Sapag, R (2014). Preparación y evaluación de proyectos. ( ) Bogotá, México, Mc Grill.

Porter. M (2009). Ser competitivo. Edición actualizada y aumentada. Barcelona, España: Ediciones Deusto Planeta De Agostini Profesional y Formación, S.L

Pressman Roger, (2010). Ingeniería de Software. McGraw-Hill Interamericana 
Reyes, O. (2013). Nuevas tendencias de mercado electrónico. Estados Unidos:

Ediciones Palibrio

Richards Davies y Sangines (2008)

Robbins Stephen P, Timothy A. Judge (2013). Comportamiento organizacional. México, D.F.: Pearson.

Sanchez y Tarodo (2015) Gestión Contable Cap 5 pg 279

Tanaka (2005) Análisis de estados Financieros para la toma de decisiones.

Thompson Arthur A. (2015). Administración estratégica. México, D.F.: McGraw Hill 


\title{
Referencias electrónicas
}

\author{
Alvarez. D, Nuñez. J, Alvarez. L, Dobarro. A, Rodriguez. C (2011) Violencia a \\ través de las tecnologías de la información y la comunicación en estudiantes de secundaria. \\ http://search.proquest.com/central/docview/1437144359/fulltextPDF/5330C352990B4BE9P \\ $\mathrm{Q} / 1$ ?accountid=43847
}

Asociación Peruana de Productores de Software (APESOFT). Recuperado de http://www.apesoft.org/boletines

El Comercio (2015, Octubre 20). Desarrolladores de software peruanos facturan US\$500 millones. Recuperado de http://elcomercio.pe/economia/negocios/desarrolladoressoftware-peruanos-facturan-us500-millones-noticia-1849607

Gestión (2015, Julio 27). Los ingenieros mejor pagados del Perú: cuánto ganan y dónde estudiaro. Recuperado de http://gestion.pe/empleo-management/ingenieros-mejorpagados-peru-cuanto-ganan-y-donde-estudiaron-2138315

Gestión (2015, Diciembre 20). ¿Sabes cuánto ganan los profesionales especializados en tecnologías de la información?. Recuperado de http://gestion.pe/empleomanagement/sabes-cuanto-ganan-profesionales-especializados-tecnologias-informacion2151359

Gestión (2016, Abril 14). Perú tiene potencial para desarrollo de software dedicado al sector empresarial. Recuperado de http://gestion.pe/tecnologia/peru-tiene-potencialdesarrollo-software-dedicado-al-sector-empresarial-2158494 
Gestión (2016, Mayo 21). Industria del software peruano seguirá creciendo a dos dígitos, según experto. Recuperado de http://gestion.pe/tecnologia/industria-softwareperuano-seguira-creciendo-dos-digitos-segun-experto-2161373

Gestión (2016, Noviembre 23). Economía peruana crecerá 4.2\% en el 2017, según sondeo de Bloomberg. Recuperado de http://gestion.pe/economia/economia-peruana-crecera42-2017-segun-sondeo-bloomberg-2175430

Jobber. D \& Lancaster. G. (2012) Administración de ventas. Octava edición. Pearson (capitulo 16, pag 458) https://www.biblionline.pearson.com/Pages/BookRead.aspx

http://sisbib.unmsm.edu.pe/bibvirtual/publicaciones/indata/v01_n2/costo.htm http://aempresarial.com/web/revitem/1_17590_12094.pdf http://www.munilince.gob.pe/sites/default/files/documents/licencia-defuncionamiento/02-01-ley-28976-ley-marco-de-licencias-de-funcionamiento.pdf http://www.munilince.gob.pe/atencion-al-ciudadano/licencias-de-funcionamiento http://www.caballerobustamante.com.pe/plantilla/profe/profe_111008.pdf

Ministerio de trabajo y promoción del empleo. Preguntas frecuentes. Recuperado de http://www.mintra.gob.pe/archivos/file/faqs/PREGUNTAS_FRECUENTES_2012.pdf

Reporte de la inflación Marzo 2017. Panorama actual y proyecciones macroeconómicas 2017 2018. http://www.bcrp.gob.pe/docs/Publicaciones/ReporteInflacion/2017/marzo/reporte-de-inflacion-marzo-2017.pdf

Proinversion Cuadro comparativo de sociedades. Recuperado de http://www.proinversion.gob.pe/modulos/JER/PlantillaStandard.aspx ?prf=0\&jer=5732\&sec= 
SUNAT Inscripción al RUC - Empresa. Recuperado de http://orientacion.sunat.gob.pe/index.php/empresas-menu/ruc-empresaas/inscripcion-al-rucempresas/3197-inscripcion-al-ruc-empresas

50 minutos. Modelo CAPM . Recuperado en:

https://books.google.com.pe/books?id=NnAODAAAQBAJ\&printsec=frontcover\&dq=capm\&h $\underline{\mathrm{l}=q u \& s a=X \& v e d=0 a h U K E w j 6 r K G m 15 X b A h X E t F M K H f z X D q U Q 6 A E l \mid z A A \# v=o n e p a g e \& q=c a p m \& f=f a l s e}$ 